\title{
Integration of Expanding Thermal Plasma deposited hydrogenated amorphous silicon in solar cells
}




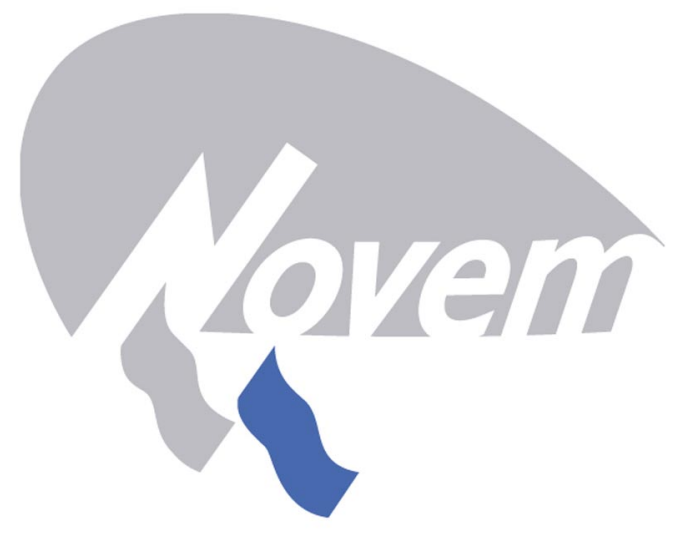

The work presented in this thesis was carried out at the Department of Applied Physics of the Eindhoven University of Technology and at Delft Institute of Microelectronics and Submicron Technology (DIMES). It is part of the research programme of the "Nederlandse Onderneming Voor Energie en Milieu" (NOVEM). This research is carried out within the framework of a TDO project (Centre of Technology for durable development) entitled:

"Rapid deposition of hydrogenated amorphous silicon solar cells"

Printed and bound by Universiteitsdrukkerij Technische Universiteit Eindhoven Cover design by Jan-Willem Luiten

CIP-DATA LIBRARY TECHNISCHE UNIVERSITEIT EINDHOVEN

Korevaar, Bastiaan Arie

Integration of Expanding Thermal Plasma deposited hydrogenated amorphous silicon in solar cells / by Bastiaan Arie Korevaar. - Eindhoven : Eindhoven University of Technology, 2002. - Proefschrift.

ISBN 90-386-1909-X

NUGI 812

Trefwoorden: gehydrogeneerd amorf silicium / zonnecel / expanderend thermisch plasma / hoge depositie snelheid

Subject headings: hydrogenated amorphous silicon / solar cell / expanding thermal plasma / high deposition rate 


\title{
Integration of Expanding Thermal Plasma deposited hydrogenated amorphous silicon in solar cells
}

\author{
PROEFSCHRIFT
}

ter verkrijging van de graad van doctor aan de Technische Universiteit van Eindhoven, op gezag van de Rector Magnificus, prof.dr. R.A. van Santen, voor een commissie aangewezen door het College voor

Promoties in het openbaar te verdedigen op maandag 4 maart 2002 om 16.00 uur

door

\section{Bastiaan Arie Korevaar}

geboren te Ottoland 
Dit proefschrift is goedgekeurd door de promotoren:

prof.dr.ir. M.C.M. van de Sanden

en

prof.dr. C.I.M. Beenakker

Co-promotor:

dr. R.A.C.M.M. van Swaaij 
Laat u niet overwinnen door het kwade, maar overwin het kwade door het goede (Romeinen 12:21)

Do not be overcome by evil, but overcome evil with good (Romans 12:21)

leder onzer trachte zijn naaste te behagen, ten goede, tot opbouwing (Romeinen 15:2)

Let every one of us please his neighbour for his good to edification (Romans 15:2)

If you think: "It is love", put it away.

If it comes back, it is true love.

If it does not come back, it was never there.

(From the movie: "The Wild Life")

The more you suffer, the more it shows you really care

(From the song: Self Esteem (The Offspring)) 



\section{Contents}

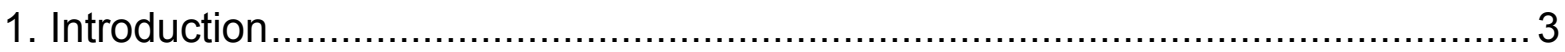

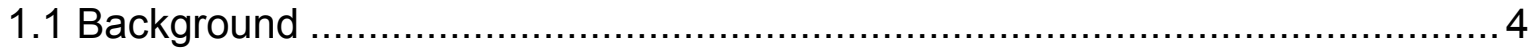

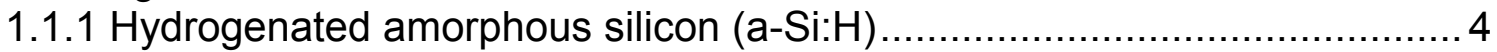

1.1.2 a-Si:H based solar cells ............................................................

1.1.3 Cost reduction of a-Si:H solar cells ............................................... 7

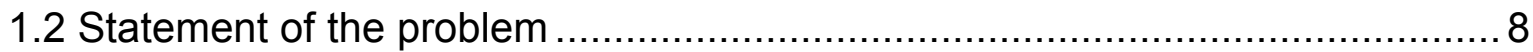

1.3 Motivation for the CASCADE project ...................................................

1.3.1 Material properties of hydrogenated amorphous silicon ......................... 10

1.3.2 Drift mobility of ETP a-Si:H..................................................... 12

1.3.3 The first solar cells within the project................................................... 16

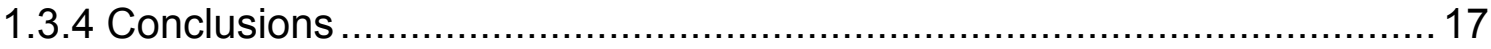

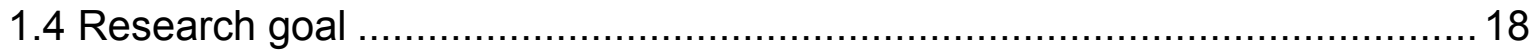

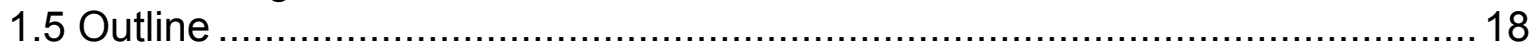

2. Experimental: combining RF-PECVD and Expanding Thermal Plasma (ETP)....23

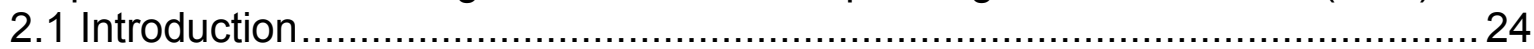

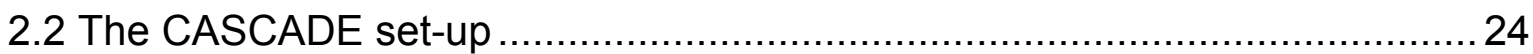

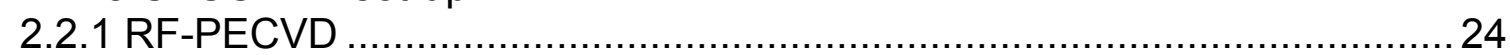

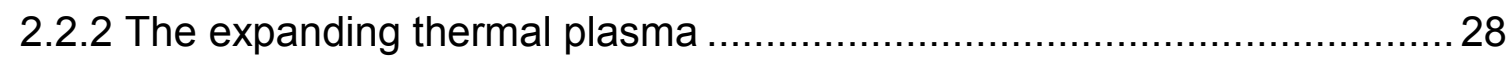

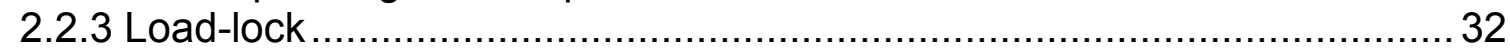

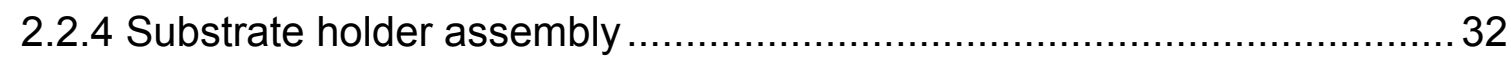

2.2.5 Data acquisition and machine control................................................... 35

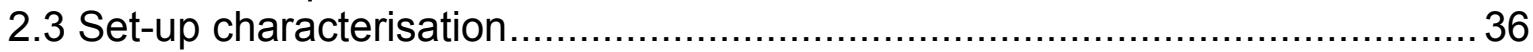

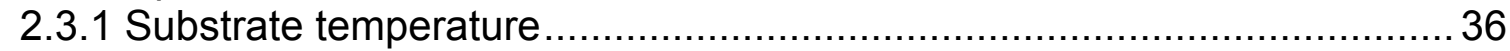

2.3.2 Homogeneity and reproducibility of layers grown using RF-PECVD ........ 37

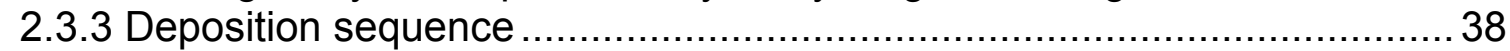

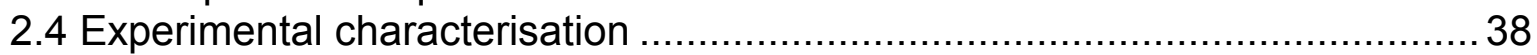

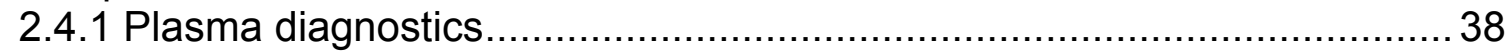

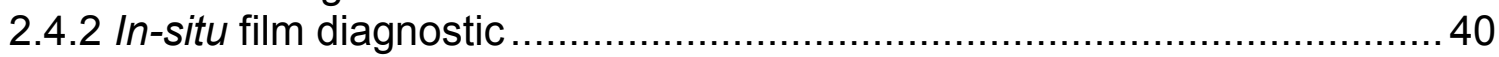

2.4.3 Ex-situ film diagnostics ................................................................. 41

2.4.4 Solar cell characterisation and simulation ........................................... 43

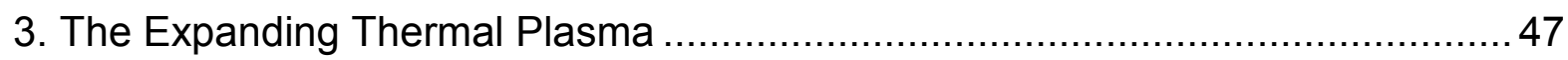

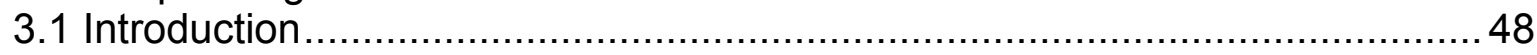

3.2 Plasma physics and chemistry of ETP method: review of previous work .......48

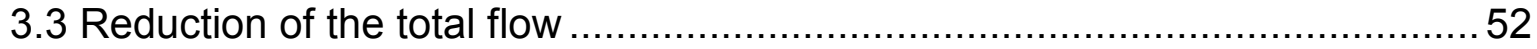

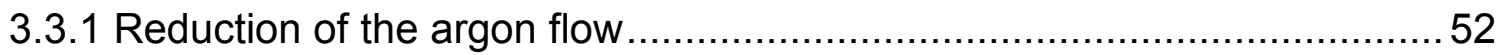

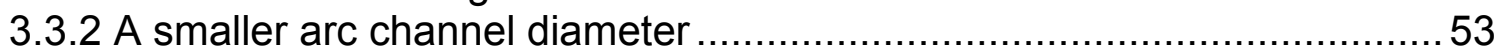

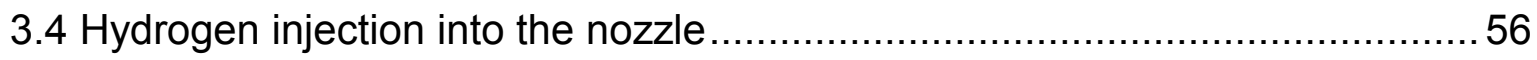

3.5 a-Si:H deposited using a smaller arc channel diameter ................................. 58

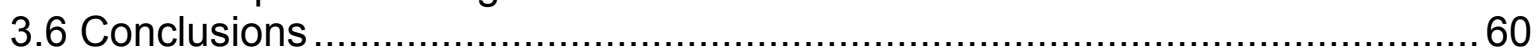




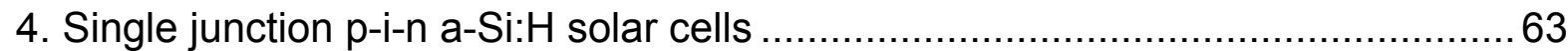

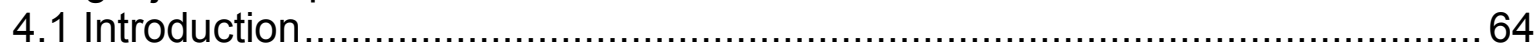

4.2 Intrinsic a-Si:H deposited with the expanding thermal plasma .....................64

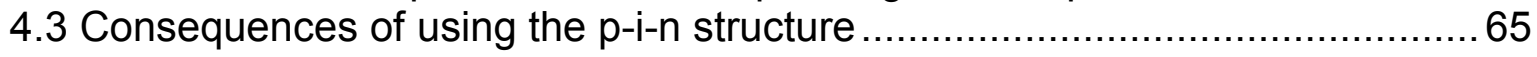

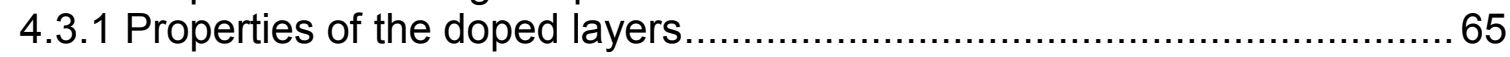

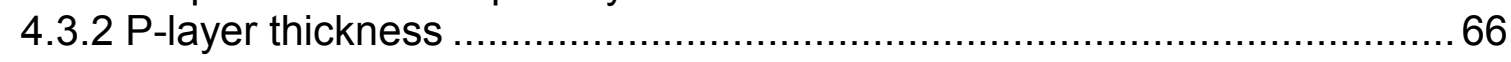

4.3.3 Influence of deposition temperature on solar cell performance ...............69 69

4.4 Influence of defects near the $\mathrm{p}$-i interface ............................................. 74

4.5 Use of an intermediate layer between the $p$ - and i-layer ........................... 80

4.6 Conclusions ..................................................................................... 81

5. Single junction a-Si:H solar cells with the intrinsic layer deposited above $250^{\circ} \mathrm{C} 85$

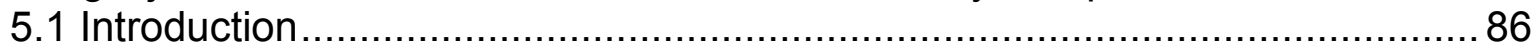

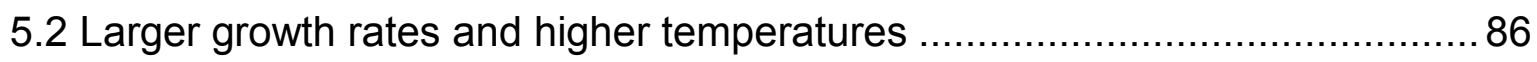

5.2.1 Expanding thermal plasma a-Si:H at larger growth rate and higher

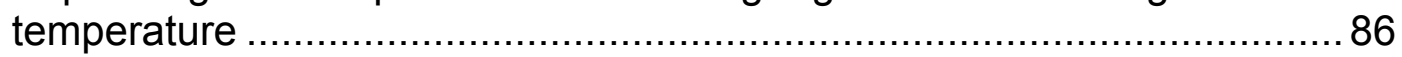

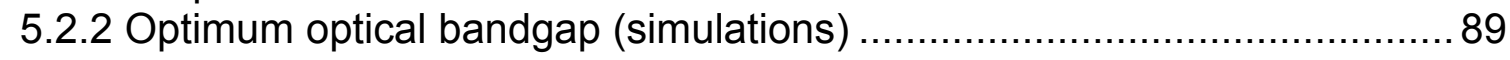

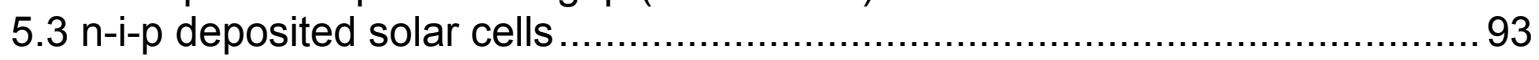

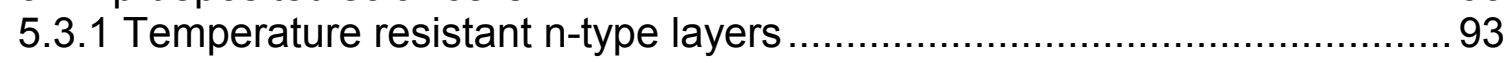

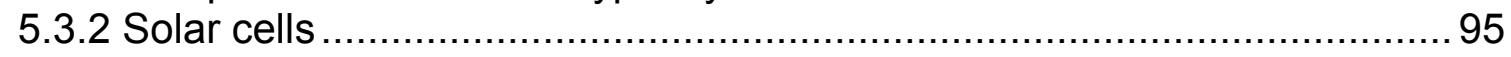

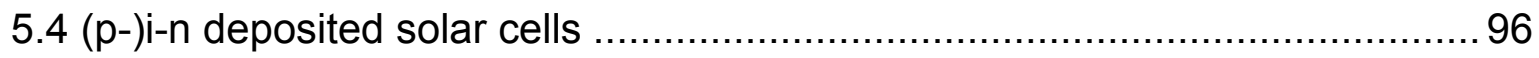

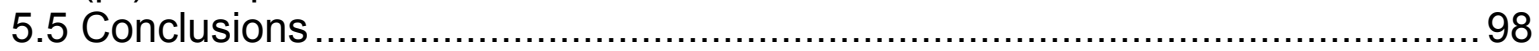

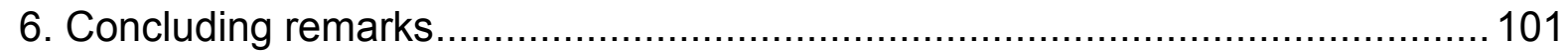

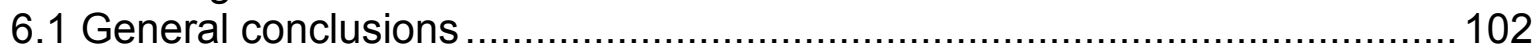

6.2 Recommendations for future research .......................................... 103

Appendix : Influence of the distance between arc plasma source and substrate.. 105

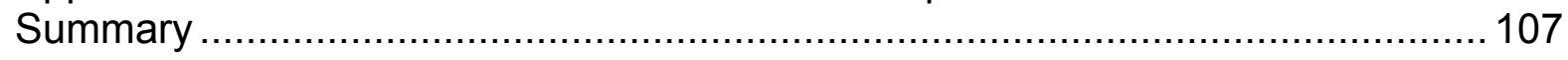

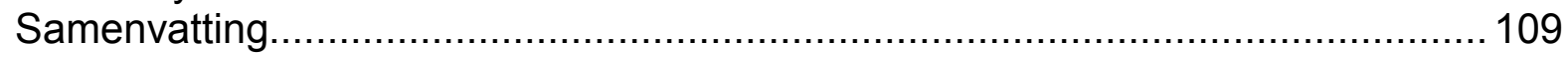

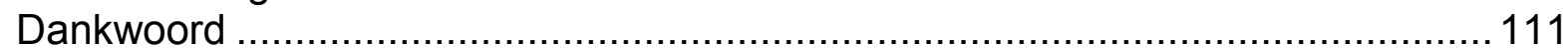

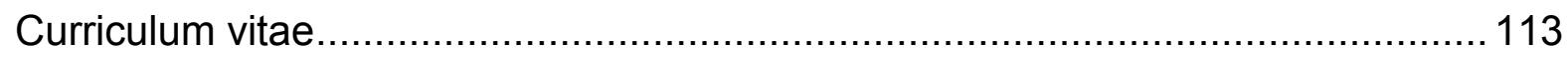


$-3-$

\section{Chapter 1}

1. Introduction 
CASCADE is the acronym for 'Cascaded Arc Solar Cell Apparatus Delft Eindhoven' and is a collaboration between the Delft Institute of Micro-Electronics and Sub-micron technology (DIMES) from the Delft University of Technology and the group "Equilibrium and Transport in Plasmas" from the Eindhoven University of Technology.

\subsection{Background}

Over the last decade the expected increase in energy demand in combination with the expected decline in conventional energy production has prompted research in renewable energy, for example wind energy, bio-mass (photosynthesis), hydro power, solar heating, and solar electricity. Annually the earth receives $\sim 7.6 \cdot 10^{8} \mathrm{PJ}$ from the sun of which $\sim 1 \%$ is converted into wind energy and $\sim 0.5 \%$ is used for photosynthesis. In 1990 the energy consumption on earth was $\sim 3.8 \cdot 10^{5} \mathrm{PJ}$, which is a factor 2000 less than the amount of energy that the sun delivers. From this comparison it is clear that the sun is a huge energy source. ${ }^{1}$ Several methods have been developed to harvest the energy from the sun, e.g., windmills, solar collectors (for heating), and solar cells (for electricity generation).

In solar cell research the effort is mainly concentrated on the optimisation of materials and the development of new solar cell device structures. Development of high-efficiency solar cells is required, such that the area for energy production is minimised. However, it is also important that the price of solar electricity is competitive with the price of electricity obtained from oil or gas electricity plants. In particular, hydrogenated amorphous silicon (a-Si:H) [1] and its alloys have proven to be an excellent alternative for large-scale production of low-cost solar cells. In laboratories conversion efficiencies of more than $13 \%$ have been achieved [2] while, in production, panel efficiencies exceed $7 \%$ [e.g. 3].

\subsubsection{Hydrogenated amorphous silicon (a-Si:H)}

Deposition of hydrogenated amorphous silicon (a-Si:H) was first reported by Sterling and Swann [4] and by Chittick et al. [5], who demonstrated the growth of a-Si:H from silane gas by radio-frequency (RF) glow discharge deposition. About ten years later [6] it was found that amorphous silicon can be doped, which makes it a suitable material for devices like solar cells, TFTs, and photo-detectors.

Amorphous silicon is mainly characterised by a lack of long-range order in contrast to its counterpart crystalline silicon (c-Si). As a result of the lack of longrange order there is a distribution in bonding lengths and angles, leading to strained silicon-silicon bonds and three-fold co-ordinated silicon atoms. The latter are commonly referred to as dangling bonds. The electronic properties of the material are strongly influenced by these dangling-bond defects. In pure a-Si the density of dangling-bond defects is $\sim 10^{20} \mathrm{~cm}^{-3}$, which makes this material unsuitable for application in electronic devices. However, if hydrogen is incorporated in the material this passivates the dangling-bond defects, reducing the defect density to $\sim 10^{16} \mathrm{~cm}^{-3}$. Furthermore, as a result of the amorphous structure a-Si:H has a direct bandgap and the absorption is much higher than of $\mathrm{c}-\mathrm{Si}$, which has an indirect bandgap. Hydrogen is therefore important for the electrical and optical properties of a-Si:H [7]. By addition of hydrogen the optical gap of a-Si:H can be varied between $\sim 1.65$ to $\sim 2 \mathrm{eV}$,

\footnotetext{
${ }^{1}$ Data are obtained from the presentation given by A.P. van Ulden during the KNAW day of 18 October 2001, Amsterdam, on challenges for physicist in energy sources.
} 
depending on the configuration in which the hydrogen resides [8]. The higher absorption of a-Si: $\mathrm{H}$ is a considerable advantage as much thinner layers are required for solar cells $(\sim 400 \mathrm{~nm}$ instead of $\sim 20 \mu \mathrm{m})$.

In 1977 Staebler and Wronski found that a-Si:H degrades under the influence of illumination [9] and that this effect is reversible when the material is annealed at a temperature of $\sim 150^{\circ} \mathrm{C}$. Several models for this so-called Staebler-Wronski effect (SWE) have been proposed [e.g. 10,11]. This degradation is due to the creation of extra dangling-bond defects. It is generally believed that the energy for this process is provided by the recombination of electron-hole pairs. Obviously, these additional defects have a large influence of the electronic properties of the material.

\subsection{2 a-Si:H based solar cells}

In order to explain the operation of a-Si:H solar cells, the operation of a c-Si solar cell will first briefly be described. This solar cell consists of a p-type substrate on which an n-type layer is created, thereby forming a p-n junction. Around the junction there is a thin region where an electric field is present, the so-called depletion region, and further away from this junction no electric field is present. Under illumination charge carriers are generated throughout the solar cell. The generated charge carriers diffuse towards the junction where they experience an electric field in the depletion region. As diffusion is the main transport mechanism in these devices, these devices are referred to as diffusion devices.

The diffusion length of the charge carriers, and especially the holes, in a-Si:H is too small for devices based on a-Si:H to act as a diffusion device. Therefore the solar cell concept as it is used for c-Si is not applicable for a-Si:H based thin film solar cells. The a-Si:H cells require an internal electric field which is achieved by sandwiching an intrinsic layer between a p-and n-type layer (Fig. 1.1). In this case the charge carriers are transported under the influence of an electric field and therefore this device is called a drift device. The contacts to the cell are formed by transparent conductive oxide (TCO) on the top and a metal at the back of the solar cell. In 1976 Carlson and Wronski made the first a-Si:H based solar cell, achieving an efficiency of $\sim 2.4$ [12].

In a-Si:H solar cells the light passes through the glass, the TCO (normally Asahi U-type), and the p-type layer. In order to optimise the absorption of light in the solar cell the TCO is textured, which leads to scattering of the incoming light. The scattering implies that the optical path is enlarged. For the cells presented in this thesis the metal back contact consists of $100 \mathrm{~nm} \mathrm{Ag}$ and $200 \mathrm{~nm}$ Al. The Ag back contact has a high reflectivity and thus also contributes to a higher absorption of light in the intrinsic layer. In our experiments the Ag back contacts were covered with $\mathrm{Al}$ in order to prevent oxidation of the Ag. The light that is transmitted through the TCO and p-layer can be absorbed in the intrinsic layer where electron-hole pairs are generated. The holes drift towards the p-type layer where they recombine with electrons that arrive there via the TCO. The electrons drift towards the n-type layer and are collected at the metal back contact.

In order to make p-type material, diborane (from $2 \% \mathrm{~B}_{2} \mathrm{H}_{6}$ in $\mathrm{H}_{2}$ ) is admixed with the silane. The incorporation of boron in the silicon network shifts the Fermi energy to the valence band. However, boron is known to decrease the optical gap of a-Si:H. As the p-type layer is used as the first layer through which the light of the sun enters the solar cell, high absorption in this layer is undesirable and the optical gap should be higher. Therefore carbon (from $\mathrm{CH}_{4}$ feed gas) is added to increase the 
gap. A disadvantage of the carbon atoms is that the p-type layer becomes more porous and contains more defects. An advantage of carbon is that it makes the refractive index of the p-type layer smaller, which reduces the reflectivity of the incoming light on the TCO-p interface $[13,14]$. In order to make n-type material, phospine (from $2 \% \mathrm{PH}_{3}$ in $\mathrm{H}_{2}$ ) is admixed with the silane, which results in a shift of the Fermi level to the conduction band as phosphorus is incorporated. Phosphorus does not influence the optical gap and no other gases are added to enhance the properties of the n-layer.
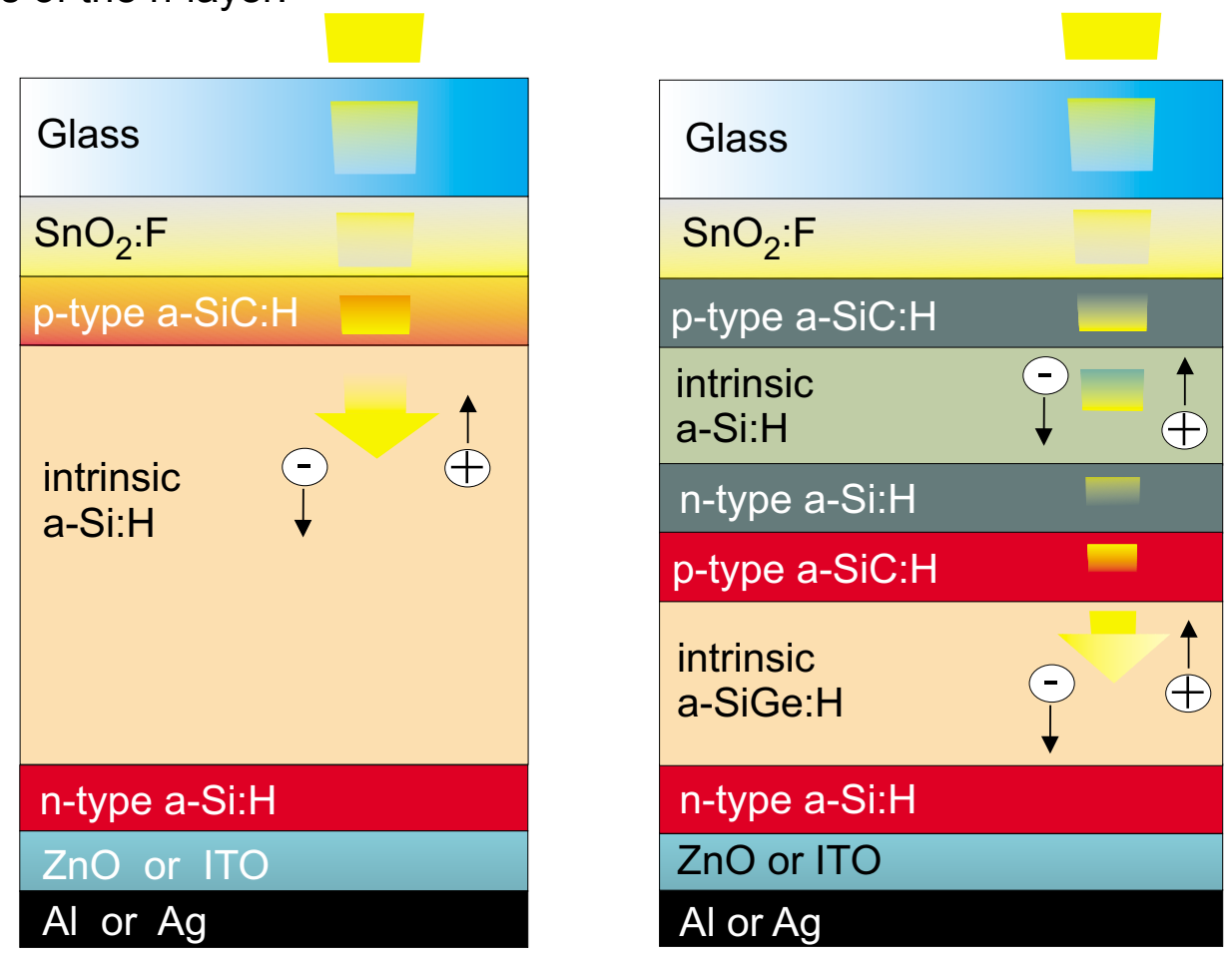

Figure 1.1: Single junction $p-i-n$ solar cell and a multi-junction solar cell. ${ }^{2}$

The thickness of the intrinsic layer is normally $400 \mathrm{~nm}$, resulting in $15 \%$ to $25 \%$ light-induced degradation. The degradation depends on the thickness of the intrinsic layer, having more degradation with increasing intrinsic layer thickness. Therefore multi-junction solar cells [15] have been developed. In these cells two or more $p$-i-n structures are stacked on top of each other (Fig. 1.1). The thickness of the multi-junction cell is similar to that of a single-junction cell, but each individual component cell is thinner and is therefore less sensitive to light-induced degradation of the intrinsic layer. An additional advantage of the multi-junction approach is that the response of each component cell can be tuned to a specific part of the solar spectrum, by using material with another bandgap for the intrinsic layer of each individual p-i-n cell. Nowadays $\mu \mathrm{c}-\mathrm{Si}: \mathrm{H}$ (gap $\sim 1.1 \mathrm{eV}$ ) and a-SiGe:H (gap $\sim 1.4 \mathrm{eV}$ ) are used as intrinsic material for the bottom cells. Using the multi-junction, multibandgap approach triple-junction cells have been reported with initial efficiencies in excess of $15 \%$ [2].

\footnotetext{
${ }^{2}$ Figure obtained from the lecture notes on "solar cell physics" by M. Zeman.
} 


\subsubsection{Cost reduction of a-Si:H solar cells}

To be competitive with electricity from oil, gas, or coal the price of solar electricity has to become at least 2.3 euro/ $\mathrm{Wp}^{3}$. It is expected that this will be achieved before 2010 and groups in the field even believe that it is possible to reach a lower limit of 1 euro/Wp [3]. In the Netherlands the price for electricity in 1998 was about 12 cents (euro cents) per kWh when using the electricity from the electricity grid and for solar electricity the price was about 57 cents per $\mathrm{kWh}$, or in other units: 7 euro/Wp ${ }^{4}$. This can be separated in 4.2 euro/Wp for the modules and 2.8 euro/Wp for BOS $^{5}$ (inverters, cables, installations, frames, etc.). Table 1.1 (from 1998) presents the expected and realised prices for the modules, the BOS, and the complete system for the period from 1996-2000 [16]. From this table it can be seen that at the end of 1998 the expected module prices are realised, but the expected prices for BOS are not realised. At the end of 2001 the price for solar electricity was reduced to 5 euro/ $\mathrm{Wp}^{6}$.

Table 1.1: Prices in euro/Wp of c-Si solar-cell modules, BOS, and total system [16]. The expectations are made 1995.

\begin{tabular}{|c|c|c|c|c|c|c|}
\hline & \multicolumn{2}{|c|}{ Module } & \multicolumn{2}{c|}{ BOS } & \multicolumn{2}{c|}{ Total system } \\
\hline Year & expected & realised & Expected & Realised & expected & realised \\
\hline 1996 & 5.2 & 5.1 & 2.9 & 3.3 & 8.1 & 8.4 \\
\hline 1997 & 4.8 & 4.5 & 2.7 & 2.9 & 7.4 & 7.5 \\
\hline 1998 & 4.3 & 4.2 & 2.5 & 2.8 & 6.8 & 7.0 \\
\hline 1999 & 3.9 & - & 2.3 & - & 6.2 & - \\
\hline $\mathbf{2 0 0 0}$ & 3.3 & - & 2.1 & - & 5.4 & - \\
\hline
\end{tabular}

In 2001 the market for solar cells is dominated by cells based on c-Si technology $(\sim 80 \%)$. Using a-Si:H solar cell technology a price reduction can be achieved [17], mainly because the production is much less expensive. Table 1.2 presents the predictions that were made in 1998 for the system prices until the year 2007 for modules based on c-Si solar cells and for modules based on thin-film a-Si:H solar cells [16]. This table shows clearly that it is expected that this thin-film solar cell technology becomes competitive with electricity from the grid.

A way to make the production of a-Si:H solar cells cheaper is to reduce the production costs. This can be achieved by using larger growth rates for the intrinsic layers of the solar cell. Decreasing the i-layer deposition-time cannot only directly reduce the manufacturing time and costs, but can also reduce the capital investment when the production capacity is kept the same ${ }^{7}$. The standard way for the deposition of a-Si:H is Radio Frequency Plasma Enhanced Chemical Vapour Deposition (RFPECVD) with typical growth rates of $0.1-0.5 \mathrm{~nm} / \mathrm{s}$ [18]. The a-Si:H single-junction

\footnotetext{
${ }^{3}$ Watt-Peak (Wp) is the power supplied by a solar cell module under standard test conditions (1000 $\mathrm{W} / \mathrm{m}^{2}, \mathrm{AM} 1.5$, normal incidence, $\left.25^{\circ} \mathrm{C}\right)$.

4 In order to convert euro/Wp to euro/kWh it is a good estimation to divide by the average lifetime (in years) of the solar panel.

${ }^{5}$ BOS is the abbreviation of: Balance Of Systems

${ }^{6}$ Number is obtained from the presentation given by W.C. Sinke during the KNAW day of 18 October 2001, Amsterdam, on challenges for physicist in energy sources.

${ }^{7}$ Increasing the production capacity will also decrease the production costs.
} 
solar-cell consists of three silicon layers (Section 1.1.2), two thin layers with a thickness in the order of $10 \mathrm{~nm}$ and a $\sim 400 \mathrm{~nm}$ thick intrinsic layer for light absorption. The deposition time can be reduced considerably by preparing the intrinsic layer at larger growth rates.

Table 1.2: Expected prices ${ }^{8}$ in euro/Wp for complete systems, for modules based on c-Si solar cells and thin-film solar cells [16]. The expectations were made in 1998.

\begin{tabular}{|l|c|c|c|c|c|c|c|c|}
\hline Year & $\mathbf{1 9 9 9}$ & $\mathbf{2 0 0 0}$ & $\mathbf{2 0 0 1}$ & $\mathbf{2 0 0 2}$ & $\mathbf{2 0 0 3}$ & $\mathbf{2 0 0 4}$ & $\mathbf{2 0 0 5}$ & $\mathbf{2 0 0 7}$ \\
\hline c-Si & 6.2 & 5.4 & 5.1 & 4.7 & 4.4 & 3.9 & 3.8 & 3.2 \\
\hline a-Si:H & & 5.2 & 4.5 & 4.1 & 3.7 & 3.4 & 2.9 & 2.0 \\
\hline
\end{tabular}

Various deposition techniques are being developed to obtain larger growth rates. Increasing the frequency of PECVD up to $2 \mathrm{GHz}$ (VHF), growth rates up to 2 $\mathrm{nm} / \mathrm{s}$ are obtained $[19,20]$. However, VHF exhibits technological difficulties when applied to large-area depositions [21-23]. Takeuchi et al. [24] showed that changing the antenna shape can increase the homogeneity of the grown layer and reasonable homogeneities can be obtained over an area of $40 \times 40 \mathrm{~cm}^{2}$ [25]. Another technique developed since 1985 is hot-wire chemical vapour deposition (HW-CVD), or catalytic chemical vapour deposition [26]. HW-CVD uses a hot filament to dissociate the silane and hydrogen gas. Using multiple wires can increase the growth rate and good material properties are obtained at deposition rates up to $13 \mathrm{~nm} / \mathrm{s}$ [27]. A technological problem regarding large area deposition might be that longer wires will bend more when they become hot, resulting in inhomogeneous deposition, and the lifetime of the wires.

\subsection{Statement of the problem}

In this thesis we follow the approach of the cascaded arc expanding thermal plasma (ETP, Section 2.2.2, Fig. 2.5) as developed by the group "Equilibrium and Transport in Plasmas" from the Eindhoven University of Technology. The method was originally developed for high-rate hydrogenated amorphous carbon (up to $100 \mathrm{~nm} / \mathrm{s}$ [28]). Here this technique is applied to grow hydrogenated amorphous silicon (a-Si:H). Growth rates for a-Si:H of up to $10 \mathrm{~nm} / \mathrm{s}$ are obtained while maintaining good material properties [29-33]. Such large growth rates result in deposition times of $\sim 40$ seconds for the intrinsic layer thus reducing the deposition time significantly compared to standard RF-PECVD. The ETP method is a relatively new deposition technique and one of the first remote plasma deposition techniques. The technique has been developed for deposition by Schram et al. [34]. The technique is based on a cascaded arc as developed by Maecker [35] in 1956. Initial research on a-Si:H deposition with the cascaded arc was performed by Meeusen $[36,37]$ who obtained optimum deposition conditions while optimising on the refractive index. Further optimisation has been carried out by Severens [38], Kessels [39], and Smets [40] to get a better understanding on growth conditions and plasma conditions that would result in solar grade a-Si:H. In 1997 a project was initiated that resulted in CASCADE, a project to integrate a-Si:H deposited at large growth rates with a cascaded arc expanding thermal plasma into solar cell structures.

\footnotetext{
${ }^{8}$ These prices are for large roof integrated systems. Small stand-alone systems are more expensive.
} 
At the start of this project the state of the art was to make single junction cells of $\sim 10 \%$ [15] and the record at that time was $13.0 \%$ (stable) for a triple junction solar cells [2] using RF-PECVD. However, the intrinsic layers were grown at a deposition rate of $\sim 0.1 \mathrm{~nm} / \mathrm{s}$. By increasing the deposition rate with RF-PECVD the initial efficiency decreased and the degradation was larger [41], mainly due to a worsening of the material properties. The worsening of the initial efficiency and the larger degradation was also observed for other deposition techniques [e.g. 42,43]. New techniques like Hot Wire Chemical Vapour Deposition (HW-CVD) were focussing on $1 \mathrm{~nm} / \mathrm{s}$, but were not successful at that time. It was even said that it was impossible to grow good solar grade material at large growth rates $(>1 \mathrm{~nm} / \mathrm{s})$. By now, recent developments and new understandings have resulted in good material quality at higher growth rate. Both VHF and HW-CVD reported high efficiency single junction cells at larger growth rates. Schröder et al. [44] are working on a full HW-CVD cell, thus the doped layers are also deposited with HW-CVD, and achieved a $10 \%$ cell (7\% stable efficiency) at a growth rate of $0.4 \mathrm{~nm} / \mathrm{s}$. Yang et al. [45] reported $10 \%$ cells $(8.5 \%$ stable) deposited at $0.6 \mathrm{~nm} / \mathrm{s}$ using VHF. Mahan et al. [46] reported a $9.8 \%$ initial efficiency cell deposited at $1.6 \mathrm{~nm} / \mathrm{s}$ using HW-CVD. The latter cell was made in co-operation with USSC, utilising all the optimised properties for the window layers to achieve a record initial efficiency. At a growth rate of $2 \mathrm{~nm} / \mathrm{s}$ an initial efficiency of $9.3 \%$ and a stable efficiency of $7.4 \%$ is presented by Nishimoto et al. [20] for VHF and Nelson et al. [47] reported in 2001 for HW-CVD, for non-optimised cells, a stabilised efficiency of $5.5 \%$ at $1.8 \mathrm{~nm} / \mathrm{s}, 4.8 \%$ at $3.5 \mathrm{~nm} / \mathrm{s}, 4.1 \%$ at $8.3 \mathrm{~nm} / \mathrm{s}$, and $3.8 \%$ at $12.7 \mathrm{~nm} / \mathrm{s}$.

A consequence of the larger growth rates is that higher deposition temperatures for the intrinsic layer are required to obtain good material properties [e.g. 48]. For this reason researchers have worked on a concept in which the deposition sequence of the solar cell has been inverted, i.e., start the deposition with the n-layer. This resulted in the development of a higher temperature stable n-type layer. With these so-called n-i-p structures Jones et al. reported in 1999 a 10.3\% solar cell grown on a temperature stable n-type layer [49] at growth rates up to 1 $\mathrm{nm} / \mathrm{s}$. At high growth rates Mahan et al. [42] presented a $6 \%$ initial efficiency solar cell $(3.8 \%$ stable) with the intrinsic layer deposited at $12.7 \mathrm{~nm} / \mathrm{s}$ with HW-CVD [see also 47$]$.

\subsection{Motivation for the CASCADE project}

In this section a motivation for the construction and the building of a new set-up will be given. A new set-up to make $\mathrm{p}-\mathrm{i}-\mathrm{n}$ a-Si:H solar cells without the need to break the vacuum between the deposition steps. In this section the material properties of hydrogenated amorphous silicon (a-Si:H) are discussed and a short review of the results obtained with the set-up at the Eindhoven University is given (Section 1.3.1). Section 1.3.2 presents and discusses the larger hole drift mobility as obtained for the material grown in Eindhoven at $10 \mathrm{~nm} / \mathrm{s}$ and $400^{\circ} \mathrm{C}$. In Section 1.3.3 the incorporation of the films grown in Eindhoven into solar cells are discussed. 


\subsubsection{Material properties of hydrogenated amorphous silicon}

The material properties of a-Si:H can vary over a wide range and only a limited window within these properties can be used for application in solar cells. The optical properties are very important for the absorption of light and the electrical properties are important because the generated charge carriers have to be collected. In order to use a-Si:H in solar cells the material properties have to satisfy certain conditions [50]. When these properties are met the material is referred to as 'solar grade'. The minimum set of characteristic properties consists of a minimum dark conductivity and a maximum photoconductivity, resulting in a maximum photo-response of the material, indicating how well the material reacts to the absorption of light. Furthermore, the optical bandgap is important for the light absorption, also reflected in the absorption coefficient of the material. This is, however, not straightforward, because besides the generation of electron-hole pairs the recombination of electrons and holes is also important. A lower optical bandgap will result in more generation in the front of the cell, which will result in more recombination in the front of the cell as the recombination increases with the density of charge carriers [50]. The optical gap of a-Si: $\mathrm{H}$ is influenced by the hydrogen content and the hydrogen bonding structure [8]. Besides the charge carrier density, the recombination of electrons and holes also depends on the mid-gap electronic density of states. Correlated with this defect density is the Urbach energy [51], which is determined from the exponential part in the absorption. It is generally accepted the Urbach energy reflects the slope of the valence band-tail, which in turn is related to the disorder of the material. Other defect centres are formed by impurities incorporated in the material. Normally the films are deposited in vacuum systems with low background pressures, but when the films are too porous contaminants (like oxygen) can easily be incorporated after the films have been taken out of the system. Therefore the refractive index, which is a measure for the density of the material, has to be large enough. The measurement techniques to obtain the properties are discussed briefly in Section 2.4 .3 and in more detail by others [e.g. 1,18,50].

Table 1.3 shows the characteristics for solar grade a-Si:H as presented by Schropp and Zeman [50] for RF-PECVD deposited at approximately $200^{\circ} \mathrm{C}-250^{\circ} \mathrm{C}$ and growth rates of $0.1-0.3 \mathrm{~nm} / \mathrm{s}$. Furthermore, Table 1.3 compares the characteristics of a-Si:H deposited with RF-PECVD with the material properties of layers obtained with the ETP method at $400^{\circ} \mathrm{C}$ and $\sim 10 \mathrm{~nm} / \mathrm{s}[29,30]$.

Table 1.3: Characteristics for a-Si:H deposited with RF-PECVD at low growth rate [50] $\left(200^{\circ} \mathrm{C}-250^{\circ} \mathrm{C}\right)$ compared with the best results as obtained for a-Si:H deposited with the ETP method at $10 \mathrm{~nm} / \mathrm{s}$ and $400^{\circ} \mathrm{C}$. The properties of the ETP a-Si:H are measured for samples with a thickness of $\sim 400 \mathrm{~nm}$.

\begin{tabular}{|l|l|l|}
\hline & RF-PECVD & ETP \\
\hline AM $1.5100 \mathrm{~mW} / \mathrm{cm}^{2}$ photoconductivity $\left((\Omega \mathrm{cm})^{-1}\right)$ & $>1 \cdot 10^{-5}$ & $3.3 \cdot 10^{-5}$ \\
\hline Dark conductivity $\left((\Omega \mathrm{cm})^{-1}\right)$ & $<1 \cdot 10^{-10}$ & $3.5 \cdot 10^{-10}$ \\
\hline Activation energy $(\mathrm{eV})$ & $\sim 0.8$ & 0.75 \\
\hline Photo response & $>1 \cdot 10^{5}$ & $9.4 \cdot 10^{4}$ \\
\hline Bandgap, Tauc $(\mathrm{eV})$ & $<1.8$ & 1.66 \\
\hline Hydrogen content $($ at.- $\%)$ & $9-11$ & 6 \\
\hline Microstructure parameter $R^{*}$ & $<0.1$ & 0.1 \\
\hline Density of dangling bond states $\left(\mathrm{cm}^{-3}\right)$ & $\leq 1 \cdot 10^{16}$ & $<1 \cdot 10^{16}$ \\
\hline
\end{tabular}


To obtain dense material the ETP technique requires substrate temperatures $>350^{\circ} \mathrm{C}$ at high deposition rates $(>2 \mathrm{~nm} / \mathrm{s}$ ) [31-33]. Lower deposition rates lead to good properties at lower deposition temperatures [40,52]. For growth rates $<1 \mathrm{~nm} / \mathrm{s}$ the quality of ETP deposited a-Si:H is also better at lower substrate temperatures $\left(\sim 250^{\circ} \mathrm{C}\right)$ and becomes comparable with RF-PECVD (see also Chapter 4$)$. These criteria needed for RF-PECVD, however, may not hold for a-Si:H deposited at large growth rate with an ETP or with HW-CVD, which both require higher substrate temperatures. The main influence of the higher deposition temperature will be a lower hydrogen content in the film [53], resulting in a lower optical gap [8] and thus a higher dark conductivity [e.g. 54]. Besides the lower hydrogen content, the lower optical gap, and the higher dark conductivity, a-Si:H deposited with the ETP method has similar properties as solar grade RF-PECVD a-Si:H material.

Figure 1.2 shows the photo- and dark conductivity as a function of deposition temperature for a series of samples deposited at $7 \mathrm{~nm} / \mathrm{s}$. This figure shows that the photoconductivity is in the order of $10^{-6}-10^{-5}(\Omega \mathrm{cm})^{-1}$ for deposition temperatures > $300^{\circ} \mathrm{C}$, while it is smaller at lower substrate temperatures. The refractive index shows a comparable behaviour [55]: it increases with temperature and becomes constant above $300^{\circ} \mathrm{C}$ [29-31]. The dark conductivity for these series is $\sim 10^{-9}(\Omega \mathrm{cm})^{-1}$, resulting in a photo-response at $400^{\circ} \mathrm{C}$ of $10^{4}$.

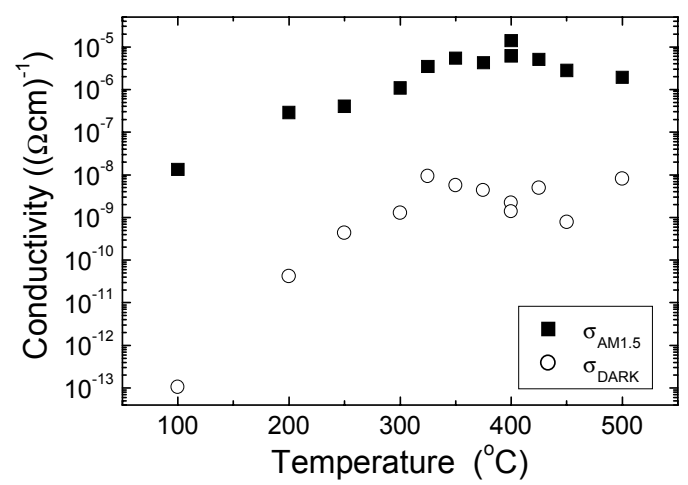

Figure 1.2: Photo- (solid squares) and dark conductivity (open circles) of a-Si:H deposited with an ETP at $7 \mathrm{~nm} / \mathrm{s}$ as a function of the deposition temperature.

More insight into the material structure can be obtained from the microstructure parameter, $R^{*}$, (Eq. 2.5) and the hydrogen concentration (Fig. 1.3). Hydrogen is used to passivate dangling bond defects [e.g. 1], decreasing the defect density from $10^{20} \mathrm{~cm}^{-3}$ for unhydrogenated a-Si to $10^{16} \mathrm{~cm}^{-3}$ for a-Si:H. $R^{*}$ is correlated to the Staebler-Wronski Effect (SWE) [e.g. 56,57], showing a more significant SWE when $R^{*}$ is larger. The hydrogen concentration of ETP material deposited at $7 \mathrm{~nm} / \mathrm{s}$ decreases with increasing deposition temperature and is lower than $10 \%$ above $300^{\circ} \mathrm{C}$. Figure 1.3 reveals that the decrease in hydrogen concentration with increasing substrate temperature is correlated to a decrease in hydrogen bonding configuration that contributes to the FTIR-peak near $2100 \mathrm{~cm}^{-1}$, indicating a reduction of $\mathrm{SiH}_{2}$-bond fraction [e.g. 58] and/or a reduction of $\mathrm{Si}-\mathrm{H}$ bonds on void surfaces [59]. For the material deposited at $400^{\circ} \mathrm{C}$ the hydrogen content in the film is $\sim 6 \%$. Therefore a lower Tauc bandgap (1.66-1.68 eV) is found, which in turn is consistent with a higher absorption coefficient and a higher dark conductivity 
(Fig. 1.2). The hydrogen concentration is lower than obtained for solar grade material with RF-PECVD, deposited at $200^{\circ} \mathrm{C}$. However, that does not imply that material with a hydrogen content of $6 \%$ cannot be used in solar cells. In particular results achieved with HW-CVD indicate that a lower hydrogen content can result in good material [e.g. 60-62].

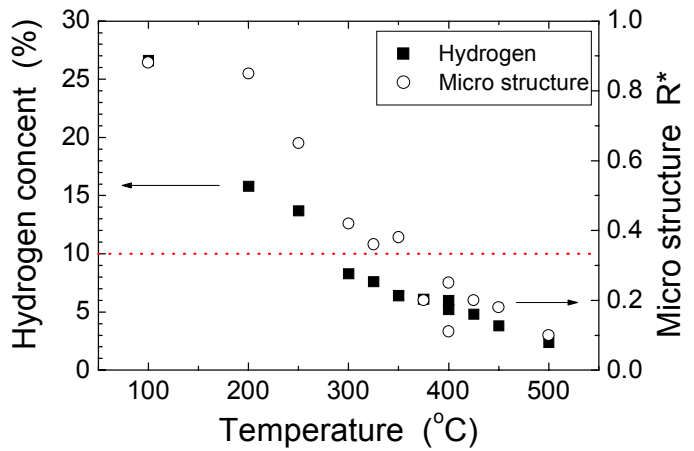

Figure 1.3: Hydrogen concentration (solid squares) in the film as a function of deposition temperature obtained from the $640 \mathrm{~cm}^{-1}$ peak with FTIR. The microstructure (open circles) indicates that the decrease in hydrogen concentration mainly comes from a decrease in bond concentration found in the region from $2060 \mathrm{~cm}^{-1}$ to $2100 \mathrm{~cm}^{-1}$. The deposition rate for these layers was $7 \mathrm{~nm} / \mathrm{s}$.

\subsubsection{Drift mobility of ETP a-Si: $\mathrm{H}^{9}$}

\section{Measurements}

For the operation of a a-Si:H solar cell, a device that is based on the drift of free charge carriers, the measurement of the drift mobility of electrons, $\mu_{\mathrm{de}}$, and holes, $\mu_{\mathrm{dh}}$, provides useful information. The drift mobility of both electrons and holes, and the density of states (DOS) distribution have been studied in $\sim 4 \mu \mathrm{m}$ thick ETP a-Si:H films by time-of-flight (TOF) experiments by Adriaenssens et al. [63] and by posttransit photo-current analysis (PTPA) [64], as a function of the temperature and applied electric field [65]. Electron-hole pairs are created by illumination with a short light pulse ( $530 \mathrm{~nm}$ for $3 \mathrm{~ns}$ ). By applying a positive or negative voltage on one of the contacts, the electrons or holes are collected and the current is measured as a function of time.

The drift mobility has been investigated by TOF measurements for samples deposited at 300 to $450^{\circ} \mathrm{C}$. For the samples deposited at lower temperatures and large deposition rates the drift mobility could not be determined as the mobility was too low, resulting in a signal that could not be extracted from the noise level. The refractive index at $2 \mathrm{eV}$ and the photoconductivity for the samples deposited at lower temperatures are much smaller than for samples deposited at higher temperatures, which indicate a larger defect density. When the defect density in the film becomes too large, fewer electrons or holes are able to reach the contacts, which makes it more difficult to determine the drift mobility accurately.

\footnotetext{
${ }^{9}$ Adapted from: B.A.Korevaar, A.H.M. Smets, W.M.M. Kessels, G. Adriaenssens, M.C.M. van de Sanden, and D.C. Schram, J. Non Cryst. Sol., 266-269 (1999) 380
} 
The drift mobility is calculated using:

$$
\mu_{d}=\frac{d^{2}}{t_{T} V},
$$

where $d$ is the sample thickness, $V$ the applied voltage across the film, and $t_{\top}$ the transit time. Figure 1.4 presents the results of TOF measurements for ETP a-Si:H deposited at $400^{\circ} \mathrm{C}$ and $10 \mathrm{~nm} / \mathrm{s}$. For this material $\mu_{\text {de }}$ is up to 3 times lower while $\mu_{\text {dh }}$ is 7-10 times larger than for RF-PECVD material deposited at its optimum substrate temperature. These results have been confirmed recently by Brinza et al. [66]. They reported that the hole drift mobility is even larger when the ETP a-Si:H is deposited at $450^{\circ} \mathrm{C}(\sim 6 \mathrm{~nm} / \mathrm{s})$ and that at a temperature of $250^{\circ} \mathrm{C}(\sim 2.5 \mathrm{~nm} / \mathrm{s})$ the larger hole drift mobility is not observed. In addition, $\mu_{\mathrm{de}}$ and $\mu_{\mathrm{dh}}$ are weakly dependent on or even independent of the electric field in the range of $2.5-25 \mathrm{kV} / \mathrm{cm}$. This fieldindependence is not observed for the $\mu_{\mathrm{de}}$ and $\mu_{\mathrm{dh}}$ of RF-PECVD a-Si:H and the reason for this is not yet understood. Furthermore, similar to RF-PECVD a-Si:H, $\mu_{\mathrm{de}, \mathrm{dh}}$ is thermally activated with activation energy, $E_{\mathrm{a}}$. In detail, for the ETP material deposited at $400^{\circ} \mathrm{C}, E_{\mathrm{a}}$ is $\sim 0.24 \mathrm{eV}$ for $\mu_{\text {de }}$ (typical RF-PECVD value is $\sim 0.15 \mathrm{eV}$ ) and $\sim 0.39 \mathrm{eV}$ for $\mu_{\mathrm{dh}}$ (typical RF-PECVD values are $0.35-0.4 \mathrm{eV}$ ). Whereas the hole mobility is larger in ETP material compared to RF-PECVD a-Si:H, it remains lower than the electron mobility. Therefore the photoconductivity is still dominated by the electron mobility, resulting in a lower photoconductivity for the ETP material compared with RF-PECVD a-Si:H (Table 1.3). For a later series reported by Brinza et al. [66] the electron mobility of the ETP material was equal to RF-PECVD material and the photoconductivity for this series was also equal. It is noted that, though the hole drift mobility for ETP is larger, the activation energy for the hole mobility is similar.

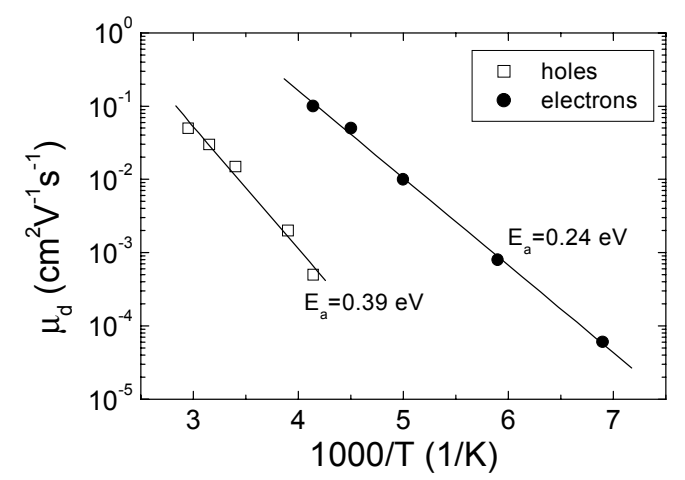

Figure 1.4: Drift-mobility of holes (open squares) and electrons (solid circles) for a-Si:H deposited with an ETP at $400^{\circ} \mathrm{C}$ and $10 \mathrm{~nm} / \mathrm{s}$ as determined from time-of-flight measurements.

TOF measurements have also been performed on samples deposited at 0.3 $\mathrm{nm} / \mathrm{s}$ and $3.0 \mathrm{~nm} / \mathrm{s}$. The samples deposited at $3.0 \mathrm{~nm} / \mathrm{s}$ have an optimum deposition temperature of $400^{\circ} \mathrm{C}$ and at this temperature the larger $\mu_{\mathrm{dh}}$ and lower $\mu_{\mathrm{de}}$ have also been observed [65]. However, for material deposited at $250^{\circ} \mathrm{C}$ and at a deposition rate of $0.3 \mathrm{~nm} / \mathrm{s}$, the $\mu_{\mathrm{dh}}$ and $\mu_{\mathrm{de}}$ were similar to that of RF-PECVD a-Si:H. 
The $\mu \tau$-product is determined both by the mobility of the charge carriers as well as by the defect density. The density of states and consequently the defect density have been determined from PTPA. Within the framework of the multiple trapping model [67] of carrier transport in amorphous semiconductors the post-transit current depends on the re-emission of carriers from the traps. In the post-transit regime the carrier released at any time will immediately leave the sample. This means the current is proportional to the number of carriers released from the traps and thus to the density of states, under the assumption of an energy independent cross-section for capture. Accordingly, from TOF measurements the DOS distribution of deep traps can be obtained revealing gap states of electrons and holes separately.

Under the same assumptions as for RF-PECVD a-Si:H the DOS distribution of electronic deep traps in ETP a-Si:H has been calculated and is shown in Figure 1.5. The three profiles obtained at different measurement temperatures match, validating the method. This figure shows that the mid-gap electron trap-density of ETP a-Si:H is located $\sim 0.8 \mathrm{eV}$ below the conduction band-edge with a maximum density of $7 \times 10^{16} \mathrm{~cm}^{-3} \mathrm{eV}^{-1}$. The integrated density of this trap density is $6.4 \times 10^{15} \mathrm{~cm}^{-3}$, which suggests good film quality. The value is similar to that obtained for RF-PECVD a-Si:H [68] except that for ETP a-Si:H the traps are located somewhat deeper. Furthermore, the data suggest that the background DOS, between the band tail and the mid-gap states, is orders of magnitude lower than the mid-gap trap density whereas only one order of magnitude difference is observed for RF-PECVD a-Si:H [68].

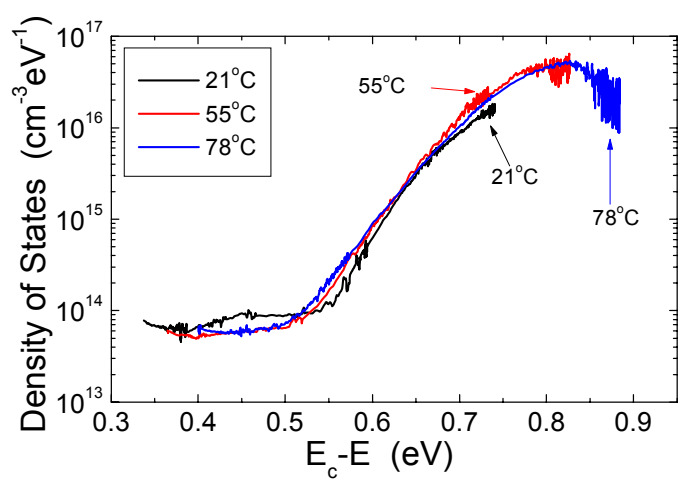

Figure 1.5: Density of states distribution of the gap states of electrons as a function of the position with regard to the conduction band resolved from PTPA [65]. The independence of temperature and the extremely low DOS in between the mid-gap and the band tails is clearly visible.

The same measurements on the DOS distribution of hole gap states revealed that the mid-gap hole trap density is located $0.8-0.9 \mathrm{eV}$ above the valence bandedge. With similar estimations as for the electrons the integrated density of mid-gap hole traps is $\sim 5 \times 10^{16} \mathrm{~cm}^{-3}$. Again the DOS between the band tail and the mid-gap traps is orders of magnitude lower than the mid-gap trap density.

\section{Discussion}

Compared with solar grade RF-PECVD a-Si:H a larger hole drift mobility, a somewhat smaller electron drift mobility, a lower optical bandgap, a lower hydrogen content in the films, and a comparable defect density are obtained with the ETP method. The larger hole mobility should be favourable as the hole mobility is a 
limiting factor for the application of a-Si:H in solar cells [e.g. 69]. Furthermore, it is interesting to note that a smaller hydrogen content does not mean that there are more defects in the material. The lower hydrogen content is a striking similarity with HW-CVD material [61]. Mahan et al. [60] showed differences in opto-electronic properties compared with RF-PECVD and reported better structural order of the HWCVD material. They suggested high substrate temperatures, deposition in a high flux of atomic hydrogen, and absence of energetic particle bombardment as possible reasons for the improved structure. The importance of well-structured material has been shown by e.g. Guha et al. [70]. They showed that improved medium-range order resulted in better light stability. For their research they compared the improved medium-range order of samples deposited with hydrogen dilution with samples deposited without using hydrogen dilution as grown with RF-PECVD. Furthermore, Middya et al. [71] reported that the improved stability of their a-Si:H, which they call quasi-amorphous, is also specifically correlated with the improved structure of the local Si-Si tetrahedral network. In addition, a relatively high ambipolar diffusion length at very low hydrogen concentration was reported for HW-CVD [60], which can be compared with the higher hole mobility [72] at relatively low hydrogen concentration for ETP a-Si:H deposited at large growth rate and high deposition temperature. The correlation between hole drift mobility and ambipolar diffusion length has for example also been made by Fölsch et al. [73], who attributed a decrease in ambipolar diffusion length to a decrease in hole mobility.

The formation of more compact structured a-Si:H requires extra energy at the growing surface, which can be provided by energetic particles, atomic hydrogen, and a higher substrate temperature. Atomic hydrogen influences the weak bond concentration [74] resulting in structural relaxation $[61,75,76]$ due to the energy that is released by this interaction. The influence of the $\mathrm{H}$-flux on the quality of the material is discussed in an extended kinetic growth model by Van de Sanden et al. [77] and by numerous other groups [e.g. 74,78]. A higher substrate temperature provides extra thermal energy over the whole growing film and the impact of ions provides some extra energy locally. Concerning the energetic ions it seems that ions with energy up to $25 \mathrm{eV}$ have an important contribution to the material quality obtained with RF-PECVD [e.g. 79-81]. Finger et al. also observed that an increased ion flux resulted in less hydrogen contributing to the stretching mode peak between 2060 and $2100 \mathrm{~cm}^{-1}$ [82]. In the ETP close to the substrate atomic hydrogen and energetic ions are nearly present [e.g. 83] except for the $\mathrm{H}$ atoms that are released from radicals during the growth process at the surface. This indicates that the substrate temperature provides the required energy for optimum growth in the case of an ETP, i.e., a high temperature is needed for the necessary cross-linking step at the surface in absence of ion bombardment [32,84-87]. At the elevated temperatures the high growth rate is needed to prevent thermal hydrogen desorption from the surface-region to become significant [53]. So for the ETP method both the high growth rate and the high temperature are required to obtain a higher hole drift mobility.

Other issues that should be taken into account are the lower defect density between the mid-gap and the tail-states (Fig. 1.5), and the deeper traps for the electrons in ETP material deposited at $400^{\circ} \mathrm{C}$ [66]. This last observation followed from the measured activation energy for electron drift-mobility, which was $\sim 0.24 \mathrm{eV}$ for ETP aSi:H and $\sim 0.15$ for RF-PECVD. Deeper traps for electrons influence the time for electrons to leave the sample in TOF measurements and therefore the electron drift 
mobility. A different activation energy for electron mobility points to different kinds of traps [88-90] or traps residing in slightly different-structured material. This last idea might be comparable with results on hydrogen in a-Si:H obtained with NMR on highly structured HW-CVD a-Si: $\mathrm{H}$, for which a non-homogeneous distribution of hydrogen throughout the material was found [61]. Dangling bonds on void surfaces or within a compact Si network will result in other activation energies for the release of trapped electrons. Therefore an NMR study on ETP material deposited at large growth rate and high temperature would possibly give some valuable additional information about the structure of the ETP a-Si:H.

Recently, Middya et al. [71] have reported lower defect density of states between mid-gap and the tail-states for their 'quasi' a-Si:H. This is another striking similarity with ETP a-Si:H deposited at large growth rate and high deposition temperature. They reported values of $5 \cdot 10^{14} \mathrm{~cm}^{-3} \mathrm{eV}^{-1}$ and reported that so far they could only attribute this effect to local small-scale ordering. Furthermore, the similarity between their material and a-Si:H deposited with ETP include a higher dark conductivity together with a lower activation energy for electron conductivity, and a hydrogen content of 6-8 at.\%.

Summarising, time-of-flight measurements on hydrogenated amorphous silicon deposited with a remote expanding thermal plasma at growth rates of $10 \mathrm{~nm} / \mathrm{s}$ and a deposition temperature of $400^{\circ} \mathrm{C}$ revealed a hole mobility $7-10$ times higher than that for films deposited with conventional RF-PECVD. Determination of the density of states by post-transit photocurrent analysis suggests a comparable defect density at mid-gap, but a lower defect density between mid-gap and the tail-states. The traps also seem to be deeper. These material properties have been obtained at a substrate temperature of $400^{\circ} \mathrm{C}$, which is needed to obtain good a-Si:H at these high growth rates.

\subsubsection{The first solar cells within the project}

Incorporating material with a larger hole mobility could lead to solar cells with a higher efficiency as the hole mobility is the limiting factor in solar cells [e.g. 69]. The larger hole mobility, however, was only obtained at deposition temperatures $\geq 300^{\circ} \mathrm{C}$. This temperature would adversely affect the p-layer properties, as will be discussed in Section 4.3.3.

Three p-i-n structured solar cells were made for which the deposition temperature of the intrinsic layers was varied. These layers were deposited at $250^{\circ} \mathrm{C}$, $300^{\circ} \mathrm{C}$, and $350^{\circ} \mathrm{C}$. The intrinsic layers have a thickness of $\sim 400 \mathrm{~nm}$ and are deposited at a growth rate of $\sim 10 \mathrm{~nm} / \mathrm{s}$. For these $\mathrm{p}$-i-n structures a vacuum break was necessary, as the doped layers were made at the Delft University of Technology and the intrinsic layers at the Eindhoven University of Technology.

The highest efficiency (4.1\%) was obtained with the intrinsic layer deposited at $300^{\circ} \mathrm{C}$ (Fig. 1.6). The efficiency is mainly limited by the $V_{\text {oc }}$, which is $\sim 0.2 \mathrm{~V}$ lower than that normally obtained for a-Si:H solar cells ${ }^{10}$. The $V_{o c}$ is influenced both by the deposition temperature as well as by the vacuum breaks in between the deposition of the subsequent layers. As a result of the vacuum breaks the fill factor is lower than obtained normally. At $250^{\circ} \mathrm{C}$ the $V_{\text {oc }}$ was higher and the $J_{\mathrm{sc}}$ was lower, indicating that

\footnotetext{
${ }^{10}$ Good solar cell characteristics for single junction a-Si:H solar cells are: $V_{\mathrm{oc}}>0.8 \mathrm{~V}, \mathrm{~J}_{\mathrm{sc}}>16 \mathrm{~mA} / \mathrm{cm}^{2}$, and $\mathrm{FF}>0.7$.
} 
the internal electric field in the cell is larger but that the intrinsic material quality is inferior. At $350^{\circ} \mathrm{C}$ the intrinsic layer is better but the p-type layer is damaged much more than in the $300^{\circ} \mathrm{C}$ case, resulting in an even lower $V_{\text {oc }}$. Important to note here is that a $J_{\mathrm{sc}}$ of $14.3 \mathrm{~mA} / \mathrm{cm}^{2}$ was already achieved at a temperature of $300^{\circ} \mathrm{C}$, even though this is not the best material regarding the hole mobility and photoconductivity. This shows the potential of the material if it was to be incorporated in a solar cell configuration that would not suffer from deterioration of the $\mathrm{p}$-layer.

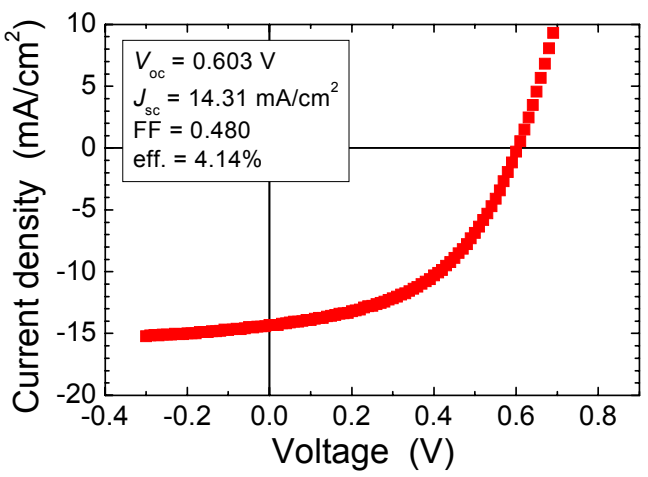

Figure 1.6: J, V-characteristics of a p-i-n deposited solar cell, with the $p$-and n-layer deposited at the Delft University of Technology, and with the $400 \mathrm{~nm}$ thick intrinsic layer deposited at $300^{\circ} \mathrm{C}$ and $10 \mathrm{~nm} / \mathrm{s}$ at the Eindhoven University of Technology using the ETP technique. The cell was measured at the Utrecht University.

One more remark has to be made regarding experiments with a vacuumbreak in between the doped layers and the intrinsic layer. Increasing the time of the vacuum-break between the p-layer and the intrinsic layer will increase the oxidation of this interface. This will lead to an S-curve shaped $J, V$-characteristic, which primarily leads to a reduced fill factor. The influence on solar cell performance of oxidation between the n-layer and the intrinsic layer is much less.

\subsubsection{Conclusions}

It has been shown that ETP deposited a-Si:H, grown at $10 \mathrm{~nm} / \mathrm{s}$ and $400^{\circ} \mathrm{C}$, is promising for its application in thin a-Si:H solar cells. This a-Si:H shows many similarities on material properties with highly structured HW-CVD a-Si:H. For the ETP a-Si:H a mid-gap density of states of the same order of magnitude and a hole mobility of one order of magnitude higher, compared with RF-PECVD a-Si:H, was reported. This will most probably lead to a higher $\mu \tau$-product. However, the deposition temperature of $400^{\circ} \mathrm{C}$ poses a problem because it results in the deterioration of the p-type layer in the standard sequence of a p-i-n solar cell. Making a solar cell with the intrinsic layer deposited at $300^{\circ} \mathrm{C}$ resulted in a cell with an initial efficiency of $4.1 \%$, mainly due to a smaller $V_{\text {oc }}$ and $F F$, but with a good $J_{\text {sc. }}$.

The main challenge would be to use the material deposited at $400^{\circ} \mathrm{C}$ in a solar cell configuration for which the doped layers do not deteriorate due to the high temperature. With regard to this it is important to look at cells made using HW-CVD as this technique also requires higher substrate temperatures and has achieved reasonable solar cells efficiencies. Furthermore, optimisation of material quality at lower temperature and optimisation of the entire solar cell is required as well as the investigation of new solar cell concepts and more fundamental insight into the 
material properties. Therefore a new set-up has been constructed and built with which it is possible to make complete solar cells incorporating intrinsic a-Si:H deposited with the ETP method. Furthermore, a way to confirm the material properties of the material deposited at $10 \mathrm{~nm} / \mathrm{s}$ and $400^{\circ} \mathrm{C}$ would be to measure the ambipolar diffusion length and the $\mu \tau$-product before and after light-induced degradation.

\subsection{Research goal}

With the ETP method the possibility to grow solar grade material at growth rates of $\sim 10 \mathrm{~nm} / \mathrm{s}$ has been shown [e.g. 38,91,92]. The next step was to integrate this material in a-Si:H based solar cells. Therefore a new set-up has been built which allows for the production of solar cells within one machine. This new set-up is part of the project named CASCADE. The aim of CASCADE is to demonstrate the possibility of incorporating solar grade material grown at growth rates $>2 \mathrm{~nm} / \mathrm{s}$ in a$\mathrm{Si}: \mathrm{H}$ solar cells resulting in solar cells with an initial efficiency of at least $7 \%$. This is a challenging goal to start with. Later on the efficiency has to increase to at least $8 \%$ in a module [15], but such an increase can largely be achieved by optimisation of the cell structure. These optimisations include buffer layers, intermediate layers, coatings, back-reflectors, etc. to enhance the optical path of the light in the solar cells.

\subsection{Outline}

The achievements presented in this thesis is a result of the co-operation between Delft and Eindhoven and will focus on the cascaded arc expanding thermal plasma for the fast deposition of hydrogenated amorphous silicon as it can be used within solar cells. After this general introduction and the motivation behind this project, the new set-up has been built to prove the expectations that good a-Si:H solar cells can be obtained with the ETP method at large growth rates. The set-up is described in Chapter 2. In the test set-up at the Eindhoven University relatively large gas flows are used and an additional aim of this project is to lower the gas flows, while maintaining large growth rates. In Chapter 3 the plasma is described that is used to deposit a-Si:H. Furthermore, Chapter 3 discusses the plasma physics and chemistry of reducing the argon flow, decreasing the plasma channel diameter of the plasma source, and injection of hydrogen into the nozzle. The optimisation of the growth rate and substrate temperature for solar cell production is presented in Chapter 4 . In first instance we concentrate in Chapter 4 on deposition experiments with low deposition rates $(<1 \mathrm{~nm} / \mathrm{s})$ at deposition temperatures of $250^{\circ} \mathrm{C}$. In Chapter 5 the focus will be on larger growth rates that require higher deposition temperatures. Results from the optimisation of the solar cells are presented after which the general conclusions are drawn in Chapter 6. 
References

1. R.A. Street, Hydrogenated amorphous silicon, Cambridge University Press, (1991)

2. J. Yang, A. Banerjee, and S. Guha, Appl. Phys. Lett., 70 (1997) 2975; J. Yang,

A. Banerjee, K. Lord, and S. Guha, Proc. of $2^{\text {nd }}$ world PVSEC (1998) 387

3. C. Beneking, B. Rech, S. Wieder, O. Kluth, H. Wagner, W. Frammelsberger, R. Geyer, P. Lechner, H. Rübel, and H. Schade, Thin Solid Films, 351 (1999) 241

4. H.F. Sterling and R.C.G. Swann, Solid-State Electron., 8 (1965) 653

5. R.C. Chittick, J.H. Alexander, and H.F. Sterling, J. Electrochem. Soc., 116 (1969) 77

6. W. Spear and P. LeComber, Solid State Comm., 17 (1975) 1193

7. M.H. Brodsky, M. Cardona, and J.J. Cuomo, Phys. Rev. B, 16 (1997) 3556

8. C.M. Fortmann, Phys. Rev. Lett., 81 (1998) 3683

9. D.L. Staebler and C.R. Wronski, Appl. Phys. Lett., 31 (1977) 292

10. R. Biswas and Y.-P. Li, Phys. Rev. Lett., 82 (1999) 2512

11. H.M. Branz, Solid State Commun., 105 (1998) 387

12. D.E. Carlson and C.R. Wronski, Appl. Phys. Lett., 28 (1976) 671

13. Y. Ushida, T. Ichimura, M. Ueno, and H. Haruki, Jap. J. Appl. Phys., 21 (1982) L586

14. A. Matsuda, Jap. J. Appl. Phys., 20 (1981) L183

15. S. Guha, J. Yang, A. Banerjee, and S. Sugiyama, Mat. Res. Soc. Symp. Proc., 507 (1998) 99

16. Achtergronddocument bij het PV convenant 2001-2007, PV stuurgroep, maart 2000

17. L. Frantzis and E. Jones, Proc. of $16^{\text {th }}$ E-PVSEC (2000) PE1.2

18. W. Luft and Y.S. Tsuo, Hydrogenated amorphous silicon alloy deposition processes, Marcel Dekker, New York (1993)

19. M. Heintze, R. Zedlitz, and G.H. Bauer, J. Phys. D: Appl. Phys., 26 (1993) 1781

20. T. Nishimoto, M. Takai, M. Kondo, and A. Matsuda, Proc. of $28^{\text {th }}$ IEEE-PVSC (2000) 876

21. J. Kuske, U. Stephan, O. Steinke, and S. Rohlecke, Mat. Res. Soc. Symp. Proc., 377 (1995) 27

22. L. Sansonnens, A. Pletzer, D. Magni, A.A. Howling, Ch. Hollenstein, and J.P.M. Schmitt, Plasma Sources Sci. Technol., 6 (1997) 170

23. L. Sansonnens, A.A. Howling, and Ch. Hollenstein, Mat. Res. Soc. Symp. Proc., 507 (1998) 541

24. Y. Takeuchi, Y. Nawata, K. Ogawa, A. Serizawa, Y. Yamauchi, and M. Murata, Thin Solid Films, 386 (2001) 133

25. U. Kroll, D. Fischer, J. Meier, L. Sansonnens, A. Howling, and A. Shah, Mat. Res. Soc. Symp. Proc., 557 (1999) 121

26. H. Matsumura, Thin Solid Films, 395 (2001) 1

27. A.H. Mahan, Y. Xu, B.P. Nelson, R.S. Crandall, J.D. Cohen, K.C. Palinginis, and A.C. Gallagher, Appl. Phys. Lett., 78 (2001) 3788

28. G.M.W. Kroesen, D.C. Schram, and J.C.M. de Haas, Plasma Chem. Plasma Proc., 10 (1990) 531

29. M.C.M. van de Sanden, W.M.M. Kessels, R.J. Severens, and D.C. Schram, Plasma Phys. Control. Fusion, 41 (1999) A365

30. W.M.M. Kessels, C.M. Leewis, M.C.M. van de Sanden, and D.C. Schram, J. Appl. Phys., 86 (1999) 4029 
31. W.M.M. Kessels, A.H.M. Smets, B.A. Korevaar, G.J. Adriaenssens, M.C.M. van de Sanden, and D.C. Schram, Mat. Res. Soc. Symp. Soc., 557 (1999) 25

32. W.M.M. Kessels, R.J. Severens, M.C.M. van de Sanden, and D.C. Schram, J. of Non Cryst. Solids, 227-230 (1998) 133

33. R.J. Severens, W.M.M. Kessels, L. Gabella, F. van de Pas, M.C.M. van de Sanden, and D.C. Schram, Proc. of $13^{\text {th }}$ Int. Symp. Plasma Chem., Beijing (1997) 1059

34. D.C. Schram and G.M.W. Kroesen, Method of treating surfaces and substrates with the aid of a plasma and a reactor for carrying out the method, American patent 4,871,580 (1989) and European patent 0297637 (1992)

35. H. Maecker, Z. Naturforsch., 11a (1956) 457

36. G.J. Meeusen, Ph. D. Thesis, Eindhoven University of Technology (1994)

37. G.J. Meeusen, R.P. Hahiya, M.C.M. van de Sanden, G. Dinescu, Z. Qing, R.F.G. Meulenbroeks, and D.C. Schram, Plasma Sources Sci. Technol., 3 (1994) 521

38. R.J. Severens, G.J.H. Brussaard, H.J.M. Verhoeven, M.C.M. van de Sanden, and D.C. Schram, Mat. Res. Soc. Symp. Proc., 377 (1995) 33

39. W.M.M. Kessels, Ph. D. Thesis, Eindhoven University of Technology (2000)

40. A.H.M. Smets, Ph. D. Thesis, Eindhoven University of Technology (2002)

41. S. Guha, J. Yang, S.J. Jones, Y. Chan, and D.L. Williamson, Appl. Phys. Lett., 61 (1992) 1444

42. A.H. Mahan, Y. Xu, E. Iwaniczko, D.L. Williamson, W. Beyer, J.D. Perkins, M. Vanecek, L.M. Gedvilas, and B.P. Nelson, Mat. Res. Soc. Symp. Proc., 664 (2001) A3.3

43. M. Takai, T. Nishimoto, M. Kondo, and A. Matsuda, Proc. of $28^{\text {th }}$ IEEE-PVSC (2000) 721

44. B. Schröder, U. Weber, H. Seitz, A. Ledermann, and C. Mukherjee, Proc. of $17^{\text {th }}$ E-PVSEC (2001) OD1.2

45. J. Yang, S. Sugiyama, and S. Guha, Mat. Res. Soc. Symp. Proc., 507 (1998) 157

46. A.H. Mahan, R.C. Reedy, E. Iwaniczko, Q. Wang, B.P. Nelson, Y. Xu, A.C. Gallagher, H.M. Branz, R.S. Crandall, J. Yang, and S. Guha, Mat. Res. Soc. Symp. Proc., 507 (1998) 119

47. B.P. Nelson, E. Iwaniczko, A.H. Mahan, Q. Wang, Y. Xu, R.S. Crandall, and H.B. Branz, Thin Solid Films, 395 (2001) 292

48. S. Guha, X. Xu, J. Yang, and A. Banerjee, Appl. Phys. Lett., 66 (1995) 595

49. S.J. Jones, X. Deng, T. Liu, and M. Izu, Mat. Res. Soc. Symp. Proc., 557 (1999) 133

50. R.E.I. Schropp and M. Zeman, Amorphous and microcrystalline silicon solar cells, Kluwer Academic Publishers (1998) Boston/Dordrecht/London

51. M. Stutzmann, Philosophical Magazine B, 60 (1989) 531

52. B.A. Korevaar, C. Smit, A.H.M. Smets, R.A.C.M.M. van Swaaij, D.C. Schram, and M.C.M. van de Sanden, Proc. of the $28^{\text {th }}$ IEEE-PVSC conference (2000), 916

53. W.M.M. Kessels, A.H.M. Smets, D.C. Marra, E.S. Aydil, D.C. Schram, and M.C.M. van de Sanden, Thin Solid Films, 383 (2001) 154

54. D. Lundszien, J. Fölsch, F. Finger, and H. Wagner, Proc. of $14^{\text {th }}$ EC-PVSEC (1997) 578

55. W.M.M. Kessels, M.C.M. van de Sanden, R.J. Severens, L.J. van IJzendoorn, and D.C. Schram, Mat. Res. Soc. Symp. Proc., 507 (1998) 529

56. E. Bhattacharya and A.H. Mahan, Appl. Phys. Lett., 52 (1988) 1587 
57. N. Nakamura, T. Takahama, M. Isomura, M. Nishikuni, K. Yoshida, S. Tsuda, S. Nakano, M. Ohnishi, and Y. Kuwano, Jap. J. Appl. Phys., 28 (1989) 1762

58. T. Matsumoto, Y. Murata, and J. Watanabe, Appl. Phys. Lett., 60 (1992) 1942

59. W. Beyer and H. Wagner, J. de Physique, C4 (1981) 783

60. A.H. Mahan, J. Carapella, B.P. Nelson, R.S. Crandall, and I. Balberg, J. Appl. Phys., 69 (1991) 6728

61. Y. Wu, J.T. Stephen, D.X. Han, J.M. Rutland, R.S. Crandall, and A.H. Mahan, Phys. Rev. Lett., 77 (1996) 2049

62. K.F. Feenstra, Ph. D. Thesis, Utrecht University (1998)

63. G.J. Adriaenssens, H.-Z. Song, V.I. Arkhipov, E.V. Emelianova, W.M.M. Kessels, A.H.M. Smets, B.A. Korevaar, M.C.M. van de Sanden, J. of Optoelec. And Adv. Mat., 2 (2000) 31

64. G.F. Seynhaeve, R.P. Barclay, G.J. Adriaenssens, and J.M. Marshall, Phys. Rev. B, 39 (1989) 10196

65. H.-Z. Song and G.J. Adriaenssens, unpublished results

66. M. Brinza, G.J. Adriaenssens, K. lakoubovskii, A. Stesmans, W.M.M. Kessels, A.H.M. Smets, B.A. Korevaar, and M.C.M. van de Sanden, submitted to J. Non Cryst. Sol.

67. F.W. Schmidlin, Phys. Rev. B, 16 (1977) 2362

68. B. Yan and G.J. Adriaenssens, J. Appl. Phys., 77 (1995) 5661

69. S.S. Hegedus, Proc. Of $20^{\text {th }}$ IEEE-PVSC (1988) 102

70. S. Guha, J. Yang, D.L. Williamson, Y. Lubianiker, J.D. Cohen, A.H. Mahan, Appl. Phys. Lett., 74 (1999) 1860

71. A.R. Middya, S. Hamma, S. Hazra, S. Ray, and C. Longeaud, Mat. Res. Soc. Symp. Proc., 664 (2001) A25.6

72. I. Sakata, M. Yamanaka, and T. Sekigawa, Jap. J. Appl. Phys., 33 (1994) L567

73. J. Fölsch, F. Finger, H. Stiebig, B. Rech, D. Lundszien, W. Beyer, T. Kulessa, W. Reetz, and H. Wagner, Proc. of $13^{\text {th }}$ EC-PVSEC (1995) 257

74. H.M. Branz and S.B. Zhang, Mat. Res. Soc. Symp. Proc., 664 (2001) A13.3

75. Z. Remes, M. Vanecek, A.H. Mahan, and R.S. Crandall, Phys. Rev. B, 56 (1997) R12710

76. R.A. Street, Phys. Rev. B, 43 (1991) 2454

77. M.C.M. van de Sanden, A.H.M. Smets, W.M.M Kessels, B.A. Korevaar, and D.C. Schram, to be published

78. J. Robertson, J. Appl. Phys., 87 (2000) 2608

79. P. Roca i Cabarrocas, Appl. Phys. Lett., 65 (1994) 1674

80. E.A.G. Hamers, W.G.J.H.M. van Sark, J. Bezemer, H. Meiling, and W.F. van der Weg, J. of Non Cryst. Solids, 226 (1998) 205

81. C. Rosenblad, H.R. Deller, T. Graf, E. Müller, and H. von Känel, J. of Cryst. Growth, 188 (1998) 125

82. F. Finger, U. Kroll, V. Viret, W. Beyer, X-M. Tang, J. Weber, A. Howling, and Ch. Hollenstein, J. Appl. Phys., 71 (1992) 5665

83. M. de Graaf, Ph. D. Thesis, Eindhoven University of Technology (1995)

84. G. Ganguly and A. Matsuda, Mat. Res. Soc. Symp. Proc., 258 (1992) 39

85. A. Gallagher, Mat. Res. Soc. Symp. Proc., 70 (1986) 3

86. J. Perrin, Y. Takeda, N. Hirano, Y. Takeuchi, and A. Matsuda, Surf. Sci., 210 (1989) 114 
87. B.A. Korevaar, C. Smit, R.A.C.M.M van Swaaij, A.H.M. Smets, W.M.M. Kessels, J.W. Metselaar, D.C. Schram, and M.C.M. van de Sanden, Proc. $16^{\text {th }}$ PVSEC, Glasgow (2000) B119

88. S. Heck and H.M. Branz, Mat. Res. Soc. Symp. Proc., 664 (2001) A12.2

89. J. Pearce, X. Niu, R. Koval, G. Ganguly, D. Carlson, R.W. Collins, and D.R. Wronski, Mat. Res. Soc. Symp. Proc., 664 (2001) A12.3

90. P. Stradins, S. Shimizu, M. Kondo, and A. Matsuda, Mat. Res. Soc. Symp. Proc., 664 (2001) A12.1

91. B.A.Korevaar, A.H.M. Smets, W.M.M. Kessels, G. Adriaenssens, M.C.M. van de Sanden, and D.C. Schram, J. Non Cryst. Sol., 266-269 (1999) 380

92. W.M.M. Kessels, R.J. Severens, A.H.M. Smets, B.A. Korevaar, G.J. Adriaenssens, D.C. Schram, and M.C.M. van de Sanden, J. Appl. Phys., 89 (2001) 2404 


\section{Chapter 2}

2. Experimental: combining RF-PECVD and Expanding Thermal Plasma (ETP) 


\subsection{Introduction}

In Section 1.3 it was shown that solar grade a-Si:H could be obtained at growth rates up to $10 \mathrm{~nm} / \mathrm{s}$ with the expanding thermal plasma (ETP) method [1]. The next step is to incorporate this material into actual thin film a-Si:H solar cells. Initially, this was accomplished by growing the first doped layer in the AMOR system of DIMES at Delft University of Technology or in the PASTA system at Utrecht University. Then the sample was transported to Eindhoven where the intrinsic layer was deposited. Then the solar cell was completed in Delft or in Utrecht, which made two vacuum breaks necessary. Such deposition runs lack optimisation and always need two vacuum breaks, which influences the final solar cell characteristics significantly. Therefore collaboration was started between the Delft and Eindhoven Universities of Technology to build a new set-up (Fig. 2.1) that allows the deposition of doped layers in an RF-PECVD chamber and intrinsic a-Si:H layers in an ETP chamber such that complete solar cells can be made without breaking the vacuum. The new set-up therefore consists of three vacuum chambers: an ETP deposition chamber, an RFPECVD chamber, and a load-lock. The load-lock is used for the insertion of new samples and the transport between the two deposition chambers.

In this chapter the design, construction, and characteristics of the new set-up will be described. Section 2.2 discusses the technical specifications of the set-up and its operation. This large section is divided in a section dealing with the RF-PECVD chamber (Section 2.2.1), the ETP chamber (Section 2.2.2), the load-lock (Section 2.2.3), the substrate holder (Section 2.2.4), and the machine control (Section 2.2.5). The characterisation of the new set-up is presented in Section 2.3. In Section 2.4 the experimental techniques to characterise the plasma, the deposited layers, and the solar cells are discussed. This section is followed by a short introduction to the solar cell simulation program ASA.

\subsection{The CASCADE set-up}

\subsubsection{RF-PECVD}

Radio Frequency Plasma Enhanced Chemical Vapour Deposition (RF-PECVD [e.g. 2-4]) at $13.56 \mathrm{MHz}$ is a widely used technique to produce the active layers for e.g. hydrogenated amorphous silicon (a-Si:H) solar cells, light detectors, and TFTs. RFPECVD uses a plasma to assist the dissociation of silane, hydrogen, and dopant gases needed for the deposition. This dissociation occurs due to the impact of electrons. The plasma is maintained between two electrode plates and is driven by an RF-signal (13.56 MHz). Growth rates for good quality a-Si:H are in the order of $0.2 \mathrm{~nm} / \mathrm{s}$. In this project the RF-PECVD chamber is used to deposit the doped layers of solar cells. In some cases intrinsic layers were also deposited. These intrinsic a$\mathrm{Si} \mathrm{H}$ layers are applied as intrinsic intermediate layers between the p-layer and the ilayer as grown with the ETP technique. 


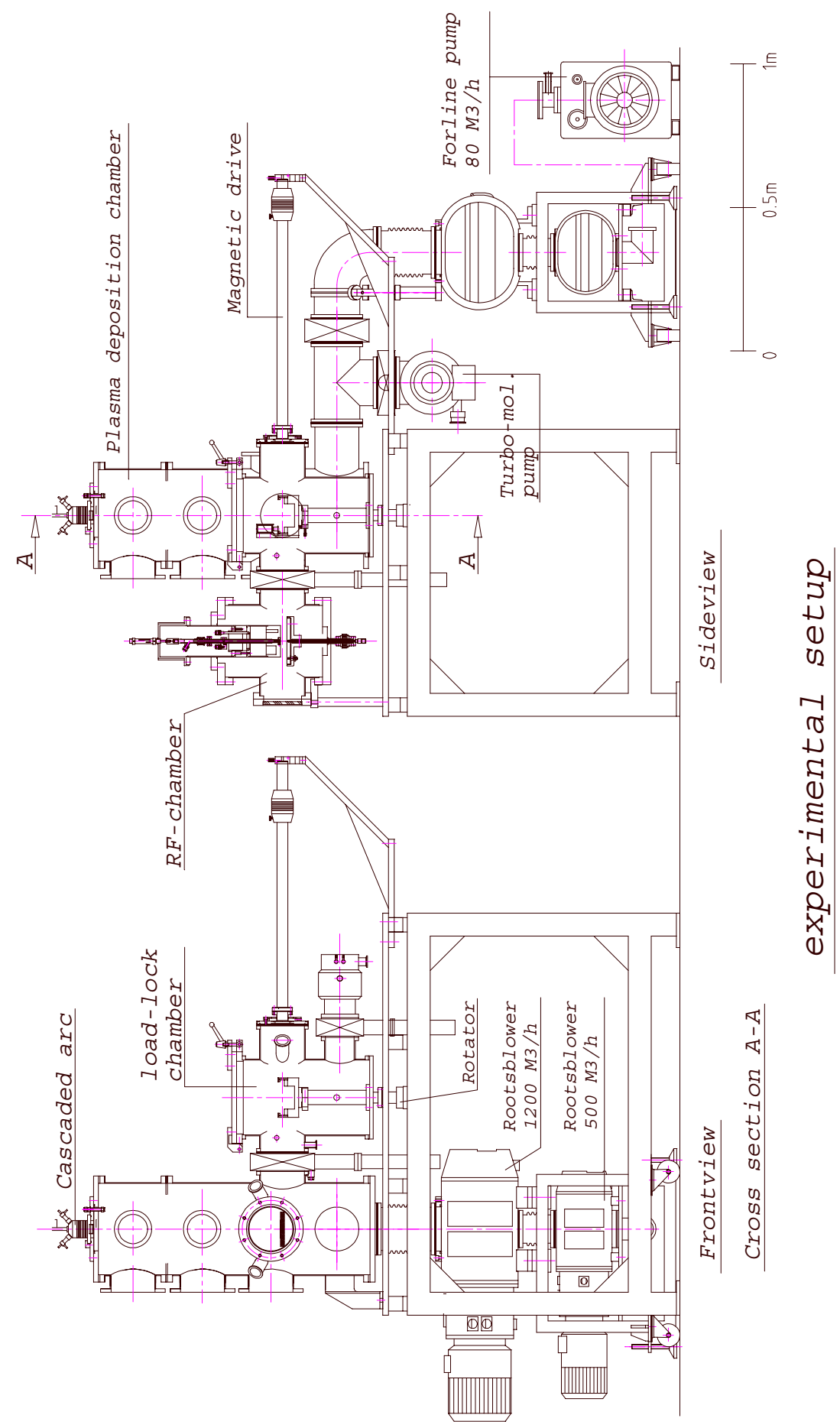

Figure 2.1: Schematic drawing of the complete set-up. A more detailed schematic drawing of the RFchamber can be found in Figure 2.2, of the cascaded arc in Figure 2.3, and a photo of an expanding thermal plasma can be seen in Figure 2.5.

In the present set-up the RF-plasma is generated between a stainless steel electrode plate with a diameter of $\sim 14 \mathrm{~cm}$ and a square substrate holder of the same 
dimensions (Fig. 2.2), which is mounted on a yoke (2.2.4) and can accommodate substrates of $10 \times 10 \mathrm{~cm}^{2}$. The substrate holder is grounded and the RF-signal is applied to the RF-electrode. The RF-generator can supply powers ranging from 0 to $100 \mathrm{~W}$ and is matched automatically by a matching network (both from Coaxial Power Systems Ltd.). The deposition is on the upper electrode, thus avoiding dust particles to fall on the substrate after termination of the RF plasma. By moving the RF-electrode up and down the distance between the substrate and the electrode can be varied between $\sim 10$ and $\sim 35 \mathrm{~mm}$. For the depositions presented in this thesis (powers $<5 \mathrm{~W}$, i.e., $<25 \mathrm{~mW} / \mathrm{cm}^{-2}$ ) the distance between the substrate and electrode is chosen to be $(19.5 \pm 0.5) \mathrm{mm}$.

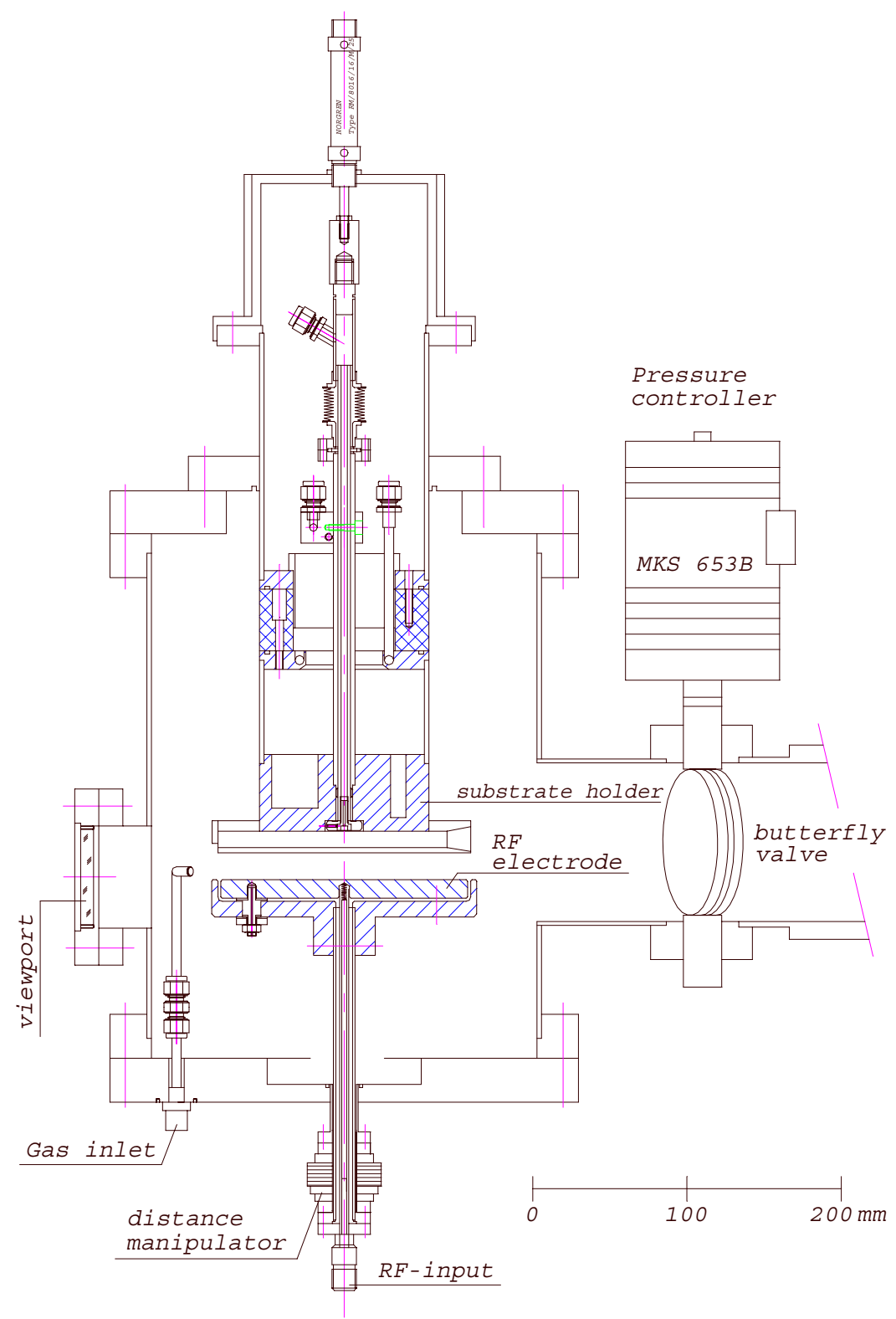

Figure 2.2: Schematic drawing of the RF-PECVD chamber. 
Due to the rather low growth rate ultra high vacuum (UHV) conditions are preferred, as experience has shown that UHV conditions resulted in good quality layers. The idea is that contaminants like oxygen, nitrogen, and water can be incorporated in the growing layers [5]. Nitrogen and oxygen act as n-type dopants in a-Si:H and all contamination will appear as defects in the a-Si:H structure, which can act as recombination centres for electrons and holes. Maintaining the background pressure in the $10^{-7}$ mbar range keeps the contamination concentration in the grown film very low and the effect of contamination is negligible.

For the RF-PECVD chamber UHV components are used, like conflat flanges with copper seals. This chamber is pumped by a chemical-resistant turbo molecular pump (Varian Turbo-V ICE) with a pumping speed of $250 \mathrm{l} / \mathrm{s}$ backed by a rotary pump (Balzers-Pfeiffer DUO $016 \mathrm{~B}$ ) with a pumping speed of $16 \mathrm{~m}^{3} / \mathrm{h}$. An MKS butterfly valve (type 653B-4-6CF-1) is used in combination with an MKS pressure regulator (1651C) and a Baratron pressure meter (627B11MLC) in order to have pressure control during processing. With this combination the pressure can be controlled in the range of $\sim 0.1$ to $\sim 10$ mbar during processing. When no deposition is performed the background pressure is $\sim 5 \cdot 10^{-7}$ mbar. This background pressure is not as low as the $10^{-7}$ mbar, but it should be sufficient, as the background pressure is still six orders of magnitude lower than the deposition pressure. This means that the partial pressure of the contamination is low enough, especially for the doped layers as these layers already contain more defects and have a higher conductivity. The reason for the somewhat higher background pressure is a small virtual leak inside the chamber and some leakage via the valve in between the load-lock and the RFPECVD chamber.

Table 2.1: Maximum condition range available within the RF-PECVD set-up and the conditions normally used to make p-, i-, and n-type a-Si:H. The $\mathrm{B}_{2} \mathrm{H}_{6}$ and the $\mathrm{PH}_{3}$ are both $2 \%$ in $\mathrm{H}_{2}$.

\begin{tabular}{|l|c|c|c|c|}
\hline & Range & $\begin{array}{c}\text { a-SiC:H:B } \\
\text { (p-type) }\end{array}$ & $\begin{array}{c}\text { a-Si:H } \\
\text { (intrinsic) }\end{array}$ & $\begin{array}{c}\text { a-Si:H:P } \\
\text { (n-type) }\end{array}$ \\
\hline $\mathrm{SiH}_{4}$-flow (nccm $\left.{ }^{11}\right)$ & $0-47$ & 19 & 37 & 37 \\
\hline $\mathrm{H}_{2}$-flow (nccm) & $0-186$ & 0 & 0 & 0 \\
\hline $\mathrm{B}_{2} \mathrm{H}_{6}$-flow (nccm) & $0-19$ & 2 & - & - \\
\hline $\mathrm{PH}_{3}$-flow (nccm) & $0-19$ & - & - & 10 \\
\hline $\mathrm{CH}_{4}$-flow (nccm) & $0-47$ & 42 & - & 0 \\
\hline He back flow (nccm) & $0-50$ & 0 & 0 & 0 \\
\hline Deposition temperature $\left({ }^{\circ} \mathrm{C}\right)$ & $0-500$ & 250 & $200-250$ & $200-400$ \\
\hline RF Power (W) & $0-100$ & 1.95 & $2-4$ & 1.70 \\
\hline Pressure (mbar) & $0.1-10$ & 0.74 & 0.74 & 0.64 \\
\hline Electrode distance (mm) & $10-35$ & 19.5 & 19.5 & 19.5 \\
\hline
\end{tabular}

Other requirements include good temperature control (see Section 2.3.1) and homogeneous deposition. To produce homogeneous layers, a good gas distribution in the chamber is required such that flow patterns do not influence the homogeneity of the growing film. Process gases are injected through a circular pipe containing five

\footnotetext{
${ }^{11}$ The Bronkhorst thermal mass-flow controllers are calibrated using the "normal millilitres per minute", in contrast to the more used "standard cubic centimetres per minute". The difference is the reference point. The "normal" is at 1013.25 mbar and $273.15 \mathrm{~K}$, whereas the "standard" is at $1013.25 \mathrm{mbar}$ and $293.15 \mathrm{~K}$, thus $100 \mathrm{nccm}=100 * 293.15 / 273.15 \mathrm{sccm}=107.32 \mathrm{sccm}$.
} 
small holes at the side of the chamber. The holes are directed towards the wall and a good gas distribution between the electrodes and homogeneous deposition is achieved (2.3.2). The plasma dissociates the gas that flows between the two plates and the radicals that are produced can contribute to the deposition [e.g. 6]. Table 2.1 shows the range of conditions available for the RF-PECVD chamber. Also indicated in this table are the deposition conditions that are usually used to grow the specified layers.

\subsubsection{The expanding thermal plasma}

The Expanding Thermal Plasma (ETP) is a relatively new deposition technique [7]. The ETP plasma is generated within a high-pressure plasma source, a cascaded arc [8]. The design of the cascaded arc (Fig. 2.3) is identical to the one used at the Eindhoven University of Technology. The cascaded arc consists of three tungsten cathode-tips that point into a small chamber, called the cathode housing. In this cathode housing argon and hydrogen gas is injected. The housing is connected to a cascade of six water-cooled copper plates with a bore in the centre having a diameter of $2.5 \mathrm{~mm}$, which form the plasma channel. The copper plates are insulated from each other by boron-nitride rings and vacuum-sealed with O-rings. A seventh, much larger plate, acts as grounded anode plate and forms the connection to the ETP chamber. In the anode plate a nozzle is mounted containing four holes through which hydrogen can be injected into the plasma beam. To create a stable, thermal plasma $^{12}$ a minimum pressure of $\sim 0.3$ bar is needed in the cathode housing. Pure argon ( 2000 nccm) is used as starting gas at an arc current of $\sim 40 \mathrm{~A}$. The current goes through the plasma channel and is controlled by the PLC (2.2.5). To generate a plasma under these conditions a voltage of $>400 \mathrm{~V}$ is temporarily needed at low current. When the argon plasma is initiated, the current increases and the voltage drops to $\sim 90 \mathrm{~V}$ around which value the plasma is maintained at a current of $\sim 40 \mathrm{~A}$ (Fig. 2.5). After starting, hydrogen can be added into the cathode housing and an $\mathrm{Ar} / \mathrm{H}_{2}$ plasma is created. This addition of hydrogen will increase the voltage (3.3.2). When the electric field between two copper plates of the arc becomes $>40 \mathrm{kV} / \mathrm{m}$ a voltage breakdown between the plates is very likely to occur and the plasma source will be damaged (Fig. 2.4). This limits the amount of $\mathrm{H}_{2}$ that can be used in the cathode housing. Due to the pressure difference between the cathode housing and the deposition chamber, the plasma flows through the arc-plasma channel and is injected into the chamber. The plasma in the arc channel has an electron temperature of $\sim 1 \mathrm{eV}$ [9] and a velocity in the order of the local velocity of sound $(\sim 2000 \mathrm{~m} / \mathrm{s})$ [10]. The plasma expands supersonically into the deposition chamber via the nozzle, shocks and moves subsonically towards the substrate. Silane is injected $\sim 4.5 \mathrm{~cm}$ after the expansion through a ring with a diameter of $\sim 8 \mathrm{~cm}$. The ring contains 8 holes with a diameter of $1 \mathrm{~mm}$ directed perpendicular to the flow direction.

\footnotetext{
${ }^{12}$ In a thermal plasma the electron temperature and the heavy particle temperature are approximately equal.
} 


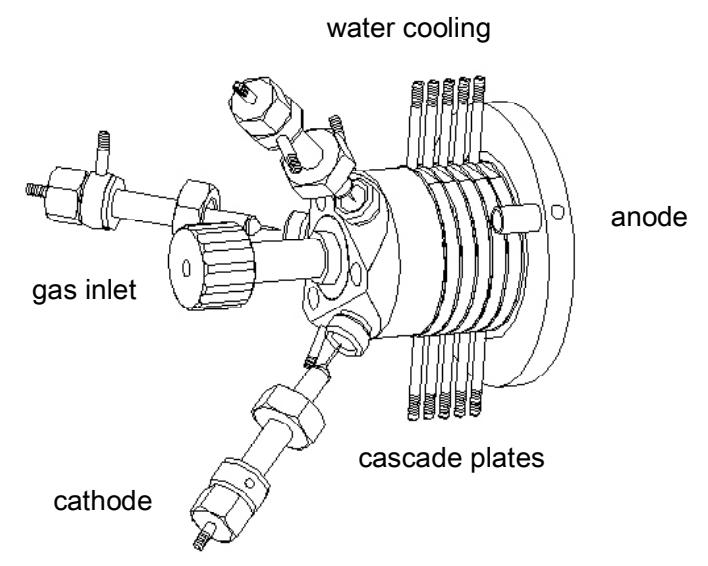

Figure 2.3: Schematic drawing of the cascaded arc. Visible are the gas inlet, the three cathodes, the cascade plates with water entrances for water-cooling, and the anode plate.

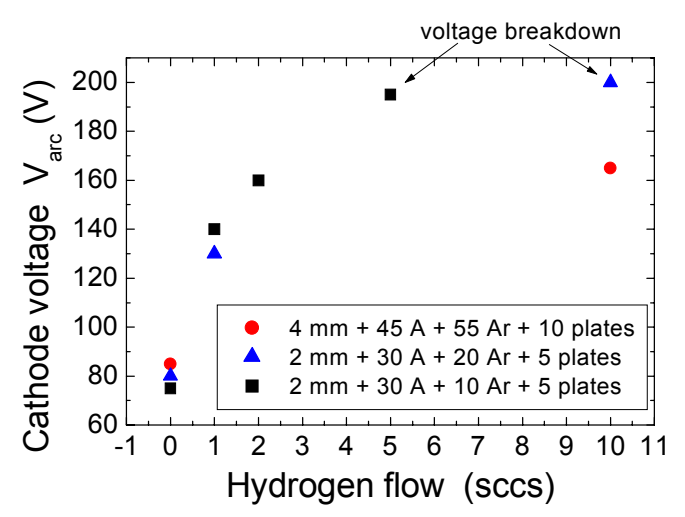

Figure 2.4: Cathode voltage as a function of the hydrogen flow. When the hydrogen flow was increased to larger values than the indicated points, a voltage breakdown occurred. The Ar flow is given in sccs.

The plasma source is mounted on top of a stainless steel vacuum chamber that has a height of $72 \mathrm{~cm}$ and a diameter of $33 \mathrm{~cm}$. An extra part with a height of 22 $\mathrm{cm}$ can be inserted in order to vary the distance from the plasma source to the substrate. The cascaded arc is placed on top of the chamber and a yoke, identical to the one used in the RF-PECVD chamber, is placed at the bottom (2.2.4). The distance from the source to the substrate can thus be varied and is either $\sim 41$ or $\sim 63$ $\mathrm{cm}$. The influence of the distance will be discussed in the Appendix; for all the other presented depositions in this thesis the distance of $\sim 41 \mathrm{~cm}$ is used, because this distance gives the best material properties. A few centimetres above the substrate a shutter is mounted, which is used to cover the substrate when starting the plasma and ending the deposition. From experiments [11] it was found that during starting up and shutting down of the plasma tungsten and copper particles from the arc can leave the source. During steady-state operation the amount of contamination is negligible.

With the ETP relatively high growth rates for a-Si:H are obtained ranging from 1 to 10 $\mathrm{nm} / \mathrm{s}$ [12]. Those high growth rates make the layers grown in this chamber less sensitive for contamination to be incorporated during growth than layers grown in the RF-PECVD chamber. Experience has shown that solar grade a-Si:H can be obtained at a background pressure in the order of $10^{-6} \mathrm{mbar}$ with this deposition technique [e.g. 1,12,13].

To obtain reasonable background pressures Viton O-rings are used in the ETP chamber. The ETP chamber is pumped with a $500 \mathrm{l} / \mathrm{s}$ turbo molecular pump (Balzers-Pfeiffer TPH 510) and a $3.3 \mathrm{~m}^{3} / \mathrm{h}$ rotary pump (Edwards RV3), resulting in a background pressure of $\sim 8 \cdot 10^{-7}$ mbar. Whereas the turbo molecular pump is used during processing in the RF-PECVD chamber, the gas flows in the ETP chamber are too large for this. Therefore, the ETP chamber uses during deposition a three stage pumping combination, consisting of a $1200 \mathrm{~m}^{3} / \mathrm{h}$ and a $500 \mathrm{~m}^{3} / \mathrm{h}$ roots blower (Edwards Mechanical Booster EH1200 and EH500A), which in turn is backed by an $80 \mathrm{~m}^{3} / \mathrm{h}$ rotary pump (Edwards Super 80 ). The effective pumping speed is $\sim 500 \mathrm{~m}^{3} / \mathrm{h}$ 
due to the extra pumping resistance as a consequence of the position of the pump with regard to the chamber geometry (Fig. 2.1). A working pressure of $0.16 \mathrm{mbar}$ is obtained for a total gas flow of $\sim 1000 \mathrm{nccm}$. The change in pressure is $\sim 0.01 \mathrm{mbar}$ per $100 \mathrm{nccm}$. It is important to obtain a working pressure of $\sim 0.2$ mbar for the homogeneity of the deposited film. At the aforementioned pressure of 0.16 mbar the film is homogeneous over an area with a diameter of $\sim 8 \mathrm{~cm}$ and this homogeneous area reduces to $\sim 5 \mathrm{~cm}$ for a pressure of $\sim 0.25$ mbar.

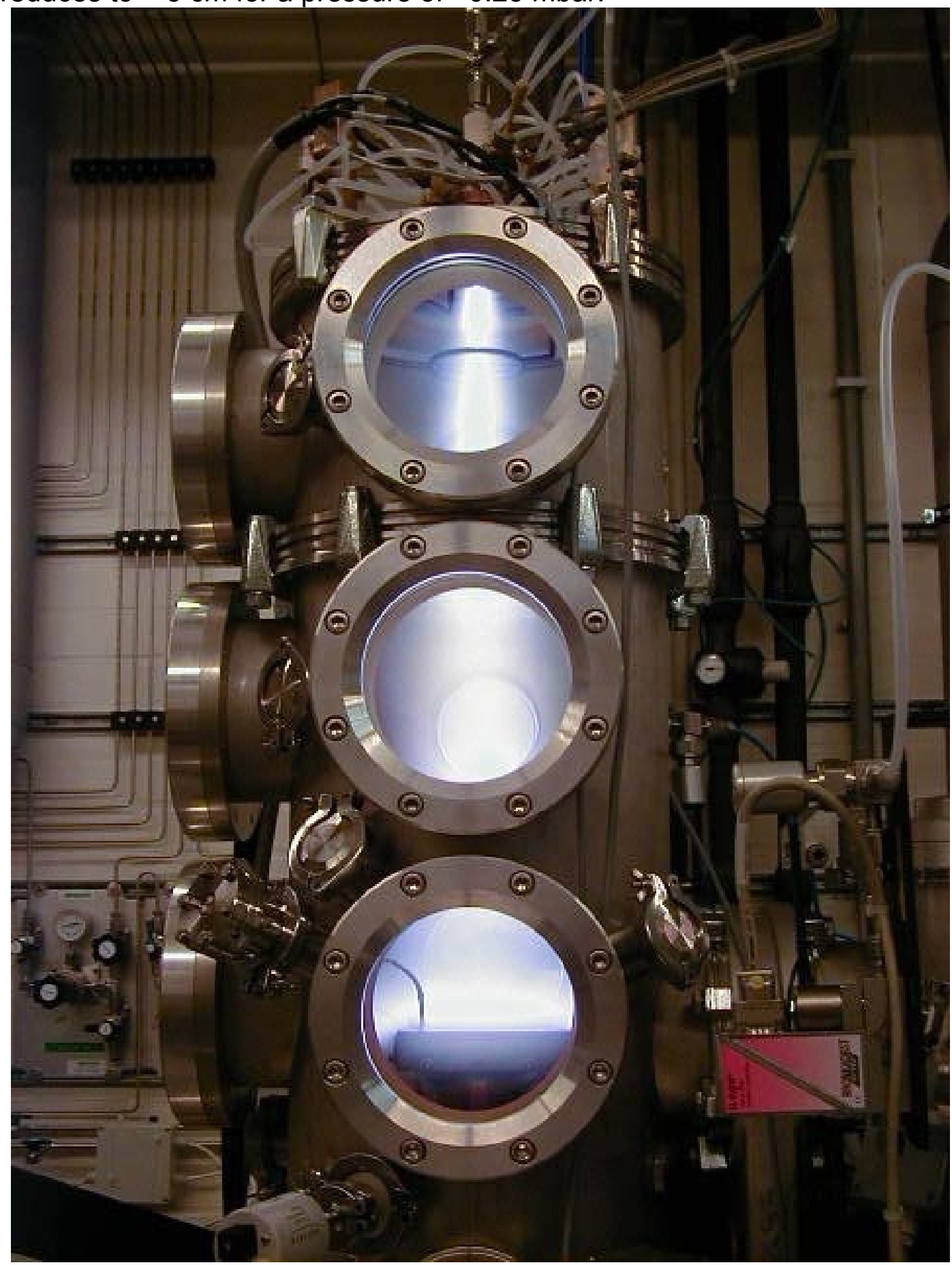

Figure 2.5: Photo of the ETP chamber, displaying a pure argon plasma at pressure of 0.5 mbar in the vacuum chamber. 
The effective pumping capacity of $\sim 500 \mathrm{~m}^{3} / \mathrm{h}$ in the present set-up is reduced by more than a factor of two compared with the traditional set-up $\left(\sim 1300 \mathrm{~m}^{3} / \mathrm{h}\right)$. Such reduction of the pumping capacity during processing will influence the background pressure and therefore the ion and electron density in the deposition chamber $[14,15]$. Both effects can have large influences on the deposited material as will be discussed in Chapter 3 . The reduction in pumping-capacity is related to a limited floor space for the set-up and thus smaller roots pumps in comparison with the large roots pumps as used at the Eindhoven University of Technology. In order to work at the same pressure during deposition as in the Eindhoven set-up, the smaller pumping-capacity requires a reduced gas flow. At the Eindhoven University of Technology the total gas flow consists of $\sim 90 \%$ processing gas and $\sim 10 \%$ helium, which is used for the temperature control of the substrate (2.3.1). The influence of decreasing the process flows will also be discussed in Chapter 3 . When the same helium flow is used for temperature control while the other flows are decreased due to pumping capacity, then the helium flow will be a much larger part of the total flow. Therefore temperature control will be an important issue. Furthermore, a reduction of the total flow can have some consequences for the operation of the plasma source, the cascaded arc. For a stable plasma a pressure in the cathode housing of the arc of $\sim 300$ mbar or larger is needed. As this pressure is directly correlated to the flow through the arc, a reduction of the gas flow through the arc is therefore not straightforward and modifications of the arc may be necessary. The influence and consequences of this reduction will also be discussed in Chapter 3.

Table 2.2: Differences between the set-up in Eindhoven (TU/e) and the new set-up in Delft TUD) with regarding the ETP deposition chamber.

\begin{tabular}{|c|c|c|}
\hline & TU/e & TUD \\
\hline Chamber diameter (cm) & 50 & 33 \\
\hline Distance from arc to substrate $(\mathrm{cm})$ & 32 & 41 or 63 \\
\hline Chamber orientation & Horizontal & Vertical \\
\hline Effective pumping speed during processing $\left(\mathrm{m}^{3} / \mathrm{h}\right)$ & 1300 & 500 \\
\hline $\operatorname{Arc~diameter~}^{13}(\mathrm{~mm})$ & 4 & 2.5 \\
\hline
\end{tabular}

Another requirement concerns the injection of $\mathrm{SiH}_{4}$ into the plasma beam. This is done via an injection ring, which contains several holes through which the $\mathrm{SiH}_{4}$ flows into the chamber. The dimensions of the holes have to be such that $\mathrm{SiH}_{4}$ leaves the holes supersonically, because it is only in that case that the admixture of $\mathrm{SiH}_{4}$ into the beam is homogeneously distributed over the beam. The maximum area of the holes is a function of the flow, the pressure in the chamber, and the local velocity of sound. The area of the holes can be calculated via:

$$
\phi=n \cdot v \cdot A=n \cdot c \cdot A
$$

in which $\phi$ is the flow rate, $n$ is the particle density (which is correlated to the pressure and the temperature at the injection ring via $p=n \mathrm{k} T), v$ is the velocity, $c$ is the local velocity of sound at the hole exit, and $A$ the total area of the holes. Taking a $\mathrm{SiH}_{4}$ flow of $100 \mathrm{nccm}$, a chamber pressure of $16 \mathrm{~Pa}$, a local temperature of $1000 \mathrm{~K}$, and

\footnotetext{
${ }^{13}$ This difference will be discussed in Chapter 3 .
} 
a local velocity of sound of $500 \mathrm{~m} / \mathrm{s}$ results in a maximum diameter for the holes of $\sim 3 \mathrm{~mm}$ when 8 holes are used. This means that for the $\mathrm{SiH}_{4}$ flows used for the experiments presented in this thesis, the holes with a diameter of $1 \mathrm{~mm}$ will result in homogeneous $\mathrm{SiH}_{4}$ injection and that it becomes critical at $\mathrm{SiH}_{4}$ flows of $\sim 10 \mathrm{nccm}$.

Table 2.3: Maximum range of conditions available within the ETP set-up and the range that is explored for the experiments presented in this thesis.

\begin{tabular}{|l|c|c|}
\hline & Range & a-Si:H \\
\hline Ar-flow $(\mathrm{nccm})$ & $0-4000$ & $500-1000$ \\
\hline $\mathrm{H}_{2}$-flow $(\mathrm{nccm})$ & $0-2200$ & $50-2000$ \\
\hline $\mathrm{SiH}_{4}$-flow $(\mathrm{nccm})$ & $0-1050$ & $50-300$ \\
\hline He back flow $(\mathrm{nccm})$ & $0-500$ & $50-200$ \\
\hline Deposition temperature $\left({ }^{\circ} \mathrm{C}\right)$ & $0-500$ & $100-400$ \\
\hline Arc current $(\mathrm{A})$ & $0-60$ & $25-50$ \\
\hline Arc power $(\mathrm{kW})$ & $0-20$ & $2.5-8$ \\
\hline
\end{tabular}

The differences between the ETP set-ups of Delft and Eindhoven are presented in Table 2.2. Furthermore, Table 2.3 shows the range of conditions available for the ETP set-up in Delft. Also indicated in this table are the conditions that are used for the depositions described in this thesis.

\subsubsection{Load-lock}

The load-lock is used for sample handling between the RF-PECVD chamber and the ETP chamber, and for loading the samples into the vacuum chamber. To load a substrate holder, the load-lock is vented while maintaining the other two chambers at low pressure. After loading the substrate holder the load-lock is pumped down to $\sim 2 \cdot 10^{-6} \mathrm{mbar}$, and then the substrate holder is transported to one of the other two chambers using magnetic linear drive manipulator arms. To be able to move the substrate holder from one to the other deposition chamber the load-lock contains a rotating table on which the substrate holder can rotate after it is released from one of the manipulator arms. To obtain a reasonable vacuum in the load-lock Viton O-rings are used. The load-lock is pumped with a $230 \mathrm{l} / \mathrm{s}$ turbo molecular pump (BalzersPfeiffer TMH 260) and a $12 \mathrm{~m}^{3} / \mathrm{h}$ rotary pump (Edwards RV12), also resulting in a pressure of $\sim 8 \cdot 10^{-7}$ mbar. The rotary pump that backs the turbo pump of the loadlock is larger than the rotary pump that backs the turbo of the ETP chamber as the load-lock is often vented to change the sample.

\subsubsection{Substrate holder assembly}

The main function of the substrate holder assembly (Fig. 2.6 and 2.7) is to mount the substrate thermally such that the temperature of the substrate is controlled within a margin of $\sim 10^{\circ} \mathrm{C}$. It is also desirable to replace the substrate holder via a load-lock and to apply an RF-signal on the substrate holder for additional biasing. This last requirement is met by using ceramic insulation. 


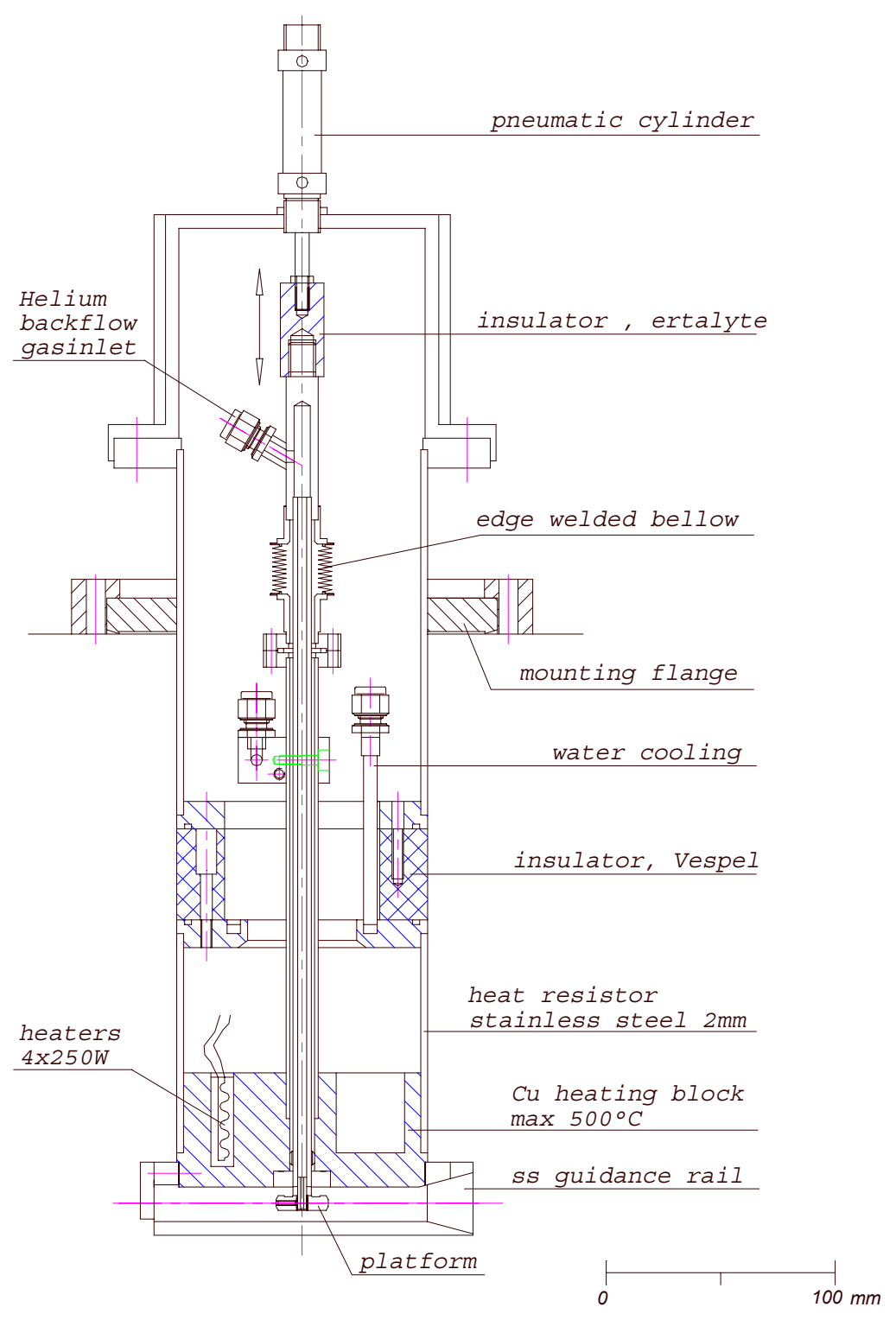

Figure 2.6: Schematic drawing of the copper yoke. Helium flows through the moveable platform in the centre, providing better temperature control of the substrate.

The handling of the substrate holder (Fig. 2.7) is accomplished by using a thermally and electrically insulated platform that is pushed by air-pressure through a hole in the backside of the substrate holder. The substrate holder is moved over the platform allowing the stalk of the platform to move into a groove in the backside of the substrate holder. When the substrate holder is in place, the air pressure is reversed and the platform clamps the substrate holder to the yoke. The procedure is reversed in order to release the substrate holder. 

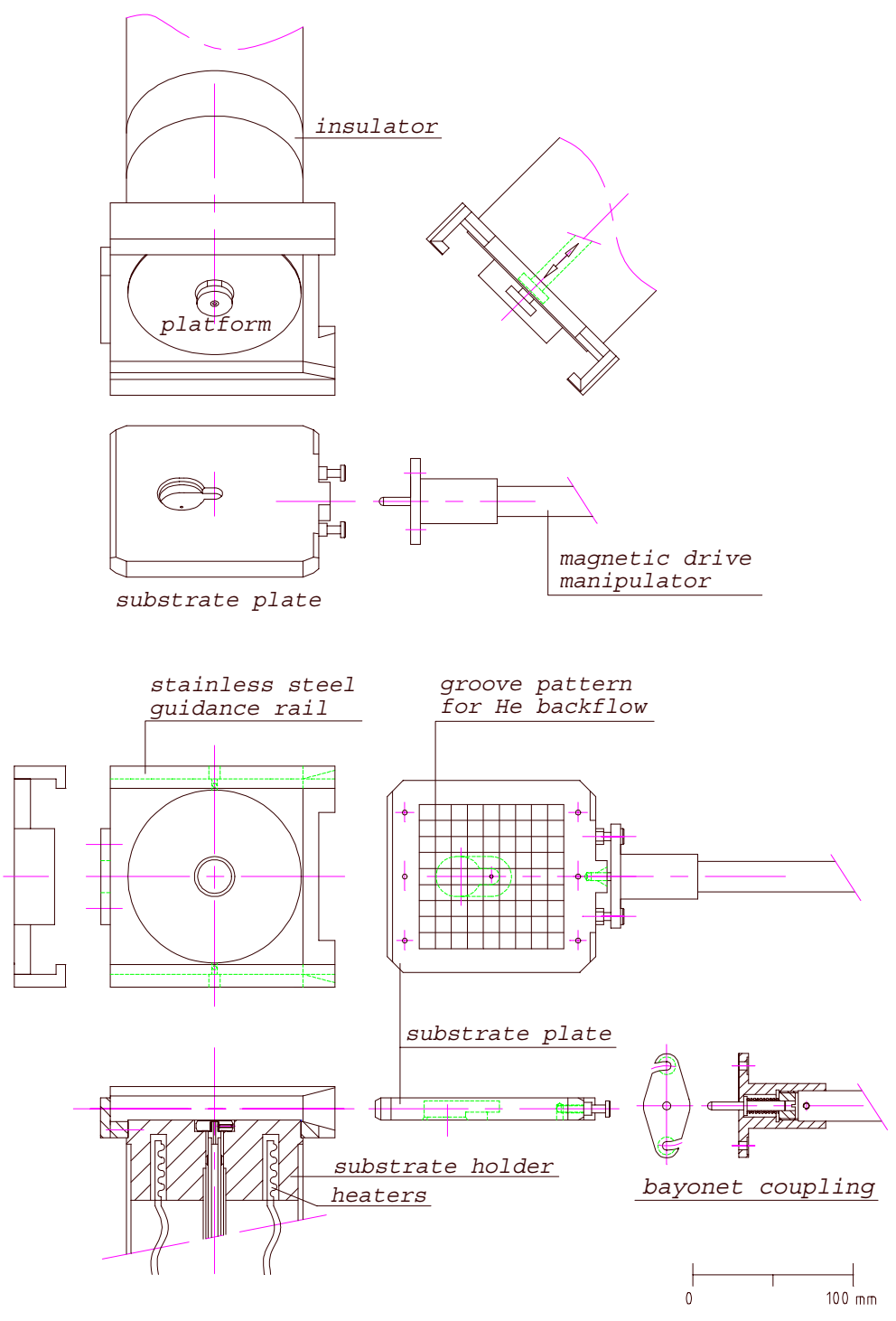

Figure 2.7: Schematic drawing of the substrate holder and how it will be mounted on the yoke.

The copper yoke contains 4 Watlow heating elements of $250 \mathrm{~W}$ each, $10 \times 40$ $\mathrm{mm}^{2}$, which are mounted in the copper yoke. These elements supply the power for the heating of the yoke. The temperature is adjusted via the computer and controlled by a PID-regulator (Eurotherm $2408 \mathrm{f}$ ). The metal-metal contact between substrate holder and copper yoke results in good thermal contact. For good temperature control of the substrate, which is mounted on the substrate holder, a helium back flow is used. Helium flows through the yoke and will have the temperature of the yoke when it leaves the yoke. It will form a heat conducting film in between the substrate holder and the substrate [16]. Helium gas is used because the thermal conductivity is high $\left(0.10-0.24 \mathrm{Wm}^{-1} \mathrm{~K}^{-1}[17]\right)$. The helium shortens the time needed to heat the substrate (see also Fig. 2.10) and the temperature of the substrate is better controlled when the plasma in the ETP-chamber is on, because otherwise the plasma will heat the substrate. The required helium flow depends on the heat that is supplied by the plasma. In Eindhoven this resulted in a helium back-flow of $\sim 400$ 
nccm. Within the new CASCADE set-up the total flow $\left(\mathrm{Ar}+\mathrm{H}_{2}+\mathrm{SiH}_{4}\right)$ was decreased by a factor of four from $\sim 4000 \mathrm{nccm}$ in Eindhoven to $\sim 1000 \mathrm{nccm}$. Whereas the $400 \mathrm{nccm}$ helium is $10 \%$ of the total gas flow in Eindhoven it would be $40 \%$ within the new set-up. This aspect made it necessary to carry out some extra tests regarding the heat transfer from the plasma to the substrate. Due to the lower total flow and the larger distance of the cascaded arc to the substrate the helium flow could be reduced to $\sim 100 \mathrm{nccm}$ (2.3.1). It is interesting to investigate the use of a $\mathrm{H}_{2}$ back flow, because this gas has a larger thermal conductivity than He [17] and is also used as a process gas.

\subsubsection{Data acquisition and machine control}

The complete set-up is controlled via a PLC (Programmable Logic Controller) (Fig. 2.8). The PLC controls the actions of the user, taking into account security schemes. Different users are given different access levels for using the program, avoiding unintentional damage.

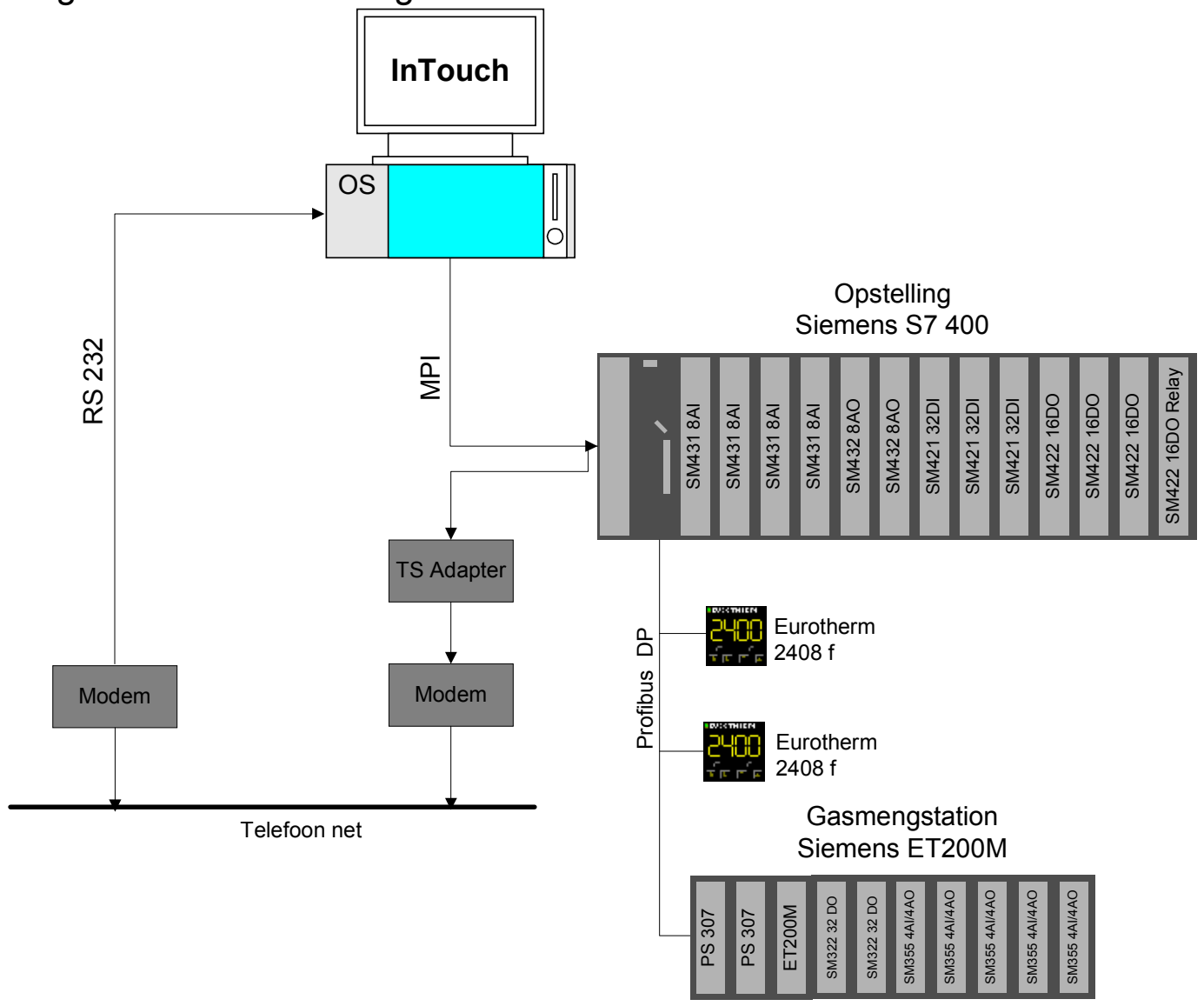

Figure 2.8: PLC control. See text for the description.

The PLC that is used is a Siemens S7-412 DP Master PLC and the gas-system is connected to the DP Master via a Siemens ET200M Profibus Slave. In total the PLC has 296 I/O-points consisting of 52 analogue inputs, 36 analogue outputs, 96 digital inputs, and 112 digital outputs. The PLC can be programmed both externally via a modem and the tele-service software package 'Laplink 2000' from Siemens, and locally via the S7 multi point interface (MPI) connection. The S7-MPI connection also 
maintains the communication with a PC. On the PC InTouch is used as the 'Human Machine Interface' using the software package 'Wonderware Factory Suite 2000'. About 460 internal variables can be controlled in this way.

\subsection{Set-up characterisation}

\subsubsection{Substrate temperature}

The temperature of the substrates was measured by interferometry (Section 2.4.2) and by a chromel/alumel thermocouple, which was attached to the surface of a glass substrate by silver paste. A certain temperature was applied to the copper yoke and this temperature was compared with the temperature of the substrate as deduced from the thermocouple and interferometry measurements. The temperature curves can be seen in Figure 2.9 and 2.10. The curves are used to determine the actual temperature of the surface of the substrate during deposition. The measurements are performed using 0,10 , and $50 \mathrm{sccm}$ of $\mathrm{He}$.

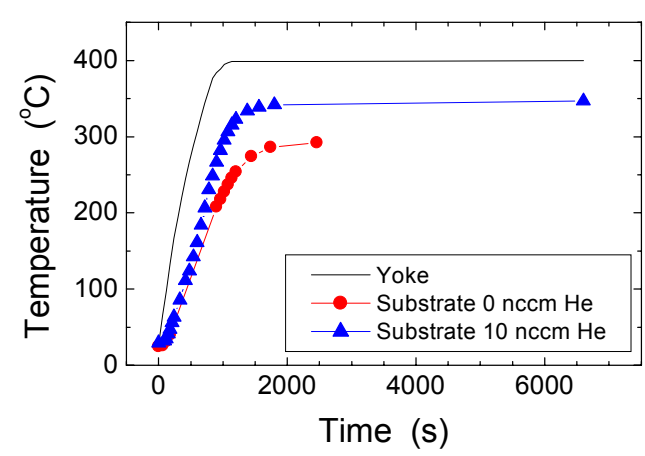

Figure 2.9: Substrate temperature as a function of the heating time. The measurement used a thermocouple mounted on a glass substrate. The measurement was carried out in the ETPchamber for two different He flows. The solid line represents the temperature of the yoke

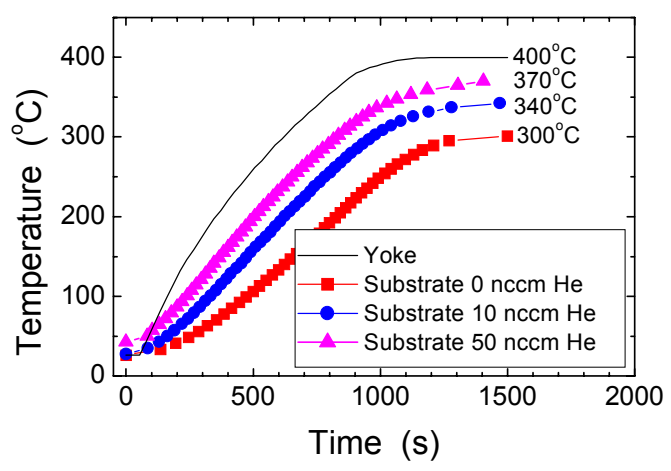

Figure 2.10: Substrate temperature as a function of the heating time. The measurement used interferometry on double polished c-Si. The measurement was carried out in the ETPchamber for various $\mathrm{He}$ flows. The solid line represents the temperature of the yoke.

Thermocouple measurements in the RF-PECVD chamber showed that the heat transfer from the plasma to the surface is negligible. Helium back-flow is therefore not needed in the RF-PECVD chamber to achieve a constant temperature during deposition. However, the curves (Fig. 2.9 and 2.10) ${ }^{14}$ show that an offset has to be taken into account, which is a function of the helium flow. The offset depends on the heat loss of the substrate to the surroundings and thus depends on the temperature. When the yoke is set to a temperature of $300^{\circ} \mathrm{C}$ the substrate temperature is $\sim 260^{\circ} \mathrm{C}$. When $50 \mathrm{nccm}$ helium is used, the temperature increases to $280^{\circ} \mathrm{C}$. As $50 \mathrm{nccm}$ is a large flow compared to the other gas flows $(\sim 50 \mathrm{nccm})$ helium is not used and the offset is taken into account. The actual substrate temperature appeared to be $20^{\circ} \mathrm{C}$ lower at a yoke temperature of $250^{\circ} \mathrm{C}$ and less than $10^{\circ} \mathrm{C}$ lower at temperatures $<200^{\circ} \mathrm{C}$. Depositions in the RF-PECVD chamber

\footnotetext{
${ }^{14}$ The temperature measurements are valid for both deposition chambers, as the temperature control for both chambers is identical.
} 
are normally carried out at yoke temperatures up to $250^{\circ} \mathrm{C}$, so the offset is not so large. The temperature that is given in the remainder of this thesis is the yoke temperature ${ }^{15}$.

In addition to thermocouple measurements IR interferometry on double polished $\mathrm{C}-\mathrm{Si}$ was also used in the ETP chamber to determine the substrate temperature $[18,19]$. Thermocouple measurements showed the same behaviour as in the RF-PECVD chamber, but it was not possible to use the thermocouple to determine the temperature during processing. During processing the thermocouple gave unrealistic values and when hydrogen was added to the plasma the thermocouple broke down. During plasma operation the temperature of the substrate was measured using interferometry. It is clearly seen that helium has a large influence (Fig. 2.10). Putting the yoke on $400^{\circ} \mathrm{C}$ gives a substrate temperature of $\sim 300^{\circ} \mathrm{C}$ when no helium is used (the same difference as is measured with the thermocouple) and up to $370^{\circ} \mathrm{C}$ when $50 \mathrm{nccm}$ helium is used. Besides obtaining a certain temperature it is also important that this temperature is maintained during exposure of the substrate to the plasma. Therefore, a flow of $100 \mathrm{nccm}$ helium is used for all the depositions in the ETP chamber presented in this thesis because at this helium flow the change in substrate temperature due to the plasma is $<10^{\circ} \mathrm{C}$ when the yoke temperature is set to $250^{\circ} \mathrm{C}$. For the ETP chamber the temperature given in the remainder of this thesis also refers to the yoke temperature and not to the actual substrate temperature.

\subsubsection{Homogeneity and reproducibility of layers grown using RF-PECVD}

For the homogeneity measurements individual $\mathrm{p}-$-, $\mathrm{i}-$, and $\mathrm{n}$-layers were deposited on $10 \times 10 \mathrm{~cm}^{2}$ Corning 1737 glass substrates. The substrates were cut into 9 pieces and transmission-reflection measurements (2.4.2) were performed on every piece. The results are shown in Table 2.4 giving the main value and the variation. From the variation it is concluded that the films grown in the RF-PECVD chamber are very homogeneous. However, this homogeneity is only observed when relatively small powers are used. Normally all films are grown at powers of $\sim 2 \mathrm{~W}\left(\sim 0.01 \mathrm{~W} / \mathrm{cm}^{2}\right)$. If higher powers $(>10 \mathrm{~W})$ are used the homogeneity is not as good. In that case interference fringes are observed on the substrate and when the distance between the substrate and the electrode is not enlarged no material is deposited in the centre of the substrate.

Table 2.4: Growth rate, optical gaps, and refractive index at $2 \mathrm{eV}$ of layers deposited in the RF-PECVD chamber. The values present the main value and the variation after performing RT-measurements on 9 pieces, which were deposited in the same run.

\begin{tabular}{|l|c|c|c|}
\hline & p-type & intrinsic & n-type \\
\hline$r(\mathrm{~nm} / \mathrm{s})$ & $0.21 \pm 0.01$ & $0.165 \pm 0.005$ & $0.115 \pm 0.004$ \\
\hline$E_{\text {Tauc }}(\mathrm{eV})$ & $1.95 \pm 0.01$ & $1.80 \pm 0.01$ & $1.74 \pm 0.02$ \\
\hline$E_{\text {cubic }}(\mathrm{eV})$ & $1.75 \pm 0.02$ & $1.62 \pm 0.01$ & $1.55 \pm 0.02$ \\
\hline$n$ at $2 \mathrm{eV}$ & $3.05 \pm 0.13$ & $4.16 \pm 0.03$ & $4.21 \pm 0.07$ \\
\hline
\end{tabular}

\footnotetext{
${ }^{15}$ Note that this means that a certain offset has to be taken into account to determine the actual substrate temperature.
} 
When depositions under the same conditions are performed within one week, the reproducibility is very good. However, over a time-span of one year the growth rate has decreased by $\sim 10 \%$ using the same conditions. We believe that this decrease in growth rate can be attributed to the subsequent depositions of semiconductor material on the electrode plate. The effect of the somewhat smaller growth rate was, however, positive regarding the material properties of the doped layers, i.e., the conductivity of those layers improved.

\subsubsection{Deposition sequence}

Using one chamber for the deposition of both the $\mathrm{p}$ - and n-type layer may lead to cross-contamination. The influence of the deposition conditions on the next layer has been investigated by depositing $n$ after $p, p$ after $n$, i after $p$, and $i$ after $n$. Only a direct correlation was found when the p-layer was deposited after the n-layer. This resulted in a drop in the conductivity of the p-layer by one order of magnitude. The bulk properties of the other layers are not influenced by the deposition that is performed beforehand. However, when a complete solar cell is deposited in the RFPECVD chamber without a dummy deposition in between the p-layer and the intrinsic layer, the solar cell has a low fill factor $(<0.4)$, indicating that the conditions to grow a p-layer have an undesirable influence on the initial growth of the intrinsic layer. From this it was concluded that a dummy deposition is needed in between the $\mathrm{p}$ - and i-layer when making a solar cell and after an n-layer when the next layer is $\mathrm{p}$ type. A complete p-i-n solar cell deposited in the RF-PECVD chamber had an initial efficiency of $\sim 8 \%$, indicating that good deposition parameters for the doped layers are obtained, which means the material is suitable for solar cells.

\subsection{Experimental characterisation}

\subsubsection{Plasma diagnostics}

\section{Langmuir probe}

An important technique to characterise the plasma is by using a Langmuir probe. Langmuir probe measurements obtain information about the ion and electron density, electron temperature, effective ion mass, and the Debye-length ${ }^{16}$. It is important to know both the density and the temperature, as these parameters are an indication of the plasma reactivity (Chapter 3 ). The theory of the Langmuir probe is well described by Brussaard [20] and uses the method and equations described by Peterson and Talbot [21].

The Langmuir probe that is used for measurements in this thesis is a cylindrical probe that consists of two tungsten wires with a length of $5 \mathrm{~mm}$ and a diameter of $0.2 \mathrm{~mm}$. The Langmuir probe can be used in two different configurations: as a single probe and as a double probe (Fig. 2.11). In the single probe configuration one wire is grounded and a voltage of $-10 \mathrm{~V}$ is applied to the other wire. This voltage is increased to $10 \mathrm{~V}$ in steps of $0.1 \mathrm{~V}$. At a negative voltage the positive ions are collected and at a positive voltage the electrons are collected. Negative ions are usually not measured, as their mass is much larger than the mass of the electrons

\footnotetext{
${ }^{16}$ The Debye-length of a plasma defines the average distance over which an electric field may exist in the plasma.
} 
and their density is much lower. From the ratio between the electron current and the ion current the effective ion mass is determined. Furthermore, from the results the ion and electron density, the electron temperature, and the Debye-length can be derived. The electron densities that can be determined, using the single probe configuration, are between $\sim 10^{15}$ and $\sim 10^{17} \mathrm{~m}^{-3}$. When the electron current becomes too high the tungsten wires will melt. This problem can be avoided by using thicker wires, though the probes should not be too thick as that might influence the plasma.

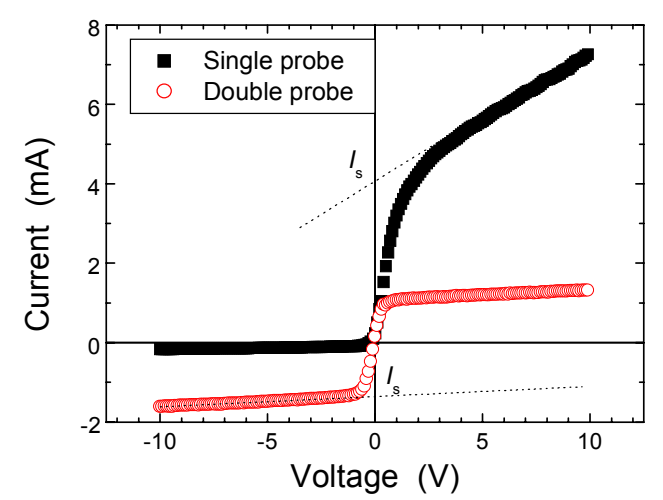

Figure 2.11: Example of a single (on an Ar/H $\mathrm{H}_{2}$ plasma) and a double probe (on a pure Ar plasma) measurement. The single probe measurement has a characteristic high electron current and low ion current, supplying information on the effective mass of the ion. The double probe measurement is characterised by its higher ion current and its comparable shape at positive and negative voltage. The temperature is determined from the slope of the steep part and the density is determined from the saturation currents $I_{s}$.

At higher densities the double probe configuration has to be used. Both wires are on a floating potential and the current is limited by the ion current [22]. Using this configuration the ion density is measured, which is, because of quasi-neutrality, equal to the electron density. As the ions are much heavier than the electrons, the current is much lower than the electron current measured when using the single probe and therefore much larger ion densities can be measured before the cathodes are heated significantly. The upper limit using this configuration is determined to be $\sim 10^{20} \mathrm{~m}^{-3}$. A disadvantage of measuring the density in this way is that an assumption about the effective ion mass has to be made. The accuracy of the Langmuir probe measurements is $\sim 15 \%$ for ion and electron densities $>10^{16} \mathrm{~m}^{-3}$ [23].

\section{Mass spectrometry}

Using mass spectrometry, the composition of the plasma can be investigated. In this study a quadrupole mass spectrometer (MicroMass VG560) is used, which can measure a mass range from 1 to 300. During deposition a Secondary Electron Multiplier is used, which is able to measure currents in the range of $10^{-13}$ to $10^{-7} \mathrm{~A}$. In order to maintain sufficiently low pressures in the mass spectrometer, it is pumped by a turbo molecular pump (Balzers-Pfeiffer TPU 050) with an effective pumping speed of $30 \mathrm{l} / \mathrm{s}$ backed by a small $1.5 \mathrm{~m}^{3} / \mathrm{h}$ rotary pump (Balzers-Pfeiffer DUO 1,5 A). A pinhole with a diameter of $50 \mu \mathrm{m}$ is placed between the mass spectrometer and the deposition chamber to allow for the required pressure difference between the deposition chamber (about 0.2 mbar during deposition) and the mass spectrometer.

Mass spectrometry is used for two reasons: firstly to check the background contamination, and secondly to measure the amount of silane that is dissociated, the 
so-called depletion or consumption of silane. The latter is determined by measuring the signal when the plasma is on and when the plasma is off. The following equation then gives the depletion, $D$, [24]:

$$
D=\frac{I_{\text {plasma,off }}-I_{\text {plasma,on }}}{I_{\text {plasma, off }}-I_{\text {background }}},
$$

where I denotes the current measured by the mass spectrometer for a specified mass. The cracking pattern of silane results in a contribution to the masses 28 to 32 . However, the masses 28, 30, and 32 have a rather high background level due to the contribution of nitrogen and oxygen. Therefore, the depletion is determined by measuring the currents at mass 29 and 31, as at these values the background contribution of other gases is minimum.

\subsubsection{In-situ film diagnostic}

\section{Interferometry}

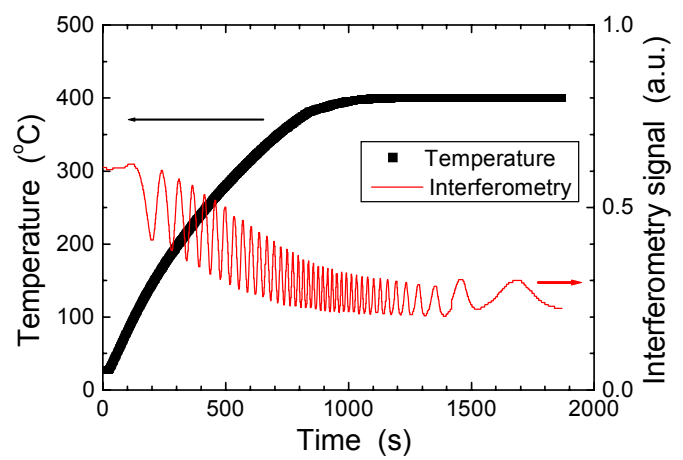

Figure 2.12: Temperature measurement with interferomtry as a function of the yoke temperature (see also Fig. 2.10).

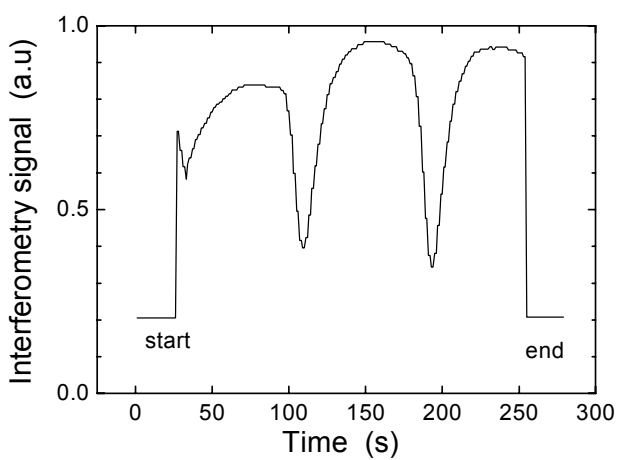

Figure 2.13: Thickness measurement with interferometry as a function of the layer thickness (final thickness $\sim 560 \mathrm{~nm}$ ).

Interferometry exploits multiple reflections within a growing film or within a substrate. When growing a film the thickness and thus the growth rate can be monitored in-situ. When no deposition is performed the technique determines the temperature variations of the substrate [19]. Here we used light with a wavelength of $1523 \mathrm{~nm}$ generated by an IR-laser. Depending on the number of wavelengths that fit within the growing film or between the top and bottom of the substrate, the intensity of the IRlight measured by the SiGe-detector changes. This intensity is influenced both by the thickness and by the refractive index of the layer. Growing a layer influences the thickness whereas a change in temperature mainly influences the refractive index of the material. With varying temperature the refractive index of the material changes and the number of wavelengths that fit within the substrate changes and a pattern can be measured [19]. By knowing the starting value the temperature can then be determined by counting the number of fringes and by multiplying that number with a temperature dependent value (Fig. 2.12), because the refractive index of a material depends on the temperature. A suitable substrate to determine the temperature is a double polished crystalline silicon wafer (thickness $0.525 \mathrm{~mm}$ ). This substrate gives a 
change in temperature of $\sim 6.5^{\circ} \mathrm{C}$ per fringe. To determine the thickness of a growing layer this technique is less sensitive (Fig. 2.13). In the configuration used in this thesis one fringe corresponds to a thickness variation of a-Si:H of $\sim 220 \mathrm{~nm}$. To have a more accurate in-situ measurement of the thickness it is better to use HeNeellipsometry [25].

\subsubsection{Ex-situ film diagnostics}

To characterise the material using various techniques films are grown on $\mathrm{C} 1737$ Corning glass and on crystalline silicon. After deposition aluminium contacts are deposited by means of electron beam evaporation. After the contacts have been deposited, the samples are annealed at $180^{\circ} \mathrm{C}$ for half an hour in order to achieve a good Ohmic contact. The contacts have a length, $a$, of $20 \mathrm{~mm}$ and are separated by a distance, $b$, of $0.5 \mathrm{~mm}$.

\section{Reflection/Transmission (RT)}

The reflection and the transmission of light as a function of the wavelength are measured with RT [e.g. 3]. From this combination of reflected and transmitted light the thickness, the refractive index, the absorption, and the optical bandgap like the Tauc-gap [26] and the cubic-gap [27] of the grown layer can be determined. For photon energies, $h v$, larger than the specified gap, $E_{\mathrm{m}}$, the absorption, $\alpha$, obeys the relation:

$$
(\alpha h v)^{1 / m}=\mathrm{A}\left(h v-E_{\mathrm{m}}\right)
$$

where $A$ is a constant and $m=2$ to obtain the Tauc-gap and $m=3$ to obtain the cubic-gap. The measurement uses the film grown on Corning glass without the contacts. A lamp and a monochromator are used to provide light of a specific wavelength in the range from 0.7 to $2.1 \mathrm{eV}$.

\section{Dual Beam Photoconductivity (DBP)}

DBP is used to measure the low absorption of light at energies smaller than the bandgap. From DBP the defect density [28] and the Urbach energy can be obtained. The measurement uses the film grown on Corning glass with Al contacts. A constant voltage (mostly $100 \mathrm{~V}$ ) is applied to the contacts and a bias light is used to illuminate the film. The bias light generates a constant photocurrent. A lamp, and a monochromator are used to get light of a specific wavelength in the range from 0.7 to $2.1 \mathrm{eV}$. The light from the monochromator generates additional electrons in addition to the electrons generated by the bias light. By using a chopper (13 Hz) and a lock-in amplifier only the generation of the chopped light is measured. The bias light is used to pin the quasi-Fermi levels of electrons and holes such that the recombination in the cell is not influenced. This increases the accuracy and makes the DBPmeasurements sensitive to absorption in the bandgap, this compared with RTmeasurements that are not sensitive in the bandgap of the material. The DBPmeasurements are relative measurements and the RT results have to be used to calibrate these measurements. 


\section{Dark conductivity and activation energy}

From this measurement the dark conductivity, $\sigma_{d}$, and the activation energy for electron conductivity in the dark, $E_{\text {act, }}$, is determined. The measurement uses the film grown on Corning glass with Al contacts. A constant voltage, $\mathrm{V}$, (mostly $10 \mathrm{~V}$ ) is applied over the contacts and the current, $I$, is measured. The sample is heated to $130^{\circ} \mathrm{C}$ to remove impurities from the surface and then cooled down. Only the cooling down trajectory is used for the measurement of the conductivity as a function of the temperature. The slope of $\sigma$ against $T$ determines the activation energy using

$$
\sigma(T)=\sigma_{0} \exp \left(-\frac{E_{\mathrm{act}}}{k T}\right)
$$

with $T$ the temperature and $\sigma_{0}$ a constant, which also follows from the fit of the measured curve. The dark conductivity is determined from the current measured at $25^{\circ} \mathrm{C}$ using

$$
\sigma_{d}=\frac{b l}{a d V}
$$

with $d$ the thickness of the sample.

\section{Photoconductivity}

From this measurement the photoconductivity is determined, which is related to the defect density of the material. The measurement uses the film grown on Corning glass with Al contacts. The sample is placed under a solar simulator, an AM-1.5 source (Oriel $300 \mathrm{~W}$ Xe-lamp) with an intensity of $\sim 100 \mathrm{~mW} / \mathrm{cm}^{2}$. A voltage of $-1 \mathrm{~V}$ to $100 \mathrm{~V}$ is applied across the contacts in steps of $0.5 \mathrm{~V}$ and the current is measured. From the slope of the I,V-curve and Eq. 2.5 the photoconductivity is determined given the thickness of the film. The photo-response of the material is now defined by the photoconductivity divided by the dark conductivity.

\section{Fourier Transform InfraRed spectroscopy (FTIR)}

From FTIR the hydrogen content of the film and the microstructure parameter are determined. The measurement uses the film grown on a crystalline silicon substrate. The transmission of infrared light is measured in the range from 370 to $7500 \mathrm{~cm}^{-1}$ using a Bruker Vector 22. The analysis performed on the transmission spectrum is similar to the method used by Langford et al. [29] and by Gielen [16]. The microstructure parameter, $R^{*}$, is determined using

$$
R^{*}=\frac{I_{2060-2100}}{I_{2000}+I_{2060-2100}},
$$

in which $I_{2060-2100}$ is the integrated absorption of the hydrogen peak that ranges from $2060-2100 \mathrm{~cm}^{-1}$ and $I_{2000}$ the integrated absorption of the hydrogen peak near $2000 \mathrm{~cm}^{-1}$. The total amount of hydrogen in the film is derived from the peak near $640 \mathrm{~cm}^{-1}$. The peak at $640 \mathrm{~cm}^{-1}$ is correlated to the rocking mode of bonded hydrogen in every possible bonding configuration. The peaks in the area from 2000 to $2100 \mathrm{~cm}^{-1}$ are correlated to the stretching bond vibrations. The contribution to $2000 \mathrm{~cm}^{-1}$ is due to isolated $\mathrm{Si}-\mathrm{H}$ bonds, whereas the contribution to the peak area in 
the region 2060 to $2100 \mathrm{~cm}^{-1}$ contains more bonds like $\mathrm{SiH}_{2}$, Si bonded to 2 hydrogen atoms, and clustered $\mathrm{Si}-\mathrm{H}$.

\subsubsection{Solar cell characterisation and simulation}

The characterisation of solar cells is also implicitly a characterisation of the material quality. In addition, the influence of the doped layers must also be taken into account. In general, unless stated otherwise, the cells presented in this thesis are pi-n deposited cells on glass coated with Asahi U-type TCO and with a Ag/Al backcontact. The p-layer is $\sim 10 \mathrm{~nm}$ thick (see also Section 4.3.2), the i-layer $\sim 400 \mathrm{~nm}$, and the n-layer $\sim 20 \mathrm{~nm}$. The presented characteristics of cells are measured on cells with an illuminated area of $0.1 \mathrm{~cm}^{2}$.

\section{Illuminated-J, $V$}

Measuring the illuminated-J,V (Fig. 2.14) gives an indication of the solar cell performance. A solar cell is illuminated using a simulated AM-1.5 source (Oriel 300 W Xe-lamp plus filters). These measurements give the external characteristics of the solar cell. The current density at zero voltage is called the short-circuit current density, $J_{\mathrm{sc}}$, and the voltage at zero current is called the open-circuit voltage, $V_{\mathrm{oc}}$. The ratio of the product of current and voltage at the maximum power point to the product of short-circuit current and open-circuit voltage is called the fill factor, FF. The efficiency is the ratio of the maximum power output to the solar energy input. Furthermore, the slope at $V_{\text {oc }}$ is correlated to the series resistance, $R_{\mathrm{s}}$, and the slope at $J_{\mathrm{sc}}$ is correlated to the parallel resistance, $R_{\mathrm{p}}$, of the solar cell under illumination. Filters can be used to vary the wavelength of the incoming light and the solar cell performance can be measured as a function of the wavelength. Measuring the illuminated-J, $V$ for different wavelengths gives some indication of the defect distribution throughout the cell.

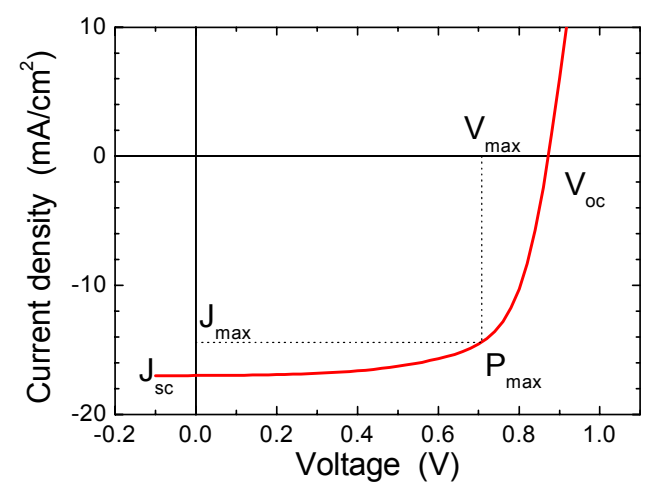

Figure 2.14: Illuminated-J,V curve defining the external characteristics of a solar cell. Indicated in the figure are the short-circuit current density, the open-circuit voltage, and the current and voltage at maximum power.

\section{External spectral response}

From this measurement the spectral sensitivity of the solar cell in the wavelength range $390-1000 \mathrm{~nm}$ is obtained by measuring the photo-generated current. The external spectral response is measured using bias voltages in the range from $-1 \mathrm{~V}$ to $0.6 \mathrm{~V}$. The measurement at $-1 \mathrm{~V}$ gives an indication of the generation of charge 
carriers in the solar cell under the assumption that all charge carriers are collected when this bias voltage is applied. The measurements at positive bias voltage give information about the collection of charge carriers in the solar cell.

\section{Degradation}

Solar cells are degraded by illumination using four lamps (Philips MHN-T 70W) at a substrate temperature of $50^{\circ} \mathrm{C}$. The spectrum of the lamps comes close to the solar spectrum and has a total intensity that is slightly higher than one sun. After degradation experiments the illuminated-J,V curve and the external spectral response can be measured again. These experiments give information on the stable solar cell performance.

\section{ASA, the solar cell simulator}

In order to gain a better understanding of the a-Si:H solar cells simulations of solar cells were carried out using the ASA program (Amorphous Semiconductor Analysis) [30]. A complete structure of a solar cell can be defined in an input file. ASA incorporates optical and electrical modelling based on thin film optics and a set of basic semiconductor equations [e.g. 3]. Several characteristics can be simulated with ASA, such as external spectral response, dark $J, V$ characteristics, and illuminated $J, V$ characteristics, etc.

Accurate optical modelling is important in order to determine the generation rate of the electron and hole pairs. The generation rate is an important parameter in for example the continuity equation. For the calculation of the generation rate profile ASA takes the whole solar cell structure into account. The program requires the refractive index, $n$, and the extinction coefficient, $k$, as a function of the wavelength for all the defined layers. The values for $n$ and $k$ for the a-Si based layers used throughout this thesis are determined from RT-measurements carried out on the layers deposited in the CASCADE set-up.

For the electrical modelling parameters are required that describe the semiconductor properties of the material. These parameters include e.g. the dopant concentration, mobility of charge carriers, and mobility gap, etc. The calculations only take the a-Si based layers into account and therefore some boundary conditions have to be given for the contacts that are used. This includes the definition of the position of the Fermi level at the contact between the p-layer and TCO and between the n-layer and metal contact. The type of contact also has to be defined. Normally, an Ohmic contact is assumed between the n-layer and the metal (silver) back contact and a Schottky barrier between the TCO and the p-layer. Furthermore, all practical a-Si:H solar cells are hetero-junction devices. Normally the mobility gap of the p-layer is different from the mobility gap of the intrinsic layer. Therefore a band offset has to be taken into account. For the simulations presented in this thesis the band offset has been chosen to occur at the conduction band and the mobility gap has been taken equal to the measured Tauc optical gap from RT-measurements, as this has been shown to give good results [31].

The electrical modelling solves the continuity equations and the Poisson equation in order to calculate the recombination rate in the a-Si:H solar cell. As the calculation of the recombination rate in a-Si:H based solar cells is much more complex than in $\mathrm{c}-\mathrm{Si}$, which only depends on the lifetime of charge carriers, a continuous defect density of state distribution in the mobility gap has to be defined. This distribution includes tail states associated with weak bonds with a characteristic exponential slope. Furthermore, it includes states in the gap associated with dangling 
bonds. For the description of these states the program can use various defect-pool models [30]. In the simulations presented in this thesis the defect-pool model as developed by Powell and Deane [32] has been used as it was shown that realistic illuminated $J, V$ characteristics could be obtained using this model [33].

\section{References}

1. B.A.Korevaar, A.H.M. Smets, W.M.M. Kessels, G. Adriaenssens, M.C.M. van de Sanden, and D.C. Schram, J. Non Cryst. Sol., 266-269 (1999) 380

2. R. van Oort, Ph. D. thesis, Delft University of Technology (1989)

3. R.E.I. Schropp and M. Zeman, Amorphous and microcrystalline silicon solar cells, Kluwer Academic Publishers (1998) Boston/Dordrecht/London

4. W. Luft and Y.S. Tsuo, Hydrogenated amorphous silicon alloy deposition processes, Marcel Dekker, New York (1993)

5. H. Lüth, Surface and interfaces of solid materials, Springer (1995)

6. G.J. Nienhuis, W.J. Goedheer, E.A.G. Hamers, W.G.J.H.M. van Sark, and J. Bezemer, J. Appl. Phys., 82 (1997) 2060

7. G.M.W. Kroesen, D.C. Schram, and J.C.M. de Haas, Plasma Chem. Plasma Proc., 10 (1990) 531

8. H. Maecker, Z. Naturforsch., 11a (1956) 457

9. J.J. Beulens, M.J. de Graaf, and D.C. Schram, Plasma Sources Sci. Technol., 2 (1993) 180

10. J.J. Beulens, G.M.W. Kroesen, P.M. Vallinga, and D.C. Schram, Proc. Int. Symp. On Plasma Chemistry (ISPC-9), (1989) 1

11. J.J.H.M. Schoonus, Analyse van vervuiling als gevolg van cascadeboog-erosie, internal report, Eindhoven University of Technology (2001)

12. A.H.M. Smets, Ph. D. thesis, Eindhoven University of Technology (2002)

13. W.M.M. Kessels, R.J. Severens, A.H.M. Smets, B.A. Korevaar. G.J. Adriaenssens, D.C. Schram, and M.C.M. van de Sanden, J. Appl. Phys., 89 (2001) 2404

14. M.C.M. van de Sanden, J.M. de Regt, and D.C. Schram, Plasma Sources Sci. Technol., 3 (1994) 501

15. S. Mazouffre. Ph. D. Thesis, Eindhoven University of Technology (2001)

16. J.W.A.M. Gielen, Ph. D. thesis, Eindhoven University of Technology (1996)

17. Handbook of Chemistry and Physics, edited by D.R. Lide (CRC, Boca Raton, 1994)

18. J.W.A.M. Gielen, W.M.M. Kessels, M.C.M. van de Sanden, and D.C. Schram, J. Appl. Phys., 82 (1997) 2643

19. V.M. Donnelly and J.A. MacCaulley, J. Vac. Sci. Technol. A, 8 (1990) 84

20. G.J.H. Brussaard, Ph. D. thesis, Eindhoven University of Technology (1999)

21. E.W. Peterson and L. Talbot, AIAA Journal, 8 (1970) 2215

22. E.O. Johnson and L. Malter, Phys. Rev., 80 (1950) 58

23. R.F.G. Meulenbroeks, M.F.M. Steenbakkers, Z. Qing, M.C.M. van de Sanden, and D.C. Schram, Phys. Rev. E, 49 (1994) 2272

24. L. Gabella, Mass spectrometry investigation of amorphous silicon deposition by the cascaded arc technique, internal report, Eindhoven University of Technology (1997)

25. A.H.M. Smets, D.C. Schram, and M.C.M. van de Sanden, J. Appl. Phys., 88 (2000) 6388 
26. J. Tauc, Optical properties of solids, edited by F. Abeles (North-Holland Publ. Co., 1972) 277

27. R.H. Klazes, M.H.L.M. van den Broek, J. Bezemer, and S. Radelaar, Phil. Mag. B, 45 (1982) 377

28. C.R. Wronski, Z.E. Smith, S. Aljishi, V. Chu, K. Shepard, D.S. Shen, R. Schwarz, D. Slobodin, and S. Wagner, AIP Conf. Proc., 157 (1987) 70

29. A.A. Langford, M.L. Fleet, B.P. Nelson, W.A. Langford, and N. Maley, Phys. Rev. B. 45 (1992) 13367

30. M. Zeman, J.J.G. van den Heuvel, M.A. Kroon, and J.A. Willemen, ASA User's Manual, internal report, Delft University of Technology (2001)

31. J.A. Willemen, Ph. D. thesis, Delft University of Technology (1998)

32. M.J. Powell and S.C. Deane, Phys. Rev. B, 48 (1993) 10815

33. M. Zeman, G. Tao, M. Trijssenaar, J.W. Willemen, J.W. Metselaar, and R.E.I. Schropp, Mat. Res. Soc. Symp. Proc., 377 (1995) 639 
Chapter 3

3. The Expanding Thermal Plasma 
The expanding thermal plasma (ETP) has been extensively studied in the group "Equilibrium and Transport in Plasmas" of the Eindhoven University of Technology. These studies have been described in theses by e.g. Kroesen [1], Van de Sanden [2], De Graaf [3], Meulenbroeks [4], Kessels [5], and Mazouffre [6]. Some conclusions from their work will be repeated here. In general three fields of interest have to be considered: 1) The plasma in the cascaded arc, 2) the expansion of the plasma and the downstream plasma properties and plasma chemistry, and 3) the deposition of a-Si:H films. Furthermore, this chapter will focus on the specific features regarding the ETP used in the CASCADE project.

\subsection{Introduction}

The gas flows used at the Eindhoven University of Technology to grow a-Si:H at high growth rates are rather large $(\sim 4200 \mathrm{nccm})$. The floor-area provided for the new setup was limited, which resulted consequently in smaller roots blower vacuum pumps. The effective pumping speed during deposition was reduced to $500 \mathrm{~m}^{3} / \mathrm{h}$ for the new set-up in comparison with the $1300 \mathrm{~m}^{3} / \mathrm{h}$ for the set-up in Eindhoven. Using the same flows in the new CASCADE set-up as used in Eindhoven would result in a working pressure of $\sim 0.6$ mbar. Due to this high pressure the expansion of the plasma beam is reduced in radial sense. Furthermore, at this pressure the area over which the deposition is homogeneous ${ }^{17}$ will be limited to a diameter of $\sim 2 \mathrm{~cm}$. Therefore, the total gas flow has to be reduced to obtain reasonable deposition pressures and a homogeneous deposition area with a diameter of $\sim 7 \mathrm{~cm}$.

In Section 3.2 the physics of an expanding thermal plasma will be discussed. This section contains a review of the previous work on the ETP. The largest part of the gas flow that is used consists of argon. The influence of the reduction of the argon flow will be discussed in Section 3.3.1. However, reducing the argon flow leads to a reduction of the ion and electron flux emanating from the arc, but also to a reduction of the atomic hydrogen flux. This reduction leads to smaller growth rates. Here we use the fact that atomic hydrogen is important for the dissociation of $\mathrm{SiH}_{4}$ for obtaining good quality a-Si:H [7]. Other arc configurations with a reduced arc channel diameter are investigated to increase the atomic $\mathrm{H}$ and ion/electron flux emanating from the arc at much lower argon flows (Section 3.3.2). Therefore it is undesirable to reduce the $\mathrm{H}_{2}$ flow and the $\mathrm{SiH}_{4}$ flow, because hydrogen is preferred in the dissociation process of $\mathrm{SiH}_{4}$ and $\mathrm{SiH}_{4}$ is needed for deposition. The reduction of the arc channel diameter leads to limitations of the amount of hydrogen that can be injected. Therefore, $\mathrm{H}_{2}$ injection into the nozzle is investigated and discussed in Section 3.4. In Section 3.5 preliminary results on deposition with a combination of $\mathrm{H}_{2}$ injected into the nozzle and in the cathode housing are discussed. Finally, in Section 3.6 the conclusions are given.

\subsection{Plasma physics and chemistry of ETP method: review of previous work}

The expanding thermal plasma was developed for deposition by Schram et al. [8]. An important feature of the ETP is that it is a remote plasma. This means that the creation of the plasma is geometrically separated from the position where the plasma

\footnotetext{
17 This is defined as the area over which deposition fringes are not seen on the substrate. Those fringes become visible when the thickness difference reaches a certain value observable by the eye.
} 
is being used. Due to a large pressure difference between the cascaded arc and the vacuum chamber, downstream properties do not influence the plasma in the cascaded arc plasma source. Operational pressures in the arc are $>0.2$ bar, while the downstream pressure in the vacuum chamber is normally 0.1 to 1 mbar, depending on the flow and pumping capacity. At pressures $>0.2$ bar the plasma in the arc is thermal with an ion and electron density of $\sim 10^{22} \mathrm{~m}^{-3}$ and with an electron and heavy particle temperature of $\sim 1 \mathrm{eV}[9,10]$. The high heavy particle temperature leads to almost full dissociation of molecular gases when these are injected into the arc.

The efficiency of the argon/hydrogen arc plasma is based on the amount of ions and electrons that are produced and on the amount of atomic $\mathrm{H}$ that is produced. De Graaf [3,11] conducted experiments on a pure $\mathrm{H}_{2}$ plasma and found that the percentage of created $\mathrm{H}$ from $\mathrm{H}_{2}$ decreased with increasing gas flow, i.e., increasing pressure in the arc. Simulations performed by Janssen [12] later confirmed this result. Furthermore, Janssen [12] varied the arc current in the simulations, i.e., power input, and the geometry of the arc. With increasing current the arc efficiency increases. The arc channel length, given by the number of plates, and the diameter of the plasma channel are varied to simulate the geometry effect. It was found that the length did not have much influence on the arc efficiency, unless too small a length is chosen (less than $2.5 \mathrm{~cm}$, i.e., 4 plates), and that the arc efficiency increases with decreasing arc channel diameter. The latter result was also obtained by Burm [13] who simulated a pure Ar plasma. The increase in arc efficiency with decreasing arc channel diameter was attributed to an increase in power density that seems more important than the increase in pressure. It is important to note that in plasmas in which $\mathrm{H}_{2}$ is included the variation of the ionelectron production efficiency is much larger than the variation of the atomic $\mathrm{H}$ production efficiency [12].

The plasma in the cascaded arc is usually started using $\mathrm{Ar}$. In the $\operatorname{arc~}^{-{ }^{+}}{ }^{-}$-ions and electrons are produced according to the reaction:

$$
\mathrm{Ar}+\mathrm{e}^{-} \rightarrow \mathrm{Ar}^{+}+2 \mathrm{e}^{-}
$$

The behaviour of an Ar plasma in the vacuum chamber, i.e., expansion and shock region, has been investigated in detail by Kroesen et al. [9], Van de Sanden et al. $[14,15]$, and Beulens et al. [16]. The ion and electron density in these kinds of plasmas is downstream between $10^{19}$ and $10^{21} \mathrm{~m}^{-3}$, depending on the distance from the source exit [17]. When a pure Ar plasma is used for the deposition of a-Si:H very porous a-Si:H is deposited at very high growth rates of up to $100 \mathrm{~nm} / \mathrm{s}$ [7].

In order to obtain good a-Si: $\mathrm{H}$ it is necessary to add $\mathrm{H}_{2}$ to the plasma source [7]. The power needed to maintain the plasma will increase when $\mathrm{H}_{2}$ is added (Section 3.3.2). The molecular hydrogen will dissociate in the arc forming a wide variety of particles, for example $\mathrm{H}, \mathrm{H}^{+}, \mathrm{H}^{*}, \mathrm{H}_{2}{ }^{+}, \mathrm{H}_{3}{ }^{+}, \mathrm{H}_{2}{ }^{\mathrm{v}, \mathrm{r}}$, etc. ${ }^{18}$ The formation of these particles and their influence on the plasma has been discussed in the aforementioned refs. [3,4,6,12,18] and by Van de Sanden et al. [19]. The most important information regarding the growth of good quality a-Si: $\mathrm{H}$, is the production of atomic hydrogen and the reduction of ion and electron flux (Fig. 3.1). When

\footnotetext{
${ }^{18} \mathrm{H}^{*}$ is here defined as excited atomic hydrogen and $\mathrm{H}_{2}^{\mathrm{v}, \mathrm{r}}$ is here defined as rovibrational excited molecular hydrogen, with $v$ defined as the vibrational quantum number.
} 
hydrogen is injected into the arc dissociative electron-excitation of molecular hydrogen [18] becomes an important reaction in the arc:

$$
\mathrm{H}_{2}+\mathrm{e}^{-} \rightarrow \mathrm{H}^{*}+\mathrm{H}+\mathrm{e}^{-}
$$

Via this reaction and by many more similar reactions with other $\mathrm{H}$ containing particles atomic hydrogen is produced in the arc. An important loss mechanism for atomic $\mathrm{H}$ is the reaction at the channel wall [6]:

$$
\mathrm{H}+\mathrm{H}_{\text {wall }} \rightarrow \mathrm{H}_{2}^{\mathrm{v}, \mathrm{r}}
$$

In this way the efficiency in producing atomic $\mathrm{H}$ in the cascaded arc is reduced. An estimated production efficiency of atomic hydrogen in the arc is $~ 75 \%[3,14]$.

Both inside the arc as well as in the expansion the dominant loss mechanism of ions and electrons is the interaction with molecular hydrogen [e.g. 6]:

$$
\begin{aligned}
& \mathrm{Ar}^{+}+\mathrm{H}_{2} \rightarrow \mathrm{ArH}^{+}+\mathrm{H}, \\
& \mathrm{H}^{+}+\mathrm{H}_{2} \rightarrow \mathrm{H}_{2}^{+}+\mathrm{H} .
\end{aligned} \quad \text { (endothermic, } 1.4 \mathrm{eV} \text { ) }
$$

Equation $3.4 \mathrm{~b}$ is only effective if the molecule is rovibrationally excited to the $v=4$ state $[3,6]$. At electron densities higher than about $10^{16}-10^{17} \mathrm{~m}^{-3}$ these reactions are immediately followed by [e.g. 4]:

$$
\begin{aligned}
& \mathrm{ArH}^{+}+\mathrm{e}^{-} \rightarrow \mathrm{Ar}+\mathrm{H}^{*}, \\
& \mathrm{H}_{2}^{+}+\mathrm{e}^{-} \rightarrow \mathrm{H}+\mathrm{H}^{*} .
\end{aligned}
$$

Thus, one ion and an electron can create two $\mathrm{H}$-atoms out of $\mathrm{H}_{2}$.

Silane is injected $\sim 4.5 \mathrm{~cm}$ from the nozzle into the expanding thermal plasma. A good overview of the possible reactions of particles emanating from the cascaded arc plasma with $\mathrm{SiH}_{4}$ has been presented by Van de Sanden et al. [19] and by Kessels et al. [20]. At zero or very low $\mathrm{H}_{2}$, flows $\mathrm{Ar}^{+}$is the dominant ion and dissociative charge transfer of $\mathrm{Ar}^{+}$with $\mathrm{SiH}_{4}$ dissociates the silane, according to:

$$
\mathrm{Ar}^{+}+\mathrm{SiH}_{4} \rightarrow \mathrm{Ar}+\mathrm{SiH}_{\mathrm{n}}^{+}+\ldots
$$

In this reaction $\mathrm{n} \leq 3$ and the resultant molecular ion will dissociatively recombine with an electron to form a reactive radical $\left(\mathrm{SiH}_{\mathrm{m}}\right.$, with $\left.\mathrm{m} \leq 2\right)$, which is reactive both in the gas phase as well as on the surface. Furthermore, the ion or radical that is formed can react again with $\mathrm{SiH}_{4}$ to form hydrogen containing silicon clusters, which can be charged or neutral [21]. When the $\mathrm{H}_{2}$ flow is increased the ion and electron flux decrease and the atomic $\mathrm{H}$ flow increases (Fig. 3.1). The hydrogen ions emanating from the arc behave in the same way as the argon ions as described by Equation 3.6. However, atomic $\mathrm{H}$ mainly leads to $\mathrm{SiH}_{3}$ production via:

$$
\mathrm{SiH}_{4}+\mathrm{H} \rightarrow \mathrm{SiH}_{3}+\mathrm{H}_{2}
$$

Another mechanism for $\mathrm{SiH}_{4}$ dissociation is by electron collisions. However, the electron temperature in the downstream region is rather low $(\sim 0.2 \mathrm{eV})$ and dissociation of $\mathrm{SiH}_{4}$ by electron collisions is therefore negligible. The low electron 
temperature results in a low plasma potential [19] and is therefore also the reason that the influence of ion bombardment on the growing film can be neglected.

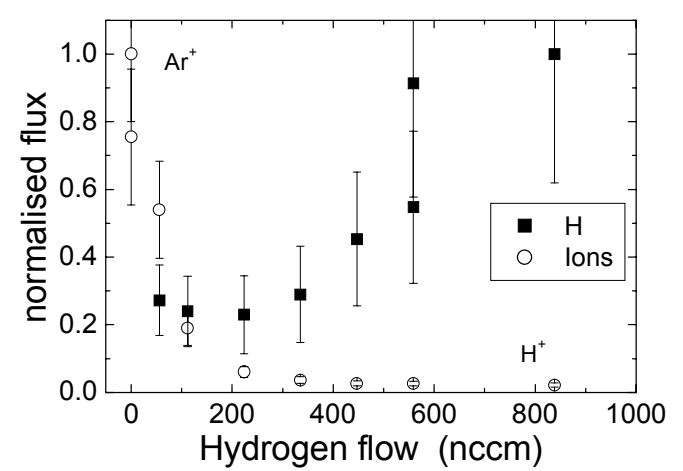

Figure 3.1: Normalised ion density and normalised atomic $\mathrm{H}$ density as a function of the $\mathrm{H}_{2}$ flow in the arc. The normalisation is done by dividing by the $\mathrm{Ar}^{+}$-flux $\left(\sim 10^{19} \mathrm{~m}^{-3}\right)$ when no $\mathrm{H}_{2}$ is added. In a pure argon plasma the dominant ion is $\mathrm{Ar}^{+}$whereas it is $\mathrm{H}^{+}\left(\sim 4 \cdot 10^{16} \mathrm{~m}^{-3}\right)$ at larger hydrogen flows.

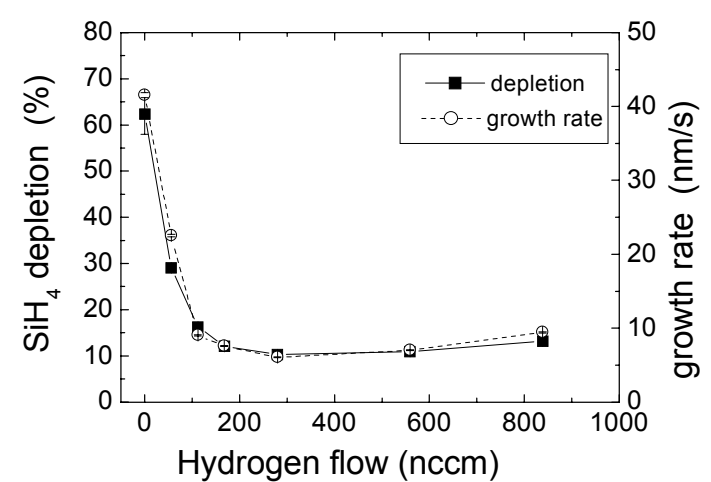

Figure 3.2: Silane depletion and growth rate as a function of the $\mathrm{H}_{2}$ flow [20].

For a-Si:H deposited with the ETP method it is found from detailed cavity ringdown absorption and appearance potential mass spectrometry measurements that solar grade material is obtained when the $\mathrm{SiH}_{3}$ contribution to growth is $~ 90 \%[20,22]$. These conditions are obtained at hydrogen flows $>200$ nccm injected in the arc source, under which conditions the dissociation of $\mathrm{SiH}_{4}$ is dominated by atomic hydrogen (Fig. 3.1). At lower $\mathrm{H}_{2}$ flows the material becomes porous and the dissociation is dominated by ions and electrons. The more effective dissociation by ions and electrons is reflected by the depletion measurements as a function of the $\mathrm{H}_{2}$ flow (Fig. 3.2). At a small $\mathrm{H}_{2}$ flow the $\mathrm{Ar}^{+}$density is comparable with the $\mathrm{H}$ density at larger $\mathrm{H}_{2}$ flow (Fig. 3.1), but the depletion at small $\mathrm{H}_{2}$ flows is larger. Furthermore, the sticking coefficient of $\mathrm{SiH}_{3}(\sim 0.3)$ is smaller than those of most other radicals. Both the larger reaction constant and the formed radicals with larger sticking coefficient will result in a contribution of $\sim 10 \%$ of other radicals and ions to growth then $\mathrm{SiH}_{3}$ [5] even under optimum conditions. The contribution of $\mathrm{SiH}_{3}$ to the growth is mainly influenced by the $\mathrm{H}_{2}$ flow admixed to the plasma in the arc, forming more atomic hydrogen and quenching the ions and electrons when the $\mathrm{H}_{2}$ flow is increased (Fig. 3.1). The contribution of other radicals and ions investigated so far weakly depends on the $\mathrm{H}_{2}$ flow [5], in particular $\mathrm{Si}$ [23], $\mathrm{SiH}$ [23], $\mathrm{SiH}_{2}$ [5], disilanes [24], and large hydrogen-poor ion clusters $\left(\mathrm{Si}_{n} \mathrm{H}_{\mathrm{m}}{ }^{+}\right)$[25]. 


\subsection{Reduction of the total flow}

\subsubsection{Reduction of the argon flow}

A reduction of the argon flow is required due to the smaller pumping capacity. From Section 3.2 it can be understood that the reduction of the Ar flow is not straightforward, as Ar is more than just a carrier gas. The largest influence of the reduction of the Ar flow is the decrease of the total ion and electron flow (Fig. 3.3). However, when $\mathrm{H}_{2}$ is added a reduction of the Ar flow also means that the partial $\mathrm{H}_{2}$ pressure increases compared with the partial Ar pressure.

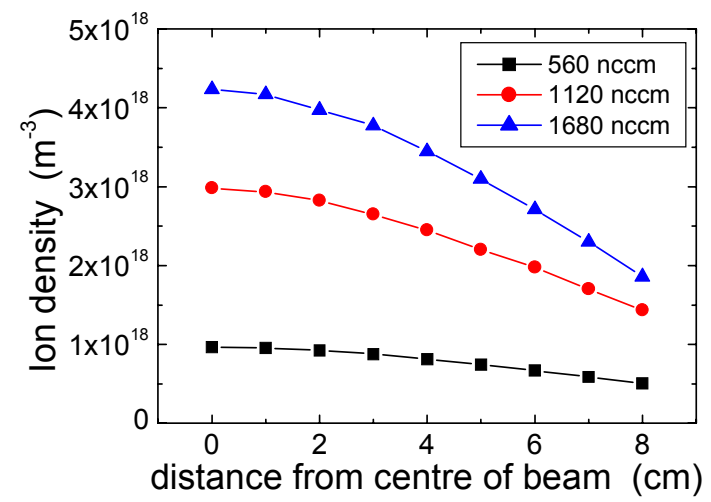

Figure 3.3: Ion saturation current as obtained with a Langmuir probe as a function of the $\mathrm{Ar}$ flow and the distance from the centre of the beam measured $25 \mathrm{~cm}$ from the nozzle. The pressure in the vacuum chamber was kept constant $(0.06 \pm 0.01)$ mbar and the arc current was $30 \mathrm{~A}$.

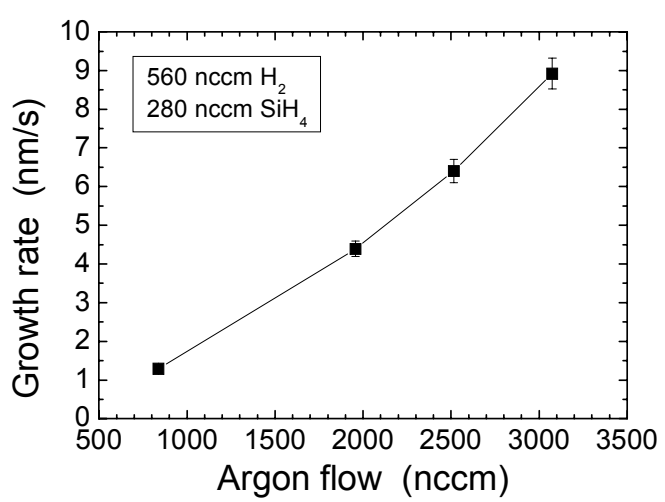

Figure 3.4: Growth rate, as obtained from ellipsometry [26], as a function of the Ar flow [27]. The substrate temperature was $400^{\circ} \mathrm{C}$ and the pressure in the vacuum chamber was fixed to $(0.18 \pm 0.01) \mathrm{mbar}$.

Furthermore, in Section 3.2 it was shown that the contribution of the $\mathrm{Ar}^{+}$-ions and electrons to the dissociation of $\mathrm{SiH}_{4}$ and thus to the growth of a-Si:H is two-fold. Firstly, the ions and electrons produce a large amount of radicals other than $\mathrm{SiH}_{3}$ according to Equation 3.6 and $3.7[19,20]$. Secondly, $\mathrm{Ar}^{+}$-ions and electrons can produce two hydrogen atoms from $\mathrm{H}_{2}$ (Eq. 3.4 and 3.5). The atomic hydrogen that is formed can react with $\mathrm{SiH}_{4}$ to form $\mathrm{SiH}_{3}$. In the first experiments the Ar flow was reduced from $\sim 3100 \mathrm{nccm}$ to $\sim 800 \mathrm{nccm}$ while keeping the other parameters constant. The pressure in the deposition chamber was kept constant at $(0.15 \pm 0.01)$ mbar $^{19}$, the arc current at $45 \mathrm{~A}$, the hydrogen flow was $\sim 560 \mathrm{nccm}$, and the $\mathrm{SiH}_{4}$ flow $\sim 280 \mathrm{nccm}^{20}$. These experiments were carried out in the 'depo2 set-up' of Eindhoven using a cascaded arc with a channel diameter of $4 \mathrm{~mm}$ and 10 copper plates.

Figure 3.4 shows the growth rate as a function of the Ar flow. The growth rate decreases from $\sim 8.5 \mathrm{~nm} / \mathrm{s}$ to $\sim 1.3 \mathrm{~nm} / \mathrm{s}$ when the Ar flow is reduced from $\sim 3100$ to $\sim 800 \mathrm{nccm}$. This reduction in growth rate is mainly attributed to a reduction of the

\footnotetext{
${ }^{19}$ The pressure in the deposition chamber can be kept constant by adjusting the opening in the valve between the roots pump and the deposition chamber.

${ }_{20} \mathrm{This}_{\mathrm{SiH}}$ flow is not very accurate due to a floating thermal mass flow controller. The growth rate suggests that the $\mathrm{SiH}_{4}$ flow was $\sim 500 \mathrm{nccm}$ during those experiments. However, a variation in this regime will not influence the results much, except for the slight changes in the growth rate.
} 
production efficiency of reactive species by the cascaded arc. When the Ar flow is decreased both the ion production efficiency (Fig. 3.3) as well as the atomic hydrogen production efficiency decrease [11,12]. From FTIR measurements (not shown) it is concluded that the microstructure parameter, $R^{*}$, decreases, implying that the material improves when the Ar flow is decreased. At the lowest flows even the peaks between 2060 and $2100 \mathrm{~cm}^{-1}$ are absent, indicating a more homogeneous distribution of Si-H bonds throughout the material [28]. The improvement in material properties can be understood because the decrease in ion and electron density will probably be larger than the decrease in atomic $H$ density [12]. The relative contribution of $\mathrm{SiH}_{3}$ to the growth will increase, resulting in better material. The reduction of the growth rate in combination with the constant deposition temperature $\left(400^{\circ} \mathrm{C}\right)$ can also result in better-structured material. The refractive index is high for all samples and varies between 4.4 and 4.6 (Fig. 3.5), indicating that the bulk density remains the same while reducing the Ar flow. The same density, a lower microstructure parameter, and less incorporated hydrogen means that only the amount of hydrogen is reduced that resides at internal interfaces [29] and/or $\mathrm{SiH}_{2}$ configurations.

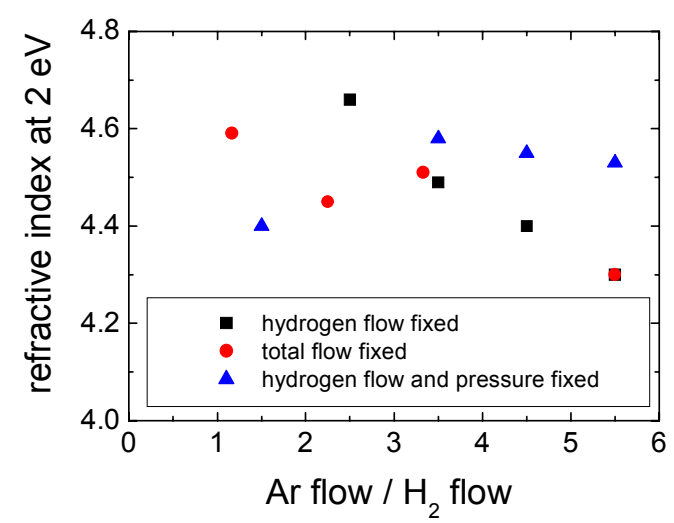

Figure 3.5: Refractive index as a function of the Ar flow divided by the $\mathrm{H}_{2}$ flow for various conditions [27]. The deposition temperature was $400^{\circ} \mathrm{C}$ and the refractive index was obtained using ellipsometry at $632.8 \mathrm{~nm}$ [26].

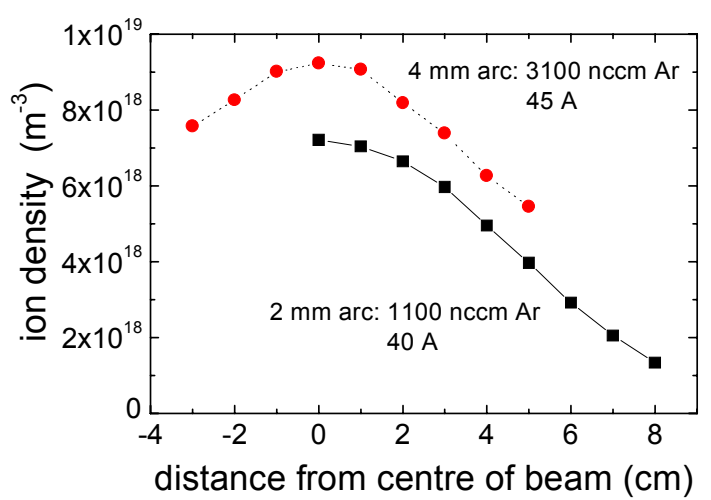

Figure 3.6: Ion density as obtained with a Langmuir probe for two different arc channel diameters as a function of the radial distance from the centre of the plasma beam measured $25 \mathrm{~cm}$ behind the nozzle.

\subsubsection{A smaller arc channel diameter}

A reduction of the Ar flow from 3100 to $800 \mathrm{nccm}$ leads to a decrease in growth rate due to the less efficient production of ions, electrons, and atomic hydrogen in the arc. In the new set-up the Ar flow has to decrease to $\sim 700 \mathrm{nccm}$, in order to get homogeneous deposition over an area with a diameter of $\sim 7 \mathrm{~cm}$. This Ar flow corresponds to deposition rates of $<1 \mathrm{~nm} / \mathrm{s}$, an important reduction of the beneficial high growth rate $(\sim 10 \mathrm{~nm} / \mathrm{s})$ as reported for the ETP elsewhere [30]. Therefore, the arc channel diameter has been reduced with the aim to increase the ionisation efficiency of $\mathrm{Ar}$ and consequently the production efficiency of atomic hydrogen. Janssen [12] concludes from his simulations that the atomic $\mathrm{H}$ production also increases slightly with decreasing channel diameter. However, in these simulations the interaction of $\mathrm{H}$ with $\mathrm{H}$ at the wall of the plasma channel, forming $\mathrm{H}_{2}$, is not included, which can have a large influence [6]. 
A decrease in arc channel diameter results in a power density increase in the channel [12] and a pressure increase in the cathode chamber. Both the power density increase and the higher pressure in the cathode housing lead to more efficient ionisation. Figure 3.6 shows the radial ion density for two different arc channel diameters at two different flows and arc currents. The difference in this figure can be explained completely by the difference in arc current. From this experiment it can be concluded that the same ion and electron density can be obtained at much smaller Ar flows when using a cascaded arc with a channel diameter of $2 \mathrm{~mm}$. A slightly other approach has been taken by Burm [13] who carried out calculations on a so-called "pinched arc". Instead of using a straight arc channel, i.e., a constant diameter, in his calculations he simulated water-cooled copper plates with a varying plasma channel diameter. Calculation results indicated that with the "pinched" configuration higher ionisation efficiencies could be obtained in argon. First the plasma channel was narrowed, increasing the power density and the velocity of the plasma in the channel to the velocity of sound. Further downstream the diameter was increased again, resulting in a further increase in velocity in the plasma channel to supersonic values before expanding into the vacuum chamber. Only a couple of experiments were undertaken using a "pinched" arc starting with a channel diameter of $2 \mathrm{~mm}$, then reducing the diameter to $1.5 \mathrm{~mm}$, and increasing again to $2 \mathrm{~mm}$. In these experiments no significant difference was found compared with an arc with a straight plasma channel with a diameter of $2 \mathrm{~mm}$.

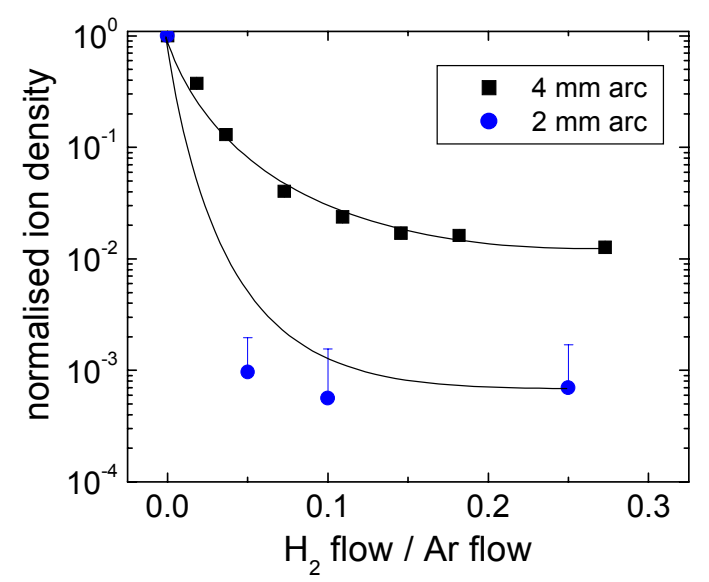

Figure 3.7: Quenching of the ions and electrons due to hydrogen that is injected into the arc. The smaller channel results in a more effective quenching. The density was measured at $25 \mathrm{~cm}$ behind the nozzle in the centre of the beam. The normalisation is carried out in order to put the point when no $\mathrm{H}_{2}$ is added at the same position. The profiles for the absolute values, without $\mathrm{H}_{2}$, are plotted in Figure 3.6. The lines are a guide to the eye.

Addition of $\mathrm{H}_{2}$ to the Ar plasma in the cathode housing using a channel diameter of $2 \mathrm{~mm}$ results in more effective quenching of ions and electrons. In Figure 3.7 the normalised ion density as a function of the $\mathrm{H}_{2}$ flow is presented for both a 4 $\mathrm{mm}$ arc and a $2 \mathrm{~mm}$ arc. The ion density decreased up to two orders of magnitude for the $4 \mathrm{~mm}$ arc and three orders of magnitude for the $2 \mathrm{~mm}$ arc when $\mathrm{H}_{2}$ is added. This so-called quenching of the ions and electrons is also much faster (i.e., at smaller $\mathrm{H}_{2}$ flows) for the $2 \mathrm{~mm}$ arc than for the $4 \mathrm{~mm}$ arc. However, the reduction of the amount of ions and electrons emanating from the arc is no indication for the atomic hydrogen production. For a large contribution of $\mathrm{SiH}_{3}$ to the growth the 
molecular hydrogen flow should be optimised regarding a low ion and electron density and a high atomic hydrogen density. However, the production of atomic hydrogen under the discussed conditions was not measured so far.

In addition to a more effective quenching of the ions and electrons in the case of the small channel arc an increase in power is needed to sustain the plasma. This increase is explained by an increase in thermal conductivity due to the addition of hydrogen to the plasma. The hydrogen diffuses faster to the arc walls than $\mathrm{Ar}$ due to the lower mass. At the arc walls hydrogen atoms can recombine, creating $\mathrm{H}_{2}$ and releasing energy, which is lost for the plasma and transported to the arc wall, effectively cooling the plasma in the outer regions. The increase in $\mathrm{H}_{2}$ density at the walls and the more effective heat transport to the wall lead to a decrease in heavyparticle temperature near the wall and a narrowing of the plasma channel [12]. Two regions can be identified in the arc channel: a region where the heavy-particle temperature equals the electron temperature, which is called the active plasma region, and a region outside this active plasma region, where the heavy-particle temperature is lower than the electron temperature (Fig. 3.8). An increase in hydrogen therefore results in a decrease in the active plasma region (Fig. 3.9), i.e., an increase in resistance. The reduction of the active plasma region now leads to an increase in plasma power, as the power source will maintain the plasma current. A constant current through a smaller area requires an increase in electric field, and thus a larger cathode voltage. This increase in voltage appeared to be more dramatic when the diameter of the plasma channel is smaller. With increasing voltage the electric field between two cascade plates increases and a voltage breakdown between two copper plates can occur at $\sim 40 \mathrm{kV} / \mathrm{m}$. These kinds of electric fields were reached in a $2 \mathrm{~mm}$ arc (Fig. 2.4) but were never reached using a $4 \mathrm{~mm}$ arc, because the resistance of the plasma is much lower in the case with an arc channel diameter of $4 \mathrm{~mm}$. For a $2.5 \mathrm{~mm}$ arc as used for most experiments presented in this thesis this implied that a maximum $\mathrm{H}_{2}:$ Ar ratio of about 1:2 can be used.

a

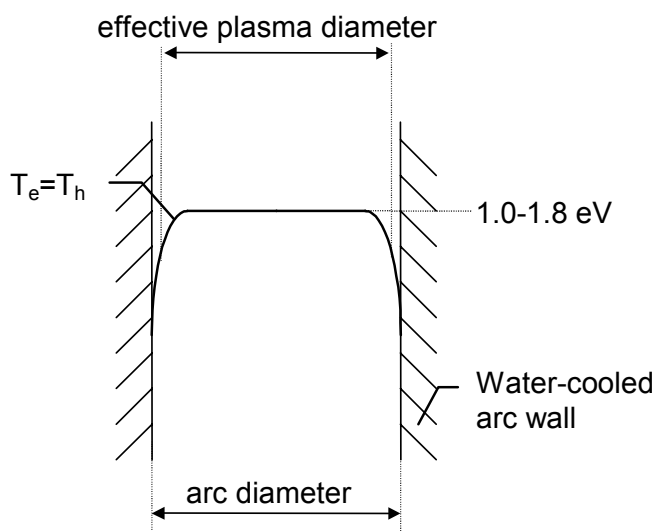

b

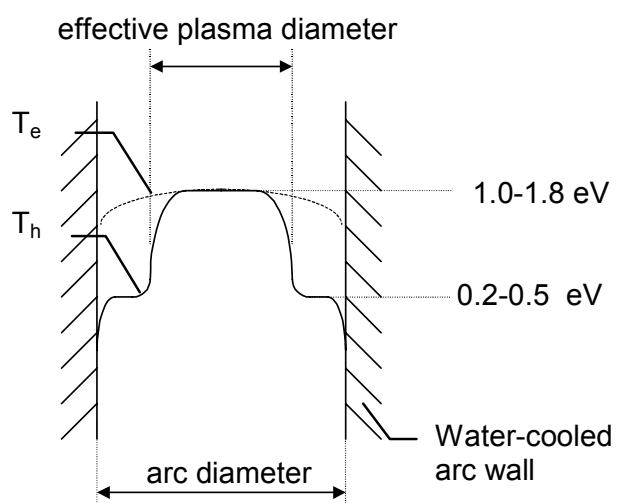

Figure 3.8: Temperature profile in the arc for pure Ar (a) [18] and for an $\mathrm{Ar} / \mathrm{H}_{2}$ mixture (b). In this figure $T_{e}$ is the electron temperature and $T_{h}$ the heavy-particle temperature [27].

First deposition experiments with an arc channel of $2.5 \mathrm{~mm}$ using $600 \mathrm{nccm} \mathrm{Ar}, 200$ nccm $\mathrm{H}_{2}, 200 \mathrm{nccm} \mathrm{SiH}_{4}$, and an arc current of $40 \mathrm{~A}$ resulted in solar-grade material deposited at $0.85 \mathrm{~nm} / \mathrm{s}$ at $250^{\circ} \mathrm{C}$. These conditions will be used in experiments presented in Chapter 4. Comparing these results with results obtained with an arc with a channel diameter of $4 \mathrm{~mm}$ the growth rate does not seem to be much higher than expected from the $4 \mathrm{~mm}$ arc at low Ar flows (Fig. 3.4). However, this is mainly 
due to the lower $\mathrm{SiH}_{4}$ flow as is shown in Figure 5.1. From this it can be concluded that larger growth rates can be obtained with a smaller arc channel diameter when the Ar flow is kept constant.

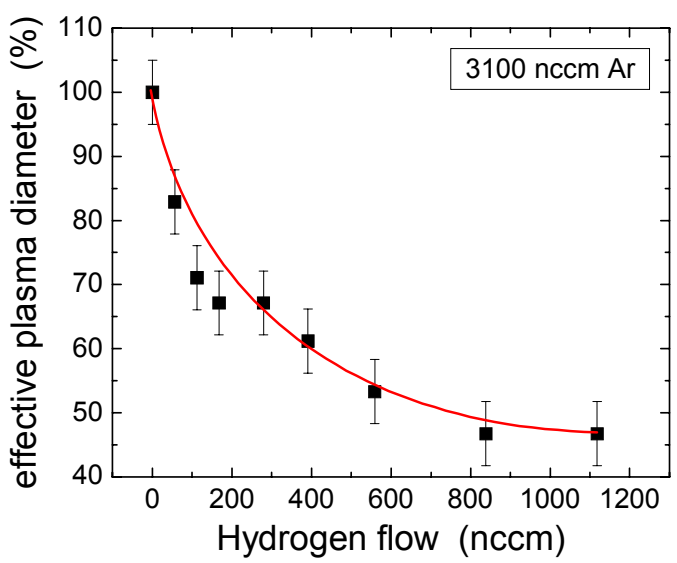

Figure 3.9: Active plasma region as a function of the hydrogen flow. The active plasma region is the diameter of this region as a percentage of the arc channel diameter [18,27]. The line is a guide to the eye.

\subsection{Hydrogen injection into the nozzle}

In the new set-up we choose to go to lower total flows and therefore a cascaded arc with a smaller plasma channel was constructed (see Section 3.3.2). The $\mathrm{H}_{2}$ flow that can be injected into the cathode housing while maintaining the plasma is limited to a $\mathrm{H}_{2}$ :Ar ratio of $1: 2$ as discussed in Section 3.3.2. With $\mathrm{H}_{2}$ only injected in the cascaded arc good quality material can be obtained at relatively low growth rates (< $1 \mathrm{~nm} / \mathrm{s}$ ). Results under these conditions will be discussed in Chapter 4. Furthermore, the power needed to maintain the plasma at an $\mathrm{H}_{2}$ :Ar ratio of $1: 2$ is $\sim 8 \mathrm{~kW}$ compared with $<4 \mathrm{~kW}$ when no $\mathrm{H}_{2}$ is added. The possibility of decreasing the power consumption and of avoiding the limitation on the $\mathrm{H}_{2}$ flow injected into the arc when using a small arc channel, are the main reasons for looking for other options for $\mathrm{H}_{2}$ injection. Two options for $\mathrm{H}_{2}$ injection are therefore investigated. The first option is to inject the $\mathrm{H}_{2}$ into one of the copper plates. This reduces the power consumption but the electric field across the plate where the $\mathrm{H}_{2}$ is injected can still exceed $40 \mathrm{kV} / \mathrm{m}$, at which breakdown can occur (see Section 2.2.2). The experiment with hydrogen injection into one of the plates was done using a pinched arc [13] as described in Section 3.3.2. The $\mathrm{H}_{2}$ is injected into plate four ${ }^{21}$, at which a change in slope is observed in the data presented in Figure 3.10. At flows $>300 \mathrm{nccm} \mathrm{H}_{2}$ a breakdown occurred. This breakdown might be avoided by exploiting a larger increase in diameter of the plasma channel just after the plate where the $\mathrm{H}_{2}$ is injected.

\footnotetext{
${ }^{21}$ Plate 1 is at the side of the vacuum chamber, so the plasma flows from plate 10 to plate 1.
} 

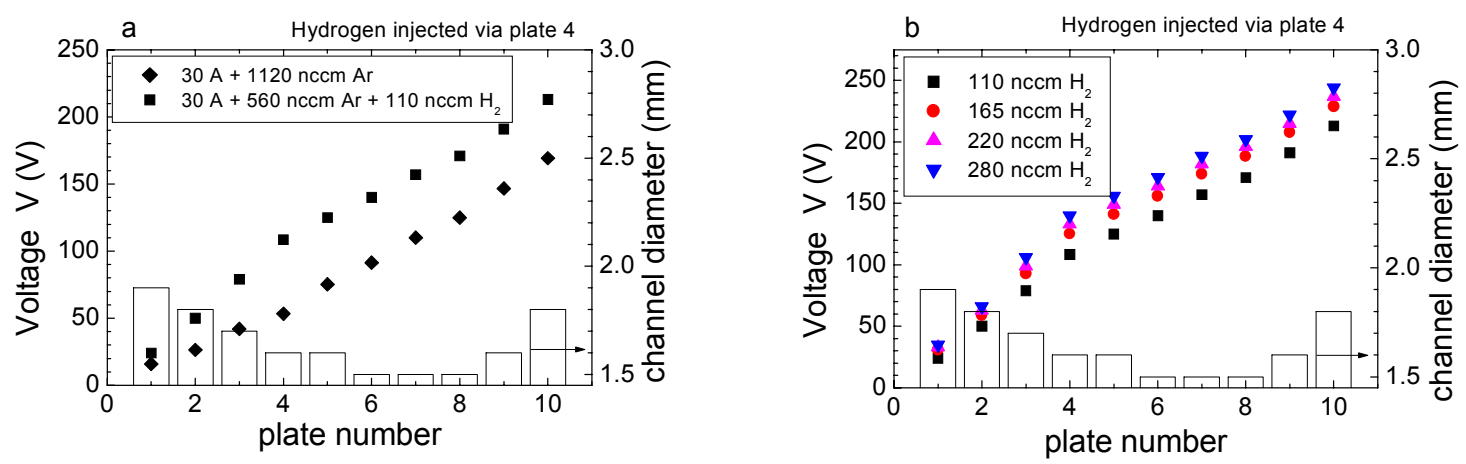

Figure 3.10: Voltage of the arc plate as a function of the $\mathrm{H}_{2}$ flow as injected into one of the cascaded arc plates. Figure 3.10a compares the voltage per plate for a pure Ar plasma with a plasma in which $\mathrm{H}_{2}$ is injected into plate 4 and Figure $3.10 \mathrm{~b}$ shows the results of increasing $\mathrm{H}_{2}$ flow. The voltage is measured using a multi-meter. The right-hand axis of the graph gives an indication of the plasma channel diameter, i.e., the diameter of the bore in the copper plate.

The second option is to inject $\mathrm{H}_{2}$ into the nozzle. This is more or less the same as the first option, but in this case the $\mathrm{H}_{2}$ is injected at a position where no power is coupled into the plasma and the plasma is already expanding in the nozzle. The idea is that an $\mathrm{H}_{2}$-screen is created that the $\mathrm{Ar}^{+}$-ions and electrons have to pass before these can interact with the $\mathrm{SiH}_{4}$. If this $\mathrm{H}_{2}$-screen is sufficiently dense all $\mathrm{Ar}^{+}$-ions and electrons react with $\mathrm{H}_{2}$, forming atomic hydrogen according to Equation 3.4 and 3.5. When these reactions occur in the plasma channel, the atomic hydrogen will interact with the wall and the nozzle surface and form $\mathrm{H}_{2}$ again (Eq. 3.3).

Langmuir probe measurements and depletion measurements using a mass spectrometer are performed (see Section 2.4.1) to get a better understanding of $\mathrm{H}_{2}$ injection in the nozzle. When hydrogen is injected only into the nozzle, visually the plasma shows a much brighter, reddish colour when compared with hydrogen injected into the cascaded arc. Furthermore, the $\mathrm{Ar}^{+}$-ion and electron flux emanating from the cascaded arc is unaffected. The $\mathrm{Ar}^{+}$-ions and electrons then pass through the $\mathrm{H}_{2}$-screen, enabling Equations 3.4 and 3.5 to occur. Figure 3.11 shows the ion density as a function of the $\mathrm{H}_{2}$ flow injected into the nozzle. The $\mathrm{H}_{2}$ flow through the nozzle was varied from $0 \mathrm{nccm}$ to $2000 \mathrm{nccm}$ in a $700 \mathrm{nccm}$ Ar plasma. The pressure in the vacuum chamber increases from $\sim 0.14$ to $\sim 0.42 \mathrm{mbar}$ for 0 and 2000 nccm $\mathrm{H}_{2}$, respectively. In the pure Ar plasma (i.e., $0 \mathrm{nccm} \mathrm{H}_{2}$ ) an electron temperature of $\sim 0.3 \mathrm{eV}$ is obtained, which is in agreement with Thomson scattering results $[4,14]$. The electron temperature drops to $\sim 0.17 \mathrm{eV}$ at flows $>800 \mathrm{nccm}$, indicating that the plasma is dominated by hydrogen. When increasing the $\mathrm{H}_{2}$ from 0 nccm to $500 \mathrm{nccm}$ the ion density decreases, indicating that the $\mathrm{Ar}^{+}$-ions and electrons emanating from the arc are quenched (Eq. 3.4 and 3.5). However, increasing the $\mathrm{H}_{2}$ flow further increases the ion density. When it is assumed that the total amount of ions and electrons does not change, this increase in density can be attributed to the pressure increase in the vacuum chamber due to the larger flow, which has a large influence on the ion and electron density found on the axis [e.g. $6,14,15]$. 


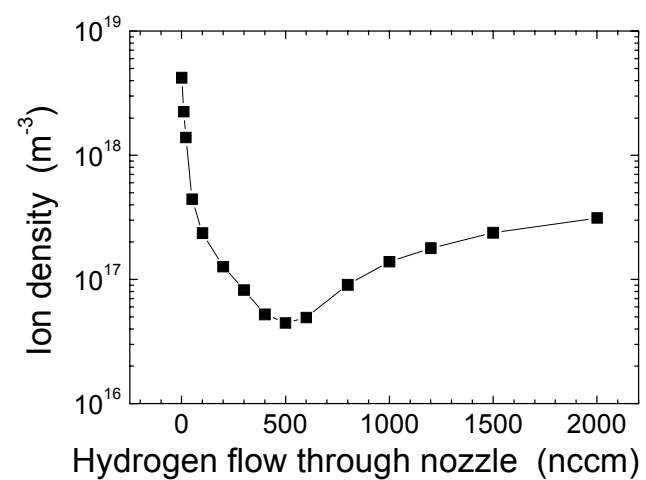

Figure 3.11: Ion density for varying hydrogen flows through the nozzle as obtained in the centre of the plasma beam $15 \mathrm{~cm}$ from the nozzle. The argon flow was $700 \mathrm{nccm}$ and the arc current was $40 \mathrm{~A}$.

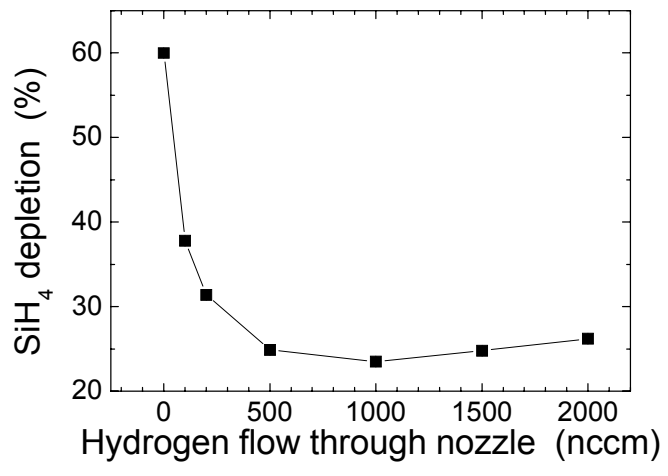

Figure 3.12: Silane depletion as a function of the hydrogen flow through the nozzle. The argon flow was $700 \mathrm{nccm}$, the silane flow $100 \mathrm{nccm}$, and the arc current was $40 \mathrm{~A}$.

Under the conditions of Figure 3.11 porous a-Si:H is obtained at a deposition temperature of $250^{\circ} \mathrm{C}$. Furthermore, these conditions are use to perform depletion measurements (Fig. 3.12). In a pure Ar plasma a large fraction of the $\mathrm{SiH}_{4}(100$ $\mathrm{nccm}$ ) is dissociated, leading to a depletion of $\sim 60 \%$. Injection of hydrogen into the nozzle leads to a decrease in ion and electron density and thus to a lower depletion. At a $\mathrm{H}_{2}$ flow of 1000 nccm a minimum can be observed, after which the depletion increases slightly. That the depletion does not increase as rapidly as the ion and electron density (Fig. 3.11) indicates that although the ion and electron density increases, the ions and electrons flux does not increase as $\mathrm{SiH}_{4}$ dissociation is very effective using ions. The slight increase can be attributed to the increase in pressure in the vacuum chamber, because more secondary reactions [25] can occur.

In conclusion, the large amount of ions and electrons (Fig. 3.11) and the large dissociation degree of $\mathrm{SiH}_{4}$ (Fig. 3.12) makes the case with $\mathrm{Ar}$ in the arc and $\mathrm{H}_{2}$ only in the nozzle unsuitable for the production of solar grade a-Si:H, using an arc channel diameter of $2.5 \mathrm{~mm}$. From earlier experience it is expected that an optimum for solar grade a-Si:H using a $2.5 \mathrm{~mm}$ arc can be obtained when the number of ions and electrons emanating from the arc is reduced. This can be obtained by injecting a small amount of $\mathrm{H}_{2}$ into the arc (Fig. 3.7). The remaining ions and electrons have to pass an $\mathrm{H}_{2}$-screen created by injecting $\mathrm{H}_{2}$ into the nozzle, forming atomic hydrogen. As the ion and electron flux coming from the arc is low, the atomic hydrogen that is formed will probably not be ionised and is available to dissociate the $\mathrm{SiH}_{4}$ in accordance with Equation 3.7.

\section{5 a-Si:H deposited using a smaller arc channel diameter}

Preliminary deposition results in Eindhoven have shown some promising material properties, using an arc with a channel diameter of $3 \mathrm{~mm}$, an Ar flow of $1400 \mathrm{nccm}$, a $\mathrm{H}_{2}$ flow of $560 \mathrm{nccm}$, and a $\mathrm{SiH}_{4}$ flow of $280 \mathrm{nccm}$. Two depositions were performed, one with $\mathrm{H}_{2}$ in the cathode housing and one with $\mathrm{H}_{2}$ in the nozzle. Some measured 
material properties are given in Table 3.1. Note that the deposition temperature was $400^{\circ} \mathrm{C}$, resulting in very dense material as reflected by the high value of the refractive index at $2 \mathrm{eV}$. The pressure in the vacuum chamber during these depositions was $\sim 0.18$ mbar. Comparing the results for $\mathrm{H}_{2}$ injection into the nozzle with injection into the cathode housing (Table 3.1), it is observed that the growth rate is approximately twice as large, that the films contain somewhat less $H$, and that the film surface is somewhat rougher (concluded from fits of in-situ HeNe-ellipsometry data [26]).

Table 3.1: Preliminary results as obtained in Eindhoven for material deposited with $\mathrm{H}_{2}$ injected into the nozzle compared with the 'conventional' method. Given are the hydrogen concentration, $[\mathrm{H}]$, the refractive index at $2 \mathrm{eV}, n$, the thickness of a rough surface layer, $d_{\mathrm{top}}$ [26], and the growth rate, $r$. These films are deposited at $400^{\circ} \mathrm{C}$ and are $\sim 600 \mathrm{~nm}$ thick.

\begin{tabular}{|c|c|c|}
\hline & Nozzle & Cathode Housing \\
\hline$[\mathrm{H}]($ at.\%) & 7 & 9 \\
\hline $\mathrm{n}($ at $2 \mathrm{eV})$ & 4.6 & 4.6 \\
\hline $\mathrm{d}_{\text {top }}(\mathrm{nm})$ & 8 & 5 \\
\hline $\mathrm{r}(\mathrm{nm} / \mathrm{s})$ & 7.5 & 3.5 \\
\hline
\end{tabular}

However, preliminary results in the CASCADE set-up for films deposited at $250^{\circ} \mathrm{C}$ with a cascaded arc channel diameter of $2.5 \mathrm{~mm}$ resulted in porous films with only $\mathrm{H}_{2}$ injection in the nozzle (Fig. 3.13). The deposition of porous material is mainly attributed to the relatively high ion and electron density (Fig. 3.11). To reduce the ion and electron density some $\mathrm{H}_{2}$ has to be injected into the cascaded arc. The remainder of this section discusses deposition experiments performed with both hydrogen injected into the arc and into the nozzle as will be used in Chapter 5.

Figure 3.13 shows the results of the growth rate, the refractive index at $2 \mathrm{eV}$, the optical gap, and the photoconductivity as a function of the ratio of hydrogen flow injected into the arc over the hydrogen flow injected into the nozzle, keeping the total hydrogen flow constant at $400 \mathrm{nccm}$. The deposition temperature for all films in this figure is $250^{\circ} \mathrm{C}$. From Figure 3.13 it can be seen that when all hydrogen is injected into the nozzle the growth rate is much higher and porous material with a high bandgap results. A small amount of hydrogen in the arc decreases the amount of ions and electrons from the arc considerably (Fig. 3.7), which results in a significantly smaller growth rate. Kessels et al. [20] showed that a further increase in hydrogen flow in the arc also increases the growth rate. This is also observed when the ratio of hydrogen in the arc over hydrogen in the nozzle is increased. The best material properties for all these films are obtained for the smallest growth rates, mainly due to the deposition temperature [Section 4.3.3,31]. If a larger growth rate is used, the optimum in material properties is found at a higher deposition temperature [31]. In general, the material quality depends both on the growth rate and the deposition temperature when the plasma, and thus the arriving radical flux, is kept constant. Further research regarding depositions using a combination $\mathrm{H}_{2}$ injection into the nozzle and $\mathrm{H}_{2}$ injection in the arc is presented in the experiments of Chapter 5. 

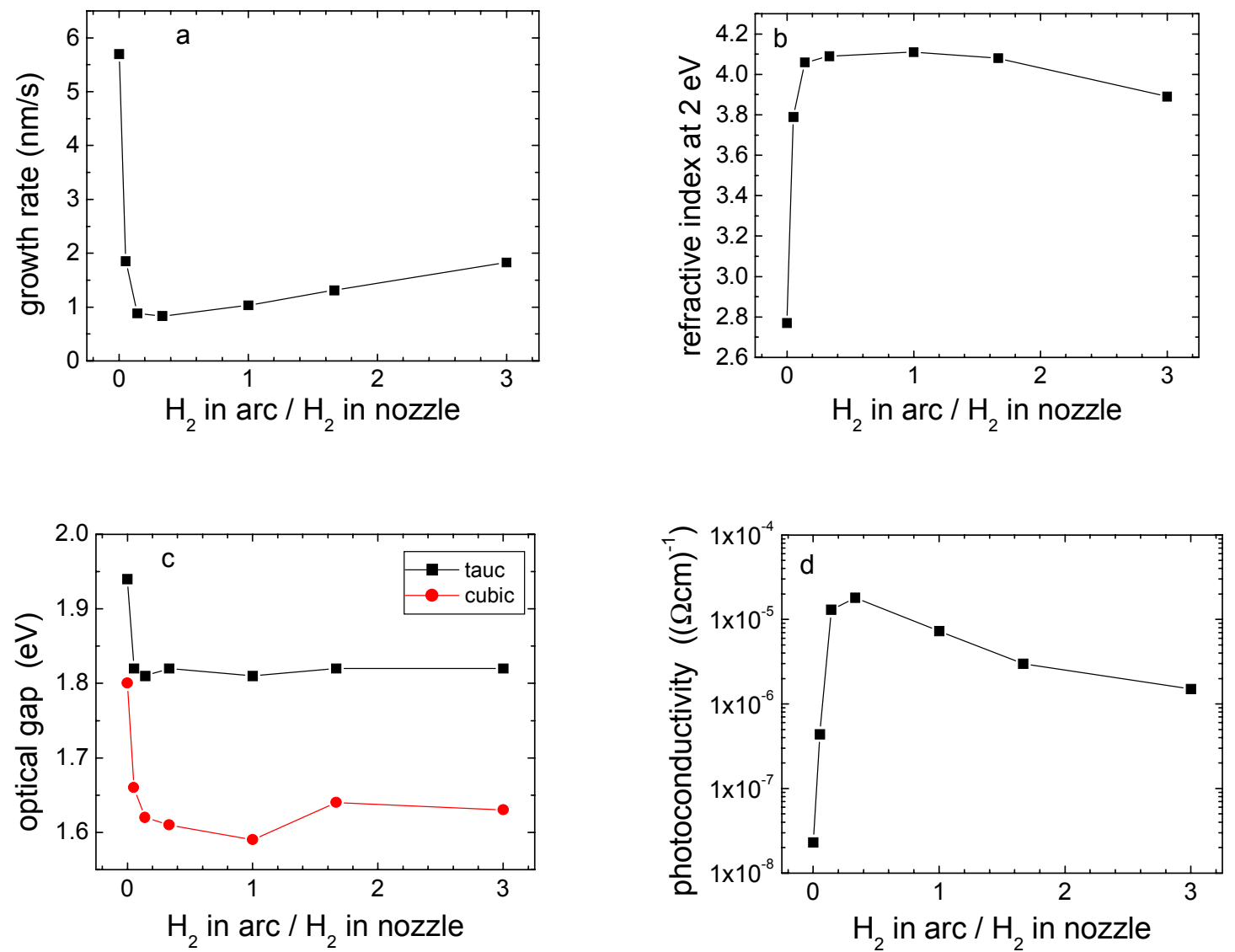

Figure 3.13: Growth rate (a), refractive index at $2 \mathrm{eV}$ (b), Tauc and cubic optical gap (c), and the photoconductivity (d) as a function of the ratio of hydrogen injected into the cascaded arc plasma source and in the nozzle. The conditions are $700 \mathrm{nccm} \mathrm{Ar}, 400 \mathrm{nccm} \mathrm{H} \mathrm{H}_{2}$ (total), $100 \mathrm{nccm} \mathrm{SiH}$, $35 \mathrm{~A}$, and $250^{\circ} \mathrm{C}$.

\subsection{Conclusions}

The Ar flow in the cascaded arc was reduced in order to be able to use a smaller pumping capacity while maintaining a homogeneous deposition area with a diameter of $\sim 7 \mathrm{~cm}$. To obtain the same ion and electron flux emanating from the arc at a smaller Ar flows the arc channel diameter is reduced from $4 \mathrm{~mm}$ to $2.5 \mathrm{~mm}$. By using a smaller arc channel diameter the deposition rate can be increased when the argon flow is kept constant. This increase is mainly attributed to an increase in power density in the arc channel and thus more effective dissociation of $\mathrm{H}_{2}$ and ionisation. However, a smaller arc channel diameter reduces the maximum amount of hydrogen that can be admixed in the cascaded arc, because with increasing $\mathrm{H}_{2}$ flow in the arc the power required to maintain the plasma would increase. The electric fields can, however, not become too large because exceeding electric fields between two plates of $40 \mathrm{kV} / \mathrm{m}$ can result in a voltage breakdown between two copper plates. Therefore the influence of $\mathrm{H}_{2}$ injection into the nozzle has been investigated. $\mathrm{H}_{2}$ injection into the nozzle decreases the power consumption considerably and increases the amount of $\mathrm{H}_{2}$ that can be admixed. The arc operates on pure $\mathrm{Ar}$ and only $\mathrm{Ar}^{+}$-ions and electrons are produced. These ions and electrons have to go through an $\mathrm{H}_{2}$ 
screen and the $\mathrm{Ar}^{+}$-ions and electrons are quenched. However, $\mathrm{H}^{+}$-ions are produced and the total ion and electron density within the deposition chamber is still high when $\mathrm{H}_{2}$ is admixed only in the nozzle of an arc with a channel diameter of $2.5 \mathrm{~mm}$. This large flux of $\mathrm{H}^{+}$-ions results in at least $25 \% \mathrm{SiH}_{4}$ dissociation. Radicals formed by the ions and electrons are not favourable for the production of solar-grade a-Si:H and porous films are obtained [7]. To reduce the amount of ions and electrons emanating from the arc, a small amount of hydrogen should also be injected into the arc when using hydrogen in the nozzle in the case of a $2.5 \mathrm{~mm}$ arc.

\section{References}

1. G.M.W. Kroesen, Ph. D. Thesis, Eindhoven University of Technology (1988)

2. M.C.M. van de Sanden, Ph. D. Thesis, Eindhoven University of Technology (1991)

3. M.J. de Graaf, Ph. D. Thesis, Eindhoven University of Technology (1994); M.J. de Graaf, R. Severens, R.P. Dahiya, M.C.M. van de Sanden, and D.C. Schram, Phys. Rev. E, 48 (1993) 2098

4. R.F.G. Meulenbroeks, Ph. D. Thesis, Eindhoven University of Technology (1996); R.F.G. Meulenbroeks, A.J. van Beek, A.J.G. van Helvoort, M.C.M. van de Sanden, and D.C. Schram, Phys. Rev. E, 49 (1994) 4397

5. W.M.M. Kessels, Ph. D. thesis, Eindhoven University of Technology (2000)

6. S. Mazouffre, Ph. D. Thesis, Eindhoven University of Technology (2001); S. Mazouffre, P. Vankan, R. Engeln, and D.C. Schram, Phys. Plasmas, 8 (2001) 3824

7. W.M.M. Kessels, R.J. Severens, A.H.M. Smets, B.A. Korevaar, M.C.M. van de Sanden, and D.C. Schram, J. Appl. Phys., 89 (2001) 2404

8. D.C. Schram and G.M.W. Kroesen, Method of treating surfaces and substrates with the aid of a plasma and a reactor for carrying out the method, American patent 4,871,580 (1989) and European patent 0297637 (1992)

9. G.M.W. Kroesen, D.C. Schram, and J.C.M. de Haas, Plasma Chem. Plasma Proc., 10 (1990) 531

10. J.J. Beulens, M.J. de Graaf, P.M. Vallinga, and D.C. Schram, Proc. ISPC-9 (1989) 1; J.J. Beulens, M.J. de Graaf, G.M.W. Kroesen, and D.C. Schram, Mat. Res. Soc. Symp. Proc., 190 (1991) 311

11. M.J. de Graaf, R.P. Dahija, J.L. Jeauberteau, F.J. de Hoog, M.J.F. van de Sande, and D.C. Schram, Coll. Phys., 18 C5 (1990) 387

12. G.M. Janssen, Ph. D. Thesis, Eindhoven University of Technology (2000)

13. K.T.A.L. Burm, Ph. D. thesis, Eindhoven University of Technology (2001); K.T.A.L. Burm, W.J. Goedheer, J.A.M. van der Mullen, G.M. Janssen, and D.C. Schram, Plasma Sources Sci. Technol., 7 (1998) 395

14. M.C.M. van de Sanden, J.M. de Regt, and D.C. Schram, Plasma Sources Sci. Technol., 3 (1994) 501

15. M.C.M. van de Sanden, R. van den Bercken, and D.C. Schram, Plasma Sources Sci. Technol., 3 (1994) 511

16. J.J. Beulens, D. Milojevic, D.C. Schram, and P.M. Wallinga, Phys. Fluids, B3 (1991) 2548

17. R.F.G. Meulenbroeks, M.F.M. Steenbakkers, Z. Qing, M.C.M. van de Sanden, and D.C. Schram, Phys. Rev. E, 49 (1994) 2272 
18. Z. Qing, Dr. thesis, Eindhoven University of Technology (1995); Z. Qing, D.K. Otorbaev, G.J.H. Brussaard, M.C.M. van de Sanden, and D.C. Schram, J. Appl. Phys., 80 (1996) 1312

19. M.C.M. van de Sanden, R.J. Severens, W.M.M. Kessels, R.F.G. Meulenbroeks, and D.C. Schram, J. Appl. Phys., 84 (1998) 2426

20. W.M.M. Kessels, M.C.M. van de Sanden, and D.C. Schram, J. Vac. Sci. Technol. A, 18 (2000) 2153

21. W.M.M. Kessels, C.M. Leewis, M.C.M. van de Sanden, and D.C. Schram, J. Vac. Sci. Technol. A, 17 (1999) 1531

22. W.M.M. Kessels, M.G.H. Boogaarts, J.P.M. Hoefnagels, M.C.M. van de Sanden, and D.C. Schram, J. Vac. Sci. Technol. A, 19 (2001) 1027

23. W.M.M. Kessels, J.P.M. Hoefnagels, M.G.H. Bogaarts, D.C. Schram, and M.C.M. van de Sanden, J. Appl. Phys., 89 (2001) 2065

24. L. Gabella, master thesis, Eindhoven University of Technology (1997)

25. W.M.M. Kessels, C.M. Leewis, M.C.M. van de Sanden, and D.C. Schram, J. Appl. Phys., 86 (1999) 4029

26. A.H.M. Smets, D.C. Schram, and M.C.M. van de Sanden, J. Appl. Phys., 88 (2000) 6388

27. S. van Egmond, master thesis, Eindhoven University of Technology (1998)

28. Z. Remes, M. Vanecek, A.H. Mahan, and R.S. Crandall, Phys. Rev. B, 56 (1997) R12710

29. K.K. Gleason, M.A. Petrich, and J.A. Reimer, Phys. Rev. B, 36 (1987) 3259

30. B.A. Korevaar, G.J. Adriaenssens, A.H.M. Smets, W.M.M. Kessels, H.-Z. Song, M.C.M. van de Sanden, and D.C. Schram, J. Non-Cryst. Sol., 266-269 (2000) 380

31. B.A. Korevaar, C. Smit, A.H.M. Smets, R.A.C.M.M. van Swaaij, D.C. Schram, and M.C.M. van de Sanden, Proc. of the $28^{\text {th }}$ IEEE-PVSC conference (2000), 916 
Chapter 4

4. Single junction $p-i-n$ a-Si:H solar cells 


\subsection{Introduction}

In Section 1.3 we concluded that good material properties could be obtained for aSi:H deposited with the expanding thermal plasma (ETP) method. The focus of this chapter is to incorporate films deposited at $0.85 \mathrm{~nm} / \mathrm{s}$ and $250^{\circ} \mathrm{C}$ into $p-i-n$ solar cells. Although this approach will not fully exploit the possibilities of a-Si:H deposited with the ETP at large growth rates (>2 nm/s), it will help in understanding the growth of a$\mathrm{Si} \mathrm{H}$ solar cells using the ETP. The properties of this a-Si:H film deposited with the ETP in the CASCADE set-up will be presented in Section 4.2. Section 4.3 discusses the background for this combination of deposition temperature and growth rate. In that section the properties of the p-type and n-type layers are also discussed as well as the influence of the thickness of the p-type layer. In Section 4.4 the best ETP cell is compared with an RF-PECVD cell of $\sim 9 \%$ deposited in the UHV AMOR-system. It is shown that good properties for the individual layers of the solar cell do not result in a solar cell with a high initial efficiency. Luft and Tsuo [1] argued that the properties of the component layers of hydrogenated amorphous silicon (a-Si:H) thin-film solar cells prepared by plasma-enhanced chemical vapour deposition (PECVD) may differ substantially from those of thicker layers deposited separately. The properties that are generally obtained are bulk-properties that do not give information about interface properties, which is important because the solar-cell performance is largely influenced by the interfaces. Especially, defects at the interface can have a large influence on the solar cell performance. In Section 4.5 the effect of intermediate layers, so-called buffer layers, will be presented. These layers are deposited with RFPECVD between the p-layer and the intrinsic layer to improve the solar cell performance.

\subsection{Intrinsic a-Si:H deposited with the expanding thermal plasma}

Table 4.1: Characteristics for solar grade a-Si:H as obtained with RF-PECVD [2] $\left(200^{\circ} \mathrm{C}-250^{\circ} \mathrm{C}\right)$ compared with the best results as obtained for a-Si:H deposited with ETP in the CASCADE project at growth rates $<1 \mathrm{~nm} / \mathrm{s}$ at $\sim 250^{\circ} \mathrm{C}$. The properties of the ETP a-Si:H are measured for samples with a thickness $>400 \mathrm{~nm}$.

\begin{tabular}{|l|l|l|}
\hline & RF-PECVD & ETP \\
\hline AM $1.5100 \mathrm{~mW} / \mathrm{cm}^{2}$ photoconductivity $\left((\Omega \mathrm{cm})^{-1}\right)$ & $>1 \cdot 10^{-5}$ & $2 \cdot 10^{-5}$ \\
\hline Dark conductivity $\left((\Omega \mathrm{cm})^{-1}\right)$ & $<1 \cdot 10^{-10}$ & $<1 \cdot 10^{-11}$ \\
\hline Activation energy $(\mathrm{eV})$ & $\sim 0.8$ & $\sim 0.8$ \\
\hline Photo response & $>1 \cdot 10^{5}$ & $>1 \cdot 10^{5}$ \\
\hline Bandgap, Tauc $(\mathrm{eV})$ & $<1.8$ & $\sim 1.8$ \\
\hline Hydrogen content $($ at.- $\%)$ & $9-11$ & $\sim 10$ \\
\hline Microstructure parameter $\mathrm{R}^{*}$ & $<0.1$ & $\sim 0.1$ \\
\hline Density of dangling bond states $\left(\mathrm{cm}^{-3}\right)$ & $\leq 1 \cdot 10^{16}$ & $<1 \cdot 10^{16}$ \\
\hline
\end{tabular}

Properties comparable with solar grade a-Si:H deposited with RF-PECVD can be achieved at $250^{\circ} \mathrm{C}$ using an ETP. For most films presented in this chapter the following conditions are used: $600 \mathrm{nccm} \mathrm{Ar,} 200 \mathrm{nccm} \mathrm{H}_{2}$ in the arc, $200 \mathrm{nccm} \mathrm{SiH}_{4}$, and an arc current of $40 \mathrm{~A}$. Under these conditions the pressure in the deposition 
chamber is $\sim 0.18$ mbar. The argon flow is low and $\mathrm{H}_{2}$ is only injected into the cathode housing. The ion and electron density under these conditions are low $\left(\sim 10^{16}\right.$ $\mathrm{m}^{-3}$ ) and the depletion is $\sim 8 \%$. Table 4.1 displays the best results obtained on material using the described deposition conditions and compares these properties with the demands for solar grade a-Si:H as described by Schropp and Zeman [2].

The results obtained with the ETP method at a growth rate of $0.85 \mathrm{~nm} / \mathrm{s}$ deposited at $250^{\circ} \mathrm{C}$ are very similar to the characteristics for solar grade a-Si:H as deposited with RF-PECVD. This in contrast to the results presented in Section 1.3 for the ETP material deposited at $400^{\circ} \mathrm{C}$ at a growth rate of $\sim 10 \mathrm{~nm} / \mathrm{s}$. That material shows some differences, which makes it fundamentally different. For example, from the TOF measurements presented in Section 1.3 it was shown that the larger hole drift mobility was not observed at $250^{\circ} \mathrm{C}$. From the presented properties in Table 4.1 it is in first instance expected that similar efficiencies will be reached as with RFPECVD.

\subsection{Consequences of using the p-i-n structure}

\subsubsection{Properties of the doped layers}

The doped layers are deposited using RF-PECVD and are mainly characterised by the conductivity in combination with the activation energy for electron or hole conduction. Furthermore, it is important that the optical bandgap of the p-layer is large such that in that $p$-layer no significant absorption occurs. The optical gap for the p-layer is in between 1.95 and $2.0 \mathrm{eV}$ due to the addition of carbon. The properties of the doped layers as well as the properties of a microcrystalline n-type layer are listed in Table 4.2. The conditions under which microcrystalline n-type a$\mathrm{Si}: \mathrm{H}$ has been grown are: $100 \mathrm{nccm} \mathrm{H} \mathrm{H}_{2}, 2 \mathrm{nccm} \mathrm{SiH}, 1.5 \mathrm{nccm} \mathrm{PH}_{3}(2 \%$ diluted in $\mathrm{H}_{2}$ ), pressure of $0.74 \mathrm{mbar}$, deposition temperature between $200^{\circ} \mathrm{C}$ and $300^{\circ} \mathrm{C}$, distance between substrate and RF-electrode of $(23.5 \pm 0.5) \mathrm{mm}$, and a power of $\sim 30 \mathrm{~W}\left(\sim 0.15 \mathrm{~W} / \mathrm{cm}^{2}\right)$.

Table 4.2: Properties of the doped layers as deposited with RF-PECVD in the CASCADE system. These properties are measured on $400 \mathrm{~nm}$ thick films for the amorphous films and on $100 \mathrm{~nm}$ thick films for the microcrystalline film.

\begin{tabular}{|l|c|c|c|}
\hline & $\begin{array}{c}\text { a-SiC:H:B } \\
(p-t y p e)\end{array}$ & $\begin{array}{c}\text { a-Si:H:P } \\
(n-t y p e)\end{array}$ & $\begin{array}{c}\mu c-S i: H: P \\
\text { (n-type) }\end{array}$ \\
\hline Conductivity $\left((\Omega \mathrm{cm})^{-1}\right)$ & $>10^{-6}$ & $>10^{-2}$ & $>3$ \\
\hline Activation energy $(\mathrm{eV})$ & 0.40 & 0.17 & 0.03 \\
\hline Optical gap $(\mathrm{eV})$ & 2.0 & 1.8 & 2.0 \\
\hline Growth rate $(\mathrm{nm} / \mathrm{s})$ & 0.19 & 0.14 & 0.03 \\
\hline
\end{tabular}

The properties of the doped amorphous films fulfil the requirements for the doped layers as presented by Schropp and Zeman [2]. The properties obtained for the microcrystalline n-layer are similar to those presented by Rubinelli et al. [3]. From this it is concluded that the quality of the doped layers is sufficient for incorporation into solar cells. Incorporating the doped amorphous layers into a solar cell that is made completely in the RF-PECVD chamber resulted in an initial cell efficiency of 
$8.0 \%$, again indicating that the layer properties are sufficient to be incorporated in solar cells.

However, from Luft and Tsuo [1] it well known that the material properties of thick layers are not the same as for thin layers. In addition, initial contact of the ETP with the p-type layer can also influence the interface properties. An experiment in which a p-type layer is exposed to an expanding thermal $\mathrm{Ar} / \mathrm{H}_{2}$ plasma showed no differences in material properties of the p-type layer and no reduction in thickness. However, this experiment was performed on a $160 \mathrm{~nm}$ thick layer and the measurements give the bulk properties only. Surface properties might be influenced and a small thickness reduction within the error of relatively thick films implies a large change for thin films. Therefore, a thickness optimisation for $p-i-n$ cells with the intrinsic layer deposited with the ETP method is necessary.

\subsubsection{P-layer thickness}

The optimum in p-layer thickness is based upon two aspects associated with the player: band bending at the TCO/p interface and absorption of light. The TCO/p interface is a conductor-semiconductor junction and depending on the properties of the materials involved a Schottky barrier may be formed. In the Schottky barrier the bands in the semiconductor are bend near the interface with the conductor [4]. When the p-layer is made thick enough, the band bending at the TCO/p interface should not affect the $V_{\text {oc }}$ [5-7]. When the p-layer is made too thin the $V_{\text {oc }}$ will decrease with decreasing p-layer thickness. However, a thicker p-layer absorbs more light, which virtually does not contribute to the photocurrent generated in the solar cell. To investigate the relative importance of these effects the p-layer thickness has been varied for cells with the intrinsic layer deposited with an expanding thermal plasma. The thickness of the p-layer is extrapolated from the growth rate that is obtained for thicker layers, thereby introducing an error as the initial growth rate might differ from the bulk growth rate.

Figure 4.1 presents the solar cell characteristics of the solar cells as a function of the p-layer thickness. The intrinsic layer has been deposited with the ETP at a growth rate of $0.85 \mathrm{~nm} / \mathrm{s}$ and a deposition temperature of $250^{\circ} \mathrm{C}$. The $V_{\text {oc }}$ and fill factor increase with increasing p-layer thickness and saturate at a p-layer thickness of $\sim 9 \mathrm{~nm}$. The effect on $V_{\text {oc }}$ is comparable with results published by Hegedus [5], Hadjadj et al. [6], and by Nuruddin and Abelson [7], who reported a constant built-in voltage when the p-layer thickness is $>15 \mathrm{~nm}$ and that the layers are depleted for a p-type layer thickness $<10 \mathrm{~nm}$. The depletion region depends on the properties of the p-layer material and on the TCO [4]. An optimum value for $J_{\text {sc }}$ with $p$-layer thickness is found at $11.5 \mathrm{~nm}$, resulting in an optimum for the efficiency at a thickness of $11.5 \mathrm{~nm}$. The decrease in $J_{\mathrm{sc}}$ due to absorption is also clearly visible for the thicker p-layers. The extra absorption is clearly seen when the internal quantum efficiency of the solar cells is measured. Figure 4.2 shows the results of the spectral response measurements at $0 \mathrm{~V}$ bias voltage. With increasing thickness of the p-layer the quantum efficiency of the cells decreases for the shorter wavelengths, which implies a lower $J_{\text {sc. }}$. It is not clear from this figure what determines the optimum in the $J_{\mathrm{sc}}$ at a p-layer thickness of $11.5 \mathrm{~nm}$ as the quantum efficiency for a cell with a $\mathrm{p}$ layer thickness of $4.5 \mathrm{~nm}$ is higher in the wavelength range of 400 to $550 \mathrm{~nm}$. Hegedus [5] reported that the quantum efficiency at $400 \mathrm{~nm}$ decreases and that the fill factor increases with increasing p-layer thickness from $4.5 \mathrm{~nm}$ to $12 \mathrm{~nm}$. Both results are confirmed by the results presented here. 

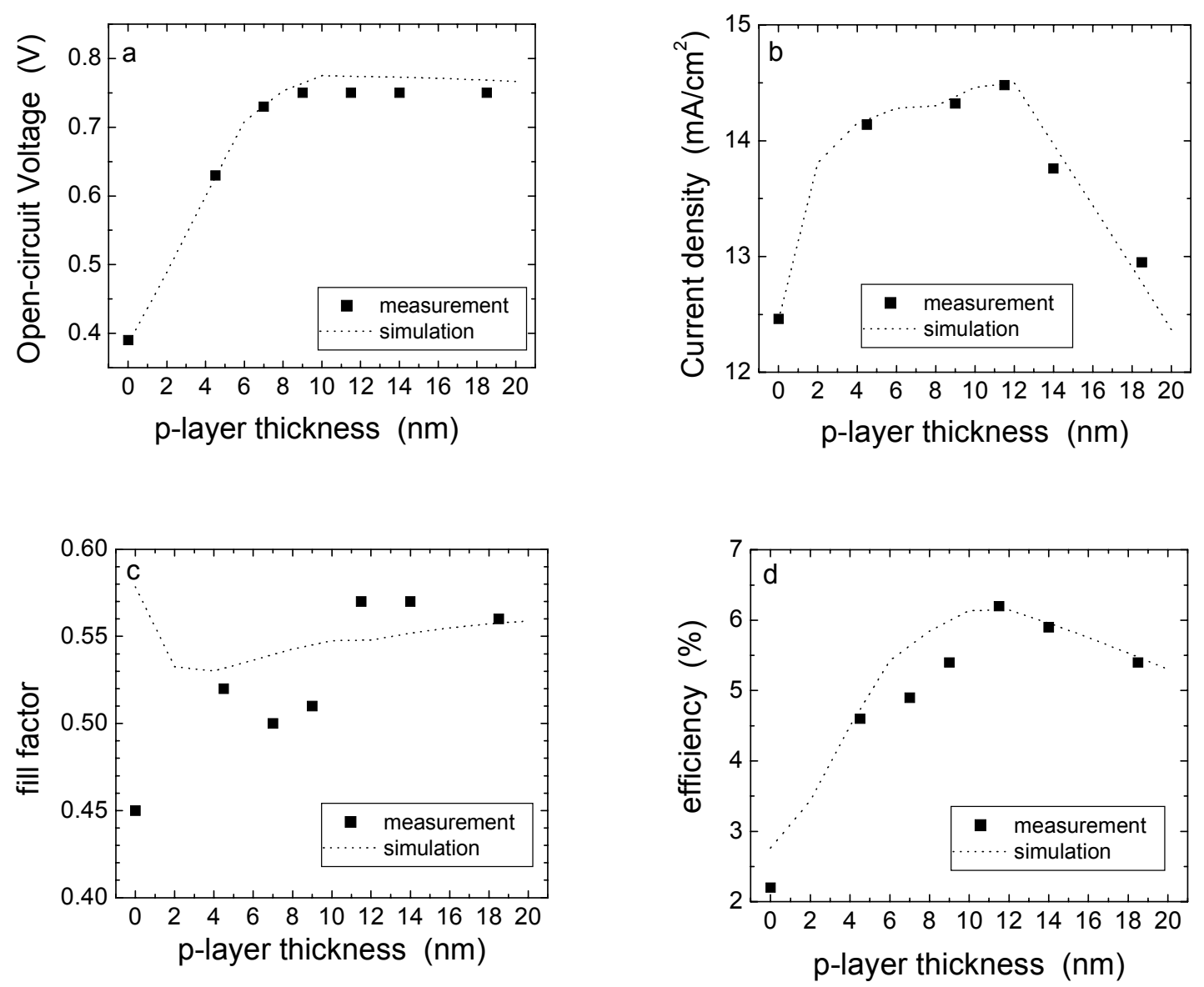

Figure 4.1: Solar cell characteristics as a function of the p-layer thickness. The points represent the data and the line represents simulations with ASA [8].

Simulations have been performed using ASA [8] for solar cells with varying $p$ layer thickness (Fig. 4.1) to get a better understanding of the trend of the measured data. These simulations have been fitted to the data accounting for two regions: thinner and thicker than $12 \mathrm{~nm}$. For a thickness $>12 \mathrm{~nm}$ the data are fitted to the $J_{\mathrm{sc}}$ because there the influence of band bending is no longer present and the characteristics are mainly influenced by the extra absorption in the p-layer. In order to simulate the dependence properly, the absorption of the thin p-layer was assumed to be about one order of magnitude higher in the band tails compared to the absorption measured for thick p-layers. This higher absorption effectively implies a large Urbach energy [9] and reflects a higher defect density in the layer. The higher defect density is most likely caused by initial growth effects [10] and is particular dominant for very thin layers. This argument is supported by Luft and Tsuo [1] who stated that properties of thin layers are different from those of thick layers. The larger absorption for thin layers is also used for the region where the thickness $<12 \mathrm{~nm}$. 


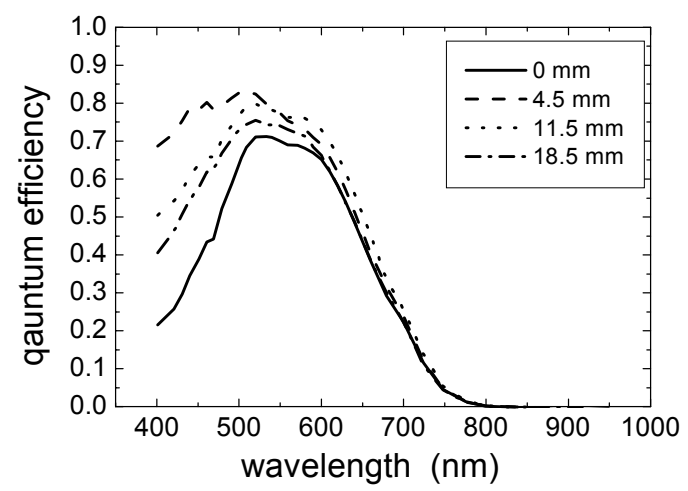

Figure 4.2: Spectral response of p-i-n cells with varying p-layer thickness. The measurements are performed using a bias voltage of $0 \mathrm{~V}$.

Two effects had to be taken into account to simulate the data. Firstly, the $V_{\text {oc }}$ dependence in the region in the p-layer close to the TCO/p interface is dominated by the influence of the band bending in the p-layer. This band bending results in $a$ narrow depletion region near the TCO/p interface. In ASA it is quite difficult to simulate the band bending and therefore in the simulations the height of the Schottky barrier at the TCO/p interface has been decreased with decreasing p-layer thickness. This decrease results in a decrease in width of the depletion region. Secondly, the decrease in current with decreasing p-layer thickness can be simulated when the defect density of the $p$-layer increases with decreasing p-layer thickness. Simulations with an increasing defect density of the p-layer showed that this has a large influence on the current, while the fill factor is hardly affected.

Interesting to note are the characteristics of a cell without a p-layer. Table 4.3 presents the results for an i-n cell with the intrinsic layer deposited with the ETP method compared with an i-n cell with the intrinsic layer deposited with RF-PECVD. It is clear from these results that the current density is lower for the ETP cell and more important that the fill factor is lower than for the RF-PECVD cell. This lower fill factor is an indication to more recombination in the ETP layer. This observation will be discussed more extensively in Section 4.4.

Table 4.3: Solar cell characteristics of $\mathrm{i}-\mathrm{n}$ cells for a cells with the intrinsic layer deposited at $\sim 0.75$ $\mathrm{nm} / \mathrm{s}$ and $260^{\circ} \mathrm{C}$, and a cell with the intrinsic layer deposited at $\sim 1.4 \mathrm{~nm} / \mathrm{s}$ and $400^{\circ} \mathrm{C}$. The intrinsic layers are $\sim 400 \mathrm{~nm}$ thick.

\begin{tabular}{|l|c|c|}
\hline & ETP & RF-PECVD \\
\hline$J_{\text {sc }}\left(\mathrm{mA} / \mathrm{cm}^{2}\right)$ & 12.4 & 15.8 \\
\hline$V_{\mathrm{oc}}(\mathrm{V})$ & 0.39 & 0.35 \\
\hline FF & 0.45 & 0.59 \\
\hline Efficiency (\%) & 2.2 & 3.3 \\
\hline
\end{tabular}

In conclusion, simulations of the p-layer thickness variation indicate that high defect densities largely influence the properties of thin p-type layers. Thin layers exhibit more absorption and have a larger defect density than the bulk properties of layers thicker than $\sim 100 \mathrm{~nm}$. Furthermore, it is observed that the best results for solar cells 
are obtained with a p-layer thickness of $11.5 \mathrm{~nm}$ with the intrinsic layers deposited with the ETP method at $0.85 \mathrm{~nm} / \mathrm{s}$ at $250^{\circ} \mathrm{C}$. This optimum thickness is a trade-off between light absorption in the p-layer and increase of the electric field in the cell due to band bending.

\subsubsection{Influence of deposition temperature on solar cell performance ${ }^{22}$}

A big challenge regarding the high growth rates obtained with the ETP method is the deposition temperature. When the growth rate is increased a higher deposition temperature is needed to obtain solar grade material. Whereas the refractive index always increases with increasing temperature, indicating more compact films, the dependence of the photoconductivity as a function of the deposition temperature at one particular growth rate has a maximum (see also [11,12]).

In this section we compare the properties of intrinsic material that is deposited at two growth rates, $0.22 \mathrm{~nm} / \mathrm{s}$ and $0.85 \mathrm{~nm} / \mathrm{s}$, and the performance of the solar cells with these intrinsic layers. The plasma conditions used for both growth rates are comparable, i.e., the depositions are hydrogen dominated (see Section 3.2) and the depletion is $\sim 7 \%$. For both growth rates the deposition temperature of the intrinsic layer is varied and the material properties and solar cell performances are measured. When increasing the growth rate the available time window becomes smaller for a particle to rearrange such that the amorphous structure is optimised. Therefore the material properties will be a function of the deposition temperature. Figure 4.3 shows the correlation between deposition temperature, growth rate, and material quality, represented by the refractive index as obtained from Fourier Transform Infra-Red spectroscopy. This figure shows that at higher growth rates a higher deposition temperature is needed to obtain a refractive index in the infrared $>3.5$. More results on intrinsic layers deposited over this wide range of growth rates are reported by Smets et al. [13].

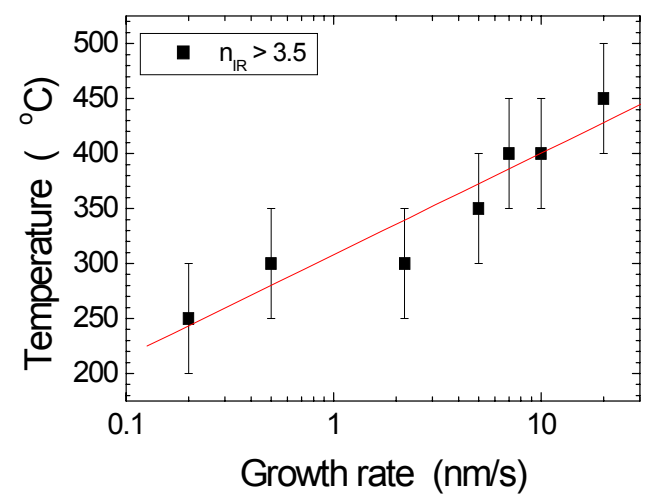

Figure 4.3: Temperature at which the refractive index as obtained with Fourier Transform InfraRed spectroscopy becomes $>3.5$ as a function of the growth rate [13]. The line is a guide to the eye.

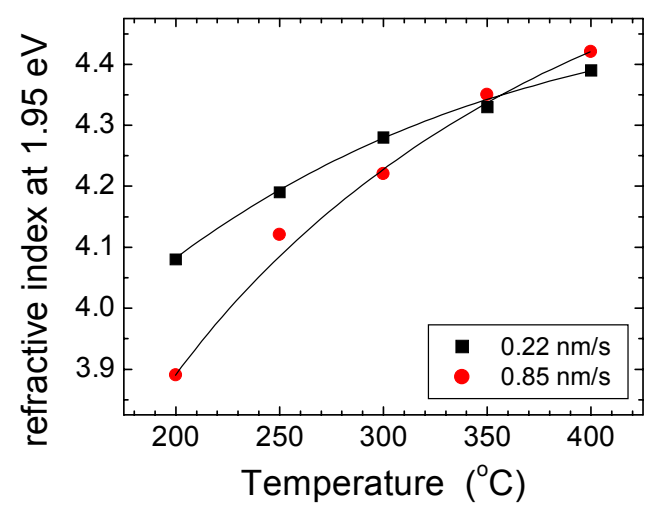

Figure 4.4: Refractive index as a function of the deposition temperature for two growth rates. The lines are guides to the eye.

\footnotetext{
${ }^{22}$ Adapted from: B.A. Korevaar, C. Smit, A.H.M. Smets, R.A.C.M.M. van Swaaij, D.C. Schram, and M.C.M. van de Sanden, Proc. of the $28^{\text {th }}$ IEEE-PVSC conference (2000), 916
} 
The refractive index at $2 \mathrm{eV}$ for both growth rates as a function of the deposition temperature is displayed in Figure 4.4. The refractive index of films deposited at a rate of $0.22 \mathrm{~nm} / \mathrm{s}$ is higher at lower deposition temperature than of films deposited at $0.85 \mathrm{~nm} / \mathrm{s}$. When a value of 4.1 is taken as a measure for good material a comparable shift in deposition temperature is observed as in Figure 4.3 to obtain that refractive index.

Figure 4.5 shows the behaviour of the dark- and photoconductivity, the photo response, and the Urbach energy as a function of the deposition temperature. Although these parameters do not give a clear indication on the solar-cell performance when these layers are incorporated, the properties do reflect the material quality. The dark conductivity increases with temperature and is always smaller than $10^{-10}(\Omega \mathrm{cm})^{-1}$. The dark conductivity scales with the optical gap of the material, i.e., increases with decreasing optical gap (not shown: Cubic-gap decreases from $1.62 \mathrm{eV}$ to $1.48 \mathrm{eV}$, and the Tauc-gap decreases from $1.85 \mathrm{eV}$ to $1.73 \mathrm{eV})$. The activation energy for the dark conductivity is $(0.79 \pm 0.02) \mathrm{eV}$ for the samples deposited at $0.85 \mathrm{~nm} / \mathrm{s}$ and varies between $0.75 \mathrm{eV}$ and $0.90 \mathrm{eV}$ for the samples deposited at $0.22 \mathrm{~nm} / \mathrm{s}$. The photoconductivity for the good layers is higher than $10^{-5}(\Omega \mathrm{cm})^{-1}$, resulting in a photo response that is always higher than $10^{5}$. At a growth rate of $0.85 \mathrm{~nm} / \mathrm{s}$ the photoconductivity and photo response show an optimum at $250^{\circ} \mathrm{C}$, whereas for a growth rate of $0.22 \mathrm{~nm} / \mathrm{s}$ they increase with decreasing temperature.
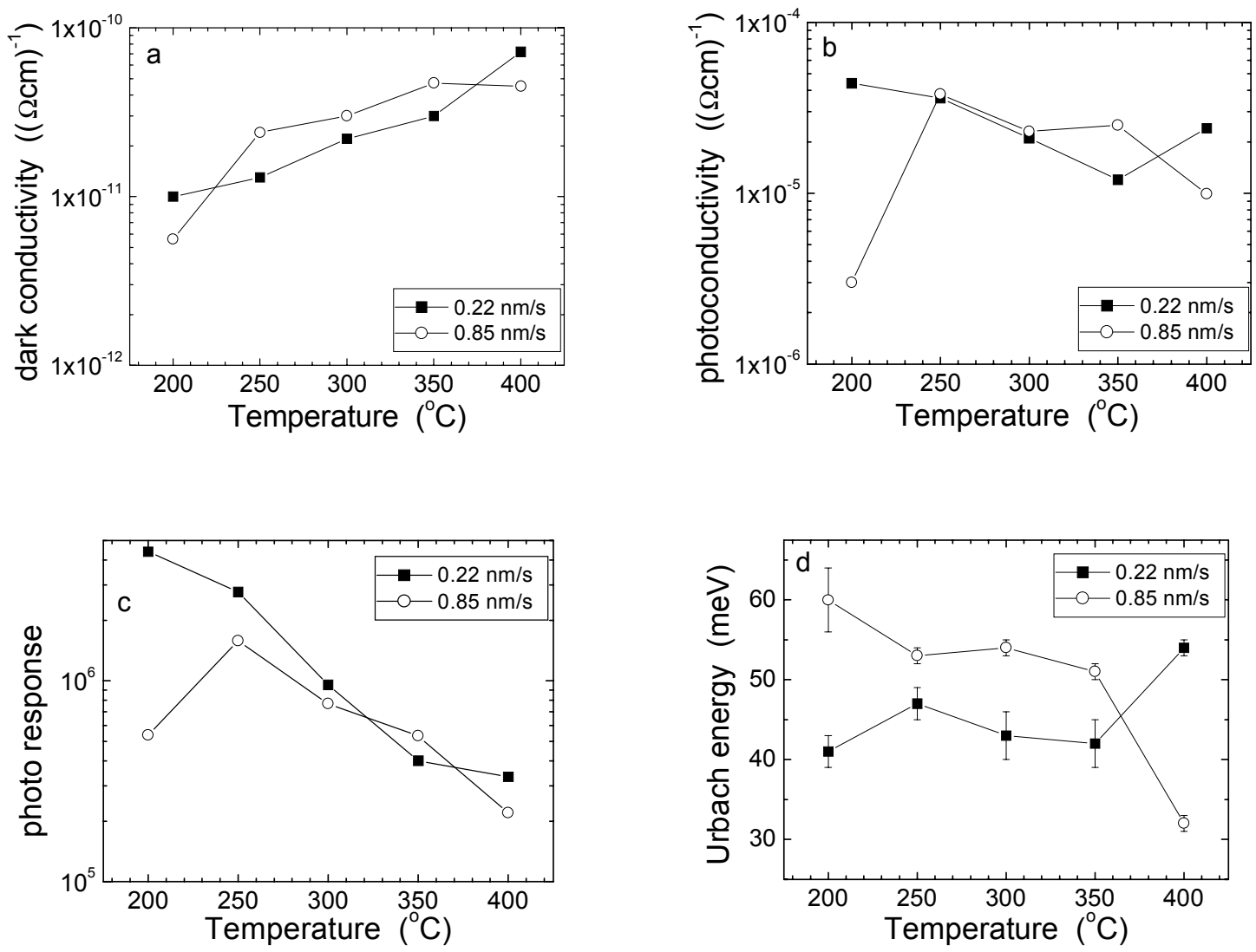

Figure 4.5: Dark conductivity (a), photoconductivity (b), photo response (c), and Urbach energy (d) for the intrinsic material as grown with the cascaded arc expanding thermal plasma at growth rates of 0.22 $\mathrm{nm} / \mathrm{s}$ and $0.85 \mathrm{~nm} / \mathrm{s}$ for various temperatures. 
The decrease of photoconductivity and photo response at $0.85 \mathrm{~nm} / \mathrm{s}$ and $200^{\circ} \mathrm{C}$ can be understood when considering the defect density of the material, as determined by DBP measurements [14]. At the growth rate of $0.85 \mathrm{~nm} / \mathrm{s}$ the defect density is higher than for the lower growth rate (in this case $\sim 6 \cdot 10^{16} \mathrm{~cm}^{-3}$ compared with $\sim 1 \cdot 10^{16} \mathrm{~cm}^{-3}$ for the samples deposited at $0.22 \mathrm{~nm} / \mathrm{s}$ ), resulting in a lower photoconductivity. At higher temperatures $\left(\geq 250^{\circ} \mathrm{C}\right)$ the defect density is $<10^{16} \mathrm{~cm}^{-3}$ for the samples deposited at $0.85 \mathrm{~nm} / \mathrm{s}$. It is interesting to note that there is hardly any correlation between the defect density and the deposition temperature, whereas the hydrogen content in the film decreases with temperature [15]. This implies that the lower $\mathrm{H}$ content does not result in more defects and thus Si-Si bonds are formed on the position where otherwise $\mathrm{Si}-\mathrm{H}$ bonds would be found. This implies a densification of the a-Si:H film with increasing deposition temperature as confirmed by the increase in refractive index at $2 \mathrm{eV}$ [13] (Fig. 4.4). The Urbach energy is $\sim 45$ $\mathrm{meV}$ for the material deposited at $0.22 \mathrm{~nm} / \mathrm{s}$ except for the material deposited at $400^{\circ} \mathrm{C}$. For the material deposited at $0.85 \mathrm{~nm} / \mathrm{s}$ the Urbach energy is $\sim 52 \mathrm{meV}$ in the temperature range from $250^{\circ} \mathrm{C}$ to $350^{\circ} \mathrm{C}$. For a temperature of $200^{\circ} \mathrm{C}$ the Urbach energy is slightly higher, indicating the worse of the material. For the material deposited at $400^{\circ} \mathrm{C}$ a remarkably low Urbach energy of $\sim 32 \mathrm{meV}$ is found. This indicates a very steep band tail, which is in agreement with results obtained from post-transit photo-current analysis [12] where it was found that the defect density in between the band tails and the mid-gap dangling bond density was much lower than for standard RF-PECVD grown a-Si:H (Section 1.3).

As can be concluded from Figure 4.5 all the results obtained on the intrinsic films are comparable with intrinsic layers deposited by RF-PECVD at $0.2 \mathrm{~nm} / \mathrm{s}$ and $\sim 200^{\circ} \mathrm{C}$ (Section 4.2), using the UHV AMOR system. Both intrinsic films deposited with the ETP method at $0.22 \mathrm{~nm} / \mathrm{s}$ and $0.85 \mathrm{~nm} / \mathrm{s}$ are incorporated in $\mathrm{p}$-i-n solar cells and the deposition temperature has been varied. In these experiments a $9 \mathrm{~nm}$ thick p-layer, a $\sim 400 \mathrm{~nm}$ thick i-layer, and a $20 \mathrm{~nm}$ thick n-layer were used. It is important to note that the exposure time of the p-layer to the temperature is not so much different for the two growth rates $^{23}$ (see also Section 5.4). Figure 4.6 shows the results for the energy conversion efficiency, fill factor, short-circuit current density, and open-circuit voltage for the two growth rates for five different intrinsic layer deposition temperatures. The efficiency and the fill factor show a maximum at $250^{\circ} \mathrm{C}$ for both growth rates. It is clear that the efficiency and fill factor are lower than expected on the basis of the properties of the individual layers. A possible explanation for this will be discussed in Section 4.4. At lower temperatures (< $250^{\circ} \mathrm{C}$ ), the efficiency of the smaller growth rate is clearly better than for the higher growth rate. This observation follows the results on dark- and photoconductivity of the intrinsic layers deposited at $200^{\circ} \mathrm{C}$. At $150^{\circ} \mathrm{C}$ the material quality is not good enough as reflected by the low short-circuit current density and fill factor. At temperatures $\geq 250^{\circ} \mathrm{C}$ the cell efficiency is a trade-off between changes in p-layer properties and intrinsic film quality. For both growth rates the open-circuit voltage decreases. Two effects contribute to the lower $V_{\text {oc }}$ : Firstly, the $V_{\text {oc }}$ decreases due to a smaller bandgap of the intrinsic layer whne deposited at higher temperature. Furthermore, the smaller bandgap results in more absorption near the p/i interface, increasing the charge carrier density in that region. This effectively results in more

\footnotetext{
${ }^{23}$ The exposure time is mainly determined by the time is takes to heat up the sample (10-15 minutes). The difference in exposure time is due the time it takes to grow the first $20 \mathrm{~nm}$ as will be shown in section 5.4 .
} 
recombination in that region and will lower the fill factor. Secondly, the $V_{\text {oc }}$ decreases because the high temperature deteriorates the $p$-layer, creating a smaller internal electric field in the solar cell and thus less collection. Experiments in which the player was annealed at $300^{\circ} \mathrm{C}$ showed a decrease in bandgap while the p-like conductivity was maintained. The decrease in bandgap can be explained by outdiffusion of hydrogen, which is likely because hydrogen is the most mobile atom in aSi:H [16-18]. The lower bandgap of the p-layer, however, should result in a decrease of the short-circuit current density due to more absorption in the p-layer, which is not observed for the cells with the intrinsic layer deposited at $0.22 \mathrm{~nm} / \mathrm{s}$. It is not understood why the short-circuit current density is about constant as a function of the temperature for a deposition rate of about $0.22 \mathrm{~nm} / \mathrm{s}$ and decreases for $0.85 \mathrm{~nm} / \mathrm{s}$, when the results are compared with the properties of the intrinsic layer (Fig. 4.5).
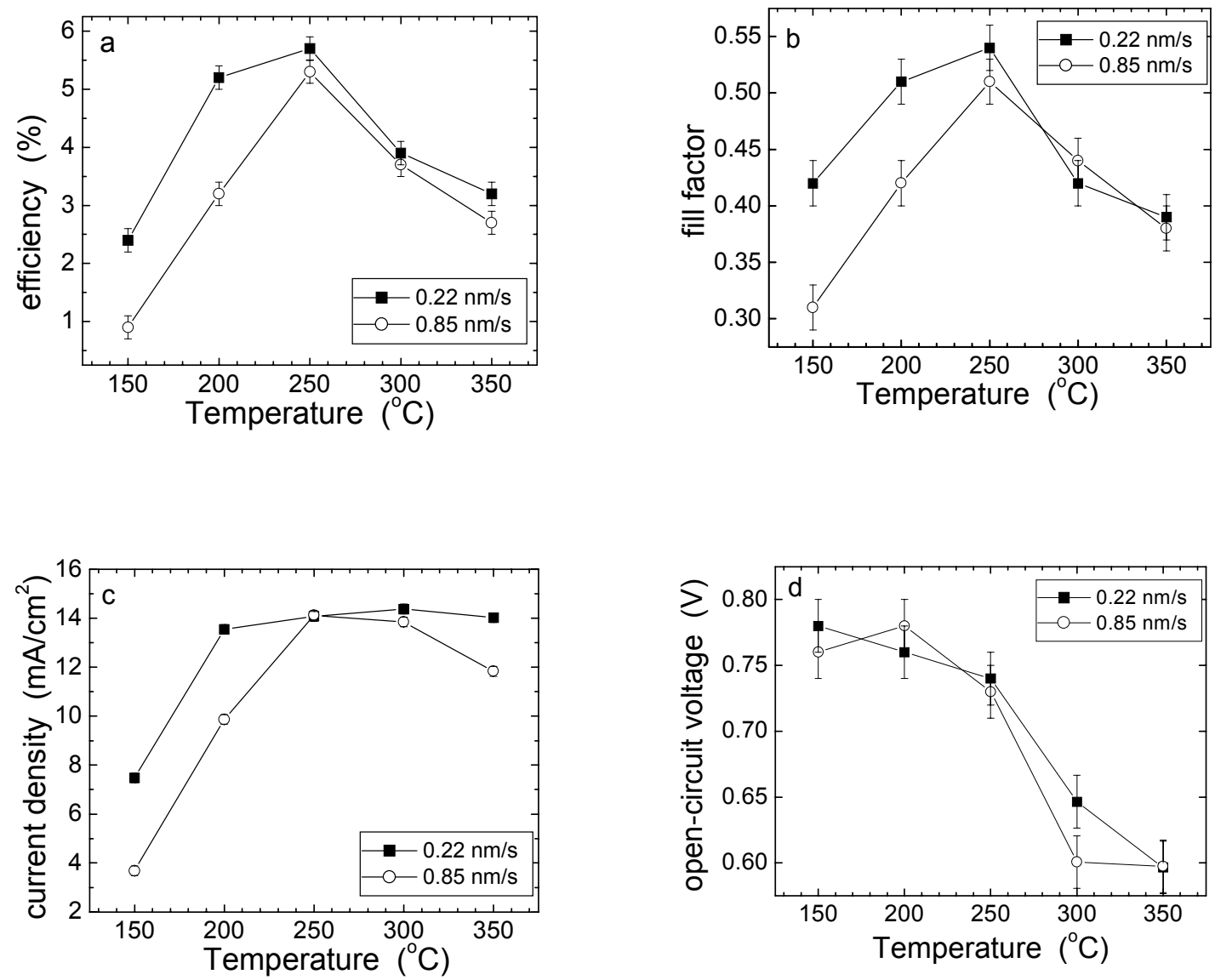

Figure 4.6: Solar cell efficiency (a), fill factor (b), short-circuit current density (c), and open-circuit voltage (d) as a function of the deposition temperature at two different intrinsic growth rates. The presented characteristics are for cells with an area of $0.1 \mathrm{~cm}^{2}$. The cells consist of a $9 \mathrm{~nm}$ thick player, a $400 \mathrm{~nm}$ intrinsic layer, and a $20 \mathrm{~nm}$ n-layer.

A better understanding can be gained when examining the results of the spectral response measurements (Fig. 4.7). Starting with the cell deposited at $250^{\circ} \mathrm{C}$ a shift in response to the red is observed when the intrinsic layer is deposited at higher temperatures. This shift corresponds to the reduction of the optical bandgap due to less $\mathrm{H}$ in the intrinsic layer. The decrease in optical bandgap of the p-layer due to the higher deposition temperature is also seen by the decrease in blue 
response with increasing temperature. The spectral response of the cell of which the intrinsic layer is deposited at $150^{\circ} \mathrm{C}$ is remarkably low. The defect density is probably so high at this temperature that the recombination is very high in the cell. The effect of a very low response when the defect density is high is even clearer (not shown) for the higher deposition rate.

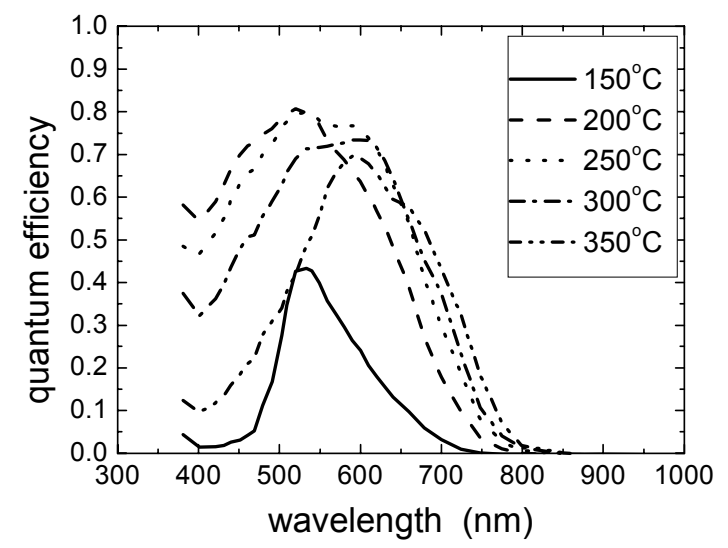

Figure 4.7: Spectral response measurements of the solar cells with the intrinsic layer deposited at $0.22 \mathrm{~nm} / \mathrm{s}$ at $0 \mathrm{~V}$ bias-voltage.

When applying a large reverse bias-voltage the response of the ETP cell and the RF-PECVD cell are similar. From this it is concluded that the generation of charge carriers was not a problem within the cells deposited at $250^{\circ} \mathrm{C}$. However, at forward biases the spectral response of the ETP cells decreases much more than cells deposited with RF-PECVD (Fig. 4.8). Though not straightforward this is an indication of more recombination. The enhanced recombination in the cells deposited with the ETP method will be discussed in the next section.

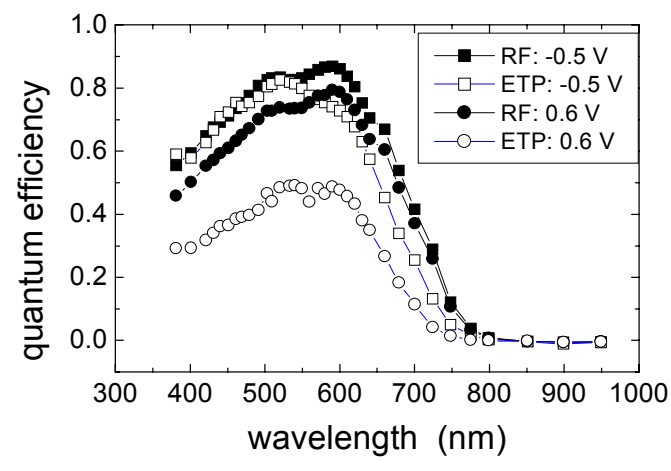

Figure 4.8: Spectral response in forward and reverse bias of the ETP-cell and the RF-cell. The thickness of both cells is about the same and the ETP-cell has a somewhat larger bandgap than the RF-PECVD cell, $1.82 \mathrm{eV}$ and $1.78 \mathrm{eV}$, respectively.

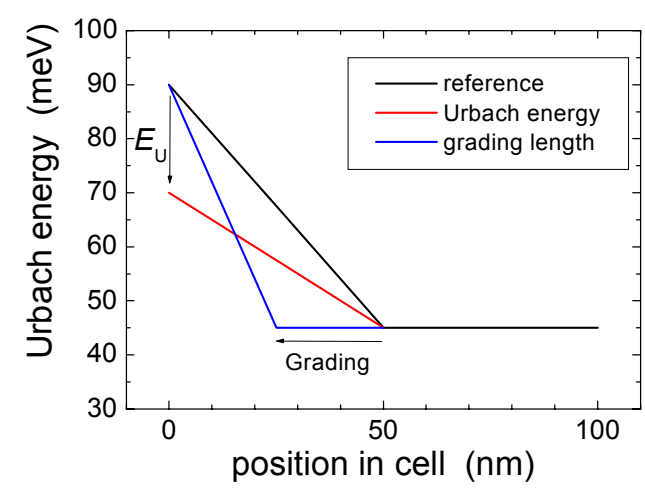

Figure 4.9: Schematic overview of how the Urbach energy is defined at a certain position in the intrinsic layer, as used in the simulations presented in Figure 4.10. The red line represents the variation of the Urbach energy at the interface and the green line represents the grading length of the extra defects into the intrinsic layer. 


\subsection{Influence of defects near the $p-i$ interface ${ }^{24}$}

Optimising the p-layer thickness to $11.5 \mathrm{~nm}^{25}$ and using a growth rate of $0.85 \mathrm{~nm} / \mathrm{s}$ at a deposition temperature of $250^{\circ} \mathrm{C}$ for the intrinsic layer resulted in a highest initial efficiency of $6.7 \%$. This is about $2-3 \%$ lower than for standard RF-PECVD solar cells grown in the same configuration. The largest difference between ETP cells and cells made with RF-PECVD is observed in the fill factor. This lower fill factor cannot be attributed to the growth rate of $0.85 \mathrm{~nm} / \mathrm{s}$, because cells with the intrinsic layer deposited at $0.22 \mathrm{~nm} / \mathrm{s}$ exhibit the same low fill factor. The i-n cells described in Table 4.3 indicate that the lower fill factor is also not due the p-layer or the deterioration of the p-layer. For a better understanding of the lower efficiency obtained when the intrinsic layer is deposited with the ETP method, a comparison has been made with a cell grown with RF-PECVD ${ }^{26}$ by measuring the spectral response before and after light-induced degradation. After the degradation the cells were annealed and the spectral response was measured again. Furthermore, solar cells are simulated with the ASA program [8] in order to understand and analyse the differences found between both cells.

The spectral response of the $6.7 \%$ ETP cell and a $~ 9 \%$ RF-PECVD cell are shown in Figure 4.8. The blue-response is nearly equal, and the red response is lower which is attributed to the higher bandgap of the intrinsic material of the ETP cell at that deposition temperature. At forward bias the response of the ETP cell is much lower, indicating more recombination in this cell, which might be due to a higher defect density of the intrinsic material. However, the bulk defect density is comparable with the density of intrinsic RF-PECVD material, i.e., $<10^{16} \mathrm{~cm}^{-3}$, as measured with dual beam photoconductivity (DBP), and thus this is not very likely. We suggest that in addition to bulk defects a defect-rich region near the p-i interface in the intrinsic layer can have a large influence on the cell performance of the ETP cell. Experimental work for RF-PECVD a-Si:H by Jackson et al. [10] showed that initial growth of intrinsic layers results in more defects near the interface. Shimizu et al. [19] reported electron spin resonance measurements resulting in a defective layer of $\sim 20 \mathrm{~nm}$ for undoped a-Si:H films and they were able to fit their data assuming a defective layer of $12 \mathrm{~nm}$ with a defect density of $1.2 \times 10^{18} \mathrm{~cm}^{-3}$.

That the defect density near the $p-i$ interface can influence the fill factor is demonstrated with simulations using ASA [8]. In ASA the defect density is directly correlated to the Urbach energy as reported by Stutzmann [9]. In this analysis therefore we use the Urbach energy as a measure for the defect density. In Figure 4.10 the simulated FF and $J_{\mathrm{sc}}$ are plotted as a function of the Urbach energy, $E_{\mathrm{U}}$, of the i-layer at the $\mathrm{p}-\mathrm{i}$ interface and as a function of the grading length, i.e., the thickness over which $E_{U}$ is extended into the i-layer. In Figure 4.10a the distance of which $E_{U}$ is linearly graded into the solar cell is $50 \mathrm{~nm}$. The $E_{U}$ given by the value on the horizontal axis is the $E_{U}$ at the interface and is reduced to $45 \mathrm{meV}$, which is chosen as the $E_{U}$ for the remainder of the $450 \mathrm{~nm}$ thick intrinsic layer (Fig. 4.9). Increasing $E_{\mathrm{U}}$ at the interface from $45 \mathrm{meV}$ to $90 \mathrm{meV}^{27}$ results in a decrease of the

\footnotetext{
${ }^{24}$ Adapted from: B.A. Korevaar, C. Smit, R.A.C.M.M. van Swaaij, D.C. Schram, and M.C.M. van de Sanden, Mat. Res. Soc. Symp. Proc., 664 (2001) A24.4

${ }^{25}$ Earlier experiments were performed with a p-layer thickness of $\sim 9 \mathrm{~nm}$, because this thickness is used in the RF-PECVD cell deposited in the AMOR system.

${ }^{26}$ This cell is deposited in the AMOR system.

${ }^{27}$ According to Stutzmann [9] an Urbach energy of $45 \mathrm{meV}$ corresponds to a defect density of $<10^{16}$ $\mathrm{cm}^{-3}$, while an Urbach energy of $90 \mathrm{meV}$ corresponds to a defect density of $\sim 10^{18} \mathrm{~cm}^{-3}$.
} 
FF of $\sim 10 \%$ while the open-circuit voltage, $V_{\text {oc }}$ (not shown), and short-circuit current density, $J_{\mathrm{sc}}$, hardly vary. Above $E_{\mathrm{U}}=90 \mathrm{meV}$ the FF increases and the $J_{\mathrm{sc}}$ decreases. In Figure $4.10 \mathrm{~b}$ the FF is plotted as a function of the thickness over which the $E_{U}$ is graded (Fig. 4.9). In this case the $E_{U}$ is varied from $90 \mathrm{meV}$ to $45 \mathrm{meV}$. A decrease of the FF is observed by increasing the thickness of the defect rich layer from 10 to $50 \mathrm{~nm}$, showing the large influence of defects near the interface on the FF. The increase after $50 \mathrm{~nm}$ is again accompanied by a decrease in $J_{\mathrm{sc}}$. In this case the $V_{\text {oc }}$ is also independent of the $E_{U}$ near the interface (not shown).
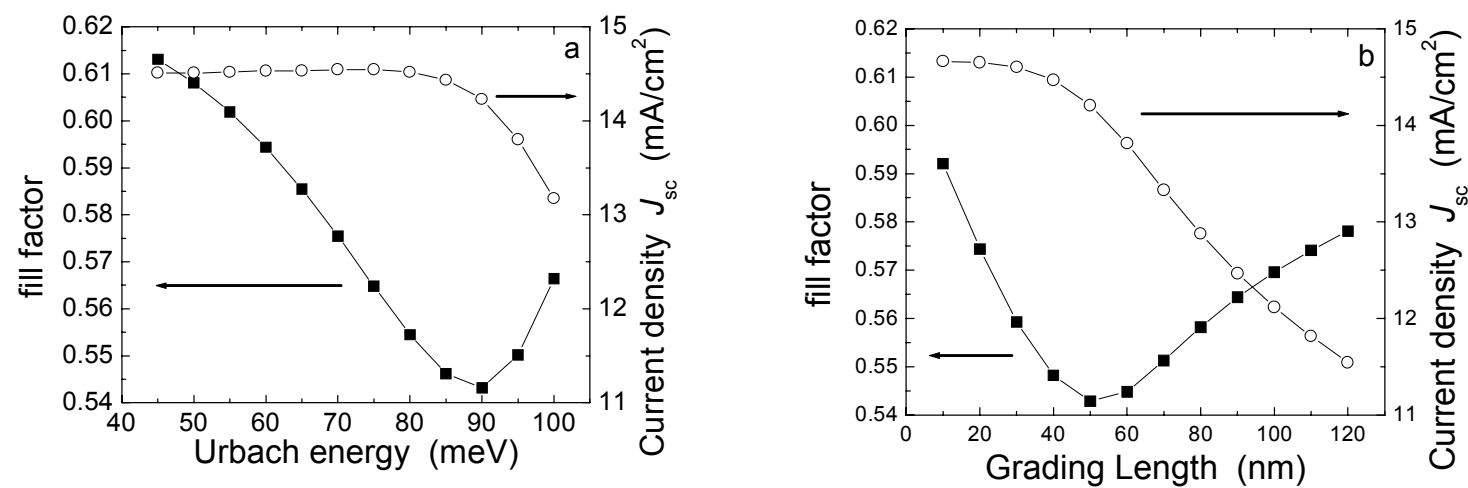

Figure 4.10: Simulations with ASA [8] of the fill factor and short-circuit current density as a function of the Urbach energy at the $p-i$ interface (a) and the grading length (b). For more information see the text. For (a) the grading length is chosen to be $50 \mathrm{~nm}$ and for (b) the Urbach energy at the p-i interface is chosen to be $90 \mathrm{meV}$.

A.M.-1.5 illuminated $J, V$-measurements of both cells before degradation are shown in Figure 4.11a. The main difference between the two cells is the lower FF for the cell deposited with the ETP technique. The $J_{\text {sc }}$ is also somewhat lower due to the higher bandgap of the intrinsic layer and the $V_{\text {oc }}$ is slightly higher. Both the $8.4 \%$ RFPECVD cell and the ETP cell (with an initial efficiency of 6.7\%) deposited at 0.85 $\mathrm{nm} / \mathrm{s}$ are degraded under 1.5 sun at $50^{\circ} \mathrm{C}$ over a period of two months (Fig. $4.11 \mathrm{~b}$ ). The RF-PECVD cell degraded $25 \%$, whereas the ETP cell degraded by more than $50 \%$ to a stable efficiency of $\sim 3.1 \%$. It is interesting to note that the $V_{\text {oc }}$ for the ETP cell decreases $\sim 10 \%$, whereas the $V_{\text {oc }}$ of the RF-PECVD cell hardly decreases. The short-circuit current density decreases much more for the ETP cell than for the RFPECVD cell. Guha et al. [20] reported an increasing degradation (> 40\%) with increasing growth rate. They attributed that to an increasing microvoid density with increasing growth rate. This might explain a part of the difference between the cells after degradation, because the microstructure parameter is still somewhat higher for ETP a-Si:H than for solar grade RF-PECVD a-Si:H. 

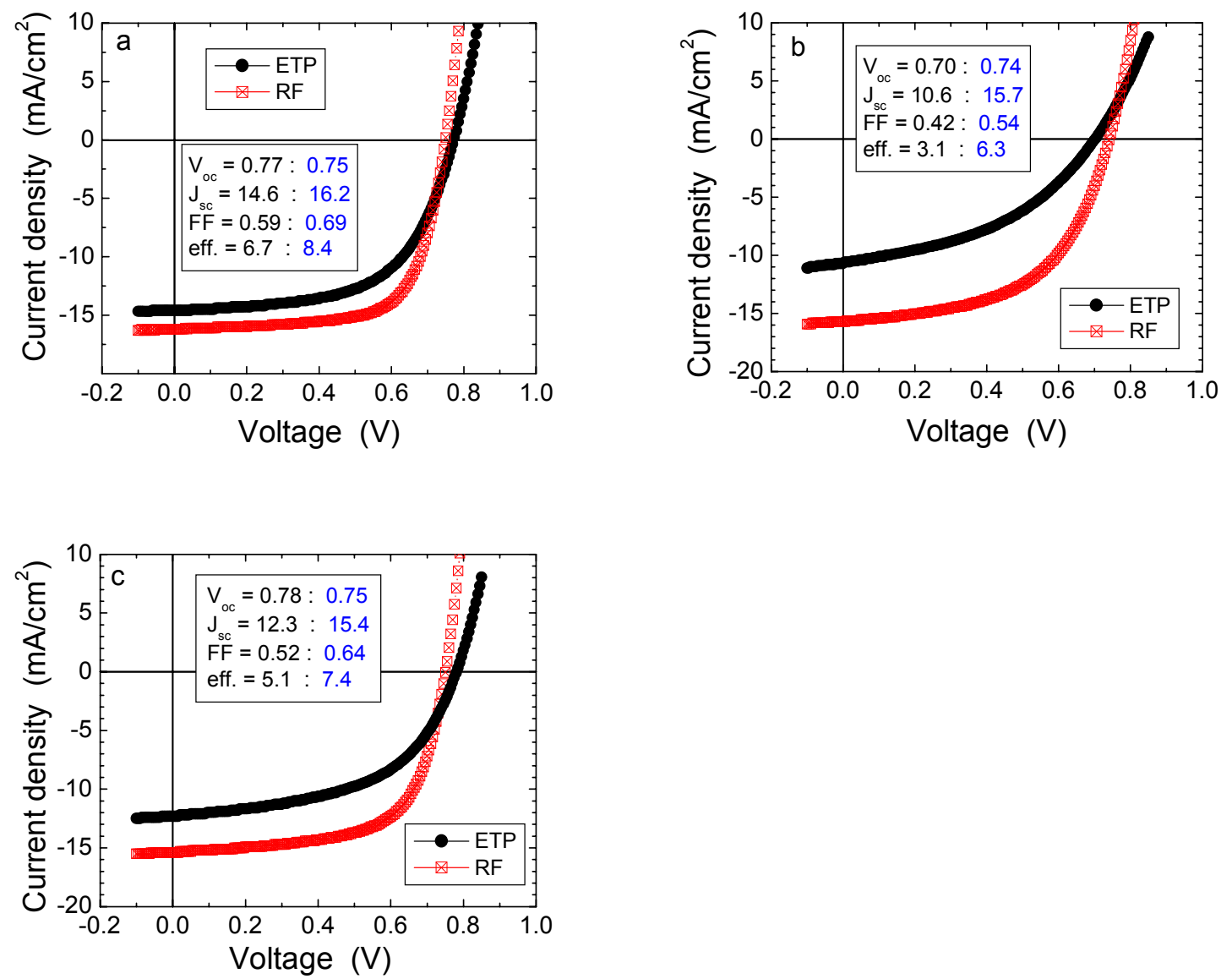

Figure 4.11: A.M.-1.5 illuminated J,V-measurements before (a) and after (b) degradation for two month under 1.5 sun at $50^{\circ} \mathrm{C}$ and after an anneal treatment (c). A comparison between the ETP-cell and the RF-cell. The numbers on the left belong to the ETP-cell and on the right to the RF-PECVD cell.

Before and after degradation spectral response measurements were performed. Figure 4.12 shows the relative decrease of the quantum efficiency (at 0 $\mathrm{V})$. A relative quantum efficiency decrease of 0.6 means that the cell has degraded $60 \%$ for that wavelength. It is clear that the ETP cell degrades much more than the RF-PECVD cell and that the largest part of the degradation occurs in the blue for both cells. A remarkable difference is that there is hardly any degradation $(<10 \%)$ at wavelengths $>550 \mathrm{~nm}$ for the RF-PECVD cell, whereas the relative degradation of the ETP cell increases again at larger wavelengths. 

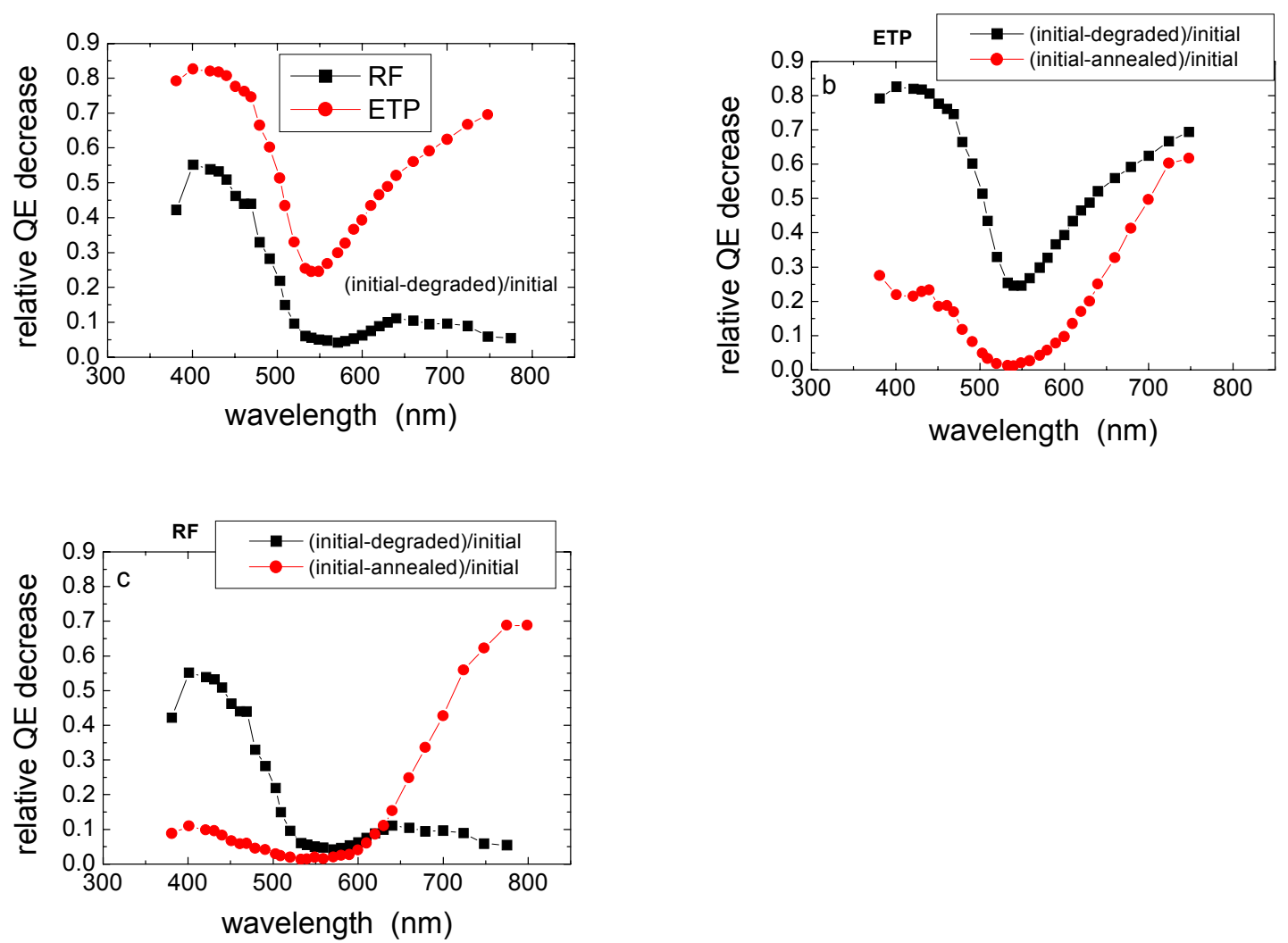

Figure 4.12: Relative quantum efficiency showing the degradation per wavelength for the ETP-cell and the RF-cell (a). $4.12 \mathrm{~b}$ shows the improvement of the relative quantum efficiency after annealing of the ETP cell and $4.12 \mathrm{c}$ after annealing of the RF-PECVD cell.

The FF of the ETP cell is lower than with RF-PECVD, although the individual intrinsic layers have similar material properties (except for the bandgap). The defect density and $E_{U}$, as obtained from DBP measurements, resulted in a similar defect density and $E_{U}$ for both intrinsic layers. It is therefore concluded that the lower initial FF is not caused by a difference in bulk defect density. The simulations, as presented in Figure 4.10, show that a higher $E_{U}$, and thus extra defects near the interface can have a large influence on the FF. Thus the lower FF for the ETP cell might be explained by extra defects near the interface compared with RF-PECVD cells. A lower FF and a somewhat lower short-circuit current density also suggest that the area over which the extra defects are spread can be larger in the ETP cell than in the RF-PECVD cell (Fig. 4.10b).

Various groups [e.g. 19, 21-23] also present results that may indicate more defects at the interface. According to Fujiwara et al. [24] roughness is controlled by nucleation and according Koh et al. [25] the smoothest films leads to solar cells with the highest efficiency and stability. Smets et al. showed with ellipsometry [26] that the microscopic surface roughness evolution of intrinsic films grown with the ETP method is $\sim 4 \mathrm{~nm}$ for a film thickness of $\sim 500 \mathrm{~nm}[21,27]$. This roughness is 2-10 times larger than generally reported for solar grade RF-PECVD material [24,25,2830]. However, only Tanenbaum et al. [30] reports result for conditions at reasonable deposition rate and thickness, i.e., deposition rate of $0.17 \mathrm{~nm} / \mathrm{s}$ and $500 \mathrm{~nm}$ thick 
films. They obtained a roughness of $1.1 \mathrm{~nm} .{ }^{28} \mathrm{Koh}$ et al. [25] and Kondo et al. [28] used very low deposition rates of less than $0.1 \mathrm{~nm} / \mathrm{s}$, while Fujiwara et al. [24] only reports on very thin films $(<50 \mathrm{~nm})$. Robertson and Gallagher [31] related the surface roughness to high sticking radicals like $\mathrm{SiH}$ and $\mathrm{SiH}_{2}$. Kessels [32] reported that in the ETP plasma always $\sim 10 \%$ of these high sticking radicals contribute to growth. Furthermore, the ETP plasma does not have a large amount of atomic hydrogen and energetic ions (up to $25 \mathrm{eV}$ ) at the growing surface under conditions that result in good quality a-Si:H. The ions have low energy and the only hydrogen is the hydrogen that is released from the radicals that contribute to growth [33]. Both hydrogen and ions can help to rearrange the growing silicon atoms [34-37]. Therefore, it is possible that besides the larger growth rate [26], the lower hydrogen content and/or the lack of energetic ions at the growing surface can result in a somewhat rougher surface of the ETP layers.

Cavity ring down spectroscopy (CRDS) was used by Smets et al. [22] to investigate the absorption in the gap for several intrinsic films as a function of the thickness. They found that the number of defects increases linearly with thickness for thick layers (> $500 \mathrm{~nm}$ ). For layers thinner than $500 \mathrm{~nm}$, however, the influence of the interface could still be measured, i.e., the absorption per unit of thickness increases with decreasing film thickness [e.g. 22,38-40], resulting in a larger defect density for thinner layers. These results are similar to the photothermal deflection spectroscopy (PDS) results on RF-PECVD a-Si:H of Jackson et al. [10]. Smets et al. [41] also estimated an effective defect density from their CRDS measurements for a small defective area of in between $10^{18}$ and $10^{19} \mathrm{~cm}^{-3}$, which is somewhat larger than values reported by Shimizu et al. [19].

A consequence of more defects near the $p-i$ interface could be a larger microstructure for the material near the p-i interface. Guha et al. [20] correlated a larger microstructure with more degradation of the cell. Pearce et al. [42] and Koval et al. [43], who reported that layers with a minimum thickness of $400 \mathrm{~nm}$ are needed to ensure that the degradation is determined by the bulk, also report that defects near the interface have an influence on the degradation. A sufficient increase of the defect density near the interface, hereby exceeding a critical level, might also explain the decrease of the $V_{\text {oc }}$ due to light soaking [42].

A further indication of a larger defect density near the p/i interface is obtained from the spectral response measurements after degradation (Fig. 4.12). A comparison is made between the responses of the degraded RF-PECVD cell and the initial response of an ETP cell with the intrinsic layer deposited at $150^{\circ} \mathrm{C}$ (Fig. 4.13). The bulk defect density of the corresponding intrinsic film deposited with an ETP at $150^{\circ} \mathrm{C}$ is $\sim 10^{17} \mathrm{~cm}^{-3}$, which is comparable with the bulk defect density of devicequality intrinsic a-Si:H in the degraded state prepared with RF-PECVD [e.g. 44-46]. The response of the cell deposited at $150^{\circ} \mathrm{C}$ is lower than the response of a degraded RF-PECVD cell over the whole measured spectral range. As the bulk defect density is expected to be similar the difference is attributed to the defect distribution in the solar cell, pointing towards more defects near the interface for the cell with the intrinsic layer deposited at $150^{\circ} \mathrm{C}$. The presented results suggest that initial growth leads to more defects during the initial stages of the growth and that extra defects near the $p$-i interface are possible for the ETP technique. The influence of more defects near the interface, and thus the higher microstructure, can explain the difference between the ETP cell and the RF-PECVD cell.

\footnotetext{
${ }^{28}$ They measured this with AFM, which according to Fujiwara [24] would result in $\sim 2 \mathrm{~nm}$ when measured with spectroscopic ellipsometry.
} 


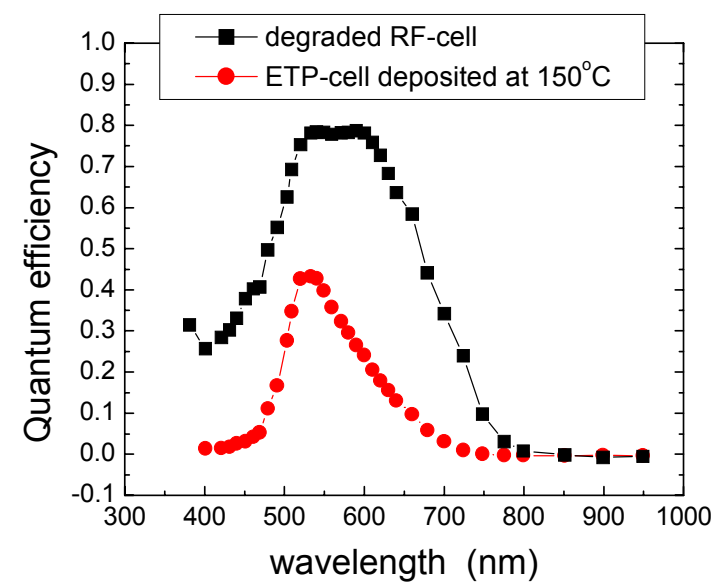

Figure 4.13: Spectral response of a degraded RF-cell with an as-grown ETP-cell with the intrinsic layer deposited at $150^{\circ} \mathrm{C}$. Both individual intrinsic layers have a bulk defect density of $\sim 10^{17} \mathrm{~cm}^{-3}$, $V_{\text {bias }}=0 \mathrm{~V}$.

Finally, the solar cell characteristics and the spectral response compared to the initial response are given after annealing at $120^{\circ} \mathrm{C}$ in Figure $4.11 \mathrm{c}$ and Figure 4.12c, respectively. Due to the anneal treatment both cells degrade significantly in the red. This drop is due to degradation of the Ag/Al back contact [47], which influences the reflectivity of this contact. Furthermore, the RF-PECVD cell recovers almost completely for wavelengths $<600 \mathrm{~nm}$, whereas the ETP cell does not recover completely in the blue. Apparently, the defect density in the intrinsic layers near the $\mathrm{p}-\mathrm{i}$ interface is too large to allow more recovery. A possible explanation can be that a larger defect density will result in a larger hydrogen content in the area near the interface and a larger microstructure parameter. Elevated temperatures can cause hydrogen to move out of the defect rich layers through the p-layer into the TCO, as $\mathrm{H}$ tends to accumulate in the layers that easily accommodate higher densities of $\mathrm{H}$ [48], leaving defects behind in the i-layer and causing some degradation of the Asahi Utype TCO. These influences are mainly seen by irreversible degradation in the blue $[49,50]$.

From the experiments and simulations we conclude that a larger defect density near the p/i interface can explain the differences observed between the ETP cell and the RF-PECVD cell. It is possible that this larger defect density is caused by initial growth. Therefore control of the initial growth of the intrinsic layer is crucial for a high fill factor (and thus for a high efficiency) of a-Si:H based solar cells. Initial growth and a higher generation rate of charge carriers make the first tens of nanometres an important region for recombination. A buffer layer grown at small growth rates with RF-PECVD to utilise controlled initial growth and which would result in a less defective area near the $p$-i interface therefore seems essential for good $p$-i-n solar cell performance. 


\subsection{Use of an intermediate layer between the $p$ - and i-layer}

A dense a-Si:H buffer layer can probably serve as intermediate layer to overcome extra defects near the $p-i$ interface. Less defects at the interface has to result in less recombination at the interface and thus an increase in fill factor of the solar cells. Furthermore, a buffer layer can serve as a seed layer for ETP a-Si:H and by the decrease of the number of defects at the interface, the $V_{\text {oc }}$ can increase [42]. The use of a buffer layer in between the $\mathrm{p}$ - and i-layer of hydrogenated amorphous silicon (a-Si:H) solar cells to improve the solar cell efficiency is proposed by several groups [e.g. 5,6,26,42,51-54]. In these papers various arguments are discussed like 'bandgap engineering' [51], a starting layer for proto-crystalline intrinsic material [25], higher bandgap material to increase the $V_{\text {oc }}$ [e.g. 7], and a hydrogen source for the p-type layer to overcome $\mathrm{H}$ out-diffusion [25,55], etc. Yang et al. [53] reported that the effect of a interface buffer layer was to increase the fill factor which is mainly due to an improvement of the cell performance in the long wavelength $(\lambda>530 \mathrm{~nm})$ region, which means that the electron-hole pairs that are created at the back of the cell have a larger probability to reach the contacts. In all cases the buffer layer is grown at larger hydrogen dilution and low growth rate in order to obtain a better structure and less defects. Nuruddin and Abelson [7] showed that when the buffer layer is not made of good material, the expected effect could not be observed. In this section we will discuss the effect of a buffer layer on cells with the intrinsic layer deposited with the ETP method at moderate growth rate $(\sim 0.85 \mathrm{~nm} / \mathrm{s})$.

Intermediate layers, or buffer layers, are reported with a thickness varying from $2.5 \mathrm{~nm}$ to $100 \mathrm{~nm}$. Kroon and Van Swaaij [56] report that the recombination peak for p-i-n a-Si:H solar cells is positioned $\sim 30 \mathrm{~nm}$ from the $\mathrm{p} / \mathrm{i}$ interface. This suggests that it should be favourable to make the buffer layer at least $30 \mathrm{~nm}$ thick. However, Yoshida et al. [52] for example report an effective buffer layer thickness of $\sim 10 \mathrm{~nm}$ based on the recombination current near the p/i interface. On the other hand Mahan et al. [55] utilised a $100 \mathrm{~nm}$ thick buffer layer for $\mathrm{n}$-i-p cells. In this case they needed this thickness to retard $\mathrm{H}$ out-diffusion from the $\mathrm{n}$-type layer due to the high deposition temperatures needed to deposit intrinsic a-Si: $\mathrm{H}$ at $1.6 \mathrm{~nm} / \mathrm{s}$ with $\mathrm{HW}$ CVD.

Figure 4.14 shows the results of $p$-i-n solar cells with the intrinsic layer deposited with the ETP method and in which the thickness of a buffer layer, which is incorporated in between the $p$ - and the i-layer, is varied. The thickness of the ETP layer was adjusted such that the total thickness of all cells was $400 \mathrm{~nm}$. The buffer layer is made with RF-PECVD and has an optical bandgap of $\sim 1.80 \mathrm{eV}$, comparable with the gap of the intrinsic layer grown with the ETP method. The intrinsic layer of the ETP method has been deposited at a growth rate of $0.75 \mathrm{~nm} / \mathrm{s}$ and a deposition temperature of $260^{\circ} \mathrm{C}$. 


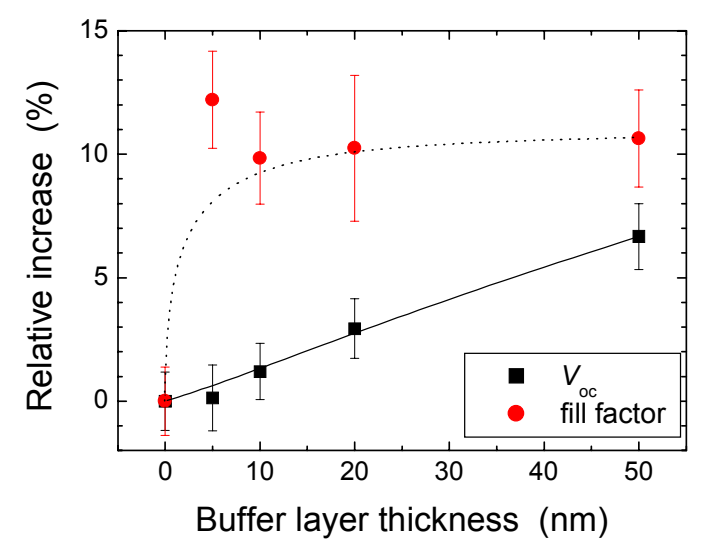

Figure 4.14: Improvement of fill factor and open-circuit voltage of a solar cell as a function of the buffer layer thickness. The total thickness of the intrinsic layer was kept constant at $400 \mathrm{~nm}$. Furthermore, the cells consist of a $12 \mathrm{~nm}$ thick p-layer and a $20 \mathrm{~nm}$ n-layer. The improvement is with regard to the value when no buffer layer is applied.

Figure 4.14 shows clearly the higher fill factor when a buffer layer grown at low growth rate is incorporated between the p-layer and the intrinsic layer. The fill factor increases from $\sim 10 \%$ when a buffer layer of any thickness from 5 to $50 \mathrm{~nm}$ is incorporated, which is close to the predicted change from the simulations (Fig. 4.10). The open-circuit voltage increases and this might be attributed to the decrease of defect density near the p/i interface, though the simulations do not support this idea. However, it might also be attributed to a better protection of the p-type layer, in accordance with results of Mahan et al. [55], as in this case the intrinsic layer is also deposited at a slightly higher deposition temperature $\left(\sim 20^{\circ} \mathrm{C}\right)$ than the p-layer. With regard to the $V_{\text {oc }}$ it is interesting to note that the cell grown completely in the RFPECVD chamber of CASCADE exhibited a $V_{\text {oc }}$ of $0.82 \mathrm{~V}$, whereas the $V_{\text {oc }}$ for the cell with a buffer layer of $50 \mathrm{~nm}$ is $\sim 0.80 \mathrm{~V}$. When the $50 \mathrm{~nm}$ buffer layer would be applied to the $6.7 \%$ cell a relative increase of $\sim 16 \%\left(10 \%\right.$ in $\mathrm{FF}$ and $6 \%$ in $V_{\text {oc }}$ ) is expected and a cell of $\sim 7.8 \%$ can be obtained. This efficiency would be similar to the efficiency of the $p-i-n$ cell grown completely in the RF-PECVD chamber of CASCADE.

\subsection{Conclusions}

In this chapter we have shown that intrinsic a-Si:H can be deposited with comparable material properties as obtained for solar grade RF-PECVD a-Si:H. This is realised by using the ETP at a relative low growth rate, for this technique, of $0.85 \mathrm{~nm} / \mathrm{s}$ and low deposition temperature of $250^{\circ} \mathrm{C}$. This temperature is the upper limit for the deposition of intrinsic layers when the p-layer is deposited first, because otherwise the p-layer properties are largely affected. However, the increase in open-circuit voltage by applying a buffer layer suggests that the deposition temperature of $250^{\circ} \mathrm{C}$ for the intrinsic layer also affects the p-layer somewhat. The maximum temperature limits the growth rate of the intrinsic layer, because larger growth rates require higher deposition temperatures. It is found that for material properties like the photoconductivity an optimum deposition temperature could be observed as a function of the growth rate. The combination of temperature and growth rate is also 
the reason why ETP material grown at $0.85 \mathrm{~nm} / \mathrm{s}$ and $250^{\circ} \mathrm{C}$ is comparable with RFPECVD a-Si:H. This in contrast to the material reported in Section 1.3, which is deposited at high growth rate and $400^{\circ} \mathrm{C}$, that resulted in material that was much more comparable with HW-CVD a-Si:H.

Incorporating the layers deposited at $250^{\circ} \mathrm{C}$ and $0.85 \mathrm{~nm} / \mathrm{s}$ into solar cells resulted in an initial efficiency of $6.7 \%$, which is still $\sim 3 \%$ lower than for a good RFPECVD cell using the same configuration and only $1.3 \%$ lower than the RF-PECVD cell deposited in CASCADE. The lower efficiency is mainly due to the lower fill factor for the ETP cell (<0.6 instead of 0.7). This lower fill factor is also found for cells deposited at $0.22 \mathrm{~nm} / \mathrm{s}$ and for $\mathrm{i}-\mathrm{n}$ structures. The lower fill factor is attributed to more recombination in the cell, which is supported by spectral response measurements. However, the bulk defect density for both ETP and RF-PECVD a$\mathrm{Si}$ :H is comparable $\left(<10^{16} \mathrm{~cm}^{-3}\right)$. Simulations with ASA showed that a large defect density near the $\mathrm{p} / \mathrm{i}$ interface can explain the lower fill factor, while it does not affect the short-circuit current density and the open-circuit voltage. That initial growth results in more defects near the interface was already observed for RF-PECVD a$\mathrm{Si}: \mathrm{H}$ and due to differences in deposition technique it seems possible to have even more defects when deposited with the ETP. The effect of a defect rich layer can be minimised by depositing a buffer layer with RF-PECVD between the $p$-type layer and the ETP intrinsic layer. Already a $5 \mathrm{~nm}$ thick buffer layer resulted in a $10 \%$ increase in fill factor, as predicted by the simulations. Further research concerning the bandgap of the buffer layer and buffer layer material is needed to obtain further optimisation.

\section{References}

1. W. Luft and Y.S. Tsuo, Hydrogenated amorphous silicon alloy deposition processes, Marcel Dekker, New York (1993); Y.J. Ye, W.A. Anderson, and Y.S. Tsuo, Solar Cells, 283 (1988) 191; L. Yang, I. Balberg, A. Catalano, and Mat. Res. Soc. Symp. Proc., 192 (1990) 243

2. R.E.I. Schropp and M. Zeman, Amorphous and microcrystalline silicon solar cells, Kluwer Academic Publishers (1998) Boston/Dordrecht/London

3. F.A. Rubinelli, J.K. Rath, and R.E.I. Schropp, J. of Appl. Phys., 89 (2001) 4010

4. D.A. Neamen, Semiconductor physics and devices, Richard D. Irwin, Inc., (1992) Boston

5. S.S. Hegedus, Proc. of $20^{\text {th }}$ IEEE-PVSC (1988) 102

6. A. Hadjadj, M. Favre, B. Equer, and P. Roca i Cabarrocas, Solar Energy Mat. and Solar Cells, 51 (1998) 145

7. A. Nuruddin and J.R. Abelson, Thin Solid Films, 394 (2001) 49

8. M. Zeman, G. Tao, M. Trijssenaar, J.W. Willemen, J.W. Metselaar, and R.E.I. Schropp, Mat. Res. Soc. Symp. Proc., 377 (1995) 639

9. M. Stutzmann, Philosophical Magazine B, 60 (1989) 531

10. W.B. Jackson, D.K. Biegelsen, R.J. Nemanich, and J.C. Knights, Appl. Phys. Lett., 42 (1983) 105

11. A.H.M. Smets, W.M.M. Kessels, M.C.M. van de Sanden, to be published

12. B.A. Korevaar, G.J. Adriaenssens, A.H.M. Smets, W.M.M. Kessels, H.-Z. Song, M.C.M. van de Sanden, and D.C. Schram, J. Non-Cryst. Sol., 266 (2000) 380

13. A.H.M. Smets, Ph. D. thesis, Eindhoven University of Technology, (2002)

14. C.R. Wronski, Z.E. Smith, S. Aljishi, V. Chu, K. Shepard, D.S. Shen, R. Schwarz, D. Slobodin, and S. Wagner, AIP Conf. Proc., 157 (1987) 70 
15. W.M.M. Kessels, R.J. Severens, M.C.M. van de Sanden, and D.C. Schram, J. Non-Cryst. Sol., 227-230 (1998) 133

16. D.E. Carlson and C.W. Magee, Appl. Phys. Lett., 33 (1978) 81

17. W. Beyer and H. Wagner, J. Appl. Phys., 53 (1982) 8745

18. R.A. Street, C.C. Tsai, W.B. Jackson, and J. Kakalios, Phil. Mag. B, 56 (1987) 305

19. T. Shimizu, X. Xu, H. Kidoh, A. Morimoto, and M. Kumeda, J. Appl. Phys., 64 (1988) 5045

20. S. Guha, J. Yang, S.J. Jones, Y. Chan, and D.L. Williamson, Appl. Phys. Lett., 61 (1992) 1444

21. A.H.M. Smets, D.C. Schram, and M.C.M. van de Sanden, Mat. Res. Soc. Symp. Proc., 609 (2000) A7.6

22. A.H.M. Smets, J.H. van Helden, and M.C.M. van de Sanden, Mat. Res. Soc. Symp. Proc., 664 (2001) A22.4; A.H.M. Smets, J.H. van Helden, and M.C.M. van de Sanden, submitted to Phys. Rev. Lett.

23. A. Asano and M. Stutzmann, J. Non-Cryst. Sol., 137-138 (1991) 623

24. H. Fujiwara, J. Koh, P.I. Rovira, and R.W. Collins, Phys. Rev. B, 61 (2000) 10832

25. J. Koh, Y. Lee, H. Fujiwara, C.R. Wronski, and R.W. Collins, Appl. Phys. Lett., 73 (1998) 1526

26. A.H.M. Smets, D.C. Schram, and M.C.M. van de Sanden, J. Appl. Phys., 88 (2000) 6388

27. A.H.M. Smets, M. Bakker, and M.C.M. van de Sanden, to be published

28. M. Kondo, T. Ohe, K. Saito, T. Nishimiya, and A. Matsuda, J. of Non-Cryst. Solids, 227-230 (1998) 890

29. D.M. Tanenbaum, A. Laracuente, and A.C. Gallagher, Mat. Res. Soc. Symp. Proc., 377 (1995) 143

30. D.M. Tanenbaum, A. Laracuente, and A.C. Gallagher, Mat. Res. Soc. Symp. Proc., 336 (1994) 49

31. R. Robertson and A. Gallagher, J. Appl. Phys., 59 (1986) 3402

32. W.M.M. Kessels, Ph. D. thesis, Eindhoven University of Technology (2000); W.M.M. Kessels, C.M. Leewis, M.C.M. van de Sanden, and D.C. Schram, J. Appl. Phys., 86 (1999) 4029; W.M.M. Kessels, M.C.M. van de Sanden, and D.C. Schram, J. Vac. Sci. Technol. A, 18 (2000) 2153; W.M.M. Kessels, J.P.M. Hoefnagels, M.G.H. Bogaarts, D.C. Schram, and M.C.M. van de Sanden, J. Appl. Phys., 89 (2001) 2065

33. M.C.M. van de Sanden, W.M.M. Kessels, A.H.M. Smets, B.A. Korevaar, R.J. Severens, and D.C. Schram, Mat. Res. Soc. Symp. Proc., 557 (1999) 13

34. A.H. Mahan, Y. Xu, E. Iwaniczko, D.L. Williamson, B.P. Nelson, and Q. Wang, to be published J. of Non-Cryst. Solids, (2002)

35. P. Roca i Cabarrocas, Appl. Phys. Lett., 65 (1994) 1674

36. E.A.G. Hamers, W.G.J.H.M. van Sark, J. Bezemer, H. Meiling, and W.F. van der Weg, J. of Non Cryst. Solids, 226 (1998) 205

37. C. Rosenblad, H.R. Deller, T. Graf, E. Müller, and H. von Känel, J. of Cryst. Growth, 188 (1998) 125

38. N. Wyrsch, F. Finger, T.J. McMahon, and M. Vanecek, J. Non-Cryst. Sol., 137138 (1991) 347

39. Z.E. Smith, V. Chu, K. Shepard, S. Aljishi, D. Slobodin, J. Kolodzey, S. Wagner, and T.L. Chu, Appl. Phys. Lett., 50 (1987) 1521 
40. G. Amato, G. Benedetto, L. Boarino, and R. Spagnolo, Appl. Phys. A, 50 (1990) 503

41. A.H.M. Smets, J.H. van Helden, and M.C.M. van de Sanden, J. Non-Cryst. Sol., accepted for publication

42. J.M. Pearce, R.J. Koval, A.S. Ferlauto, R.W. Collins, C.R. Wronski, J. Yang, and S. Guha, Appl. Phys. Lett., 77 (2000) 3093

43. R. Koval, X. Niu, J. Pearce, L. Jiao, G. Ganguly, J. Yang, S. Guha, R.W. Collins, C.R. Wronski, Mat. Res. Soc. Symp. Proc., 609 (2000) A15.5

44. M. Gunes and C.R. Wronski, J. Appl. Phys., 81 (1997) 3526

45. H.M. Branz, Solid State Commun., 105 (1998) 387

46. I.S. Osborne, N. Hata, and A. Matsuda, Appl. Phys. Lett., 66 (1995) 965

47. J.A. Willemen, Ph. D. Thesis, Delft University of Technology (1998)

48. B.P. Nelson, Y. Xu, R.C. Reedy, R.S. Crandall, A.H. Mahan, and H.M. Branz, Mat. Res. Soc. Symp. Proc., 664 (2001) A28.2

49. D.E. Carlson and K. Rajan, Appl. Phys. Lett., 68 (1996) 28

50. D.E. Carlson and K. Rajan, Appl. Phys. Lett., 69 (1996) 1447

51. Q. Wang, E. Iwaniczko, Y. Xu, B.P. Nelson, A.H. Mahan, R.S. Crandall, and H.M. Branz, Proc. of $28^{\text {th }}$ IEEE-PVSC (2000) 717

52. T. Yoshida, S. Fujikake, H. Shimabukuro, Y. Ichikawa, and H. Sakai, Proc. of $20^{\text {th }}$ IEEE-PVSC (1988) 335

53. J. Yang, B. Yan, J. Smeets, and S. Guha, Mat. Res. Soc. Symp. Proc., 664 (2001) A11.3

54. B. Schröder, U. Weber, H. Seitz, A. Ledermann, and C. Mukherjee, Proc. of $17^{\text {th }}$ E-PVSEC (2001) OD1.2

55. A.H. Mahan, R.C. Reedy, E. Iwaniczko, Q. Wang, B.P. Nelson, Y. Xu, A.C. Gallagher, H.M. Branz, R.S. Crandall, J. Yang, and S. Guha, Mat. Res. Soc. Symp. Proc., 507 (1998) 119

56. M.A. Kroon and R.A.C.M.M. van Swaaij, J. Appl. Phys., 90 (2001) 994 


\section{Chapter 5}

5. Single junction a-Si:H solar cells with the intrinsic layer deposited above $250^{\circ} \mathrm{C}$ 


\subsection{Introduction}

The requirement to set the deposition temperature at $250^{\circ} \mathrm{C}$, at which value the properties of the p-layer are not modified, limits the growth rate of the intrinsic layer in a p-i-n solar cell. Furthermore, results reported by Roschek et al. [1] seem to suggest that $\mathrm{p}$-type $\mu \mathrm{c}-\mathrm{Si} \mathrm{H}$ is also not temperature resistant (i.e., $>250^{\circ} \mathrm{C}$ ). However, larger growth rates are required as it shortens the production time. With the expanding thermal plasma (ETP) method it has been shown that good a-Si:H can be obtained at large growth rates (Section 1.3), exhibiting a larger hole drift mobility than a-Si:H obtained with RF-PECVD. Larger growth rates require higher deposition temperatures to obtain solar-grade material and at these temperatures the properties of the p-type a-Si:H layer will be significantly affected. Therefore, we need to investigate the possibilities to deposit a-Si:H at large growth rate and high deposition temperature without affecting the p-layer. For example, a buffer layer may be used that protects the p-layer from the higher temperature. Dalal et al. [2] showed that in this way a deposition temperature of up to $375^{\circ} \mathrm{C}$ could be used for the intrinsic layer. To overcome the deterioration of the p-layer, the growth sequence of the solar cell can be reversed, as it is possible to make the amorphous n-layer more temperature resistant. Furthermore, a microcrystalline $n$-layer can be made temperature resistant up to $400^{\circ} \mathrm{C}$ with a thin incubation layer. A small incubation layer for the n-layer is not so detrimental as for the p-layer, because the doping efficiency of phosphorus is much better than for boron in a-Si:H [3]. This means that even at a small doping concentration the thin incubation layer still has a relatively good conductivity when compared with the conductivity of an amorphous p-type layer.

In Section 5.2 the material properties of the films grown at larger growth rates and at a higher substrate temperature will be discussed. A consequence of the higher substrate temperature is that the optical bandgap of a-Si:H decreases. It is reported that dense material containing less hydrogen and with a lower optical bandgap (a consequence of the lower hydrogen concentration) has a lower saturation defect density [e.g. 4]. This would make more stable solar cells [5], because a smaller bandgap corresponds to a higher ordering of the lattice and/or a shorter bond length [6]. Therefore, simulations are performed in order to find a relation between the optical bandgap and the intrinsic layer thickness in a solar cell (5.2.2). In Section 5.3 results on temperature stability of n-type layers are discussed (5.3.1) as well as preliminary results for the $n$-i-p solar cells (5.3.2). Finally, in Section 5.4 the incorporation of layers deposited at large growth rates in i-n and p-i-n structures are described. To protect the p-layer from the temperature an RF-PECVD buffer layer is incorporated in between the $p$ - and the i-layer.

\subsection{Larger growth rates and higher temperatures}

\subsubsection{Expanding thermal plasma a-Si: $\mathrm{H}$ at larger growth rate and higher temperature}

The two most effective ways to increase the deposition rate is to increase the $\mathrm{SiH}_{4}$ flow or the Ar flow. Figure 5.1 presents the experiment in which the $\mathrm{SiH}_{4}$ flow is increased from $10 \mathrm{nccm}$ to $500 \mathrm{nccm}$ at a deposition temperature of $400^{\circ} \mathrm{C}$. The growth rate (Fig. 5.1a) increases with the $\mathrm{SiH}_{4}$ flow and shows two regimes that scales with the $\mathrm{SiH}_{4}$ depletion (Fig. 5.1b). This has also been observed by Smit et al. 
[7] and by Kessels et al. [8]. The $\mathrm{SiH}_{4}$ depletion is higher at lower $\mathrm{SiH}_{4}$ flows, indicating that more $\mathrm{SiH}_{4}$ is dissociated and contributes to the growth. At these low flows the $\mathrm{SiH}_{4}$ will first be dissociated by the ions and electrons emanating from the arc, which is much more effective than the dissociation due to atomic hydrogen. Above a certain $\mathrm{SiH}_{4}$ flow the dissociation due to atomic hydrogen becomes dominant. The radicals that are produced by the ion/electron $/ \mathrm{SiH}_{4}$ interaction are also different than the radicals produced due to atomic hydrogen [8]. This explains the poorer material properties at low $\mathrm{SiH}_{4}$ flows, while the growth rate is very low. The refractive index at $2 \mathrm{eV}$ (Fig. 5.1c) has an optimum regarding the $\mathrm{SiH}_{4}$ flow, but the material is dense over the whole $\mathrm{SiH}_{4}$ range due to the temperature. The optical Tauc gap (not shown) is $(1.70 \pm 0.02) \mathrm{eV}$ over the whole investigated regime, which is mainly due to the high temperature at these growth rates. The photo- and dark conductivity (Fig. 5.1d) are $\sim 10^{-5}$ and $<10^{-10}(\Omega \mathrm{cm})^{-1}$, respectively, in the range from 20 to $300 \mathrm{nccm}$. The activation energy for electron conductivity in the dark (not shown) is $(0.82 \pm 0.02) \mathrm{eV}$ in the range from $20 \mathrm{nccm}$ to $300 \mathrm{nccm} \mathrm{SiH}_{4}$ and $\sim 0.75 \mathrm{eV}$ for the lowest and largest $\mathrm{SiH}_{4}$ flow. The defect density (Fig. 5.1e) and Urbach energy (Fig. 5.1f) decrease with increasing $\mathrm{SiH}_{4}$ flow and the defect density becomes constant at $\sim 10^{16} \mathrm{~cm}^{-3}$ for flows $>100 \mathrm{nccm}$.

Table 5.1: Conditions of the experiments shown in Figure 5.2. The growth rate is the growth rate at $400^{\circ} \mathrm{C}$ and will be higher at lower deposition temperatures.

\begin{tabular}{|l|c|c|}
\hline Growth rate (nm/s) & $\mathbf{1 . 3}$ & $\mathbf{2 . 1}$ \\
\hline Ar flow (nccm) & 800 & 800 \\
\hline $\mathrm{H}_{2}$ in arc (nccm) & 200 & 250 \\
\hline $\mathrm{H}_{2}$ in nozzle (nccm) & 200 & 200 \\
\hline $\mathrm{SiH}_{4}$ flow (nccm) & 115 & 200 \\
\hline Arc current (A) & 35 & 40 \\
\hline Pressure (mbar) & 0.21 & 0.23 \\
\hline
\end{tabular}

Compared with the conditions discussed in chapter 4, a larger Ar flow results in a larger ion and electron density, more $\mathrm{H}_{2}$ dissociation, and a larger pressure in the deposition chamber. These effects lead to an increase in the deposition rate. To optimise the flows while maintaining the material properties we choose to compensate the larger ion and electron flux emanating from the arc due to the larger argon flow by injecting hydrogen in the nozzle. The parameter that is used as a first check of the grown material is the photoconductivity. Two conditions are used to obtain deposition rates of $1.3 \mathrm{~nm} / \mathrm{s}$ and $2.1 \mathrm{~nm} / \mathrm{s}$. For these conditions the deposition temperature is varied to extend the experiments described in Section 4.3.3. Figure 5.2 shows the material properties as a function of the deposition temperature for the conditions described in Table 5.1. The $\mathrm{SiH}_{4}$ depletion using these conditions was $\sim 10 \%$. 

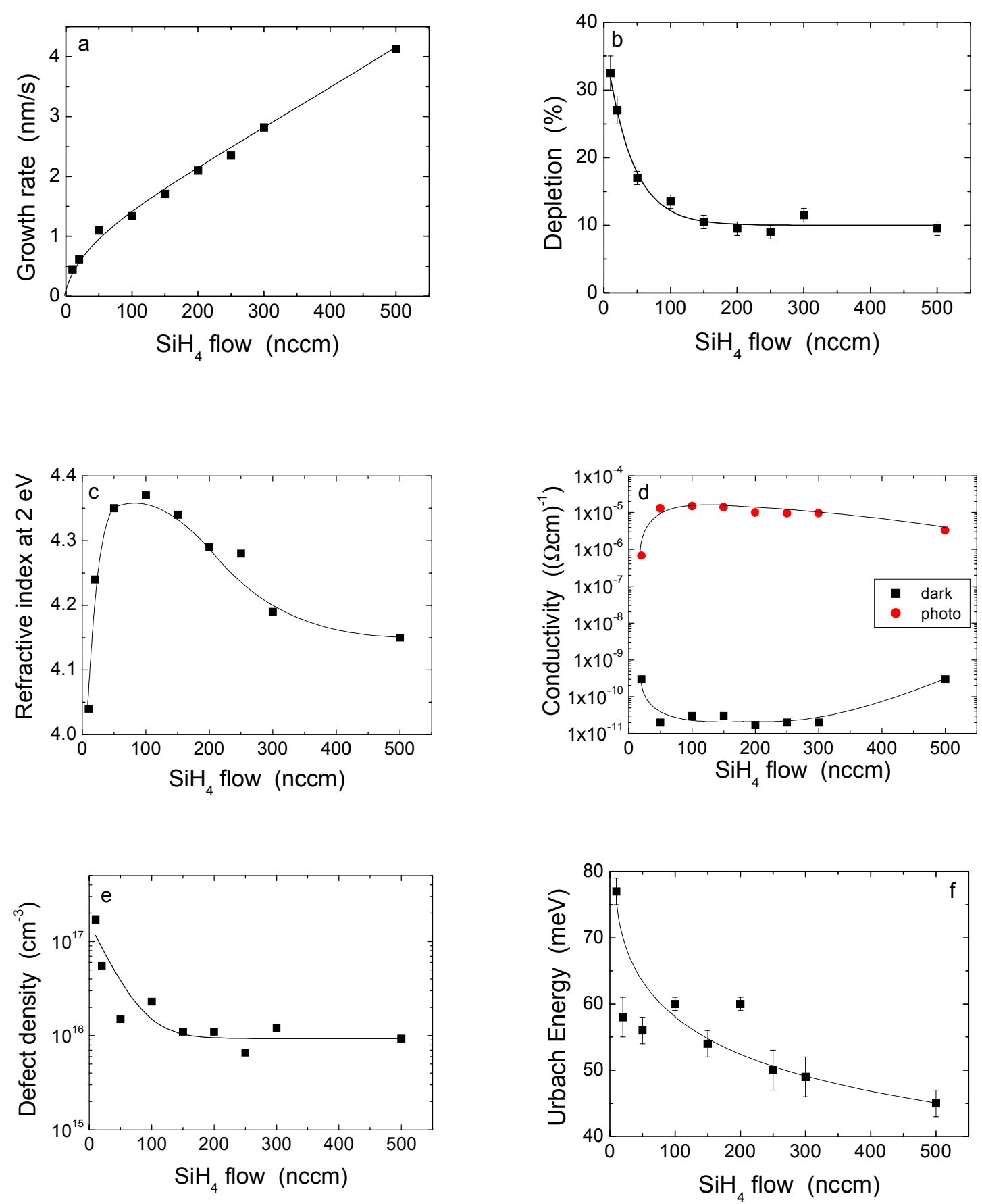

Figure 5.1: Growth rate (a), $\mathrm{SiH}_{4}$ depletion (b), refractive index at $2 \mathrm{eV}$ (c), photo- and dark conductivity (d), defect density (e), and Urbach energy (f) as a function of the $\mathrm{SiH}_{4}$ flow. The other conditions were: $800 \mathrm{nccm} \mathrm{Ar,} 250 \mathrm{nccm} \mathrm{H_{2 }}$ in the arc, $200 \mathrm{nccm} \mathrm{H}_{2}$ in the nozzle, $40 \mathrm{~A}$ arc current, and a deposition temperature of $400^{\circ} \mathrm{C}$. The lines are a guide to the eye.

The refractive index at $2 \mathrm{eV}$ and the photoconductivity are lowest at $200^{\circ} \mathrm{C}$. At higher temperature the films are denser and the photoconductivity approaches $10^{-5}$ $(\Omega \mathrm{cm})^{-1}$. The dark conductivity is $\sim 1 \cdot 10^{-11}(\Omega \mathrm{cm})^{-1}$ for all films, resulting in a photo response $>10^{5}$. The activation energy for electron conductivity is $(0.80 \pm 0.05) \mathrm{eV}$ for all films. Both the activation energy and the dark conductivity seem independent of the deposition temperature. The Urbach energy scatters and is $(50 \pm 4) \mathrm{meV}$ over 
the range between $250^{\circ} \mathrm{C}$ and $400^{\circ} \mathrm{C}$. Correlated with this is the defect density of states as obtained from dual beam photoconductivity (DBP) measurements that gives values of $\sim 1 \cdot 10^{16} \mathrm{~cm}^{-3}$ in the same temperature range. At $200^{\circ} \mathrm{C}$ the properties are worse resulting in a DOS of $\sim 2 \cdot 10^{16} \mathrm{~cm}^{-3}$ and an Urbach energy of $(62 \pm 4) \mathrm{meV}$. The optical gap (Fig. 5.2c) decreases with increasing deposition temperature.
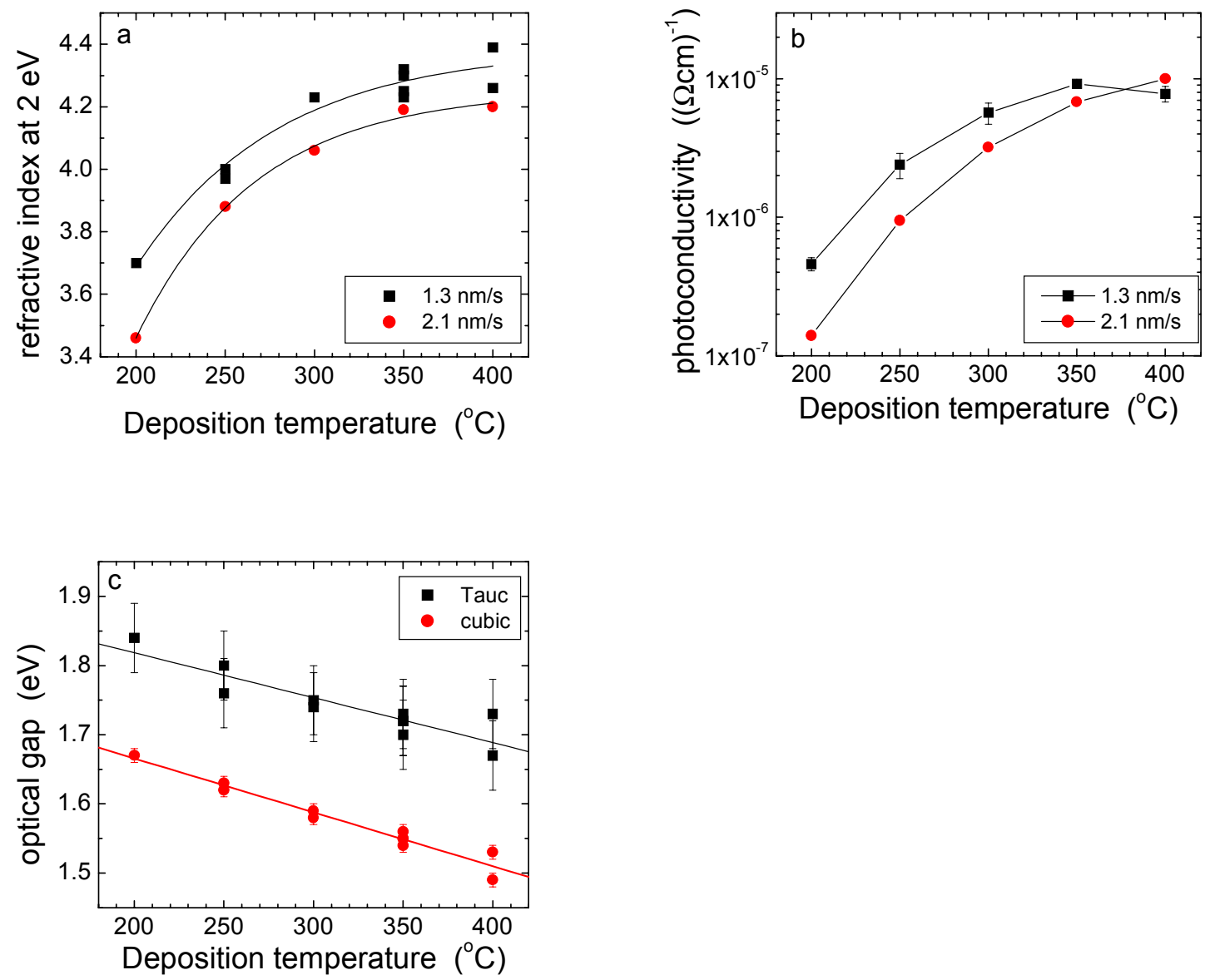

Figure 5.2: Refractive index (a), photoconductivity (b), and optical gap (c) as a function of the deposition temperature for two different growth rates. The optical gap is only displayed for the growth rate of $1.3 \mathrm{~nm} / \mathrm{s}$. The lines are a guide to the eye.

\subsubsection{Optimum optical bandgap (simulations)}

The optical bandgap of a-Si:H depends on the deposition temperature and the growth rate. Furthermore, the optical bandgap also determines the absorption of the incoming light and therefore the solar cell performance. The material obtained in Eindhoven at large growth rate $(\sim 10 \mathrm{~nm} / \mathrm{s})$ and $400^{\circ} \mathrm{C}$ has an optical Tauc gap of $1.66 \mathrm{eV}$ [9], which is $\sim 0.1 \mathrm{eV}$ lower than obtained for a-Si:H deposited by RFPECVD. A lower optical gap implies that more light is absorbed. More charge carriers are generated but this will also result in more recombination, especially near the $p$-i interface, as the generation is the largest in this region. Therefore an optimum for the bandgap of a-Si:H is expected. In order to determine the optimum bandgap simulations are performed in which the optical bandgap is varied from 1.70 to 1.85 $\mathrm{eV}$. The results of these simulations on the external solar cell characteristics are shown in Figure 5.3. The simulations used data files that contain the refractive index and the absorption as a function of the wavelength as determined from experimental 
grown films for the gap values of 1.70 to $1.85 \mathrm{eV}$. In the simulations the optical gap of the p-layer is chosen to be $1.95 \mathrm{eV}$ and for the n-layer $1.75 \mathrm{eV}$. These properties of the doped layers are used for all the simulations and thus only the bandgap and the material properties of the intrinsic film are varied. It is noted that in order to obtain an optimum solar cell the properties of the doped layers might have to be adjusted to the properties and the bandgap of the intrinsic layer. Furthermore, the defect-pool distribution is also shifted with the bandgap, such that the centre of the defect pool is always at the same position with regard to the bands.
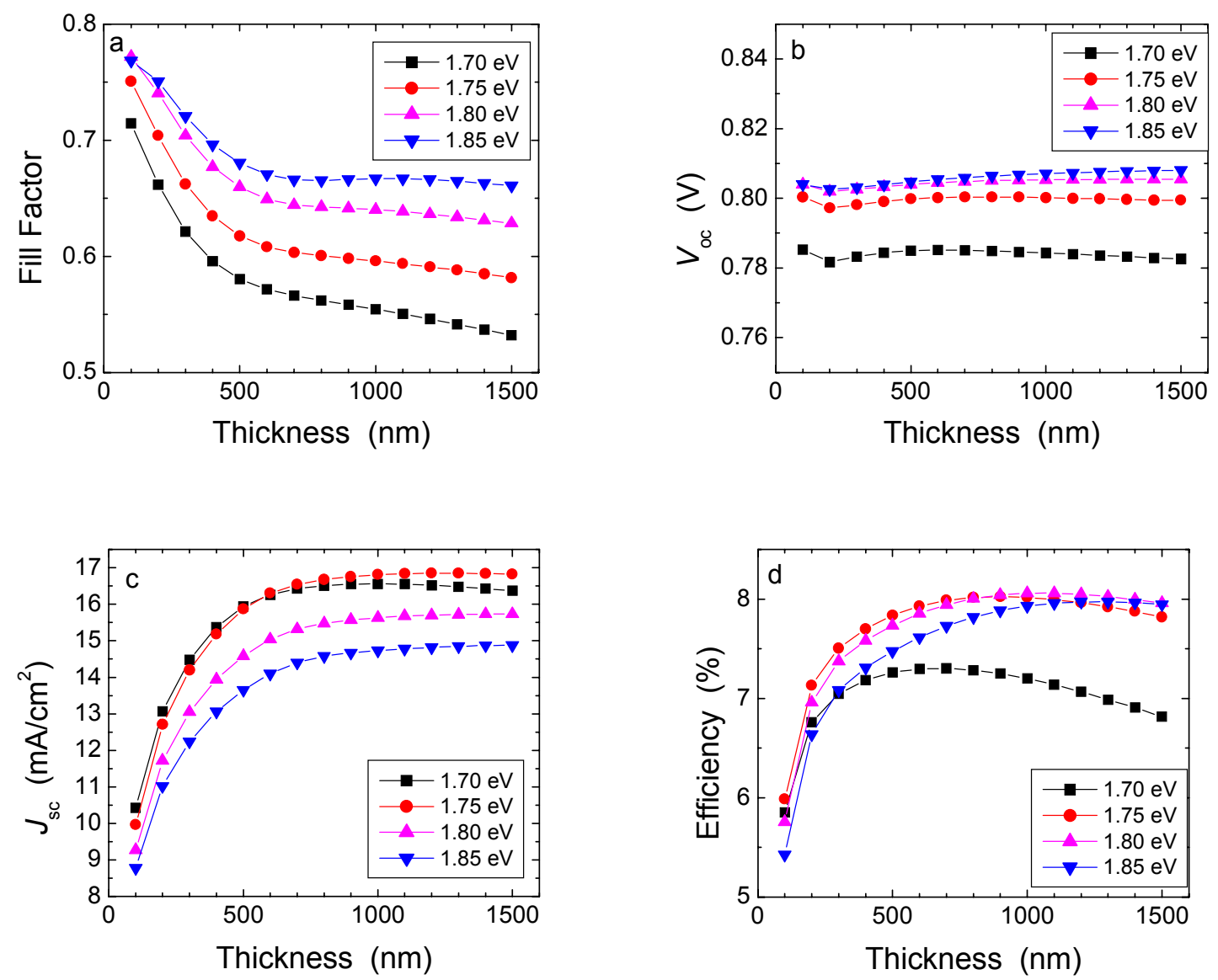

Figure 5.3: Fill factor (a), open-circuit voltage (b), short-circuit current (c), and efficiency (d) of a solar cell as a function of a varying mobility gap of the intrinsic layer and varying thickness of the intrinsic layer. The simulations use the results of RT-measurements for the calculation of the generation profile.

Figure 5.3 shows the fill factor, the open-circuit voltage, the short-circuit current density, and the efficiency as a function of the mobility gap and the thickness of the intrinsic layer. The mobility gap is set to be equal to the measured optical Tauc gap. The fill factor (Fig. 5.3a) decreases with decreasing optical gap. This reflects the larger recombination rate when the generation of charge-carriers is larger throughout the intrinsic film and is differently distributed. Figure 5.3a also shows that the fill factor decreases with increasing intrinsic layer thickness. Experimentally this was observed when comparing two cells, both grown completely in the RF-PECVD chamber of CASCADE, having intrinsic layers of 190 and $450 \mathrm{~nm}$. The fill factor were $\sim 0.73$ and $\sim 0.63$, respectively. The same trend of the fill factor with regard to the thickness is also observed by Koval et al. [10], indicating that more recombination 
occurs when the i-layer is thicker. The open-circuit voltage (Fig. 5.3b) does not depend on the thickness and is mainly determined by the optical bandgap of the material, i.e., it decreases with decreasing optical gap [11]. The short-circuit current density (Fig. 5.3c) first increases with increasing thickness as a thicker layer absorbs more light. At a certain thickness the current saturates after which it decreases again. This saturation point occurs when the extra-generated electron-hole pairs all recombine, as the recombination rate increases faster with thickness than the generation rate, also explaining the decrease in current density ${ }^{29}$. Regarding the current density an optimum thickness can be found for the intrinsic layer, which depends on the optical gap of the intrinsic a-Si:H (Fig. 5.3d). For a gap of $1.70 \mathrm{eV}$ the optimum thickness is $\sim 600 \mathrm{~nm}$ whereas this is $\sim 1000 \mathrm{~nm}$ for a gap of $1.75 \mathrm{eV}$. At larger optical gaps the optimum thickness increases and is not reached within the simulated range. It is important to note that the optimum thickness is determined for the initial solar cell characteristics, but in reality it will be determined mainly by the light-induced degradation of the solar cell, because thicker cells degrade more than thinner cells. As a consequence the optimum thickness of the intrinsic layer will be thinner.

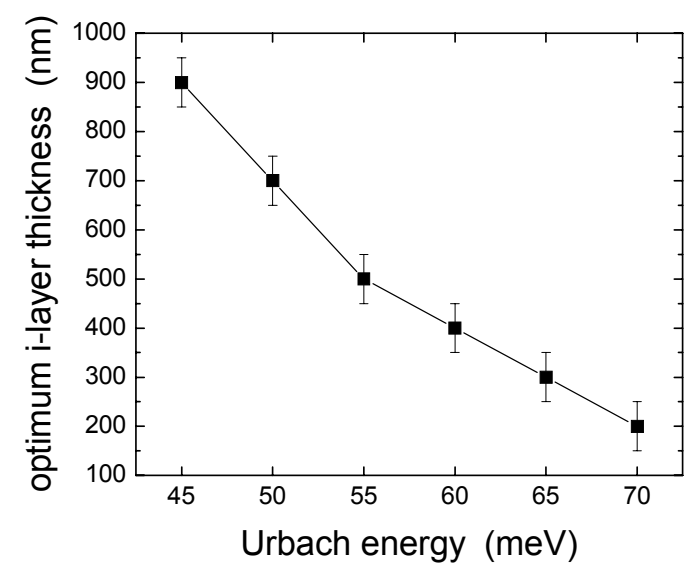

Figure 5.4: Optimum thickness of the intrinsic layer $(1.75 \mathrm{eV})$ regarding efficiency of a a-Si:H single junction solar cell as a function of the defect density of the intrinsic layer, represented by the Urbach energy.

To account for degraded solar cells, simulations are performed in which a larger Urbach energy is used for the intrinsic material, which is correlated to a larger defect density [12] $]^{30}$. Figure 5.4 and 5.5 present the results of these simulations. Figure 5.4 represents the optimum thickness of the solar cell regarding the efficiency as a function of the Urbach energy for a film with a bandgap of $1.75 \mathrm{eV}$. It is clearly seen that the optimum thickness of the cell decreases with increasing Urbach energy and thus with increasing defect density. In Figure 5.5 the external parameters are shown as a function of the thickness of the intrinsic layer. In this figure the Urbach energy of the intrinsic layers was $65 \mathrm{meV}\left(\sim 10^{17} \mathrm{~cm}^{-3}\right)$, whereas $45 \mathrm{meV}$ was used in the simulations presented in Figure 5.3. In these simulations the possible lower degraded state defect density for material with a lower optical gap is thus not

\footnotetext{
${ }^{29}$ For a layer that is infinitely thick the current density will approach zero.

${ }^{30}$ In reality the Urbach energy does not increase due to light illumination; however, at this moment it is the only way to increase the defect density in the simulation program ASA when the defect-pool model is used, and in that way to account for the degraded state.
} 
accounted for [4,5]. From a comparison of Figure 5.3 with Figure 5.5 it can be concluded that the fill factor decreases much more rapidly with thickness when the Urbach energy of the intrinsic layer is larger, indicating more recombination. Consequently the current is also lower. The open-circuit voltage is also slightly lower in the case of the larger Urbach energy, and thus higher defect density. Regarding the efficiency it is interesting to note that the highest efficiency for the simulated configuration is now for the cell with an intrinsic layer of $1.85 \mathrm{eV}$. This means that extra defects seem to have the least influence on a film with a bandgap of $1.85 \mathrm{eV}$, mainly represented by the smallest change in open-circuit voltage of all the presented cells.
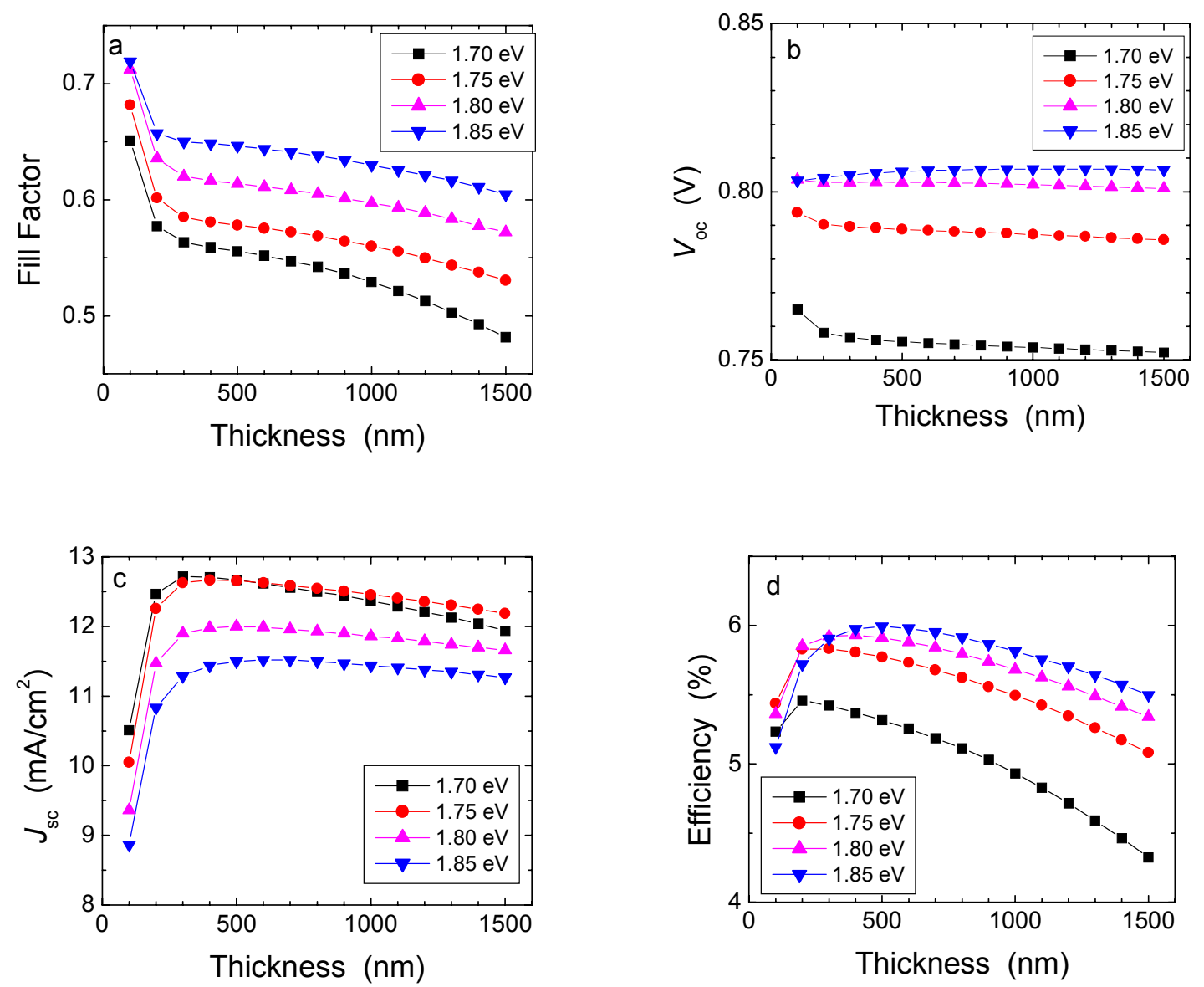

Figure 5.5: Fill factor (a), open-circuit voltage (b), short-circuit current density (c), and efficiency (d) of a solar cell as a function of a varying optical gap of the intrinsic layer and varying thickness of the intrinsic layer. For these simulations the Urbach energy was set to $65 \mathrm{meV}$ to account for the degraded solar cell.

Summarising, regarding the simulated solar cell configuration the optimum optical gap of the intrinsic material has to be $\sim 1.75 \mathrm{eV}$ when taking the initial efficiency into account. However, the fill factor at $1.85 \mathrm{eV}$ is much better and the open-circuit voltage at $1.85 \mathrm{eV}$ is larger than for $1.75 \mathrm{eV}$. Regarding the simulations performed with a larger Urbach energy for the intrinsic layer to account for the extra defects created due to light soaking, the optimum bandgap for the intrinsic layer should be in between 1.8 and $1.85 \mathrm{eV}$, when the creation of extra defects is taken independent of the optical gap. 
The results shown in Figure 5.3 and 5.5 suggest that an optical gap of $1.65 \mathrm{eV}$ seems to be disadvantageous as material for single junction $\mathrm{p}-\mathrm{i}-\mathrm{n}$ a-Si: $\mathrm{H}$ based solar cells, although the simulations do also suggest that an efficiency of $\sim 7 \%$ is possible. Both the open-circuit voltage and the fill factor decrease by lowering the bandgap of the intrinsic layer. When low bandgap material is applied in solar cells, adjustment of the $p$-layer and n-layer might be necessary, for example to account for the effects of the higher deposition temperature. Furthermore, an optimisation of those doped layers to low bandgap material can improve the fill factor. Also a high bandgap intrinsic intermediate layer in between the p-layer and the intrinsic layer may be used to increase the $V_{\text {oc }}$ and fill factor [e.g. 13-19]. To increase the fill factor it might be very promising to grade the material properties at the $\mathrm{p}-\mathrm{i}$ interface, as abrupt changes will result in more recombination at these interfaces. Therefore, it can also be advantageous to have a p-layer with another (lower) optical bandgap. The absorption-loss in the p-layer can be compensated by a higher fill factor and the increased absorption in the intrinsic layer due to the lower bandgap. In order to have a p-layer with a lower bandgap the optimisation of the cell also has to include the search towards other type of $\mathrm{p}$-layers such as $\mu \mathrm{c}-\mathrm{SiC}: \mathrm{H}: \mathrm{B}$.

\section{3 n-i-p deposited solar cells}

\subsubsection{Temperature resistant n-type layers}

In contrast to p-type a-Si:H, n-type a-Si:H maintains its properties while deposited at higher temperatures and keeping the other conditions constant. Figure 5.6a shows the growth rate of the layer as a function of the deposition temperature. The growth rate increases slightly with temperature up to $350^{\circ} \mathrm{C}$. Increasing the deposition temperature further to $400^{\circ} \mathrm{C}$ results in a larger increase in growth rate. Figure $5.6 \mathrm{~b}$ shows the refractive index at $2 \mathrm{eV}$ as obtained from RT-measurements. The refractive index shows a similar behaviour as the growth rate: more or less constant below $350^{\circ} \mathrm{C}$ and higher at $400^{\circ} \mathrm{C}$, indicating denser material at that temperature. The same dependence is also observed for the conductivity (Fig. 5.6c). Figure 5.6d and 5.6 e show the activation energy for electron conductivity and the Tauc gap of the n-layer, respectively. These properties are also more or less constant for temperatures $\leq 350^{\circ} \mathrm{C}$ and decrease when deposited at $400^{\circ} \mathrm{C}$. All material properties fulfil the requirements for n-type layers as given by Schropp and Zeman [20].

In general, all material properties presented for the amorphous n-type layer are independent of the deposition temperature below $350^{\circ} \mathrm{C}$. The change at $400^{\circ} \mathrm{C}$ can be ascribed to a decrease in hydrogen content in the film. Effusion experiments [21] by Beyer have shown that hydrogen diffuses out of the a-Si network in the temperature range between $200^{\circ} \mathrm{C}$ and $500^{\circ} \mathrm{C}$, depending on the composition of the film [22]. The bandgap decreases [23] and correspondingly the conductivity increases. 

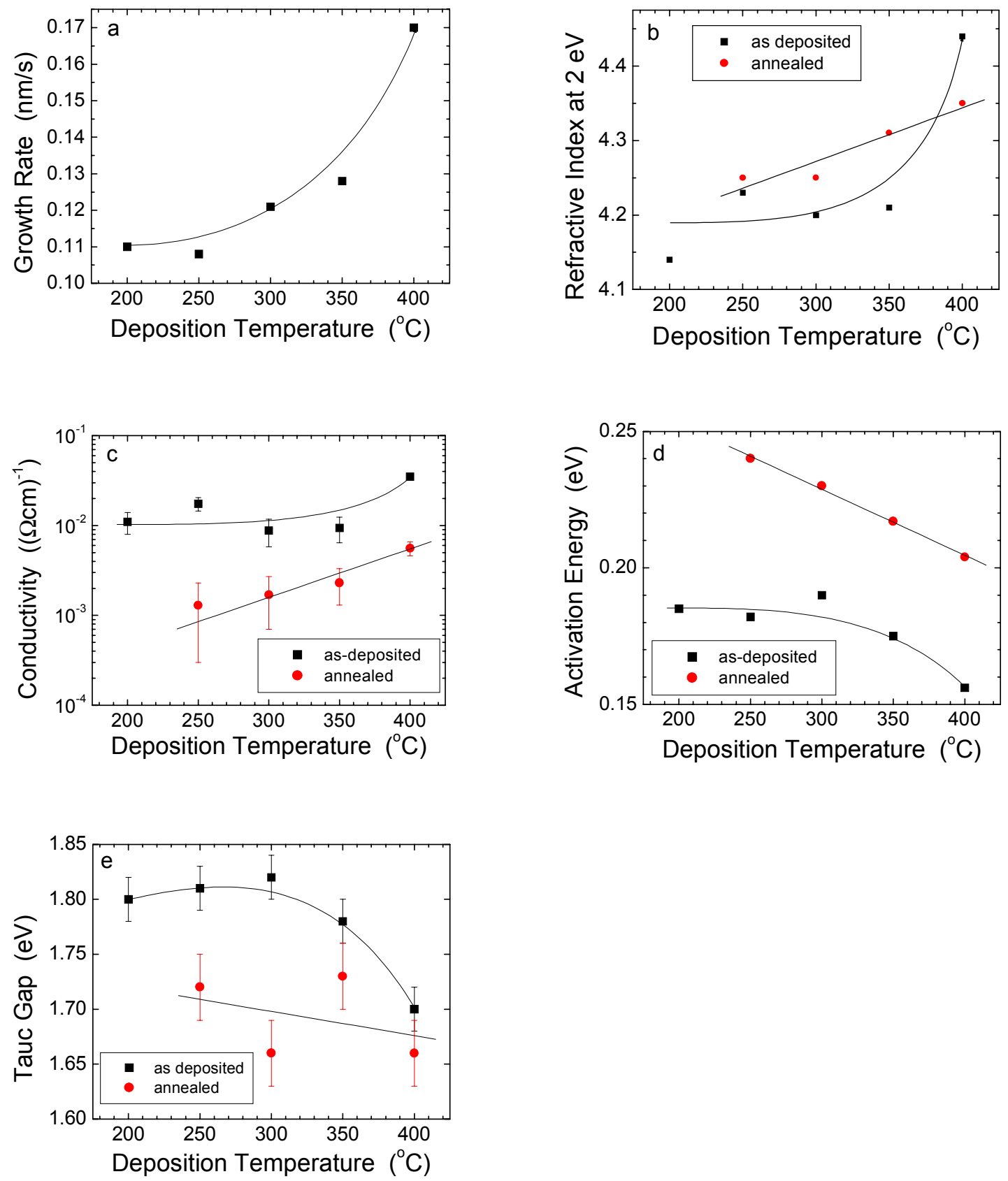

Figure 5.6: Growth rate (a), refractive index at $2 \mathrm{eV}$ (b), Tauc gap (c), activation energy for electrons (d), and the conductivity (e) of n-type a-Si:H as a function of the deposition temperature before and after an anneal treatment at $400^{\circ} \mathrm{C}$. The lines are a guide to the eye.

However, the dependence on deposition temperature is different for intrinsic a-Si:H where a more continuous increase or decrease of the parameters is observed as a function of the deposition temperature [24]. It is possible that the phosphorus blocks the hydrogen motion in the a-Si:H network [25]. This makes the n-layer more favourable for use at higher temperature than the p-layer as boron improves the hydrogen diffusion in the a-Si:H network $[21,22,26]$. Another important aspect regarding hydrogen out-diffusion is that the $p$-i interface has much more influence on 
the solar cell performance than the i-n interface $[14,27,28]$. Therefore a reduction of the hydrogen content in the n-layer will not be as detrimental.

It should be noted that annealing of the layers for 1 hour at a temperature of $400^{\circ} \mathrm{C}$ results in a change of the properties due to $\mathrm{H}$ out-diffusion. This $\mathrm{H}$ out-diffusion manifests itself at the surface as craters as the $\mathrm{H}$ tends to form bubbles inside the material before it comes out [29]. The effects due to annealing on the material properties are also displayed in Figure 5.6. The $\mathrm{H}$ out-diffusion is mainly seen by a reduction of the optical gap and more defects in the films, reducing the conductivity and increasing the activation energy.

Regarding an anneal treatment at $400^{\circ} \mathrm{C}$ it is better to use a microcrystalline n-type layer. This layer can be made at temperatures between $200^{\circ} \mathrm{C}$ and $300^{\circ} \mathrm{C}$. At temperatures lower than $200^{\circ} \mathrm{C}$ and larger than $300^{\circ} \mathrm{C}$ the same conditions (Table 4.2) resulted in an amorphous n-type layer with a conductivity of $\sim 10^{-5}(\Omega \mathrm{cm})^{-1}$ and an activation energy for electron conductivity of $\sim 0.4 \mathrm{eV}$. Others have also observed this temperature dependence for the growth of microcrystalline material [30,31]. However, when the microcrystalline n-type layers are annealed for 1 hour at $400^{\circ} \mathrm{C}$, the conductivity properties are not influenced resulting in a conductivity $>3(\Omega \mathrm{cm})^{-1}$ and an activation energy of $\sim 0.03 \mathrm{eV}$. The optical properties are still influenced as these properties are mainly determined by the amorphous fraction in the layer, resulting in a decrease of the optical Tauc gap and thus more absorption in this layer.

\section{$\underline{\text { 5.3.2 Solar cells }}$}

$\mathrm{N}$-i-p solar cells were grown on a stainless steel foil (thickness $\sim 0.2 \mathrm{~mm}$ ) starting with a $50 \mathrm{~nm}$ thick amorphous n-type layer, followed by the intrinsic layer, and a $20 \mathrm{~nm}$ thick p-type layer. As a front contact $\mathrm{ZnO}$ or $\mathrm{ZnO}: \mathrm{Al}$ is used with a thickness of $1 \mu \mathrm{m}$. These layers are deposited using a cascaded arc expanding thermal plasma [32]. The lateral conductivity of the $\mathrm{ZnO}$ and $\mathrm{ZnO}: \mathrm{Al}$ is similar to the lateral conductivity of Asahi U-type TCO and the transmission is $>80 \%$ [33]. These values fulfil the requirements for a good TCO $[14,20]$. The aim was to deposit these layers at a temperature of $200^{\circ} \mathrm{C}$, but due to poor temperature control this temperature could have been easily $200^{\circ} \mathrm{C}$ higher. The area of the cell is defined by the area of the $\mathrm{ZnO}(: \mathrm{Al})$, using a shadow mask. The contact probes are placed at the corner of the $\mathrm{ZnO}(: \mathrm{Al})$ contact, which results in a small reduction of the illuminated cell area.

Rech et al. [15] has shown that good solar cells can be obtained using $\mathrm{ZnO}: \mathrm{Al}$ as TCO at the top of the cell. However, due to a poor temperature control during the $\mathrm{ZnO}: \mathrm{Al}$ deposition the cells that were not short-circuited showed hardly any solar cell behaviour, achieving fill factors ranging from 0.25 to 0.27 . Remarkably, those cells have a respectable open-circuit voltage $(\sim 0.6 \mathrm{~V})$ and a short-circuit current density ranging from $8.0 \mathrm{~mA} / \mathrm{cm}^{2}$ to $18.0 \mathrm{~mA} / \mathrm{cm}^{2}$, without accounting for the reduction of the illuminated area due to the contact between the $\mathrm{ZnO}(: \mathrm{Al})$ and the probe. So the cells that are not short-circuited have probably a high series resistance. However, as the illuminated $J, V$-measurements do provide a short-circuit current density and an open-circuit voltage a short comparison between various solar cells might still be valid on those parameters. Note that the measured current density rules out shunting and thus that the low fill factor cannot be attributed to a low parallel resistance.

Two $n-i-p$ reference cells have been grown in the UHV AMOR system. One cell is covered with $\mathrm{ZnO}$ and one with $\mathrm{ZnO}: \mathrm{Al}$ as TCO. The cell using $\mathrm{ZnO}: \mathrm{Al}$ has an 
efficiency of $2.4 \%$ (Fig. 5.7), mainly due to the very low fill factor. The open-circuit voltage and short-circuit current are slightly lower than for the p-i-n grown cells that normally give $\sim 10 \%$ efficiency. The $V_{\text {oc }}=0.66 \mathrm{~V}$ instead of $0.75 \mathrm{~V}$ and the $J_{\mathrm{sc}}=14.8$ $\mathrm{mA} / \mathrm{cm}^{2}$ instead of $16 \mathrm{~mA} / \mathrm{cm}^{2}$. The difference between the $\mathrm{ZnO}$ and the $\mathrm{ZnO}: \mathrm{Al}$ is in the current density which is for $\mathrm{ZnO}: \mathrm{Al}$ is $\sim 2 \mathrm{~mA} / \mathrm{cm}^{2}$ larger. The positive influence of $\mathrm{ZnO}: \mathrm{Al}$ on the current density was also reported by Rech et al. [15].

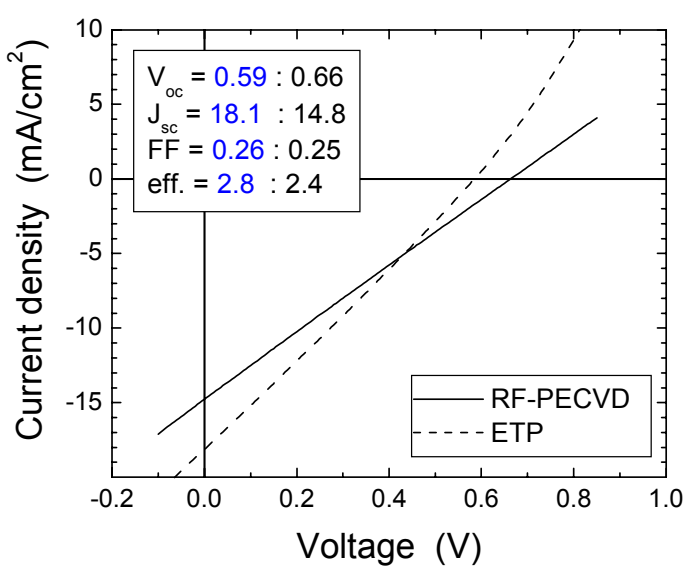

Figure 5.7: Illuminated J,V-characteristics of $n$-i-p cells grown on stainless steel. Note that a shortcircuited (or shunted) cell will also give a straight line, but such a line goes close to the origin of the graph. These cells have an a-Si:H n-layer of $\sim 20 \mathrm{~nm}, 400 \mathrm{~nm}$ intrinsic, and $12 \mathrm{~nm}$ p-layer. The values on the left correspond to the ETP cell and the values on the right to the RF-PECVD cell.

Several n-i-p solar cells have been grown using the ETP method. The $n-i-p$ cell with the intrinsic layer of a-Si:H deposited at $350^{\circ} \mathrm{C}$ and $1.5 \mathrm{~nm} / \mathrm{s}$ (bandgap $\sim 1.73$ $\mathrm{eV}$ ) gave the most interesting results. This cell achieved a $V_{\mathrm{oc}}$ of $0.59 \mathrm{~V}$ and a $J_{\mathrm{sc}}$ of $18.1 \mathrm{~mA} / \mathrm{cm}^{2}$, resulting in an initial efficiency of $2.8 \%$ despite the low fill factor of 0.26 (Fig. 5.7). Especially the larger current compared to the RF-PECVD cell makes this cell very interesting, indicating that more electron-hole pairs are collected at the contacts under short-circuit conditions. Two possible aspects can explain the higher current density. Firstly, the lower bandgap of the intrinsic layer of the ETP cell will increase the current density (Fig. 5.3c), and secondly, it may be possible that this intrinsic layer exhibits less recombination. The bandgap can account for a large part of the higher current density, but not completely (Fig. 5.3c). We assume that the conditions used to deposit the intrinsic layer $\left(800 \mathrm{nccm} \mathrm{Ar,} 200 \mathrm{nccm} \mathrm{\textrm {H } _ { 2 }}\right.$ in the arc, $200 \mathrm{nccm} \mathrm{H}_{2}$ in the nozzle, $115 \mathrm{nccm} \mathrm{SiH}_{4}, 35 \mathrm{~A}, 350^{\circ} \mathrm{C}$, and $1.5 \mathrm{~nm} / \mathrm{s}$ ) are conditions for which the higher hole mobility will be found (Section 1.3). As the hole mobility in a-Si:H is the limiting factor in solar cells [e.g. 16,34] a variation of this property can also have influence on the short-circuit current.

\section{4 (p-)i-n deposited solar cells}

A way to avoid the deterioration of the p-layer by growing at higher substrate temperature is by leaving the p-layer out of the cell and making i-n cells. This will give very low solar cell performances, but the characteristics can be compared, as only the intrinsic layer is different. Table 5.2 compares the results of an intrinsic layer deposited at $250^{\circ} \mathrm{C}$ and a growth rate of $\sim 0.85 \mathrm{~nm} / \mathrm{s}$ with an intrinsic layer deposited 
at $400^{\circ} \mathrm{C}$ and a growth rate of $\sim 1.4 \mathrm{~nm} / \mathrm{s}$. The fill factor and the current density are about the same for both cells, and the difference is in the open-circuit voltage. The open-circuit voltage is mainly influenced by the optical bandgap of the intrinsic layer, which is $\sim 1.8 \mathrm{eV}$ for the layer deposited at $250^{\circ} \mathrm{C}$ and $\sim 1.7 \mathrm{eV}$ for the layer deposited at $400^{\circ} \mathrm{C}$. From Figure 5.3 it is clear that this difference in $V_{\text {oc }}$ is expected due to the bandgap, resulting in a lower $V_{\text {oc }}$ at a smaller bandgap. Furthermore, it is expected that for the cell with the intrinsic layer deposited at $400^{\circ} \mathrm{C}$ the short-circuit current density will be higher and the fill factor lower than for the cell with the intrinsic layer deposited at $250^{\circ} \mathrm{C}$, due to the lower bandgap at $400^{\circ} \mathrm{C}$ (Fig. 5.3). This, however, is not observed. One possible explanation for this may be that the simulations use data based on intrinsic films grown at growth rates $<1 \mathrm{~nm} / \mathrm{s}$, for which the optimum growth rate is between $250^{\circ} \mathrm{C}$ and $300^{\circ} \mathrm{C}$ and does not account for possible differences in microstructure as expected from Section 1.3. In order to improve the cell deposited at $1.4 \mathrm{~nm} / \mathrm{s}$ the $V_{\text {oc }}$ has to be improved, which can be achieved by using bandgap grading at the TCO/i interface. From this experiment it can be concluded that at larger growth rate and high deposition temperature solar cells can be made as good as at smaller growth rate and low deposition temperatures if it is possible to protect the p-layer.

Table 5.2: Solar cell characteristics of i-n cells for a cells with the intrinsic layer deposited at $\sim 0.85$ $\mathrm{nm} / \mathrm{s}$ and $250^{\circ} \mathrm{C}$, and a cell with the intrinsic layer deposited at $\sim 1.4 \mathrm{~nm} / \mathrm{s}$ and $400^{\circ} \mathrm{C}$. The intrinsic layers are $\sim 400 \mathrm{~nm}$ thick.

\begin{tabular}{|l|c|c|}
\hline & $0.85 \mathrm{~nm} / \mathrm{s}, 250^{\circ} \mathrm{C}$ & $1.4 \mathrm{~nm} / \mathrm{s}, 400^{\circ} \mathrm{C}$ \\
\hline$J_{\mathrm{sc}}\left(\mathrm{mA} / \mathrm{cm}^{2}\right)$ & 12.4 & 11.8 \\
\hline$V_{\mathrm{oc}}(\mathrm{V})$ & 0.39 & 0.34 \\
\hline $\mathrm{FF}$ & 0.45 & 0.43 \\
\hline Efficiency (\%) & 2.2 & 1.7 \\
\hline
\end{tabular}

A way to try to protect the p-type layer from the higher temperature is by using an intermediate layer [35]. Preliminary results are presented in Figure 5.8, showing the illuminated $J, V$-curves for two solar cells. Both solar cells have an intrinsic layer with a thickness of $400 \mathrm{~nm}$ deposited at $350^{\circ} \mathrm{C}$ and a deposition rate of $1.3 \mathrm{~nm} / \mathrm{s}$. One of the cells contains a buffer layer of $50 \mathrm{~nm}$, deposited at $200^{\circ} \mathrm{C}$, between the $\mathrm{p}$ layer and the intrinsic layer ${ }^{31}$. The buffer layer was deposited by RF-PECVD and has a bandgap of $\sim 1.8 \mathrm{eV}$, whereas the ETP layer has a bandgap of $\sim 1.72 \mathrm{eV}$. Figure 5.8 shows clearly the lower $V_{\text {oc }}$ when no buffer layer is applied, in accordance with the results presented in other chapters. By applying a buffer layer the $V_{\text {oc }}$ increases significantly, the $J_{\text {sc }}$ decreases, and the fill factor increases slightly. The decrease in $J_{\text {sc }}$ can be contributed to the higher bandgap of the material for the first $50 \mathrm{~nm}$. The increase in $V_{\text {oc }}$ is especially interesting. This indicates that the $50 \mathrm{~nm}$ somehow serves as a buffer for the $\mathrm{H}$ out-diffusion [35] and hence protects the p-type layer. Mahan et al. [35] even use a $100 \mathrm{~nm}$ buffer layer, which might be necessary as the $V_{\text {oc }}$ is still $0.05 \mathrm{~V}$ to $0.1 \mathrm{~V}$ lower than obtained for cells for which low deposition temperatures are used for the intrinsic layer ${ }^{32}$.

\footnotetext{
${ }^{31}$ Note that the cell with the buffer layer has an intrinsic layer with a total thickness of $450 \mathrm{~nm}$.
} 


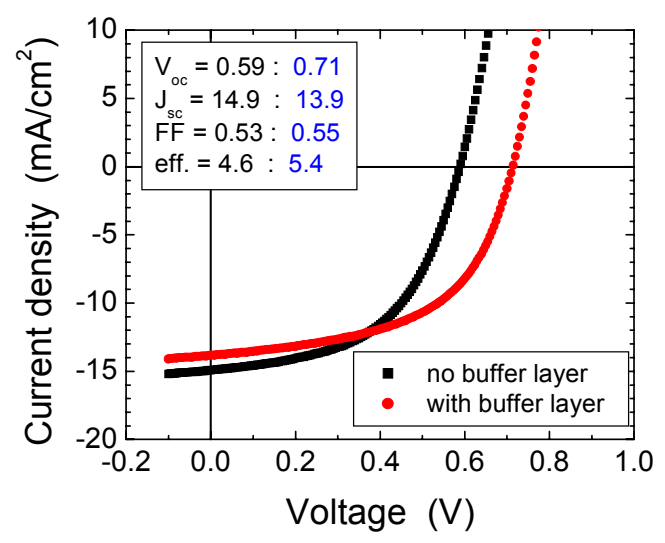

Figure 5.8: Illuminated J,V-curve for a solar cell with the intrinsic layer deposited at $1.4 \mathrm{~nm} / \mathrm{s}$ and $350^{\circ} \mathrm{C}$, with and without a $50 \mathrm{~nm}$ thick intermediate layer between the $p$ - and i-layer. The cells consist of a $12 \mathrm{~nm}$ thick p-layer, a 400 $\mathrm{nm}$ intrinsic ETP layer, and a $20 \mathrm{~nm}$ n-layer.

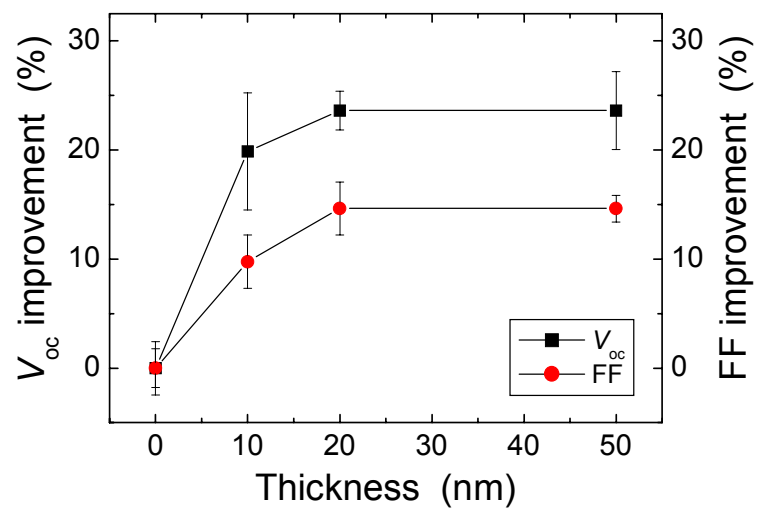

Figure 5.9: Open-circuit voltage and fill factor as a function of the buffer layer thickness for cells with the intrinsic layer deposited at $2.3 \mathrm{~nm} / \mathrm{s}$ and $400^{\circ} \mathrm{C}$. The cells consist of a $12 \mathrm{~nm}$ thick p-layer, in total a $400 \mathrm{~nm}$ intrinsic layer, and a $20 \mathrm{~nm} \mathrm{n}$ layer. The improvement is with regard to the value when no buffer layer is applied.

In Figure 5.9 the results for varying buffer layer thickness are presented for solar cells in which an intrinsic layer is incorporated that is deposited at $2.3 \mathrm{~nm} / \mathrm{s}$ and $400^{\circ} \mathrm{C}$. The buffer layer thickness is varied from $0 \mathrm{~nm}$ to $50 \mathrm{~nm}$ and the total i-layer thickness is kept constant at $400 \mathrm{~nm}$. A similar buffer layer is used as for the experiment presented in Figure 5.8. Figure 5.9 clearly shows a large increase in $V_{\text {oc }}$ when a buffer layer of $\sim 10 \mathrm{~nm}$ is applied and does not increase much for thicker buffer layers. It is important to note that the $V_{\text {oc }}$ seems to saturate at $\sim 0.7 \mathrm{~V}$, which is $\sim 0.1 \mathrm{~V}$ lower than obtained for cells with the intrinsic layer deposited at deposition temperatures of $\sim 250^{\circ} \mathrm{C}^{32}$. The fill factor shows similar behaviour as presented in Figure 4.15, i.e., increasing when a buffer layer is applied. Further research on the material properties of the buffer layer is required.

\subsection{Conclusions}

At larger deposition rates higher substrate temperatures are required to obtain solar grade material. However, deposition temperatures $>250^{\circ} \mathrm{C}$ lead to a deterioration of the p-layer properties such that the $V_{\text {oc }}$ will decrease and a high efficiency cannot be achieved (Section 4.3). To overcome the deterioration of the p-layer a protective layer on top of the p-layer can be deposited, or the solar cell can be grown in the $n$-i$\mathrm{p}$ sequence, as the n-layer can be made temperature resistant. The best option for a temperature resistant n-type layer would be to use a microcrystalline n-type layer as $\mathrm{H}$ out-diffusion of the amorphous layers results in craters in the film. The i-n structure with the i-layer deposited at $1.4 \mathrm{~nm} / \mathrm{s}$ exhibits good performance compared with the cell deposited at lower growth rate and lower substrate temperature. A $50 \mathrm{~nm}$ thick buffer layer in between the $p$ - and i-layer is successful as the $V_{\text {oc }}$ is higher than when no buffer layer is applied. Preliminary results on $n-i-p$ solar cells show that a cell with

\footnotetext{
${ }^{32}$ Note that a $V_{\text {oc }}$ of $\sim 0.8 \mathrm{~V}$ is not expected as the bandgap of the intrinsic material is lower $(\sim 1.72 \mathrm{eV})$.
} 
the intrinsic layer deposited at $1.5 \mathrm{~nm} / \mathrm{s}$ and $350^{\circ} \mathrm{C}$ achieved a very high short-circuit current and an initial efficiency of $2.8 \%$. However, those cells have a very low fill factor ( 0.26), indicating that the cells have probably a large series resistance. This large series resistance is probably caused by the contact between p-layer and the $\mathrm{ZnO}(: \mathrm{Al})$ due to poor temperature control. The larger current can be partly explained by the lower optical gap and the other part may be explained by the possible larger hole drift mobility that is expected for the a-Si:H that forms the intrinsic layer. This again is an indication that ETP material grown at high temperature and large growth rate $(>1 \mathrm{~nm} / \mathrm{s}$ ) is interesting material to be used in a-Si:H thin film solar cells. Therefore it will be very interesting to carry out more experiments using conditions of larger growth rates at higher temperature using the ETP method. This implies research towards temperature stable p-type layers for the use in $p$-i-n solar cells, buffer layers in between the $p$-layer and the intrinsic layer to protect the p-layer from higher temperatures, and a reduction of the series resistance in n-i-p solar cells.

Another important issue is the lower optical bandgap of material deposited at higher substrate temperature. Simulations show that a lower bandgap of the intrinsic material decreases the fill factor and the open-circuit voltage. An optimum between 1.8 and $1.85 \mathrm{eV}$ for the bandgap of intrinsic a-Si:H is found for solar cells, though it is reported that cells with a lower bandgap degrade less due to light soaking. In order to use the larger growth rate a-Si:H from the ETP deposited at higher substrate temperature, modifications of the existing $p$-i-n structure should be incorporated as this a-Si:H usually has a smaller bandgap. Other $\mathrm{p}$ - and/or n-layers in combination with intermediate layers near the $p$-i interface, as well as bandgap grading near the $\mathrm{p}-\mathrm{i}$ interface seem logical options that have to be investigated.

\section{References}

1. T. Roschek, T. Repmann, J. Muller, B. Rech, and H. Wagner, Proc. of $28^{\text {th }}$ IEEEPVSC (2000) 150

2. V.L. Dalal, S. Kaushal, R. Knox, K. Han, and F. Martin, J. Non-Cryst. Sol., 198200 (1996) 1101

3. P.A. Fedders and D.A. Drabold, J. Non-Cryst. Sol., 227-230 (1998) 376

4. A.H. Mahan, Y. Xu, B.P. Nelson, R.S. Crandall, J.D. Cohen, K.C. Palinginis, and A.C. Gallagher, Appl. Phys. Lett., 78 (2001) 3788

5. S. Wagner, X. Xu, X.R. Li, D.S. Shen, M. Isomura, M. Bennett, A.E. Delahoy, X. Li, J.K. Arch, J.-L. Nicque, and S.J. Fonash, Proc. of $22^{\text {nd }}$ IEEE-PVSC (1991) 1307

6. G. Yue, J.D. Lorentzen, J. Lin, D. Han, and Q. Wang, Appl. Phys. Lett., 75 (1999) 492

7. C. Smit, E.A.G. Hamers, B.A. Korevaar, R.A.C.M.M. van Swaaij, and M.C.M. van de Sanden, Proc. $4^{\text {th }}$ SAFE conference (2001)

8. W.M.M. Kessels, M.C.M. van de Sanden, and D.C. Schram, J. Vac. Sci. Technol. A, 18 (2000) 2153

9. B.A. Korevaar, G.J. Adriaenssens, A.H.M. Smets, W.M.M. Kessels, H.-Z. Song, M.C.M. van de Sanden, and D.C. Schram, J. Non-Cryst. Sol., 266-269 (2000) 380

10. R.J. Koval, J.M. Pearce, A.S. Ferlauto, R.W. Collins, and C.R. Wronski, Mat. Res. Soc. Symp. Proc., 664 (2001) A16.4

11. T. Yoshida, S. Fujikake, H. Shimabukuro, Y. Ichikawa, and H. Sakai, Proc. of $20^{\text {th }}$ IEEE-PVSC (1988) 335 
12. M. Stutzmann, Philosophical Magazine B, 60 (1989) 531

13. A. Nuruddin and J.R. Abelson, Appl. Phys. Lett., 71 (1997) 2797

14. C. Beneking, B. Rech, S. Wieder, O. Kluth, H. Wagner, W. Frammelsberger, R. Geyer, P. Lechner, H. Rübel, and H. Schade, Thin Solid Films, 351 (1999) 241

15. B. Rech, S. Wieder, C. Beneking, A. Löffl, O. Kluth, W. Reetz, and H. Wagner, Proc. of $26^{\text {th }}$ IEEE-PVSC (1997) 619

16. S.S. Hegedus, Proc. of $20^{\text {th }}$ IEEE-PVSC (1988) 102

17. Q. Wang, E. Iwaniczko, Y. Xu, B.P. Nelson, A.H. Mahan, R.S. Crandall, and H.M. Branz, Proc. of $28^{\text {th }}$ IEEE-PVSC (2000) 717

18. J. Yang, B. Yan, J. Smeets, and S. Guha, Mat. Res. Soc. Symp. Proc., 664 (2001) A11.3

19. J.M. Pearce, R.J. Koval, A.S. Ferlauto, R.W. Collins, C.R. Wronski, J. Yang, and S. Guha, Appl. Phys. Lett., 77 (2000) 3093

20. R.E.I. Schropp and M. Zeman, Amorphous and microcrystalline silicon solar cells, Kluwer Academic Publishers (1998) Boston/Dordrecht/London

21. W. Beyer and H. Wagner, J. de Physique, 42 (1981) 783; W. Beyer, J. Herion, H. Wagner, and U. Zastrow, Philos. Mag., B63 (1991) 269

22. W. Beyer, Mat. Res. Soc. Symp. Proc., 664 (2001) A9.2

23. C.M. Fortmann, Phys. Rev. Lett., 81 (1998) 3683

24. A.H.M. Smets, Ph. D. thesis, Eindhoven University of Technology (2002)

25. R.A. Street, Hydrogenated amorphous silicon, Cambridge University Press, (1991)

26. D.E. Carlson, M. Gleaton, and G. Ganguly, Proc. of $16^{\text {th }}$ E-PVSEC (2000) VB1.23

27. P. Roca i Cabarrocas, M. Favre, P. Morin, P. Sladek, and P. Stahel, Proc. of $13^{\text {th }}$ PVSEC (1995) 605

28. D.E. Carlson, Crit. Rev. Solid State, 16 (1990) 117

29. H. Matsumura, Proc. of SID conference (1998)

30. R. van Oort, Ph. D. thesis, Delft University of Technology (1989)

31. O. Vetterl, R. Carius, L. Houben, C. Scholten, M. Luysberg, A. Lambertz, F. Finger, and H. Wagner, Mat. Res. Soc. Symp. Proc., 609 (2000) A15.2

32. R. Groenen, J.L. Linden, H.R.M. van Lierop, D.C. Schram, A.D. Kuypers, and M.C.M. van de Sanden, Appl. Surf. Sci., 173 (2001) 40

33. J. Loeffler, R. Groenen, J.L. Linden, M.C.M. van de Sanden, and R.E.I. Schropp, Thin Solid Films, 392 (2001) 315

34. G. Muller, M. Simon, and G. Winterling, Proc. of $16^{\text {th }}$ IEEE-PVSC (1982) 1129

35. A.H. Mahan, R.C. Reedy, E. Iwaniczko, Q. Wang, B.P. Nelson, Y. Xu, A.C. Gallagher, H.M. Branz, R.S. Crandall, J. Yang, and S. Guha, Mat. Res. Soc. Symp. Proc., 507 (1998) 119 
Chapter 6

6. Concluding remarks 


\subsection{General conclusions}

A new set-up has been built, consisting of three vacuum chambers, i.e., a load-lock, an RF-PECVD deposition chamber, and an expanding thermal plasma (ETP) deposition chamber. In this new set-up, named CASCADE, intrinsic a-Si:H deposited with the ETP method can be incorporated into solar cells without having a vacuum break in between the deposition of the doped layers and the intrinsic layers. The total gas flow in the ETP chamber has been reduced by a factor three compared to an older set-up. The doped layers are deposited in the RF-PECVD chamber and the properties are similar to properties obtained by other groups.

With the cascaded arc ETP method a wide range of growth rates for intrinsic $\mathrm{a}-\mathrm{Si}: \mathrm{H}$ can be covered. A good measure for the material quality of intrinsic a-Si:H is the photoconductivity. It is shown that the photoconductivity is a function of the growth rate in combination with the deposition temperature, i.e., a larger growth rate requires a higher deposition temperature to obtain an optimum in photoconductivity. However, this optimum in deposition temperature is not only governed by the growth rate, but is also governed by the plasma composition [1]. Two regimes are considered: 1) small growth rate ${ }^{33}$, low deposition temperature $\left(<1 \mathrm{~nm} / \mathrm{s}, \leq 250^{\circ} \mathrm{C}\right)$, and 2) large growth rate, high deposition temperature $\left(>1 \mathrm{~nm} / \mathrm{s},>250^{\circ} \mathrm{C}\right)$.

In the small growth rate regime the bulk properties for intrinsic a-Si:H made with the ETP method are similar to those obtained with RF-PECVD at $0.2 \mathrm{~nm} / \mathrm{s}$ and $200^{\circ} \mathrm{C}$. However, when incorporating an intrinsic layer deposited at $0.85 \mathrm{~nm} / \mathrm{s}$ and $250^{\circ} \mathrm{C}$ into a solar cell the initial efficiency is $\sim 6.7 \%$ and the degraded efficiency is $\sim 3.1 \%$. Both the initial and the degraded efficiencies are lower than obtained with RF-PECVD, mainly due to a lower fill factor for the ETP cells. Simulations have shown that by assuming extra defects at the $p-i$ interface the fill factor of the solar cell decreases. However, deterioration of the very thin p-layer in the solar cell cannot be excluded. A highly defective region near the $p$-i interface of the solar cell is undesirable, because this region is particularly sensitive for defects. To overcome a defective layer or deterioration of the p-layer a buffer layer deposited with RFPECVD at $0.2 \mathrm{~nm} / \mathrm{s}$ and $200^{\circ} \mathrm{C}$ has been incorporated between the p-layer and the intrinsic layer as deposited with the ETP method. A $5 \mathrm{~nm}$ thick buffer layer already results in $\sim 10 \%$ increase in fill factor and a somewhat larger open-circuit voltage. Therefore, a buffer layer at the $p$-i interface has a positive effect for the solar cell performance when the intrinsic layer is deposited with the ETP.

In the large growth rate regime, the high deposition temperature results in a hydrogen concentration of $6-8 \%$ and a bandgap $<1.7 \mathrm{eV}$, while it is $\sim 10 \%$ and 1.8 $\mathrm{eV}$, respectively, for RF-PECVD a-Si:H deposited at $200^{\circ} \mathrm{C}$. Simulations indicate that the short-circuit current increases with decreasing optical gap, the open-circuit voltage is lower and, more importantly, the fill factor is lower. Effectively a bandgap of $1.7 \mathrm{eV}$ will result in a lower initial efficiency when no changes in cell design are applied. Besides the lower optical bandgap, the high deposition temperature itself also has a more direct effect on the solar cell, i.e., the properties of the p-layer are negatively influenced by the high temperature due to hydrogen out-diffusion out of the p-layer. Effectively this results in a decrease in the open-circuit voltage. Again a buffer layer is applied between the p-layer and the intrinsic layer. With increasing buffer layer thickness the p-layer is better protected from the high temperature, i.e., the out-diffusion of hydrogen is reduced. The incorporation of a buffer layer results in

\footnotetext{
${ }^{33}$ Small growth rate is here still $\sim 4$ times faster than obtained with RF-PECVD.
} 
an increase in the fill factor and a large increase in the open-circuit voltage (from < $0.6 \mathrm{~V}$ to $>0.7 \mathrm{~V}$ ) with increasing buffer layer thickness. Furthermore, the short-circuit current density is somewhat lower, due to the higher bandgap of the buffer layer.

The goal of the project to deposit solar cells with an initial efficiency of $7 \%$ with the intrinsic layer deposited at $2 \mathrm{~nm} / \mathrm{s}$ is not yet reached. So far, good quality a-Si:H is made at growth rates $>2 \mathrm{~nm} / \mathrm{s}$ in the new set-up, while maintaining homogeneous deposition over an area with a diameter $>7 \mathrm{~cm}$. Preliminary results achieved efficiencies $>5 \%$, applying a buffer layer in between the $p$ - and i-layer.

\subsection{Recommendations for future research}

For cells made with the ETP method the initial efficiency can increase by applying a suitable buffer layer in between the p-layer and the intrinsic layer. So far, this buffer layer has been deposited with RF-PECVD from pure $\mathrm{SiH}_{4}$ and has an optical gap of $\sim 1.8 \mathrm{eV}$. Several options have to be investigated to optimise the buffer layer for solar cell performance, e.g., a buffer layer that is made denser by using $\mathrm{H}_{2}$ dilution, or a layer with an increased bandgap due to carbon incorporation. Denser material can result in a further reduction of the hydrogen diffusion, and the bandgap of the buffer layer will have influence on the open-circuit voltage of the cell [e.g. 2]. By incorporating a good buffer layer it must be possible to improve the initial efficiency to $\sim 8 \%$ for cells with the intrinsic layer deposited at growth rate $<1 \mathrm{~nm} / \mathrm{s}$ and deposition temperatures $\leq 250^{\circ} \mathrm{C}$. Furthermore, it is also important to investigate the effect of a buffer layer on the degradation. The $6.7 \%$ cell degraded more than $50 \%$, which needs to improve. If this degradation is indeed a consequence of the defects at the interface, then a buffer layer is expected to result in less degradation.

However, for cells in which the intrinsic layers require high deposition temperatures two routes can be chosen. Firstly, make p-i-n structures and overcome the detrimental effect of the high temperature on the p-layer. This research includes p-type layers that are more temperature resistant or the use of a buffer layer to protect the p-layer. However, the latter is less favourable when the process is optimised with regard to roll-to-roll processing. Furthermore, it is necessary to optimise the bandgap of the doped layers (and especially the p-layer) regarding the low bandgap of the highly structured material deposited at large growth rates $(\geq 2$ $\mathrm{nm} / \mathrm{s})$ and high deposition temperature $\left(\sim 400^{\circ} \mathrm{C}\right)$ with the ETP method. Secondly, it is essential to continu the research of $n-i-p$ structures, because microcrystalline $n$ type layers can be made temperature resistant up to $400^{\circ} \mathrm{C}$. Furthermore, in $n-i-p$ cells the region where most of the generation of charge carriers occurs and thus where the recombination peak will be found, i.e., near the p-i interface [3], is separated from the region where extra defects are created, assuming that initial growth results in a highly defective layer.

So far, only single-junction solar cells have been made in the CASCADE system. Once single-junction cells can be made at reproducible efficiencies the next step would be to make double-junction cells. Hydrogenated microcrystalline silicon can be used as intrinsic material in the bottom cell. This material can also be made with the ETP method [4], but some effort is still required before the material can be made dense enough. 
In conclusion, the outlook for higher efficiency cells with the ETP method at growth rates ranging from 0.2 to $10 \mathrm{~nm} / \mathrm{s}$ is promising. This will be made possible by carrying out more research and optimising the cell structure.

\section{References}

1. W.M.M. Kessels, Ph. D. Thesis, Eindhoven University of Technology (2000);

2. A. Nuruddin and J.R. Abelson, Thin Solid Films, 394 (2001) 49

3. M.A. Kroon and R.A.C.M.M. van Swaaij, J. Appl. Phys., 90 (2001) 994

4. C. Smit, E.A.G. Hamers, B.A. Korevaar, R.A.C.M.M. van Swaaij, and M.C.M. van de Sanden, J. Non. Cryst. Sol., accepted for publication 


\section{Appendix : Influence of the distance between arc plasma source and substrate}

An important parameter that can be changed in the new set-up, and which has not been studied before for the deposition of a-Si:H with the ETP method, is the distance from the plasma source to the substrate. This parameter is important because secondary reactions become more important when the distance between the source and the substrate is larger. Two distances from the source to the substrate are investigated: $41 \mathrm{~cm}$ and $63 \mathrm{~cm}$. The results of the refractive index at $2 \mathrm{eV}$ and the optical Tauc bandgap as a function of the deposition temperature are shown in Figure A.1. When the distance from the cascaded arc plasma to the substrate is decreased the refractive index at $2 \mathrm{eV}$ increases and the optical gap decreases. The growth rate also increases from $0.5 \mathrm{~nm} / \mathrm{s}$ to $0.85 \mathrm{~nm} / \mathrm{s}$, which can be explained by the smaller expansion when the source is positioned closer to the substrate, resulting in a smaller deposition area. As the refractive index is directly related to the density and thus to the porosity of the material, it also explains the higher bandgap of the material, as more hydrogen will be in the material when the layer is more porous [e.g. 1]. From these results we conclude that the films grown under the same arc plasma conditions and the same substrate temperature are more porous when the distance from the source to the substrate is larger.
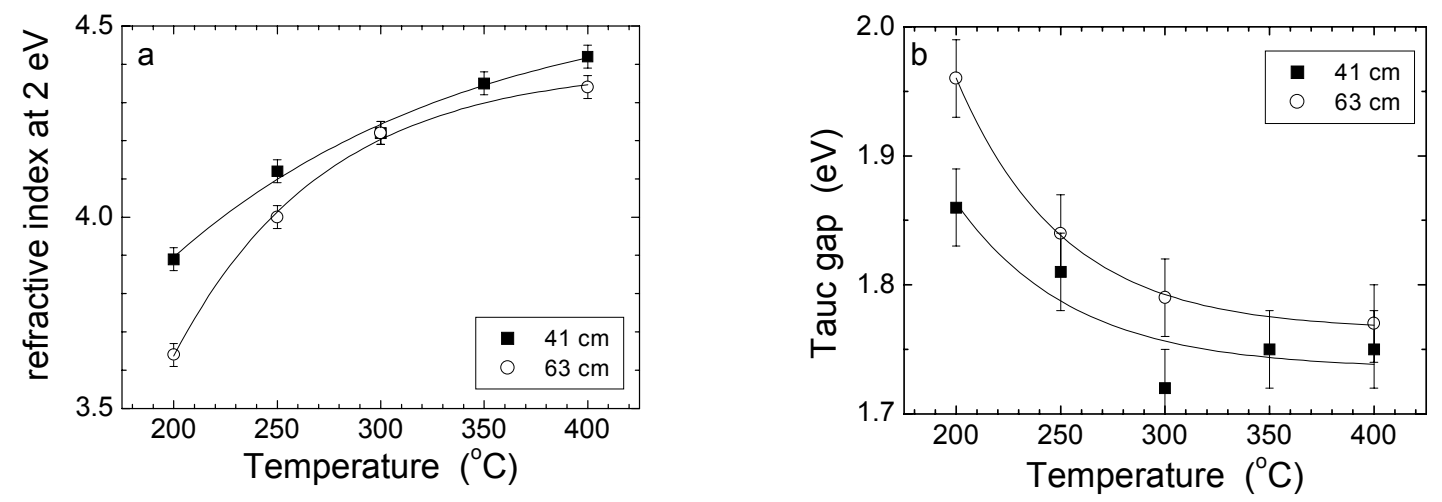

Figure A.1: Refractive index (a) and Tauc gap (b) as function of deposition temperature. The flows were $600 \mathrm{nccm} \mathrm{Ar}, 200 \mathrm{nccm} \mathrm{H}$, and $200 \mathrm{nccm} \mathrm{SiH}_{4}$. The arc current was $40 \mathrm{~A}$ and the chamber pressure $0.16 \mathrm{mbar}$. The lines are a guide to the eye.

This observation is contrary to the first general expectation that faster growth would lead to material that is less structured. Nevertheless, a possible explanation is that the plasma chemistry in which secondary reactions occur could be important to a small extent, although more research is necessary. For example, Kessels et al. [2] have shown that large ion clusters ( $>4$ Si-atoms) are formed in the ETP plasma regardless of the deposition conditions. The reaction that describes this is given by:

$$
\mathrm{Si}_{n} \mathrm{H}_{\mathrm{m}}^{+}+\mathrm{SiH}_{4} \rightarrow \mathrm{Si}_{n+1} \mathrm{H}_{\mathrm{p}}^{+}+\mathrm{qH}_{2}
$$

with $n \geq 1$ and $m+4=p+2 q$. By increasing the silane flow, i.e., increasing the partial silane density and thus decreasing the mean free path of the ion clusters, larger 
clusters are formed [3]. Increasing the distance also means that the reaction probability increases and that larger clusters are formed.

\section{References}

1. C.M. Fortmann, Phys. Rev. Lett., 81 (1998) 3683

2. W.M.M. Kessels, C.M. Leewis, M.C.M. van de Sanden, and D.C. Schram, J. Vac. Sci. Technol. A, 17 (1999) 1531

3. A. Leroux, W.M.M. Kessels, D.C. Schram, and M.C.M. van de Sanden, J. Appl. Phys., 88 (2000) 537 


\section{Summary}

Solar cells are a possible energy source for the future. However, at this moment solar electricity is still more expensive than electricity from oil and gas. Several types of solar cells are available on the market amongst which are solar cells based on hydrogenated amorphous silicon (a-Si:H). A considerable reduction in the production time and thus a reduction in the production costs of a-Si:H solar cells can be realised when the intrinsic layer of this type of solar cells is produced at higher rates.

In previous Ph.D. research at the Eindhoven University of Technology on the expanding thermal plasma (ETP) deposition technique it was shown that a-Si:H can be deposited $\sim 50$ times faster than with the conventional technique, Radio Frequency Plasma Enhanced Chemical Vapour Deposition (RF-PECVD), while maintaining the quality required for incorporation in solar cells. This patented TU/e method uses a thermal plasma that expands in a low-pressure vacuum chamber, which results in a directed transport of reactive particles to the substrate where the a$\mathrm{Si}: \mathrm{H}$ film grows at large growth rates $(0.2-10 \mathrm{~nm} / \mathrm{s})$.

A new set-up has been designed and built in which it is possible to make complete solar cells without vacuum breaks in between the different layers of the $p$-i-n structure. This set-up was named CASCADE, which is the acronym for: Cascaded Arc Solar Cell Apparatus Delft Eindhoven. The project is a co-operation between the Eindhoven and the Delft University of Technology and is financed by NOVEM and TDO. The set-up has been designed and built in Eindhoven by the GTD and the group "Equilibrium and Transport in Plasmas" and placed at the Delft Institute of MicroElectronics and Submicron technology (DIMES) in Delft. The first goal of the project is to realise a-Si:H solar cells with an initial efficiency of $7 \%$ that incorporate an intrinsic layer that has been deposited at a deposition rate larger than $2 \mathrm{~nm} / \mathrm{s}$ with the ETP method.

The material properties of the intrinsic layer depend on the deposition rate and the deposition temperature. To be incorporated into solar cells the intrinsic layer needs to have a low defect density and a high response to light. From the research performed in the new CASCADE set-up it is shown that at a particular deposition rate an optimum in material properties is achieved at a certain deposition temperature. For the conventional technique $(\sim 0.15 \mathrm{~nm} / \mathrm{s})$ this optimum is at $\sim 200^{\circ} \mathrm{C}$. For the larger deposition rates of the ETP method the optimum deposition temperature shifts to $250^{\circ} \mathrm{C}$ and $400^{\circ} \mathrm{C}$ for 1 and $10 \mathrm{~nm} / \mathrm{s}$, respectively.

For $p$-i-n solar cells one has to take care that the deposition temperature of the intrinsic layer is below $250^{\circ} \mathrm{C}$, because at higher temperature the p-layer deteriorates and the cell will not operate very well. At higher deposition temperature the hydrogen diffuses out of the p-layer, which results in an increase in defect density in this layer. This temperature requirement means that the deposition rate is limited to rates $<1 \mathrm{~nm} / \mathrm{s}$ for $\mathrm{p}$-i-n cells. This limitation is avoided for cells deposited in the $n-i-p$ sequence.

P-i-n solar cells have been made in which the intrinsic layer has been deposited at deposition rates of $0.85 \mathrm{~nm} / \mathrm{s}$. The highest achieved initial efficiency at this growth rate is $6.7 \%$. This is $\sim 3 \%$ lower than for very good cells prepared with RFPECVD and only $1.3 \%$ lower than for a cell deposited completely in the RF-PECVD chamber of CASCADE. However, the deposition rate of the i-layer with the ETP method is roughly four times larger. The lower efficiency is due to a lower fill factor, 
which points towards more recombination in the solar cells. However, the bulk defect density of ETP a-Si:H and RF-PECVD a-Si:H are similar. Simulations have shown that a higher defect density in the i-layer near the $p$-i interface can explain the lower fill factor while not affecting the open-circuit voltage and short-circuit current density. A solution to overcome extra defects at the $p$-i interface is to use a buffer layer, which is deposited with RF-PECVD at very low growth rates. From this it is found that a p-layer thickness of $5 \mathrm{~nm}$ already results in an increase in fill factor of more than $10 \%$.

In order to incorporate intrinsic layers deposited at high deposition temperature and large growth rates in p-i-n cells the effect of a buffer layer between the p-layer and the intrinsic layer has been studied. When the higher deposition temperature of the intrinsic layer deteriorates the p-layer the most important difference in the solar cell performance is the lower open-circuit voltage. By applying a buffer layer in such case it is observed that the open-circuit voltage increases drastically with increasing buffer layer thickness and saturates at a buffer layer thickness thicker than $20 \mathrm{~nm}$. However, the saturation value of the open-circuit voltage is not as high as expected from low deposition temperatures, but the increase makes clear that it is possible to protect the p-layer against high deposition temperatures. By applying a buffer layer with a thickness of $50 \mathrm{~nm}$ an initial solar cell efficiency of $5.4 \%$ has been achieved with the i-layer deposited at a deposition temperature of $350^{\circ} \mathrm{C}$ and a deposition rate of $1.3 \mathrm{~nm} / \mathrm{s}$. More research is needed to optimise the buffer layer.

Finally, some investigations are started to make $n-i-p$ solar cells. The advantage of these types of solar cells is that high deposition rates can be used because the n-type layer can be made temperature resistant up to a temperature of $400^{\circ} \mathrm{C}$. So far, an efficiency of $2.8 \%$ is achieved with the i-layer deposited at a deposition temperature of $350^{\circ} \mathrm{C}$ and a deposition rate of $1.5 \mathrm{~nm} / \mathrm{s}$. 


\section{Samenvatting}

Zonnecellen zijn een mogelijke energiebron voor de toekomst. Op het moment is elektriciteit uit zonne-energie nog flink duurder dan elektriciteit uit aardgas en aardolie. Verscheidene typen zonnecellen zijn op de markt, waarvan de amorf silicium zonnecel er één is. Een behoorlijke verkorting van het productieproces en dus een reductie van productiekosten van amorf silicium (a-Si:H) zonnecellen kan gerealiseerd worden als de intrinsieke laag in dit type zonnecel minimaal tien keer zo snel gemaakt zou kunnen worden. Tot dusver werd de totale depositie tijd van de zonnecel voornamelijk bepaald door de depositie van deze intrinsieke laag. Naast een intrinsieke i-laag ( 400 nm dik) bestaat de $p$-i-n zonnecel uit een p-type $(\sim 10$ $\mathrm{nm}$ ) en een n-type gedoteerde laag $(\sim 20 \mathrm{~nm})$. Deze gedoteerde lagen zorgen voor een elektrisch veld in de cel. Dit veld zorgt ervoor dat de elektronen en gaten, die door het licht in de intrinsieke laag worden gegenereerd, aan de contacten van de zonnecel worden gecollecteerd.

Aan de TU Eindhoven is in voorgaand promotieonderzoek aangetoond dat gehydrogeneerd amorf silicium (a-Si:H), met de juiste eigenschappen om in een zonnecel te worden toegepast, gedeponeerd kan worden met een depositiesnelheid die 50 maal hoger is dan met de conventionele techniek, Radio Frequency Plasma Enhanced Chemical Vapour Deposition (RF-PECVD). De gepatenteerde TU/e methode maakt gebruik van een expanderend thermisch plasma (ETP) dat expandeert in een vat op lage druk. Dit leidt tot een gericht transport van reactieve deeltjes naar het substraat waar de a-Si:H film groeit met een hoge groeisnelheid $(0.2-10 \mathrm{~nm} / \mathrm{s})$.

Aangezien de intrinsieke laag maar één laag is van de zonnecel, is een nieuwe opstelling ontworpen en gebouwd waarmee het mogelijk is zonnecellen te maken zonder vacuümonderbreking tussen de verschillende lagen van de $p$-i-n structuur. Deze opstelling heeft de naam CASCADE meegekregen, wat staat voor: Cascaded Arc Solar Cell Apparatus Delft Eindhoven. Het project is een samenwerking tussen de Technische Universiteiten van Eindhoven en Delft en is gefinancierd door NOVEM en TDO. De opstelling is ontworpen en gebouwd in Eindhoven door de GTD en de groep "Evenwicht en Transport in Plasma's" en staat bij het Delft Institute of MicroElectronics and Submicron technology (DIMES) in Delft. Het uiteindelijke doel van het project is om a-Si:H zonnecellen te realiseren met een initieel rendement van $7 \%$, waarbij de intrinsieke laag gegroeid is met een groeisnelheid groter dan $2 \mathrm{~nm} / \mathrm{s}$.

De materiaalkwaliteit van een intrinsieke laag hangt af van de groeisnelheid en de depositietemperatuur. Voor toepassing in een zonnecel dient de intrinsieke laag een voldoende lage defectdichtheid en een voldoende hoge licht-respons te hebben. Dit houdt in dat de bandafstand zodanig is dat er veel licht kan worden geabsorbeerd en dat de geleiding van het materiaal ook zodanig is dat de gecreëerde elektron-gat paren de contacten van de zonnecel kunnen bereiken. Uit het verrichte onderzoek in de nieuwe CASCADE opstelling blijkt dat bij gegeven depositiesnelheid er een optimum is voor de materiaalkwaliteit bij een bepaalde depositietemperatuur. Voor de conventionele techniek $(\sim 0.15 \mathrm{~nm} / \mathrm{s})$ ligt dit optimum bij $\sim 200^{\circ} \mathrm{C}$. Voor de hogere groeisnelheid van een expanderend plasma stijgt de optimale temperatuur tot $250^{\circ} \mathrm{C}$ en $400^{\circ} \mathrm{C}$ voor respectievelijk 1 en $10 \mathrm{~nm} / \mathrm{s}$.

Met betrekking tot de toepasbaarheid van verschillende lagen in $p-i-n$ zonnecellen moet er voor worden gezorgd dat de depositietemperatuur van de 
intrinsieke laag onder de $250^{\circ} \mathrm{C}$ blijft, omdat anders de p-laag dusdanig wordt aangetast dat de cel niet goed meer functioneert. Hogere temperatuur heeft tot gevolg dat waterstof uit de p-laag verdwijnt, waardoor de defectdichtheid toeneemt en de geleiding daalt. Voor een goed functionerende $p$-i-n cel wordt de depositiesnelheid dan beperkt tot snelheden kleiner dan $1 \mathrm{~nm} / \mathrm{s}$. Voor een zonnecel met een $n-i-p$ structuur geldt deze beperking niet.

Er zijn p-i-n zonnecellen gemaakt waarvan de intrinsieke laag gegroeid is met een groeisnelheid van $0.85 \mathrm{~nm} / \mathrm{s}$. De hoogste initiële efficiëntie die bij deze groeisnelheid is gevonden is $6.7 \%$. Dit is 2 à $3 \%$ lager dan wat bereikt wordt met RFPECVD. Echter de groeisnelheid van de i-laag is met de ETP techniek ongeveer vier keer sneller. De lagere efficiëntie van de CASCADE-cel wordt veroorzaakt door een lagere vulfactor, wat duidt op meer recombinatie in de cel. Uit simulaties is gebleken dat plaatselijke verhoging van de defectdichtheid nabij het $p$-i grensvlak een daling van de vulfactor kan veroorzaken met behoud van een goede openklemspanning en kortsluitstroom. Uit onderzoek is gebleken dat meer defecten aan het grensvlak kunnen worden veroorzaakt door de initiële groei bij hoge groeisnelheid van de ilaag. Als oplossing voor de extra defecten aan het $p$-i grensvlak is er voor gekozen om eerst een bufferlaag te groeien met RF-PECVD. Hieruit blijkt dat een bufferlaagdikte van $5 \mathrm{~nm}$ al genoeg is om de vulfactor met meer dan $10 \%$ toe te laten nemen.

Om ook hogere depositietempaturen en dus hogere groeisnelheden in $p-i-n$ cellen toe te passen is ook in dit geval gekeken naar wat het effect is van het toepassen van een bufferlaag tussen de p-laag en de intrinsieke laag. Het belangrijkste effect van een $p$-laag die aangetast is door een hogere depositietemperatuur voor de intrinsieke laag is dat de openklemspanning veel lager is. Door nu een bufferlaag toe te passen wordt waargenomen dat de openklemspanning toeneemt met dikker wordende bufferlaag en satureert boven een dikte van $20 \mathrm{~nm}$. De uiteindelijke bereikte waarde is echter niet zo hoog als verwacht wordt voor depositie bij lagere temperaturen, maar de stijging geeft toch duidelijk aan dat het mogelijk is de p-laag te beschermen tegen de hogere temperaturen. Met toepassing van een $50 \mathrm{~nm}$ dikke bufferlaag is er een zonnecel gemaakt met een initiële efficientie van $5.4 \%$ behaald bij een i-laag depositietemperatuur van $350^{\circ} \mathrm{C}$ en depositiesnelheid van $1.3 \mathrm{~nm} / \mathrm{s}$. Meer onderzoek naar het soort bufferlaag is nog nodig.

Tot slot is ook beginnend onderzoek verricht naar $n-i-p$ zonnecellen. Dit type zonnecel heeft als voordeel dat een hogere groeisnelheid kan worden gebruikt, omdat de n-type gedoteerde laag temperatuurstabieler is dan de p-type gedoteerde laag. Een initiële efficiëntie van $2.8 \%$ is behaald bij een i-laag depositietemperatuur van $350^{\circ} \mathrm{C}$ en depositiesnelheid van $1.5 \mathrm{~nm} / \mathrm{s}$. 


\section{Dankwoord}

Aan het einde is er plaats om mensen te bedanken voor hun bijdragen die ze geleverd hebben aan het tot stand komen van dit werk. Het gaat hier om grote bijdragen en kleine bijdragen (die overigens grote gevolgen kunnen hebben), bijdragen direct aan het werk, maar ook op het sociale vlak, want als je je sociaal niet lekker voelt, dan zal je werk daar onder lijden.

Allereerst wil ik dan ook mijn vader en moeder bedanken voor de mogelijkheid om verder te leren en de ondersteuning daarbij. Verder ook mijn broertje en zijn familie: Leen, Wendy en Michael, en de andere mensen die zich als broers en zussen voor mij willen gedragen. Ook al brengt familie ook de nodige zorgen met zich mee, ze staan ook altijd als eerste voor je klaar. Een familieband is toch altijd nog anders dan een vriendenband.

Verder wil ik op sociaal vlak graag noemen Karine Letourneur, lain Houston en Maikel van Hest. Alle drie zijn o.a. belangrijk geweest bij de verkenning van een stuk van de wereld waar ik nog niet eerder was geweest. Met Maikel op de fiets door Limburg, dankzij lain heb ik Schotland mogen bezoeken en verkennen, wat een mooi land is (als je Glasgow niet meerekent) en met Karine heb ik een aantal keren Frankrijk mogen bezoeken (als die 'rare' Fransen alleen nu eens Frans zouden praten zoals hun president doet voor de internationale TV). De kennismaking met mensen van andere landen is echt een verrijking geweest voor mijn beeld van het leven. Hierbij hoort ook de dank voor de heerlijke Franse maaltijden die ik heb mogen uitproberen dankzij de voortreffelijke kookkunst van Karine en dank voor de uren van gezellige discussie aan de pool-tafel met lain, waardoor het mogelijk was later mijn broertje (Leen) te verslaan bij het snookeren. En verder dank ik lain natuurlijk voor het corrigeren van mijn Engels naar Schots. Ook wil ik hier Tom Scholtes bedanken, die een goed toehoorder bleek te zijn, toen ik daar een keer behoefte aan had

Met betrekking tot de sociale contacten zijn ook de kamergenoten op de universiteit van belang. Dankzij de twee werkgroepen waar ik heb gezeten heb ik er ook een aantal gehad. Arno Smets (zijn promotiefeest beloofd echt onvergetelijk te worden), Erwin Kessels (zeer "dedicated"), Martin Kroon (ook een hele goede rondreis mee gemaakt door Utah, Colorado en Arizona), Barry van Dijk (voor al uw EHBC ${ }^{34}$ en onuitputtelijk in het vragen of je nog koffie wilt) en de laatste 6 maanden Dahlan Tahir. Allen bedankt voor de aanwezigheid (gezelligheid) en de discussies.

Ook de wetenschap begint natuurlijk al op de kamer en de eerste contacten in de groep. Erwin die al een poos bezig was, Arno die tegelijkertijd begon, maar al een voorgeschiedenis had in de groep. Ook heel belangrijk is voor mijn werk geweest het werk van Suzanne van Egmond, die als student bezig was op een terrein waar ik mee verder kon. Natuurlijk wordt je pas echt met grote stappen verder geholpen door de discussies met de begeleiding (supervisors worden ze ook wel genoemd). De eerste twee personen die daar heel belangrijk voor zijn geweest zijn Richard van de Sanden en Daan Schram. Beide zeer kundige personen (waarbij je soms moeite hebt om ze te volgen) en vol nieuwe ideeën over wat er nog gedaan kan worden. Richard houdt verder het enthousiasme hoog in de groep en de mensen bij elkaar, terwijl Daan de eerste was die mij afremde om niet te veel te willen. Ook belangrijk om hier te noemen is Chiel Smit. Chiel kwam na ongeveer anderhalf jaar het team versterken. Naar mijn mening hebben we soepel samengewerkt op één opstelling (wat helaas ook wel eens anders is) en de vele discussies hebben mijzelf een beter inzicht gegeven in het geheel.

In Delft bestaat de wetenschappelijke staf uit mijn $2^{\mathrm{e}}$ promoter Kees Beenakker, Wim Metselaar, Miro Zeman en René van Swaaij. Als 'dagelijks' contactpersoon moet ik vooral René bedanken en met Miro kan je heel goed praten over simulatiewerk met zijn 'kindje'

\footnotetext{
${ }^{34}$ Eerste Hulp Bij Computergebruik.
} 
ASA. Verder heeft vooral René een hele belangrijke bijdrage geleverd door het altijd heel kritisch lezen van alles wat ik opschreef.

Niet te vergeten in een dankwoord is het woord van dank aan de technische ondersteuning. Het bouwen van een nieuwe opstelling en die goed draaiend krijgen is een hele onderneming en ik moet zeggen dat dat alles heel goed is gelopen. Er werd volgens een strak schema gehandeld en zo'n 21 maanden na mijn aanstelling draaide de opstelling. In dit verband gaat in de eerste plaats mijn dank uit naar Ries van de Sande, die de hele opstelling heeft getekend en uitgewerkt. Ook tijdens het verblijf in Delft stond hij altijd klaar om mij te woord te staan en als er iets moest gebeuren hoefde ik daar nooit lang op te wachten (Ries, hartelijk bedankt). Dit mede dankzij Jo Jansen met zijn 'gouden' handjes, die echt alles lijkt te kunnen maken. Bij het bouwen van de opstelling zijn heel belangrijk geweest Peer Brinkgreve, Jan Ketelaars en hun mannen van de GTD. Voor de elektronica gaat mijn dank uit naar Jovita Moerel (ontwikkeling power-supply), Herbert Fiedler (PLC, etc.), Toon Gevers (bedrading) en die anderen die ik niet bij naam ken. Voor de installatie in Delft zijn heel belangrijk geweest Jos Custers en Alfred Apon. Jos heeft zorg gedragen voor alle gasleidingen en andere aansluitingen van dien aard en Alfred heeft al vanaf een heel vroeg stadium over de schouder van Ries meegekeken of alles een beetje voldeed. Ook wil ik Alfred bedanken voor het altijd klaar staan als er een probleempje is. Hierbij moet ik ook Ben Girwar en Gilles Goubréau noemen. Ben stond altijd klaar met een verhaal en advies en Gilles was ook altijd bereid te helpen bij een willekeurig technisch probleem (als je hem tenminste kunt vinden).

Naast de technische ondersteuning die direct met mijn nieuwe opstelling te maken had, is er natuurlijk ook een grote groep mensen die op andere technische punten heel nuttig zijn geweest. In Eindhoven gaat het dan om Marius en zijn mannen van de natuurkunde werkplaats, Bertus Hüsken voor de elektronische ondersteuning (en de hulp bij het uitzoeken van een computer voor thuis) en natuurlijk Herman de Jong. Voor ieder technisch probleempje dat niet echt in een vakje paste, was Herman voor mij de aangewezen persoon om dat op te lossen. In Delft wil ik verder op technisch gebied nog bedanken: Erik Jan Geluk, Arjan Driessen, Joost van de Heuvel (ASA), de grote groep technologen (Hugo, Ruud, Wim, etc.) en overig ondersteunend personeel.

Naast wetenschappelijk en technologisch zijn ook nog vele andere mensen in de groep die bijdragen aan een goede sfeer en de vereiste ondersteuning. Vooral het secretariaat moet hier worden genoemd met mensen die altijd voor mij klaar stonden: Jeanne Loonen, Jeanne Sirks (ik hoop dat je huis ooit af komt), Marian Roozenburg en Marysia Lagendijk. Ook de grote groep collega's die ik niet elders heb genoemd, zijn belangrijk geweest voor de sfeer. Te veel om hier allemaal uitgebreid te noemen, maar toch even kort: Joost, Jeroen, Seth, Erik, Ger, Jan, Stéphane, Marco, Ariel, Alain, Johan, Peter, Jan, Karel, Harm, Colin, Maarten, Richard, Adriana, Roland, Edward, Christian, Marcel, Wibo, Ad, Leon, Amir, Paul, Agnès (veel plezier met de voortzetting van het project), Joost en natuurlijk die 1 of 2 die ik waarschijnlijk ben vergeten.

Rest mij iedereen nogmaals hartelijk te bedanken en het allerbeste toe te wensen.

Moge Gods zegen met u allen zijn.

Bas 


\section{Curriculum vitae}

17 december $1971 \quad$ Geboren te Ottoland

8 juni 1990 Diploma VWO,

Chr. Willem de Zwijger scholengemeenschap

Schoonhoven

5 maart 1998

Doctoraal examen Technische Natuurkunde, Faculteit der Technische Natuurkunde, Technische Universiteit Delft

15 januari $1998-$

4 maart 2002

Assistent in opleiding,

Nederlandse onderneming voor energie en milieu bv, gedetacheerd aan;

de Faculteit der Technische Natuurkunde, vakgroep Evenwicht en Transport in Plasma's, Technische Universiteit Eindhoven

en

de Faculteit Informatie Technologie en Systemen, vakgroep Elektronische Componenten, Technologie en Materialen,

Technische Universiteit Delft 


\section{Stellingen}

behorende bij het proefschrift

Integration of Expanding Thermal Plasma

deposited a-Si:H in solar cells

door

Bas A. Korevaar 
Het voldoen aan de "device quality"-eisen voor de individuele lagen van een zonnecel gebaseerd op amorf silicium, garandeert geen goede zonnecel.

R.E.I. Schropp and M. Zeman, Amorphous and microcrystalline silicon solar cells, Kluwer Academic Publishers (1998) Boston/Dordrecht/London

II

De afstand van de plasmabron tot het substraat speelt een cruciale rol in het geval van depositie van gehydrogeneerd amorf silicium met een expanderend thermisch plasma.

Dit proefschrift

III

Voor het verkrijgen van gestabiliseerde 'record'-rendementen van zonnecellen gebaseerd op amorf silicium is het noodzakelijk om bufferlagen toe te passen.

IV

Waterstofinjectie in de nozzle is een serieuze kandidaat voor het verlagen van de energieconsumptie, die noodzakelijk is voor de productie van gehydrogeneerd amorf silicium met een expanderend thermisch plasma.

Dit proefschrift

In een zonnecel gebaseerd op amorf silicium zijn aangepaste gedoteerde lagen noodzakelijk als de intrinsieke laag een bandgap heeft van $1.7 \mathrm{eV}$ in plaats van $1.8 \mathrm{eV}$.

Dit proefschrift

VI

Het Staebler-Wronski effect in amorf silicium zonnecellen is te voorkomen door de intrinsieke laag van de zonnecel te groeien onder intense belichting equivalent aan enkele zonnen. 
Als Christen mag je nooit van een leider van een Christelijke kerk verwachten dat die persoon voorbehoedsmiddelen, abortus en euthanasie goedkeurt.

\section{VIII}

De gebeurtenissen die volgden op de WTC-aanslag en "de bolletjesslikkers"-affaire zijn goede voorbeelden van symptoombestrijding in de hedendaagse wereldpolitiek.

IX

Het slot is niet ter bescherming van datgene achter het slot, maar meer ter bescherming van degene die de verleiding niet kan weerstaan om de deur te openen.

$X$

Door het informatieaanbod via tal van media, hebben stellingen bij het proefschrift tegenwoordig vaak een weinig origineel karakter.

$\mathrm{XI}$

Alhoewel het "geen woorden, maar daden" tegenwoordig weer door veel Kuip-bezoekers uit volle borst wordt meegezongen, zijn $\mathrm{er}$, in de geest van deze regel uit het lied, maar weinig echte Feyenoorders.

Het Feyenoord-lied: "Hand in hand, kameraden" 